\title{
Connecting the dots : new perspectives on stress and psychosis
}

Citation for published version (APA):

Lataster, J. J. E. (2012). Connecting the dots : new perspectives on stress and psychosis. [Doctoral Thesis, Maastricht University]. Maastricht University. https://doi.org/10.26481/dis.20120127jl

Document status and date:

Published: 01/01/2012

DOI:

10.26481/dis.20120127jl

Document Version:

Publisher's PDF, also known as Version of record

\section{Please check the document version of this publication:}

- A submitted manuscript is the version of the article upon submission and before peer-review. There can be important differences between the submitted version and the official published version of record.

People interested in the research are advised to contact the author for the final version of the publication, or visit the DOI to the publisher's website.

- The final author version and the galley proof are versions of the publication after peer review.

- The final published version features the final layout of the paper including the volume, issue and page numbers.

Link to publication

\footnotetext{
General rights rights.

- You may freely distribute the URL identifying the publication in the public portal. please follow below link for the End User Agreement:

www.umlib.nl/taverne-license

Take down policy

If you believe that this document breaches copyright please contact us at:

repository@maastrichtuniversity.nl

providing details and we will investigate your claim.
}

Copyright and moral rights for the publications made accessible in the public portal are retained by the authors and/or other copyright owners and it is a condition of accessing publications that users recognise and abide by the legal requirements associated with these

- Users may download and print one copy of any publication from the public portal for the purpose of private study or research.

- You may not further distribute the material or use it for any profit-making activity or commercial gain

If the publication is distributed under the terms of Article $25 \mathrm{fa}$ of the Dutch Copyright Act, indicated by the "Taverne" license above, 


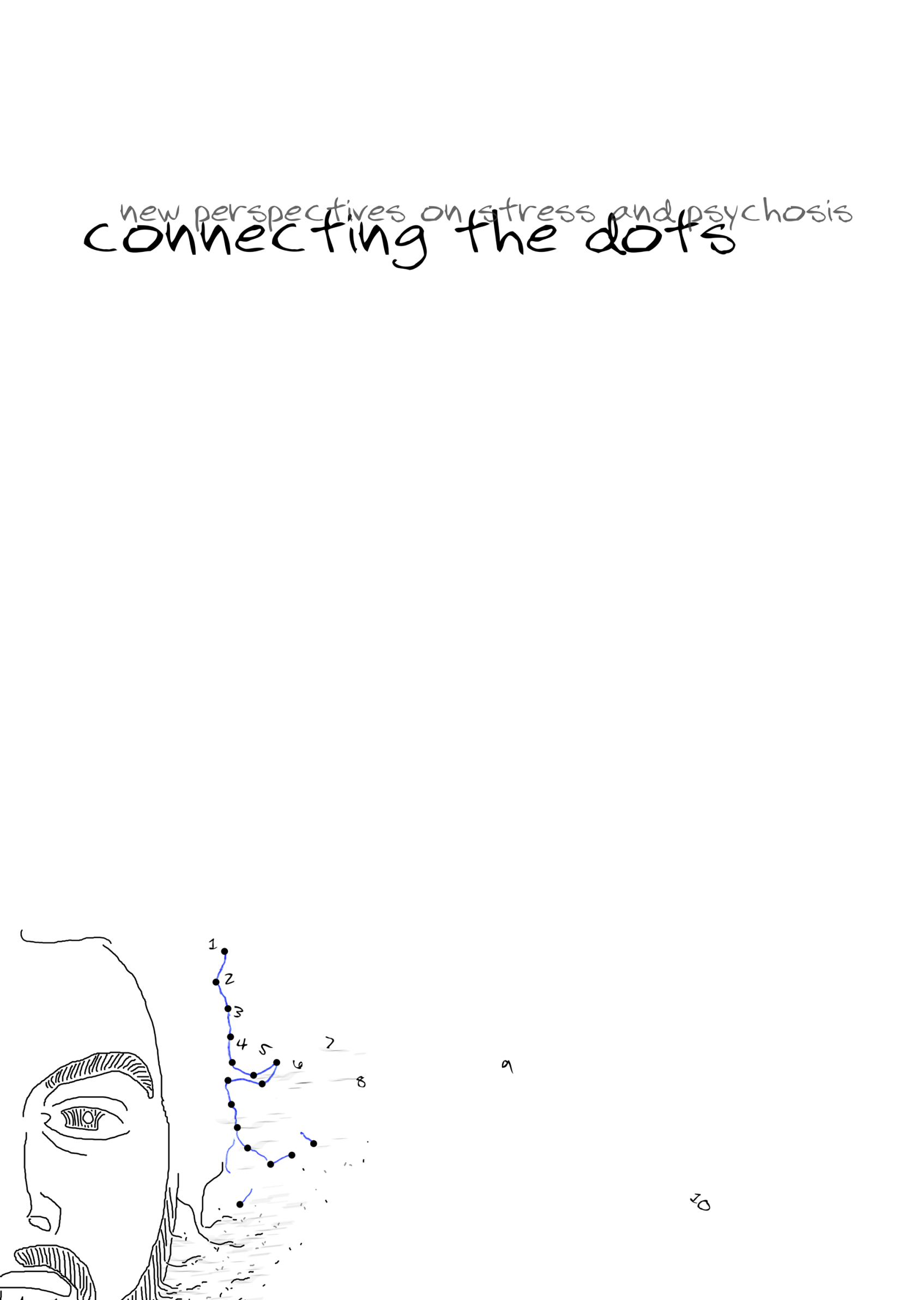




\section{ISBN | 978-90-8570-798-1}

design | artwork | layout | Johan Lataster

| printing | Wöhrmann Print Service

(C) 2012 | J.J.E. Lataster | Maastricht | the Netherlands

All rights reserved. No part of this publication may be reproduced, stored in a retrieval system, or transmitted, in any form or by any means, mechanically electronically, by photocopy, by recording, or otherwise, without prior written permission from the proprietor. 


\section{Connecting the dots \\ New perspectives on stress and psychosis}

\section{PROEFSCHRIFT}

Ter verkrijging van de graad van doctor aan de Universiteit Maastricht, op gezag van de Rector Magnificus, Prof. mr. G.P.M.F. Mols, volgens het besluit van het College van Decanen,

in het openbaar te verdedigen op vrijdag 27 januari 2012 om 12:00 uur

door

Johannes Joseph Elisabeth Lataster

Geboren op 31 mei 1983 te Kerkrade

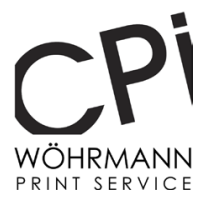




\section{Promotor}

Prof. dr. Inez Myin-Germeys

\section{Beoordelingscommissie}

Prof. dr. Marten deVries (voorzitter)

Dr. Oliver Howes (Institute of Psychiatry, London, UK)

Prof. dr. Lieuwe de Haan (Academisch Medisch Centrum, Amsterdam)

Prof. dr. Felix Mottaghy

Dr. Ruud Van Winkel

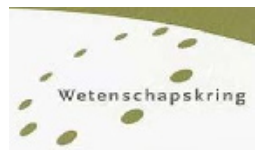

South Limburg Mental Health and Teaching Network PhD Series

The research presented in this thesis was conducted at the School for Mental Health and Neuroscience, Department of Psychiatry and Psychology of Maastricht University, Maastricht University Medical Center and Mondriaan.

Publication of this thesis was financially supported by:

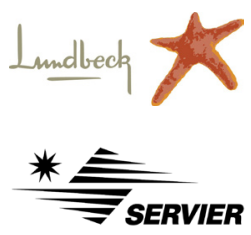


Voor mijh ouders,

mijh zus,

mijn lief 
Paranimfen

Dina Collip

Guido Visschers 


\section{Contents}

Chapter 1 | Introduction

Chapter 2 | Adversity and psychosis: a 10-year prospective study investigating synergism between early and late adversity in psychosis

Chapter 3 | Psychosocial stress is associated with in vivo dopamine release in human ventromedial prefrontal cortex: a positron emission tomography study using $\left[{ }^{18} \mathrm{~F}\right]$ fallypride

Chapter 4 | Familial liability to psychosis is associated with altered dopamine stress signaling in ventromedial prefrontal cortex

Chapter 5 | Emotional experience and estimates of $D_{2}$ receptor occupancy in psychotic patients treated with haloperidol, risperidone, or olanzapine: an experience sampling study

Chapter 6 | Psychotic exacerbation and emotional dampening in the daily life 147 of patients with schizophrenia switched to aripiprazole therapy: a collection of standardized case reports

Chapter 7 | Summary and Discussion .................. 163

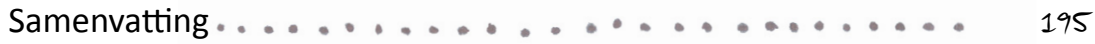

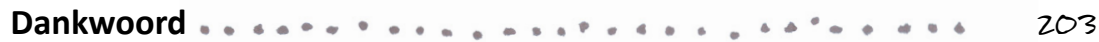

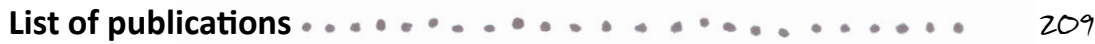

Curriculum Vitae ............. back cover 



\title{
Introduction
}

\author{
"... The schizophrenic is drawn from the entire range of human \\ variation with regard to intelligence, competence, coping ability, \\ achievement, and all other aspects of the human condition. He may \\ be a top executive, a gifted artist, an outstanding scientist, a blue- \\ collar worker, or an unskilled ne'er-do-well bowery bun. No stratum \\ of mankind is spared from this blight. The one feature that all \\ schizophrenics have in common is not the ever presence of their \\ illness, but rather the ever presence of their vulnerability..." \\ (Joseph Zubin \&̇ Bonnie Spring, 1977, p. 122)
}

\section{From normality to pathology: a continuum of psychosis}

Psychosis refers to a mental condition that is characterized by significant distortions in recognition and comprehension of reality. Individuals suffering from psychosis typically endorse hallucinatory experiences and delusional thoughts. Other hallmarks of psychotic disorder are disorganized speech, chaotic or catatonic behavior, and so-called negative symptoms (e.g., flat affect, poverty of speech, and avolition). Psychotic disorders are considered among the most severe mental illnesses, perturbing the emotional and social life of the affected individual and throwing its surrounding environment into great confusion. They affect approximately two to three percent of the population ${ }^{1}$, with a typical onset in early adolescence. Of all psychotic disorders, schizophrenia is considered the most severe illness, with a worldwide prevalence of approximately one percent ${ }^{2-4}$.

Although the psychosis phenotype is, for clinical purposes, often thought of as a dichotomous (i.e., 'all-or-nothing') entity, its natural distribution may be better represented along a continuum, extending from subtle psychotic experiences and subclinical symptoms in the healthy population to a clinically relevant disorder ${ }^{5-8}$. Although self-reported, subclinical psychotic experiences are very common in the general population and convert only rarely into clinical symptoms ${ }^{9,10}$, there is substantial evidence of familial and aetiological 
continuity between these transitory subclinical phenomena and clinically relevant psychotic disorders ${ }^{5,11-13}$. Examining psychotic symptoms in non-clinical populations at increased risk of developing the disorder, e.g., psychometrically identified individuals with high schizotypy scores or first-degree relatives of patients with a psychotic disorder, may therefore help clarifying the underlying aetiology of psychosis. An additional advantage of this approach is the circumvention of potential confounding factors that are inherent to the clinical illness, e.g., antipsychotic drug treatment or illness chronicity.

\section{Framing psychosis: the vulnerability-stress model}

Stress has been repeatedly promoted as an important factor in the aetiology of psychotic experiences. The vulnerability-stress model, as originally advanced by Zubin and Spring in $1977^{14}$, assumes that exogenous and/or endogenous threats or challenges will elicit a crisis in all humans. Whether or not this crisis will lead to an episode of disorder depends on the intensity of the elicited stress and the threshold for tolerating it, i.e., one's vulnerability, conceptualized as a stable interpersonal and possibly heritable trait. Several lines of evidence have since supported the notion of stress being involved in the development of psychotic symptoms. Stressful life events ${ }^{15-20}$, daily hassles ${ }^{21-24}$, highly emotional or averse family environments ${ }^{25-27}$, urbanicity ${ }^{28-30}$, migration ${ }^{31-35}$, victimization and childhood trauma ${ }^{36-}$ ${ }^{41}$ have all been repeatedly associated with the formation of psychotic symptoms. However, although studies collectively identify environmental stress as risk factor for psychosis, they disregard the imperative aspect of interaction between the stressful environment and the vulnerable individual, i.e., how does the stressful environment affect the vulnerable individual, and which mechanisms underlie its transition to illness?

\section{Being sensitive in an insensitive world: how stress affects the vulnerable}

A series of studies have investigated how individuals with varying levels of vulnerability to psychosis respond to stressful occurrences in the context of daily life. These studies have demonstrated that patients with a psychotic disorder (in a clinical state of remission), as well as their unaffected first-degree relative ${ }^{23,42}$ and individuals identified to be psychometrically at risk of psychosis ${ }^{43}$, react to minor daily stressors with increased intensity of psychotic 
experiences and negative emotional responses. Furthermore, results from a general population cross-trait, within-twin study by Lataster and colleagues ${ }^{44}$, showed significant associations between reactivity to stress in one twin and subclinical psychotic experiences in the other, thereby eliminating the possibility that observations of stress reactivity in psychosis-prone individuals are purely attributable to the presence of subclinical or residual psychotic symptoms. Taken together, these findings are suggestive of co-segregation and familial association between the psychosis phenotype and increased reactivity to stress, thereby advancing stress reactivity as possible endophenotype of psychosis.

Studies by Myin-Germeys et al. ${ }^{45}$ and Lardinois et al. ${ }^{46}$, using an integrative approach, have investigated how this endophenotypic expression of psychosis vulnerability is influenced by exposure to environmental stressors that have been epidemiologically identified as risk factors for psychosis. Myin-Germeys and co-workers ${ }^{45}$, investigating a sample of patients with clinically remitted psychotic illness, showed a history of stressful life events to be associated with increased emotional reactivity to daily-life stress. Extending these findings, Lardinois and colleagues ${ }^{46}$, in a sample of psychotic patients, showed higher levels of childhood trauma to be associated with increased emotional and psychotic reactivity to daily-life stress. Compatible with a continual view of the psychosis phenotype, Glaser et al. ${ }^{47}$ and Wichers et al. ${ }^{48}$ reported similar associations between environmental adversity and daily-life stress reactivity in the general population, exposure to childhood trauma being associated with increased reactivity to the stresses of daily life. This pattern has been suggested to reflect an underlying process of behavioral sensitization ${ }^{49-51}$, i.e., repeated exposure to environmental stress or adversity (e.g., childhood trauma or stressful life events) will render individuals more sensitive or responsive, rather than more resistant to the occurrence of stress. This may cause the individual to react progressively more psychotic in response to stress, eventually leading to conversion into a clinically relevant disorder. To establish causality of such a mechanism, however, requires prospective, rather than cross-sectional study designs. Although Wichers et al. ${ }^{52}$, in a prospectively designed general population study, found the experience of major life events to moderate the probability of transition from stress sensitivity to depression, adequately powered prospective studies investigating the causality of stress sensitization in psychosis are currently lacking. In the study described in Chapter 2, data from the Early Developmental Stages of Psychopathology (EDSP) study ${ }^{53,54}$, a 10-year longitudinal study of a population sample of 3021 adolescents and young adults designed to provide answers about prevalence, incidence, risk factors, comorbidity and course of mental disorders, were used to examine the hypothesis of recent 
stressful events and psychosis being moderated by previous exposure to adversity, taking into account possible confounding by other risk factors for psychosis ${ }^{55}$.

\section{Dopamine - Director of experience}

Although stress reactivity has proven a useful endophenotype for psychosis, research into its neurobiological underpinnings is currently scant. Considering the suggested central role for dopamine dysfunctions in patients with a psychotic disorder (see Howes and Kapur ${ }^{56}$ for review of the literature), and involvement of dopaminergic neurotransmission in the human stress response ${ }^{57-59}$, the dopamine system can be hypothesized to have an explanatory role in the stress-pathogenesis of psychosis.

\section{Lights, camera... dopamine - setting the scene for psychosis}

The conception of psychosis involving dopamine neurotransmission can be traced back to the discovery of antipsychotic drugs $s^{60}$, and the subsequent demonstration of their antidopaminergic properties ${ }^{61}$. Further evidence came from the observation that amphetamine, a psychostimulant that increases synaptic dopamine levels, can induce psychosis $^{62}$. Final confirmation of dopamine involvement in psychosis was provided by a number of pivotal studies ${ }^{63-65}$, showing clinical effectiveness of antipsychotic or 'antischizophrenic' compounds to be directly related to their affinity for the dopamine receptor. These findings led to the dopamine hypothesis of psychotic disorders being originally themed around excess activity of the dopamine system. Since then, the development of in vivo neuroimaging techniques has boosted research on the neuropathophysiology of psychosis, elucidating the role of dopamine therein (see Howes and Kapur ${ }^{56}$ for review).

\section{Keeping balance or losing it: a matter of regional specificity}

Whereas the initial dopamine hypothesis considered dopamine levels to be universally elevated throughout the psychotic brain, it has become clear that the effects of dopamine abnormalities vary by brain region ${ }^{66}$. Although schizophrenic patients indeed seem to suffer from excessive (or 'hyper') dopaminergic activity in mesolimbic areas ${ }^{56,67-76}$, their prefrontal brain regions are, in fact, characterized by abnormal low (or 'hypo') dopaminergic activity ${ }^{77-}$ 
${ }^{80}$. These abnormalities are mostly attributable to presynaptic dysfunctions of the dopamine system $^{72,81-83}$, rather than abnormalities in receptor density, as was previously suggested ${ }^{84-}$ 87 .

Hyperactivity of mesolimbic dopamine neurons is well-established through positron emission

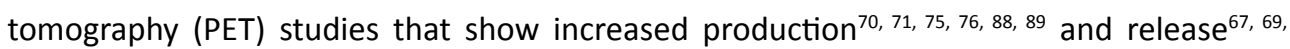
72-74, 90 of dopamine in the striatum of psychotic patients. Moreover, striatal dopamine synthesis capacity predicts conversion to psychotic illness in individuals at ultra-high-risk for psychosis ${ }^{91,92}$. In addition, medication-naïve patients display increased striatal dopamine release in response to the psychostimulant amphetamine compared to healthy controls $\mathrm{s}^{74}$. In fact, the amount of amphetamine-induced dopamine release in these regions is associated with the drug's potency to provoke psychotic symptoms ${ }^{67}$.

Evidence for hypoactivity of the prefrontal dopamine system in patients with a psychotic disorder is less abundant and largely indirect. Schizophrenia patients display cognitive deficits, primarily in the areas of working memory and executive functioning ${ }^{93-95}$ - functions that are generally associated with dopamine transmission in the prefrontal cortex ${ }^{96,97}$. Furthermore, several studies indicate that regional cerebral blood-flow ( $\mathrm{rCBF}$ ) - an indicator of neural activity - towards prefrontal brain regions is lower in schizophrenic patients compared to controls, both under rest and cognitive performance conditions ${ }^{77,80,98-102}$. Weinberger and colleagues $^{79}$ correlated rCBF towards prefrontal areas during the Wisconsin Card Sorting Test ${ }^{103}$, a cognitive task that places demands on executive functioning, with concentrations of the dopamine metabolite homovanillic acid (HVA) ${ }^{104,105}$ in the cerebrospinal fluid. Patients with schizophrenia displayed lowered rCBF towards prefrontal brain areas and, moreover, the degree of diminution of prefrontal activation correlated inversely with HVA concentrations in the cerebrospinal fluid, implying a relationship with decreased cortical dopaminergic activity. Although these studies did not assess dopaminergic activity directly, the findings appear to suggest hypofunctioning of the prefrontal dopamine system, likely associated with the cognitive deficits seen in schizophrenia.

Animal studies showing that lesions of the prefrontal cortex increase dopamine turnover rates $^{106,107}$ and amphetamine-induced dopamine release ${ }^{108,109}$ in mesolimbic areas, have given rise to the hypothesis that an interplay of prefrontal and mesolimbic structures is involved in the aetiology of psychotic disorders ${ }^{66}$. An in vivo human imaging study by MeyerLindenberg and co-workers ${ }^{110}$, in which presynaptic striatal dopamine activity and prefrontal neurotransmission ( $\mathrm{rCBF}$ ) were monitored simultaneously during a working memory task, appears to support this hypothesis. During task performance, presynaptic dopamine activity 
in the striatum was increased in schizophrenia patients relative to controls, and this increase was in turn associated with reduced neurotransmission in prefrontal brain areas.

Taken together, these findings are suggestive of asymmetry of the dopamine system in psychosis, involving 'hypoactivity' of prefrontal and 'hyperactivity' of mesolimbic dopamine structures. Importantly, dopamine transmission in these brain regions, i.e., prefrontal and mesolimbic areas, is also implicated in stress processing ${ }^{111}$, advancing anomalies within the prefrontal-mesolimbic dopamine system as candidate neurochemical culprit of the behavioral reactivity to stress observed in psychosis.

\section{Stopping a car with no brakes: the attenuating function of prefrontal dopamine}

Dopamine is considered to play a key role in the rodent stress response. Tidey and Miczek ${ }^{112}$ exposed rats to a social stressor by placing them in a cage together with a resident rat that had previously defeated them. This encounter increased extracellular dopamine levels in the prefrontal cortex and the nucleus accumbens, but not in the striatum of the intimidated rat. Similar results were obtained by Abercrombie and colleagues ${ }^{113}$ when they exposed rats to a series of electrical tailshocks; the rats responded with increased dopamine concentrations primarily in frontal cortex and to a much lesser extent in the striatum $195 \%$ and $25 \%$ increase relative to baseline, respectively). Moreover, a number of studies have shown that depletion of dopamine in the rat prefrontal cortex leads to increased stressinduced dopamine release in mesolimbic brain regions ${ }^{114-116}$. These findings have led to the hypothesis that prefrontal dopamine transmission attenuates mesolimbic dopamine release, exerting a "brake-like" function that may play a vital role in diminishing the adverse effects of stress on the brain ${ }^{117,118}$. However, few studies have investigated the direct effects of psychosocial stress on dopamine release in humans and, moreover, these studies have been limited by the methodological restrictions of in vivo imaging techniques, a lack of high affinity $D_{2 / 3}$ radioligands limiting PET exploration of dopaminergic transmission to brain regions with high $\mathrm{D}_{2}$ receptor density, primarily the striatum.

Montgomery et al. ${ }^{119}$ measured the effect of stress, induced by difficult mental arithmetic and negative performance feedback, on striatal dopamine release. Exposure to stress did not increase dopamine release in striatal regions, suggesting that a mild stressor does not necessarily increase mesolimbic dopamine release in healthy individuals. A study by 
Pruessner and colleagues ${ }^{57}$ utilized a similar psychosocial stress task in a PET paradigm to investigate striatal dopamine release in a sample of healthy college students who were classified as having received either low or high maternal care in childhood. Only those who had received low maternal care in childhood displayed increased striatal dopamine release in response to the stress task, fitting sensitization-theory ${ }^{49-51}$ by suggesting that a lack of maternal care in childhood may possibly lead to sensitivity of the dopamine system, as reflected by increased dopamine release in mesolimbic brain regions in response to stress. Similar to Montgomery et al. ${ }^{119}$, a study by Soliman and colleagues ${ }^{120}$ reported no effect of psychosocial stress on striatal dopamine release in healthy individuals. However, a group of individuals with negative schizotypy included in this study did show increased dopamine release in the striatum after being exposed to stress. Findings from these studies seem to suggest that there is no evidence for stress being associated with increased striatal dopamine levels in healthy humans, in line with aforementioned suggestions of stress-induced striatal dopamine release in rodents occurring secondary to stress-induced dopamine release in prefrontal regions ${ }^{113}$. Rather, the effects of stress on striatal dopamine might be restricted to behaviorally sensitized and/or psychosis-prone individuals. Given the observation of prefrontal dopamine transmission attenuating stress-induced mesolimbic dopamine release ${ }^{114-116}$, and suggested 'hypoactivity' of prefrontal dopamine structures in these individuals, it can be posed that individuals at risk of psychosis may suffer from a loss of control of the prefrontal dopamine system over mesolimbic dopaminergic neurotransmission, resulting in increased stress reactivity in daily life ${ }^{23,42}$. Although Soliman et al. ${ }^{120}$ showed stress-induced dopamine release in human striatum to be negatively correlated with smooth pursuit gain, an endophenotype linked to frontal lobe integrity, direct in vivo evidence for an impaired attenuating function of the prefrontal dopamine system in psychosis is currently lacking and, moreover, does not pertain to the context of stress reactivity. In fact, despite its possible vital role in stress regulation, no single study has, thus far, investigated stress-induced dopamine release in human prefrontal cortex.

Recent development of high affinity $D_{2 / 3}$ radioligands, among which $\left[{ }^{18} \mathrm{~F}\right]$ fallypride, has offered possibilities for exploration of extrastriatal dopamine sites such as the prefrontal cortex ${ }^{121-126}$. The tandem of studies presented in Chapter $\mathbf{3}$ and Chapter $\mathbf{4}$ used [ ${ }^{18} \mathrm{~F}$ ]fallypride PET imaging 122 in a sample of healthy volunteers and healthy first-degree relatives of patients with a psychotic disorder to examine (i) whether exposure to a laboratory stressor is associated with in vivo dopamine release in the human prefrontal cortex, and (ii) whether individuals at familial risk for psychosis, who have been previously observed to respond 
to minor daily stressors with increased intensity of psychotic experiences and negative emotional responses ${ }^{23}, 42,43$, display aberrations in stress-induced prefrontal dopamine signaling.

\section{Dopamine management - the unrewarding necessity of antipsychotics}

The formation of delusions and hallucinations in patients with a psychotic disorder is directly linked to hyperactivity of striatal $D_{2}$ dopamine receptors ${ }^{67,91,92}$. As such, attenuation of striatal dopamine activity through blockade of the dopamine receptor has proven a cardinal mechanism in the treatment of these symptoms. Clinical potency of antipsychotic drugs, quantified as the degree to which positive symptoms (i.e., hallucinations and delusions) are reduced, is determined by their potency to block the striatal dopamine $D_{2}$ receptor ${ }^{63-65,127}$. However, several studies have indicated that the striatal-mesolimbic dopamine system is also involved in reward, motivation, and salience ${ }^{128-136}$. Kapur and colleagues ${ }^{137,138}$ have argued that a hyperactive state of the mesolimbic dopamine system may cause aberrant salience (the assignment of salience to otherwise unimportant stimuli), and thereby fuel psychotic experiences. Accordingly, antipsychotic drugs may reduce delusions and hallucinations by dampening aberrant salience attribution through blockade of the dopamine $D_{2}$ receptor. However, the collateral attenuation of motivational salience of other experiences and thoughts may induce motivational indifference and block emotional experience associated with natural rewards ${ }^{139}$, in line with observations of altered emotional well-being in response to antipsychotic treatment ${ }^{140,141}$. More specifically, high levels of $D_{2}$ receptor occupancy are associated with feelings of dysphoria and decreased feelings of safety and self-confidence ${ }^{142,}$ ${ }^{143}$. Similarly, prolonged dopamine depletion has been shown to result in negative mood states $^{144}$.

Despite the apparent link between dopamine receptor blockade and emotional well-being, positive symptom reduction and occurrence of extrapyramidal side-effects have long been the main outcome measures in medication studies ${ }^{145}$. However, the occurrence of emotional impairment may be a more subtle yet more important side-effect of antipsychotic medication, as it already occurs at relatively low levels of dopamine receptor blockade ${ }^{146}$, independent of overall symptom severity or extrapyramidal symptoms ${ }^{142,143}$, and may have important implications for medication compliance and treatment outcome ${ }^{147,148}$. Disturbances in 
emotional experience have been previously investigated using medication-related crosssectional questionnaires in semi-experimental environments. While productive, these studies nevertheless lack ecological validity, as emotional experiences occurring in the flow of daily life are assessed retrospectively and globally using cross-sectional instruments.

The Experience Sampling Method $(E S M)^{149}{ }^{150}$, a fine-grained momentary assessment technique, holds promise in clinical psychopharmacology because of its accurate information retrieval and superior ecological validity. Furthermore, the collection of multiple data points reduces random error variance and increases sensitivity to detect subtle changes. Previous work in the field of depression ${ }^{151-154}$ has illustrated the added value of the ESM in providing more detailed information with regard to the psychological mechanisms underlying treatment effects and adherence. The studies presented in Chapter $\mathbf{5}$ and Chapter $\mathbf{6}$ aimed at extending this work into the field of psychosis, focusing on the association between antipsychotic drug interactions with the dopamine $\left(D_{2}\right)$ receptor and the experience of emotions in the natural flow of daily life assessed with the Experience Sampling Method.

\section{Aims and outline of this thesis}

The overall aim of the work presented in this thesis was to shed further light on the role of stress and adversity in psychosis. More specifically, the studies presented in this thesis aimed at:

Examining causality of the behavioral sensitization mechanism suggested to underlie observations of increased reactivity to daily-life stress in psychotic patients reporting a history of adversity In Chapter 2, a 10-year longitudinal, prospective study of a population sample of 3021 adolescents and young adults is presented that examined whether the association between recent adversity and psychosis is moderated by exposure to previous adverse events, taking into account possible confounding by other risk factors for psychosis ${ }^{55}$. It was hypothesized that exposure to adverse events early in life would render individuals more sensitive to the psychotogenic effects of later occurring adversities.

Elucidating the neurobiology of the human stress response and the specific role of prefrontal dopamine therein - The study described in Chapter 3 of this thesis used the novel and highly selective dopamine $D_{2 / 3}$ PET radioligand $\left[{ }^{18} \mathrm{~F}\right]$ fallypride to detect in vivo prefrontal dopamine release in healthy human subjects $(n=12)$ in response to a laboratory stressor 
that attempted to emulate real-world social interactions. The experience of psychosocial stress was hypothesized to be associated with dopamine release in the human prefrontal cortex, reflected by increased $\left[{ }^{18} \mathrm{~F}\right]$ fallypride ligand displacement.

Investigating whether dysfunctions in stress-induced prefrontal dopamine signaling may represent a vulnerability marker for psychosis - The study presented in Chapter 4 extended the work described in Chapter $\mathbf{3}$ by utilizing the same $\left[{ }^{18} \mathrm{~F}\right]$ fallypride PET stress paradigm in a sample of healthy subjects $(n=10)$ and healthy first-degree relatives of patients with a psychotic disorder $(n=14)$ to examine how the prefrontal dopamine stress-response pertains to the stress reactivity endophenotype of psychosis. It was hypothesized that relatives, at familial risk for psychosis, would suffer from impaired attenuation of stress-induced mesolimbic dopamine release by the prefrontal dopamine system, reflected by anomalies in stress-induced prefrontal dopamine signaling associated with psychotic reactivity to the laboratory stressor.

Mapping the adverse effects of pharmacological blockade of the dopamine receptor on subjectively experienced emotional well-being in the daily life of psychotic patients - The studies described in Chapter 5 and Chapter 6 of this thesis used the Experience Sampling Method (a structured diary technique) to untangle the working mechanisms of antipsychotic compounds with regard to their impact on emotional well-being. In Chapter 5, a study is presented that investigated, in a large sample of 109 patients with a diagnosis of psychotic disorder, to what extent emotional side-effects of antipsychotics were attributable to how strongly the drugs compete with dopamine for occupancy of the $D_{2}$ receptor. It was hypothesized that haloperidol and risperidone, which bind more 'tightly' to the $D_{2}$ receptor than dopamine itself, would have more detrimental effects on daily-life emotional experience than the 'looser' binding agent olanzapine. The study described in Chapter $\mathbf{6}$ assessed the effects of switching from treatment with traditional dopamine antagonist antipsychotics to treatment with the partial dopamine agonist aripiprazole on emotional well-being in the daily life of 13 patients with a diagnosis of schizophrenia. It was hypothesized that the partial $D_{2}$ agonistic profile of aripiprazole would favor emotional well-being compared to the pure dopamine antagonistic properties of traditional antipsychotics.

In Chapter 7, findings from the presented studies are summarized and integrated, and implications for clinical practice and future research are concisely discussed. 


\section{References}

Hintikka J, Kieseppa T, Harkanen T, Koskinen S, and Lonnqvist J. Lifetime prevalence of psychotic and bipolar I disorders in a general population. Arch Gen Psychiatry, 2007. 64(1): p. 19-28.

2. Jablensky A, Sartorius N, Ernberg G, Anker M, Korten A, Cooper JE, Day R, and Bertelsen A. Schizophrenia: manifestations, incidence and course in different cultures. A World Health Organization ten-country study. Psychol Med Monogr Suppl, 1992. 20: p. 1-97.

3. Sartorius N, Jablensky A, Korten A, Ernberg G, Anker M, Cooper JE, and Day R. Early manifestations and firstcontact incidence of schizophrenia in different cultures. A preliminary report on the initial evaluation phase of the WHO Collaborative Study on determinants of outcome of severe mental disorders. Psychol Med, 1986. 16(4): p. 909-28.

4. McGrath JJ, Pemberton MR, Welham JL, and Murray RM. Schizophrenia and the influenza epidemics of 1954, 1957 and 1959: a southern hemisphere study. Schizophr Res, 1994. 14(1): p. 1-8.

5. Johns LC and van Os J. The continuity of psychotic experiences in the general population. Clin Psychol Rev, 2001. 21(8): p. 1125-41.

6. Linscott RJ and van Os J. Systematic reviews of categorical versus continuum models in psychosis: evidence for discontinuous subpopulations underlying a psychometric continuum. Implications for DSM-V, DSM-VI, and DSM-VII. Annu Rev Clin Psychol, 2010. 6: p. 391-419.

7. van Os J, Hanssen M, Bijl RV, and Ravelli A. Strauss (1969) revisited: a psychosis continuum in the general population? Schizophr Res, 2000. 45(1-2): p. 11-20.

8. van Os J and Kapur S. Schizophrenia. Lancet, 2009. 374(9690): p. 635-45.

9. Kendler KS, Gallagher TJ, Abelson JM, and Kessler RC. Lifetime prevalence, demographic risk factors, and diagnostic validity of nonaffective psychosis as assessed in a US community sample. The National Comorbidity Survey. Arch Gen Psychiatry, 1996. 53(11): p. 1022-31.

10. van Os J, Hanssen M, Bijl RV, and Vollebergh W. Prevalence of psychotic disorder and community level of psychotic symptoms: an urban-rural comparison. Arch Gen Psychiatry, 2001. 58(7): p. 663-8.

11. Kendler KS, McGuire M, Gruenberg AM, and Walsh D. Schizotypal symptoms and signs in the Roscommon Family Study. Their factor structure and familial relationship with psychotic and affective disorders. Arch Gen Psychiatry, 1995. 52(4): p. 296-303.

12. van Os J, Verdoux H, Maurice-Tison S, Gay B, Liraud F, Salamon R, and Bourgeois M. Self-reported psychosislike symptoms and the continuum of psychosis. Soc Psychiatry Psychiatr Epidemiol, 1999. 34(9): p. 459-63.

13. van Os J, Linscott RJ, Myin-Germeys I, Delespaul P, and Krabbendam L. A systematic review and meta-analysis of the psychosis continuum: evidence for a psychosis proneness-persistence-impairment model of psychotic 
disorder. Psychol Med, 2009. 39(2): p. 179-95.

14. Zubin J and Spring B. Vulnerability--a new view of schizophrenia. J Abnorm Psychol, 1977. 86(2): p. $103-26$.

15. Bebbington $P$, Wilkins $S$, Jones $P$, Foerster A, Murray R, Toone B, and Lewis S. Life events and psychosis. Initial results from the Camberwell Collaborative Psychosis Study. Br J Psychiatry, 1993. 162: p. 72-9.

16. Bebbington P, Wilkins S, Sham P, Jones P, van Os J, Murray R, Toone B, and Lewis S. Life events before psychotic episodes: do clinical and social variables affect the relationship? Soc Psychiatry Psychiatr Epidemiol, 1996. 31(3-4): p. 122-8.

17. Carr V, Halpin S, Lau N, O'Brien S, Beckmann J, and Lewin T. A risk factor screening and assessment protocol for schizophrenia and related psychosis. Aust N Z J Psychiatry, 2000. 34 Suppl: p. S170-80.

18. Lukoff D, Snyder K, Ventura J, and Nuechterlein KH. Life events, familial stress, and coping in the developmental course of schizophrenia. Schizophr Bull, 1984. 10(2): p. 258-92.

19. Norman RM and Malla AK. Stressful life events and schizophrenia. I: A review of the research. Br J Psychiatry, 1993. 162: p. 161-6.

20. Ventura J, Nuechterlein KH, Subotnik KL, Hardesty JP, and Mintz J. Life events can trigger depressive exacerbation in the early course of schizophrenia. J Abnorm Psychol, 2000. 109(1): p. 139-44.

21. Malla AK, Cortese L, Shaw TS, and Ginsberg B. Life events and relapse in schizophrenia. A one year prospective study. Soc Psychiatry Psychiatr Epidemiol, 1990. 25(4): p. 221-4.

22. Malla AK and Norman RM. Relationship of major life events and daily stressors to symptomatology in schizophrenia. J Nerv Ment Dis, 1992. 180(10): p. 664-7.

23. Myin-Germeys I, Delespaul P, and van Os J. Behavioural sensitization to daily life stress in psychosis. Psychol Med, 2005. 35(5): p. 733-41.

24. Tessner KD, Mittal V, and Walker EF. Longitudinal Study of Stressful Life Events and Daily Stressors Among Adolescents at High Risk for Psychotic Disorders. Schizophr Bull, 2009.

25. Bebbington $P$ and Kuipers L. The predictive utility of expressed emotion in schizophrenia: an aggregate analysis. Psychol Med, 1994. 24(3): p. 707-18.

26. Butzlaff RL and Hooley JM. Expressed emotion and psychiatric relapse: a meta-analysis. Arch Gen Psychiatry, 1998. 55(6): p. 547-52.

27. Wearden AJ, Tarrier N, Barrowclough C, Zastowny TR, and Rahill AA. A review of expressed emotion research in health care. Clin Psychol Rev, 2000. 20(5): p. 633-66.

28. Krabbendam L and van Os J. Schizophrenia and urbanicity: a major environmental influence--conditional on genetic risk. Schizophr Bull, 2005. 31(4): p. 795-9.

29. Spauwen J, Krabbendam L, Lieb R, Wittchen HU, and van Os J. Does urbanicity shift the population expression of psychosis? J Psychiatr Res, 2004. 38(6): p. 613-8.

30. van Os J, Hanssen M, Bak M, Bijl RV, and Vollebergh W. Do urbanicity and familial liability coparticipate in 
causing psychosis? Am J Psychiatry, 2003. 160(3): p. 477-82. Soc Psychiatry Psychiatr Epidemiol, 2003. 38(1): p. 35-43.

32. Cantor-Graae E and Selten JP. Schizophrenia and migration: a meta-analysis and review. Am J Psychiatry, 2005. 162(1): p. 12-24.

33. Selten JP, Cantor-Graae E, and Kahn RS. Migration and schizophrenia. Curr Opin Psychiatry, 2007. 20(2): p. 111-5.

34. Zolkowska K, Cantor-Graae E, and McNeil TF. Increased rates of psychosis among immigrants to Sweden: is migration a risk factor for psychosis? Psychol Med, 2001. 31(4): p. 669-78.

35. Zolkowska K, Cantor-Graae E, and McNeil TF. Psychiatric admissions for psychosis in Malmo during the NATO bombing of Kosovo. J Nerv Ment Dis, 2003. 191(12): p. 820-6.

36. Arseneault L, Cannon M, Fisher HL, Polanczyk G, Moffitt TE, and Caspi A. Childhood trauma and children's emerging psychotic symptoms: A genetically sensitive longitudinal cohort study. Am J Psychiatry, 2011. 168(1): p. 65-72.

37. Bendall S, Jackson HJ, Hulbert CA, and McGorry PD. Childhood trauma and psychotic disorders: a systematic, critical review of the evidence. Schizophr Bull, 2008. 34(3): p. 568-79.

38. Elklit A and Shevlin M. Female Sexual Victimization Predicts Psychosis: A Case-Control Study Based on the Danish Registry System. Schizophr Bull, 2010.

39. Morgan C and Fisher H. Environment and schizophrenia: environmental factors in schizophrenia: childhood trauma--a critical review. Schizophr Bull, 2007. 33(1): p. 3-10.

40. Read J, van Os J, Morrison AP, and Ross CA. Childhood trauma, psychosis and schizophrenia: a literature review with theoretical and clinical implications. Acta Psychiatr Scand, 2005. 112(5): p. 330-50.

41. Schreier A, Wolke D, Thomas K, Horwood J, Hollis C, Gunnell D, Lewis G, Thompson A, Zammit S, Duffy L, Salvi G, and Harrison G. Prospective study of peer victimization in childhood and psychotic symptoms in a nonclinical population at age 12 years. Arch Gen Psychiatry, 2009. 66(5): p. 527-36.

42. Myin-Germeys I, van Os J, Schwartz JE, Stone AA, and Delespaul PA. Emotional reactivity to daily life stress in psychosis. Arch Gen Psychiatry, 2001. 58(12): p. 1137-44.

43. Udachina A, Thewissen V, Myin-Germeys I, Fitzpatrick S, O'Kane A, and Bentall RP. Understanding the relationships between self-esteem, experiential avoidance, and paranoia: structural equation modelling and experience sampling studies. J Nerv Ment Dis, 2009. 197(9): p. 661-8.

44. Lataster T, Wichers M, Jacobs N, Mengelers R, Derom C, Thiery E, Van Os J, and Myin-Germeys I. Does reactivity to stress cosegregate with subclinical psychosis? A general population twin study. Acta Psychiatr Scand, 2009. 119(1): p. 45-53. 
45. Myin-Germeys I, Krabbendam L, Delespaul PA, and Van Os J. Do life events have their effect on psychosis by influencing the emotional reactivity to daily life stress? Psychol Med, 2003. 33(2): p. 327-33.

46. Lardinois M, Lataster T, Mengelers R, Van Os J, and Myin-Germeys I. Childhood trauma and increased stress sensitivity in psychosis. Acta Psychiatr Scand, 2011. 123(1): p. 28-35.

47. Glaser JP, van Os J, Portegijs PJ, and Myin-Germeys I. Childhood trauma and emotional reactivity to daily life stress in adult frequent attenders of general practitioners. J Psychosom Res, 2006. 61(2): p. 229-36.

48. Wichers M, Schrijvers D, Geschwind N, Jacobs N, Myin-Germeys I, Thiery E, Derom C, Sabbe B, Peeters F, Delespaul P, and van Os J. Mechanisms of gene-environment interactions in depression: evidence that genes potentiate multiple sources of adversity. Psychol Med, 2009. 39(7): p. 1077-86.

49. Collip D, Myin-Germeys I, and Van Os J. Does the concept of "sensitization" provide a plausible mechanism for the putative link between the environment and schizophrenia? Schizophr Bull, 2008. 34(2): p. 220-5.

50. van Winkel R, Stefanis NC, and Myin-Germeys I. Psychosocial stress and psychosis. A review of the neurobiological mechanisms and the evidence for gene-stress interaction. Schizophr Bull, 2008. 34(6): p. 1095-105.

51. Yuii K, Suzuki M, and Kurachi M. Stress sensitization in schizophrenia. Ann N Y Acad Sci, 2007. 1113: p. 27690.

52. Wichers M, Geschwind N, Jacobs N, Kenis G, Peeters F, Derom C, Thiery E, Delespaul P, and van Os J. Transition from stress sensitivity to a depressive state: longitudinal twin study. Br J Psychiatry, 2009. 195(6): p. 498-503.

53. Lieb R, Isensee B, von Sydow K, and Wittchen HU. The Early Developmental Stages of Psychopathology Study (EDSP): a methodological update. Eur Addict Res, 2000. 6(4): p. 170-82.

54. Wittchen HU, Perkonigg A, Lachner G, and Nelson CB. Early developmental stages of psychopathology study (EDSP): objectives and design. Eur Addict Res, 1998. 4(1-2): p. 18-27.

55. van Os J, Kenis G, and Rutten BP. The environment and schizophrenia. Nature, 2010. 468(7321): p. $203-12$.

56. Howes OD and Kapur S. The dopamine hypothesis of schizophrenia: version III--the final common pathway. Schizophr Bull, 2009. 35(3): p. 549-62.

57. Pruessner JC, Champagne F, Meaney MJ, and Dagher A. Dopamine release in response to a psychological stress in humans and its relationship to early life maternal care: a positron emission tomography study using [11C]raclopride. J Neurosci, 2004. 24(11): p. 2825-31.

58. Pruessner JC, Dedovic K, Pruessner M, Lord C, Buss C, Collins L, Dagher A, and Lupien SJ. Stress regulation in the central nervous system: evidence from structural and functional neuroimaging studies in human populations - 2008 Curt Richter Award Winner. Psychoneuroendocrinology, 2010. 35(1): p. 179-91.

59. Pruessner JC, Dedovic K, Pruessner M, Lord C, Buss C, Collins L, Dagher A, and Lupien SJ. Stress regulation in the central nervous system: evidence from structural and functional neuroimaging studies in human 
populations - 2008 Curt Richter Award Winner. Psychoneuroendocrinology. 35(1): p. 179-91.

60. Delay J, Deniker P, and Harl JM. [Therapeutic use in psychiatry of phenothiazine of central elective action (4560 RP).]. Ann Med Psychol (Paris), 1952. 110(2:1): p. 112-7.

61. Carlsson A, Lindqvist $M$, and Magnusson T. 3,4-Dihydroxyphenylalanine and 5-hydroxytryptophan as reserpine antagonists. Nature, 1957. 180(4596): p. 1200.

62. Angrist BM and Gershon S. The phenomenology of experimentally induced amphetamine psychosis-preliminary observations. Biol Psychiatry, 1970. 2(2): p. 95-107.

63. Creese I, Burt DR, and Snyder SH. Dopamine receptor binding predicts clinical and pharmacological potencies of antischizophrenic drugs. Science, 1976. 192(4238): p. 481-3.

64. Seeman P and Lee T. Antipsychotic drugs: direct correlation between clinical potency and presynaptic action on dopamine neurons. Science, 1975. 188(4194): p. 1217-9.

65. Seeman P, Lee T, Chau-Wong M, and Wong K. Antipsychotic drug doses and neuroleptic/dopamine receptors. Nature, 1976. 261(5562): p. 717-9.

66. Davis KL, Kahn RS, Ko G, and Davidson M. Dopamine in schizophrenia: a review and reconceptualization. Am J Psychiatry, 1991. 148(11): p. 1474-86.

67. Abi-Dargham A, Gil R, Krystal J, Baldwin RM, Seibyl JP, Bowers M, van Dyck CH, Charney DS, Innis RB, and Laruelle M. Increased striatal dopamine transmission in schizophrenia: confirmation in a second cohort. Am J Psychiatry, 1998. 155(6): p. 761-7.

68. Abi-Dargham A, Mawlawi O, Lombardo I, Gil R, Martinez D, Huang Y, Hwang DR, Keilp J, Kochan L, Van Heertum R, Gorman JM, and Laruelle M. Prefrontal dopamine D1 receptors and working memory in schizophrenia. J Neurosci, 2002. 22(9): p. 3708-19.

69. Breier A, Su TP, Saunders R, Carson RE, Kolachana BS, de Bartolomeis A, Weinberger DR, Weisenfeld N, Malhotra AK, Eckelman WC, and Pickar D. Schizophrenia is associated with elevated amphetamine-induced synaptic dopamine concentrations: evidence from a novel positron emission tomography method. Proc Natl Acad Sci U S A, 1997. 94(6): p. 2569-74.

70. Dao-Castellana MH, Paillere-Martinot ML, Hantraye P, Attar-Levy D, Remy P, Crouzel C, Artiges E, Feline A, Syrota A, and Martinot JL. Presynaptic dopaminergic function in the striatum of schizophrenic patients. Schizophr Res, 1997. 23(2): p. 167-74.

71. Hietala J, Syvalahti E, Vuorio K, Rakkolainen V, Bergman J, Haaparanta M, Solin O, Kuoppamaki M, Kirvela $\mathrm{O}$, Ruotsalainen $\mathrm{U}$, and et al. Presynaptic dopamine function in striatum of neuroleptic-naive schizophrenic patients. Lancet, 1995. 346(8983): p. 1130-1.

72. Kestler LP, Walker E, and Vega EM. Dopamine receptors in the brains of schizophrenia patients: a metaanalysis of the findings. Behav Pharmacol, 2001. 12(5): p. 355-71.

73. Laruelle M, Abi-Dargham A, Gil R, Kegeles L, and Innis R. Increased dopamine transmission in schizophrenia: 
relationship to illness phases. Biol Psychiatry, 1999. 46(1): p. 56-72.

74. Laruelle M, Abi-Dargham A, van Dyck CH, Gil R, D'Souza CD, Erdos J, McCance E, Rosenblatt W, Fingado C, Zoghbi SS, Baldwin RM, Seibyl JP, Krystal JH, Charney DS, and Innis RB. Single photon emission computerized tomography imaging of amphetamine-induced dopamine release in drug-free schizophrenic subjects. Proc Natl Acad Sci U S A, 1996. 93(17): p. 9235-40.

75. Lindstrom LH, Gefvert O, Hagberg G, Lundberg T, Bergstrom M, Hartvig P, and Langstrom B. Increased dopamine synthesis rate in medial prefrontal cortex and striatum in schizophrenia indicated by L-(beta-11C) DOPA and PET. Biol Psychiatry, 1999. 46(5): p. 681-8.

76. Reith J, Benkelfat C, Sherwin A, Yasuhara Y, Kuwabara H, Andermann F, Bachneff S, Cumming P, Diksic M, Dyve SE, Etienne P, Evans AC, Lal S, Shevell M, Savard G, Wong DF, Chouinard G, and Gjedde A. Elevated dopa decarboxylase activity in living brain of patients with psychosis. Proc Natl Acad Sci U S A, 1994. 91(24): p. 11651-4.

77. Geraud G, Arne-Bes MC, Guell A, and Bes A. Reversibility of hemodynamic hypofrontality in schizophrenia. J Cereb Blood Flow Metab, 1987. 7(1): p. 9-12.

78. Park IH, Kim JJ, Chun J, Jung YC, Seok JH, Park HJ, and Lee JD. Medial prefrontal default-mode hypoactivity affecting trait physical anhedonia in schizophrenia. Psychiatry Res, 2009. 171(3): p. 155-65.

79. Weinberger DR, Berman KF, and Illowsky BP. Physiological dysfunction of dorsolateral prefrontal cortex in schizophrenia. III. A new cohort and evidence for a monoaminergic mechanism. Arch Gen Psychiatry, 1988. 45(7): p. 609-15

80. Weinberger DR, Berman KF, and Zec RF. Physiologic dysfunction of dorsolateral prefrontal cortex in schizophrenia. I. Regional cerebral blood flow evidence. Arch Gen Psychiatry, 1986. 43(2): p. 114-24.

81. Karlsson P, Farde L, Halldin C, and Sedvall G. PET study of $\mathrm{D}(1)$ dopamine receptor binding in neurolepticnaive patients with schizophrenia. Am J Psychiatry, 2002. 159(5): p. 761-7.

82. Laruelle M. Imaging dopamine transmission in schizophrenia. A review and meta-analysis. Q J Nucl Med, 1998. 42(3): p. 211-21.

83. Zakzanis KK and Hansen KT. Dopamine D2 densities and the schizophrenic brain. Schizophr Res, 1998. 32(3): p. 201-6.

84. Cross AJ, Crow TJ, Longden A, Owen F, Poulter M, and Riley GJ. Evidence for increased dopamine receptor sensitivity in post mortem brains from patients with schizophrenia [proceedings]. J Physiol, 1978. 280: p. $37 P$.

85. Lee T and Seeman P. Elevation of brain neuroleptic/dopamine receptors in schizophrenia. Am J Psychiatry, 1980. 137(2): p. $191-7$.

86. Mackay AV, Iversen LL, Rossor M, Spokes E, Bird E, Arregui A, Creese I, and Synder SH. Increased brain dopamine and dopamine receptors in schizophrenia. Arch Gen Psychiatry, 1982. 39(9): p. 991-7. 
87. Seeman P, Ulpian C, Bergeron C, Riederer P, Jellinger K, Gabriel E, Reynolds GP, and Tourtellotte WW. Bimodal distribution of dopamine receptor densities in brains of schizophrenics. Science, 1984. 225(4663): p. 72831.

88. Howes OD, Montgomery AJ, Asselin MC, Murray RM, Grasby PM, and McGuire PK. Molecular imaging studies of the striatal dopaminergic system in psychosis and predictions for the prodromal phase of psychosis. $\mathrm{Br} J$ Psychiatry Suppl, 2007. 51: p. s13-8.

89. McGowan S, Lawrence AD, Sales T, Quested D, and Grasby P. Presynaptic dopaminergic dysfunction in schizophrenia: a positron emission tomographic [18F]fluorodopa study. Arch Gen Psychiatry, 2004. 61(2): p. 134-42.

90. Abi-Dargham A, Rodenhiser J, Printz D, Zea-Ponce Y, Gil R, Kegeles LS, Weiss R, Cooper TB, Mann JJ, Van Heertum RL, Gorman JM, and Laruelle M. Increased baseline occupancy of D2 receptors by dopamine in schizophrenia. Proc Natl Acad Sci U S A, 2000. 97(14): p. 8104-9.

91. Howes O, Bose S, Turkheimer F, Valli I, Egerton A, Stahl D, Valmaggia L, Allen P, Murray R, and McGuire P. Progressive increase in striatal dopamine synthesis capacity as patients develop psychosis: a PET study. Mol Psychiatry, 2011. 16(9): p. 885-6.

92. Howes OD, Bose SK, Turkheimer F, Valli I, Egerton A, Valmaggia LR, Murray RM, and McGuire P. Dopamine Synthesis Capacity Before Onset of Psychosis: A Prospective [18F]-DOPA PET Imaging Study. Am J Psychiatry, 2011.

93. Goldman-Rakic PS. Working memory dysfunction in schizophrenia. J Neuropsychiatry Clin Neurosci, 1994. 6(4): p. 348-57.

94. Velligan DI and Bow-Thomas CC. Executive function in schizophrenia. Semin Clin Neuropsychiatry, 1999. 4(1): p. 24-33.

95. Wobrock T, Ecker UK, Scherk H, Schneider-Axmann T, Falkai P, and Gruber O. Cognitive impairment of executive function as a core symptom of schizophrenia. World J Biol Psychiatry, 2009. 10(4 Pt 2): p. 442-51.

96. Surmeier DJ. Dopamine and working memory mechanisms in prefrontal cortex. J Physiol, 2007. 581(Pt 3): p. 885.

97. Takahashi H, Kato M, Takano H, Arakawa R, Okumura M, Otsuka T, Kodaka F, Hayashi M, Okubo Y, Ito H, and Suhara T. Differential contributions of prefrontal and hippocampal dopamine $D(1)$ and $D(2)$ receptors in human cognitive functions. J Neurosci, 2008. 28(46): p. 12032-8.

98. Kanahara N, Shimizu E, Sekine Y, Uchida Y, Shibuya T, Yamanaka H, Hashimoto T, Asaka T, Sasaki T, Miyatake R, Ohkami T, Fukami G, Fujisaki M, Watanabe H, Shirayama Y, Hayashi H, Hashimoto K, Asano M, and Iyo M. Does hypofrontality expand to global brain area in progression of schizophrenia?: a cross-sectional study between first-episode and chronic schizophrenia. Prog Neuropsychopharmacol Biol Psychiatry, 2009. 33(3): p. 410-5. 
99. Li X, Tang J, Wu Z, Zhao G, Liu C, and George MS. SPECT study of Chinese schizophrenic patients suggests that cerebral hypoperfusion and laterality exist in different ethnic groups. World J Biol Psychiatry, 2005. 6(2): p. 98-106.

100. Liu Z, Tam WC, Xie Y, and Zhao J. The relationship between regional cerebral blood flow and the Wisconsin Card Sorting Test in negative schizophrenia. Psychiatry Clin Neurosci, 2002. 56(1): p. 3-7.

101. Rubin P, Holm S, Madsen PL, Friberg L, Videbech P, Andersen HS, Bendsen BB, Stromso N, Larsen JK, Lassen NA, and et al. Regional cerebral blood flow distribution in newly diagnosed schizophrenia and schizophreniform disorder. Psychiatry Res, 1994. 53(1): p. 57-75.

102. Weinberger DR, Berman KF, Suddath R, and Torrey EF. Evidence of dysfunction of a prefrontal-limbic network in schizophrenia: a magnetic resonance imaging and regional cerebral blood flow study of discordant monozygotic twins. Am J Psychiatry, 1992. 149(7): p. 890-7.

103. Heaton R. A manual for the Wisconsin card sorting test. 1980, Odessa, Florida: Psychological Assessment Resources, Inc.

104. Carrieri P, Campanella G, Mandarini A, Orefice G, and Buscaino GA. [Central metabolism of dopamine and serotonin. I. Determination of cerebrospinal fluid levels of HVA and 5-HIAA by the probenecid test (modified)]. Acta Neurol (Napoli), 1976. 31(5): p. 558-64.

105. Ebinger $G$ and Verheyden R. On the occurence of vanillic acid in human brain and cerebrospinal fluid. $J$ Neurol, 1976. 212(2): p. 133-8.

106. Pycock CJ, Carter CJ, and Kerwin RW. Effect of 6-hydroxydopamine lesions of the medial prefrontal cortex on neurotransmitter systems in subcortical sites in the rat. J Neurochem, 1980. 34(1): p. 91-9.

107. Pycock CJ, Kerwin RW, and Carter CJ. Effect of lesion of cortical dopamine terminals on subcortical dopamine receptors in rats. Nature, 1980. 286(5768): p. 74-6.

108. Adler MW. Changes in sensitivity to amphetamine in rats with chronic brain lesions. J Pharmacol Exp Ther, 1961. 134: p. 214-21.

109. Iversen D, Wilkinson S, and Simpson B. Enhanced amphetamine responses after frontal cortex lesions in the rat. Eur J Pharmacol, 1971. 13(3): p. 387-90.

110. Meyer-Lindenberg A, Miletich RS, Kohn PD, Esposito G, Carson RE, Quarantelli M, Weinberger DR, and Berman KF. Reduced prefrontal activity predicts exaggerated striatal dopaminergic function in schizophrenia. Nat Neurosci, 2002. 5(3): p. 267-71.

111. Roth RH, Tam SY, Ida Y, Yang JX, and Deutch AY. Stress and the mesocorticolimbic dopamine systems. Ann N Y Acad Sci, 1988. 537: p. 138-47.

112. Tidey JW and Miczek KA. Social defeat stress selectively alters mesocorticolimbic dopamine release: an in vivo microdialysis study. Brain Res, 1996. 721(1-2): p. 140-9.

113. Abercrombie ED, Keefe KA, DiFrischia DS, and Zigmond MJ. Differential effect of stress on in vivo dopamine 
release in striatum, nucleus accumbens, and medial frontal cortex. J Neurochem, 1989. 52(5): p. 1655-8.

115. King D, Zigmond MJ, and Finlay JM. Effects of dopamine depletion in the medial prefrontal cortex on the stress-induced increase in extracellular dopamine in the nucleus accumbens core and shell. Neuroscience, 1997. 77(1): p. 141-53.

116. Scornaiencki R, Cantrup R, Rushlow WJ, and Rajakumar N. Prefrontal cortical D1 dopamine receptors modulate subcortical D2 dopamine receptor-mediated stress responsiveness. Int J Neuropsychopharmacol, 2009. 12(9): p. 1195-208.

117. Karreman M and Moghaddam B. The prefrontal cortex regulates the basal release of dopamine in the limbic striatum: an effect mediated by ventral tegmental area. J Neurochem, 1996. 66(2): p. 589-98.

118. Pani L, Porcella A, and Gessa GL. The role of stress in the pathophysiology of the dopaminergic system. Mol Psychiatry, 2000. 5(1): p. 14-21.

119. Montgomery AJ, Mehta MA, and Grasby PM. Is psychological stress in man associated with increased striatal dopamine levels?: A [11C]raclopride PET study. Synapse, 2006. 60(2): p. 124-31.

120. Soliman A, O'Driscoll GA, Pruessner J, Holahan AL, Boileau I, Gagnon D, and Dagher A. Stress-induced dopamine release in humans at risk of psychosis: a [11C]raclopride PET study. Neuropsychopharmacology, 2008. 33(8): p. 2033-41.

121. Badgaiyan RD, Fischman AJ, and Alpert NM. Dopamine release during human emotional processing. Neuroimage, 2009. 47(4): p. 2041-5.

122. Christian BT, Lehrer DS, Shi B, Narayanan TK, Strohmeyer PS, Buchsbaum MS, and Mantil JC. Measuring dopamine neuromodulation in the thalamus: using [F-18]fallypride PET to study dopamine release during a spatial attention task. Neuroimage, 2006. 31(1): p. 139-52.

123. Mukherjee J, Christian BT, Dunigan KA, Shi B, Narayanan TK, Satter M, and Mantil J. Brain imaging of 18Ffallypride in normal volunteers: blood analysis, distribution, test-retest studies, and preliminary assessment of sensitivity to aging effects on dopamine D-2/D-3 receptors. Synapse, 2002. 46(3): p. 170-88.

124. Riccardi P, Zald D, Li R, Park S, Ansari MS, Dawant B, Anderson S, Woodward N, Schmidt D, Baldwin R, and Kessler R. Sex differences in amphetamine-induced displacement of [(18)F]fallypride in striatal and extrastriatal regions: a PET study. Am J Psychiatry, 2006. 163(9): p. 1639-41.

125. Vrieze E, Ceccarini J, Pizzagalli D, Bormans G, Vandenbulcke M, Demyttenaere K, Van Laere K, and Claes S. Measuring extrastriatal dopamine release during a reward learning task. Human Brain Mapping, in press.

126. Woodward ND, Cowan RL, Park S, Ansari MS, Baldwin RM, Li R, Doop M, Kessler RM, and Zald DH. Correlation of individual differences in schizotypal personality traits with amphetamine-induced dopamine release in striatal and extrastriatal brain regions. Am J Psychiatry, 2011. 168(4): p. 418-26. 
127. Peroutka SJ and Synder SH. Relationship of neuroleptic drug effects at brain dopamine, serotonin, alphaadrenergic, and histamine receptors to clinical potency. Am J Psychiatry, 1980. 137(12): p. 1518-22.

128. Berridge KC and Robinson TE. What is the role of dopamine in reward: hedonic impact, reward learning, or incentive salience? Brain Res Brain Res Rev, 1998. 28(3): p. 309-69.

129. Heinz A. [Anhedonia--a general nosology surmounting correlate of a dysfunctional dopaminergic reward system?]. Nervenarzt, 1999. 70(5): p. 391-8.

130. Martin-Soelch C, Leenders KL, Chevalley AF, Missimer J, Kunig G, Magyar S, Mino A, and Schultz W. Reward mechanisms in the brain and their role in dependence: evidence from neurophysiological and neuroimaging studies. Brain Res Brain Res Rev, 2001. 36(2-3): p. 139-49.

131. Robbins TW and Everitt BJ. Functional studies of the central catecholamines. Int Rev Neurobiol, 1982. 23: p. 303-65.

132. Robbins TW and Everitt BJ. Neurobehavioural mechanisms of reward and motivation. Curr Opin Neurobiol, 1996. 6(2): p. 228-36.

133. Schultz W. Dopamine neurons and their role in reward mechanisms. Curr Opin Neurobiol, 1997. 7(2): p. 1917.

134. Schultz W. Getting formal with dopamine and reward. Neuron, 2002. 36(2): p. 241-63.

135. Wise RA. Dopamine, learning and motivation. Nat Rev Neurosci, 2004. 5(6): p. 483-94.

136. Wise RA and Rompre PP. Brain dopamine and reward. Annu Rev Psychol, 1989. 40: p. 191-225.

137. Kapur S. Psychosis as a state of aberrant salience: a framework linking biology, phenomenology, and pharmacology in schizophrenia. Am J Psychiatry, 2003. 160(1): p. 13-23.

138. Kapur S, Mizrahi R, and Li M. From dopamine to salience to psychosis--linking biology, pharmacology and phenomenology of psychosis. Schizophr Res, 2005. 79(1): p. 59-68.

139. Artaloytia JF, Arango C, Lahti A, Sanz J, Pascual A, Cubero P, Prieto D, and Palomo T. Negative signs and symptoms secondary to antipsychotics: a double-blind, randomized trial of a single dose of placebo, haloperidol, and risperidone in healthy volunteers. Am J Psychiatry, 2006. 163(3): p. 488-93.

140. Van Putten T. Why do patients with manic-depressive illness stop their lithium? Compr Psychiatry, 1975. 16(2): p. 179-83.

141. Van Putten T, May PR, Marder SR, and Wittmann LA. Subjective response to antipsychotic drugs. Arch Gen Psychiatry, 1981. 38(2): p. 187-90.

142. de Haan L, Lavalaye J, Linszen D, Dingemans PM, and Booij J. Subjective experience and striatal dopamine $D(2)$ receptor occupancy in patients with schizophrenia stabilized by olanzapine or risperidone. Am J Psychiatry, 2000. 157(6): p. 1019-20.

143. Mizrahi R, Rusjan P, Agid O, Graff A, Mamo DC, Zipursky RB, and Kapur S. Adverse subjective experience with antipsychotics and its relationship to striatal and extrastriatal D2 receptors: a PET study in schizophrenia. Am 
J Psychiatry, 2007. 164(4): p. 630-7.

144. Voruganti L, Slomka P, Zabel P, Costa G, So A, Mattar A, and Awad AG. Subjective effects of AMPT-induced dopamine depletion in schizophrenia: correlation between dysphoric responses and striatal $D(2)$ binding ratios on SPECT imaging. Neuropsychopharmacology, 2001. 25(5): p. 642-50.

145. Karow A and Naber D. Subjective well-being and quality of life under atypical antipsychotic treatment. Psychopharmacology (Berl), 2002. 162(1): p. 3-10.

146. de Haan L, van Bruggen M, Lavalaye J, Booij J, Dingemans PM, and Linszen D. Subjective experience and D2 receptor occupancy in patients with recent-onset schizophrenia treated with low-dose olanzapine or haloperidol: a randomized, double-blind study. Am J Psychiatry, 2003. 160(2): p. 303-9.

147. Awad AG and Hogan TP. Subjective response to neuroleptics and the quality of life: implications for treatment outcome. Acta Psychiatr Scand Suppl, 1994. 380: p. 27-32.

148. Naber D, Karow A, and Lambert M. Subjective well-being under the neuroleptic treatment and its relevance for compliance. Acta Psychiatr Scand Suppl, 2005(427): p. 29-34.

149. Delespaul PAEG. Assessing Schizophrenia in Daily Life. 1995, Maastricht: University Press.

150. Myin-Germeys I, Oorschot M, Collip D, Lataster J, Delespaul P, and van Os J. Experience sampling research in psychopathology: opening the black box of daily life. Psychol Med, 2009. 39(9): p. 1533-47.

151. Wichers MC, Barge-Schaapveld DQ, Nicolson NA, Peeters F, de Vries M, Mengelers R, and van Os J. Reduced stress-sensitivity or increased reward experience: the psychological mechanism of response to antidepressant medication. Neuropsychopharmacology, 2009. 34(4): p. 923-31.

152. Barge-Schaapveld DQ and Nicolson NA. Effects of antidepressant treatment on the quality of daily life: an experience sampling study. J Clin Psychiatry, 2002. 63(6): p. 477-85.

153. Barge-Schaapveld DQ, Nicolson NA, van der Hoop RG, and De Vries MW. Changes in daily life experience associated with clinical improvement in depression. J Affect Disord, 1995. 34(2): p. 139-54.

154. Raoux N, Benoit O, Dantchev N, Denise P, Franc B, Allilaire JF, and Widlocher D. Circadian pattern of motor activity in major depressed patients undergoing antidepressant therapy: relationship between actigraphic measures and clinical course. Psychiatry Res, 1994. 52(1): p. 85-98. 
30

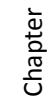




\title{
Adversity and psychosis
}

a 10-year prospective study investigating synergism between early and recent adversity in psychosis.

\author{
Johan Lataster ${ }^{1}$ \\ Inez Myin-Germeys ${ }^{1}$ \\ Roselind Lieb ${ }^{2,3}$ \\ Hans-Ullrich Wittchen ${ }^{4}$ \\ Jim van $\mathrm{Os}^{1,5}$
}
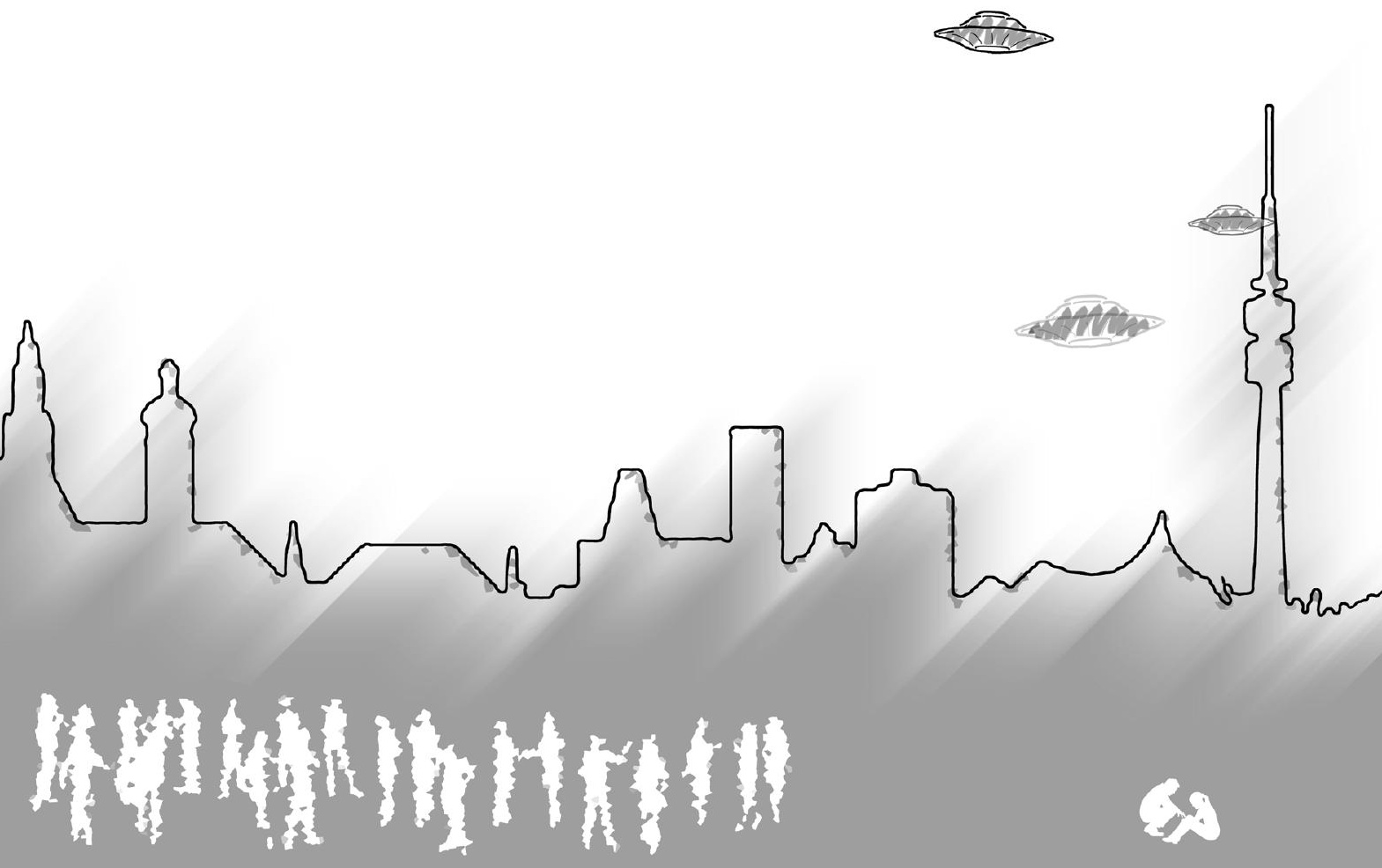
${ }^{1}$ Department of Psychiatry and Psychology, South Limburg Mental Health Research and Teaching Network, EURON, Maastricht University Medical Center, Maastricht, the Netherlands.

${ }^{2}$ Max Planck Institute of Psychiatry, Clinical Psychology and Epidemiology Unit, Munich, Germany. ${ }^{3}$ Epidemiology and Health Psychology, Institute of Psychology, University of Basel, Basel, Switzerland. ${ }^{4}$ Institute of Clinical Psychology and Psychotherapy, Technische Universitaet Dresden, Dresden, Germany. ${ }^{5}$ King's College London, King's Health Partners, Department of Psychosis Studies, Institute of Psychiatry, London, UK.

Published as:

Lataster J, Myin-Germeys I, Lieb R, Wittchen H-U, van Os J.

Adversity and psychosis: a 10-year prospective study investigating synergism between early and recent adversity in psychosis.

Acta Psychiatrica Scandinavica, 2011; epub ahead of print. doi: 10.1111/j.1600-0447.2011.01805.x 


\section{Abstract}

Objective: Recent studies have suggested that early adverse events, such as childhood trauma, may promote enduring liability for psychosis whereas more recent adverse events may act as precipitants. Examination of these environmental dynamics, however, requires prospective studies in large samples. This study examines whether the association between recent adverse events and psychosis is moderated by exposure to early adversity.

Method: A random regional representative population sample of 3021 adolescents and young adults in Munich, Germany, was assessed three times over a period of up to 10 years, collecting information on sociodemographic factors, environmental exposures, and measures of psychopathology and associated clinical relevance. Evidence of statistical nonadditivity between early adversity (two levels) and more recent adversity (four levels) was assessed in models of psychotic symptoms. Analyses were a priori corrected for age, gender, cannabis use, and urbanicity.

Results: Early and recent adversity were associated with each other ( $R R=1.32,95 \% \mathrm{Cl} 1.06$ $1.66 ; p=.014)$ and displayed statistical non-additivity at the highest level of exposure to recent adversity $\left(\chi^{2}=4.59 ; p=.032\right)$.

Conclusion: The findings suggest that early adversity may impact on later expression of psychosis either by increasing exposure to later adversity and/or by rendering individuals more sensitive to later adversity if it is severe. 


\section{Introduction}

Vulnerability for psychosis is likely determined by the interacting contributions of multiple genetic and environmental factors ${ }^{1,2}$. One environmental factor thought to impact on risk is the experience of stressful or adverse life events (hereafter: recent adversity) ${ }^{3-7}$. Despite a general acceptance in both clinical practice and the literature that recent adversity increases the risk for psychotic illness, epidemiological studies investigating the relationship between recent adversity and psychotic outcomes have yielded conflicting results (see Fallon ${ }^{8}$ for review). Although several studies report increased rates of recent adversity in the period prior to onset of psychotic symptoms or relapse $e^{3,4,9}$, other studies have failed to replicate these findings ${ }^{10-14}$. Sampling differences and methodological variation and inadequacies may, at least in part, explain these conflicting results ${ }^{3,8,15}$. However, not all inconsistencies may be attributable to differences in study design, since even studies with comparable designs have reported disparate findings ${ }^{12,16,17}$. In addition, in studies reporting associations between recent adversity and psychotic relapse, no more than half of all psychotic outcomes could be attributed to recent adversity, assuming causality ${ }^{4,8,17,18}$. These observations do not support the hypothesis that recent adversity triggers psychosis per se but, rather, suggest the existence of subgroups rendered more sensitive to the psychosis-provoking effect of recent adversity or predisposed to more frequently experience recent adversity.

It has been suggested that the experience of stressful events early in life such as childhood trauma (hereafter: early adversity) may explain, in part, the existence of predisposed or vulnerable subgroups ${ }^{19}$. However, although exposure to early adversity such as childhood trauma has been associated with increased sensitivity for small, daily stressors in adulthood ${ }^{15}$, 20,21 , the lack of prospective studies hampers interpretation. In order to investigate possible moderating effects of early adversity on the psychosis-provoking effects of stressful experiences occurring later in life, a longitudinal, prospective study is required with a relatively large sample size $\mathrm{e}^{19,22}$.

The Early Developmental Stages of Psychopathology (EDSP) study ${ }^{23,24}$ is a longitudinal study of a population sample of 3021 adolescents and young adults that was designed to provide answers about prevalence, incidence, risk factors, comorbidity and course of substance use and other mental disorders. Using data from the EDSP-study, the current study aimed at examining whether the association between recent adversity and psychosis is moderated by exposure to early adversity, taking into account possible confounding by urbanicity and cannabis use. 


\section{Materials and methods}

\section{Sample}

Data were from the Early Developmental Stages of Psychopathology (EDSP) Study, which collected data on the prevalence, incidence, risk factors, comorbidity, and course of mental disorders in a random, representative population sample of adolescents and young adults in the general population. The baseline sample, following ethics committee approval, was randomly drawn in 1994 from the respective population registry offices of Munich and its 29 counties to mirror the distribution of individuals expected to be 14-24 years of age at the time of the baseline interview in 1995. The base population were all those born between June 1, 1970, and May 31, 1981, registered as residents in these localities and having German citizenship. These registers can be regarded as highly accurate because (i) each German is registered by his town, (ii) the registers are regularly updated, (iii) in the interest of scientific studies, any number of randomly drawn addresses with a given sex and age group can be obtained, and (iv) strict enforcement of registration by law and the police applies. More details on the sampling, representativeness, instruments, procedures, and statistical methods of the sample have been presented previously ${ }^{23,24}$. The EDSP study was approved by the Ethics Committee of the Technical University Dresden ( $N^{\circ}$ : EK-13811), and was carried out in accordance with The Code of Ethics of the World Medical Association (Declaration of Helsinki) for experiments involving humans.

\section{Study design}

The longitudinal prospective design consisted of a baseline and three follow-up surveys (T1, $\mathrm{T} 2$, and T3), covering a time period of on average 1.6, 3.5, and 8.4 years, respectively, from baseline (range at T3: 7.3-10.5 years). As the primary goal of the study was to examine developmental aspects of psychopathology, the younger group (14 and 15 years of age) was sampled at twice the rate of persons 16-21 years of age, and the oldest group (22-24 years) was sampled at half this rate. For the same reason, subjects 14-17 years of age at baseline were examined at all four time points, whereas the full baseline sample was only assessed at three time points (baseline, T2, and T3). The present study is based on the three assessments that were available for the full baseline sample: 3021 individuals 14-24 years of age at baseline and their follow-up assessments at T2 ( $n=2548$; response rate=84\%) and T3 ( $n=2210 ; 73 \%$ ). Written informed consent was obtained from all participants. 


\section{Instruments}

\section{The Munich-Composite International Diagnostic Interview}

Participants were assessed using the computerized version of the Munich-Composite International Diagnostic Interview (DIA-X/M-CIDI) ${ }^{25}$, 26, an updated version of the World Health Organization's CIDI version $1.2^{27}$. The DIA-X/M-CIDI is a comprehensive, fully standardized diagnostic interview and assesses symptoms, syndromes, and diagnoses of various mental disorders in accordance with the definitions and criteria of the International Classification of Diseases, Tenth Revision (ICD-10), and Diagnostic and Statistical Manual of Mental Disorders (Fourth Edition), along with information about onset, duration, severity of symptoms, and psychosocial impairment as well as interviewer observations.

As the assessment of psychosis with the CIDI by lay interviewers is not considered reliable ${ }^{25}$, ${ }^{28}$, trained clinical interviewers at the level of psychologist, who were allowed to probe with follow-up clinical questions, conducted the interviews in the respondents' homes.

At baseline, the DIA-X/M-CIDI lifetime version was used. At each of the follow-up assessments, interviewers administered the interval version, covering the period from the last interview until the current.

\section{The Self-report Symptom Checklist-90R}

At each wave, participants completed the self-report symptom checklist- $90 \mathrm{R}^{29}$, the timeframe of which is the past 2 weeks, oriented to screen for a broad range of psychological problems and psychopathology. It contains 90 items, scored on a 5-point severity scale, measuring 9 primary symptom dimensions named "somatization", "obsessive-compulsiveness", "interpersonal sensitivity”, "depression”, "anxiety”, "hostility”, "phobic anxiety”, "paranoid ideation" and "psychoticism". Reliability and validity of the SCL-90-R have been established previously ${ }^{29,30}$. For current analyses, data from baseline and T2 were used.

\section{Munich Interview for the Assessment of Life Events and Conditions (MEL)}

At T2, the Munich Interview for the Assessment of Life Events and Conditions (Münchner Ereignis Liste; MEL) ${ }^{31}$ was used to assess the occurrence of recent adversity in the period between baseline and T2. The MEL is a three-step interview procedure for assessing recent adversity through recognition, rather than free recall, using a list of 84 very detailed and specific descriptions of positive and negative life events encompassing 11 dimensions, including school and education, family, social contacts, professional activities, and living 
circumstances. First, a life chart is used to identify anchor events and the date of their occurrence, facilitating the general timing of incidents within the period of assessment. Next, subjects are interviewed about the content, timing, and context of these events. Finally, systematic probe questions and memory aids are provided by the interviewer to identify additional events that were not yet mentioned by the subject. Incidents that were not operationalized within the MEL but were mentioned by the subjects were also coded. Reliability of the MEL has been established previously ${ }^{32}$.

\section{Definition of variables}

\section{Early adversity}

Childhood early adversity measures were derived from the trauma-section (items N1 through N19) of the DIA-X/M-CIDI lifetime interview, conducted at baseline, and information about early life parental loss and separation, assessed at T3. At baseline, participants could indicate a positive response on a visually presented list of traumatic events, including terrible experiences in a war, serious physical threats or attacks, rape, sexual abuse, natural catastrophes, serious accidents, imprisonment, and hostage or kidnap experiences. Consistent with previous work in this sample ${ }^{33,34}$, affirmative responses to any of the events were labelled 'self-reported trauma'. Furthermore, given the strong association between the experience of parental loss or separation and psychosis ${ }^{35-37}$, all participants were identified that at T3 reported death of a parent or separation from a parent preceding the date of baseline assessment. Measures of self-reported trauma and parental loss/separation were combined into a dichotomous ("yes" vs. "no") 'early adversity' variable.

\section{Recent adversity}

Classification of recent adversity was based on self-reported trauma according to the trauma-section of the DIA-X/M-CIDI interval version (items N1 through N19), self-reported negative life events according to the MEL cluster of negative life events, both assessed at T2, and information about parental loss and separation, assessed at T3. 'Self-reported trauma' measures at T2 were identical to those at baseline, with the exception of the timeframe considered. At T3, all participants were identified that reported death of a parent or separation from a parent having occurred after baseline up to T2 assessments. A continuous 'recent adversity' variable was constructed, calculated as the sum of self-reported traumatic events, negative life events and occurrences of parental loss or separation after baseline up 
to T2 assessments. The distribution of this variable was divided by its quartiles, resulting in four exposure levels: " 0 " (0-2 events); "1" (3-5 events); " 2 " (6-9 events); and " 3 " ( $\geq 10$ events).

\section{Psychosis liability}

Consistent with previous work in this sample $33,38,39$, the psychoticism and paranoid ideation subscales of the SCL-90R were combined into one psychosis scale (hereafter: 'SCL-psychosis'), by summing their scores. The resulting SCL-psychosis variable thus was a continuous score displaying a half-normal distribution at all time points (baseline-T3). Consistent with previous work in this sample ${ }^{39}$, a dichotomous 'psychosis liability' variable was created using a cutoff point to define the group of individuals with the highest $10 \%$ of scores of the SCLpsychosis variable at either baseline or T2. These participants were considered as having a psychometrically defined predisposition for psychosis prior to T3.

\section{Outcome variables}

\section{T3 Psychosis}

Interview ratings from the psychosis section of the T3 DIA-X/M-CIDI (interval version; items G1, G2a, G3-G5, G7-G13, G13b, G14, G17, G18, G20, G20C, G21, and G22a) on delusions (15 items) and hallucinations (5 items) were used to assess the outcome of T3 psychotic symptoms. These 20 items concern classic psychotic symptoms, including Schneiderian firstrank symptoms such as audible thoughts, thought insertion, thought withdrawal, and made acts and impulses. Participants were invited to read a list of all the psychotic experiences and asked whether they had ever experienced such symptoms. Each psychosis item was rated absent or present. Consistent with previous work in this sample ${ }^{38,40}$, presence of psychotic symptoms was defined as a rating of "present" on any of the 20 psychosis items.

\section{T3 Clinical relevance}

Clinical relevance of positive psychotic symptoms was assessed with interview ratings of the T3 DIA-X/M-CIDI (interval version) psychosis section. Three help-seeking items assessed whether participants had ever sought help because of psychotic symptoms: "seeking doctor's help because of delusions (G16) or hallucinations" (G23) or "seeking help from other mental health professionals" (Q1DG), ranging from a general practitioner or school psychologist to psychiatric sheltered housing. Consistent with previous work in this sample ${ }^{38,}$ 
40,41, a dichotomous 'help-seeking' variable was created, indicating a positive answer to any of the three questions (coded as 1 ) versus negative answers on all.

The diagnostic interview also assesses the effect of psychotic experiences on "feeling upset or unable to work, go places, or enjoy oneself" (G28) at the time of having these experiences; "being less able to work" (G29) or "less able to make friends or enjoy social relationships" (G29a) since these experiences began; and how much their "life and everyday activities were impaired when these experiences were at their worst" (G36). Consistent with previous work in this sample ${ }^{38,40,41}$, a dichotomous 'dysfunction' variable was created representing a positive answer on any of the four questions (coded as 1) versus negative answers on all.

Finally, consistent with previous work in this sample $38,40,41$, a dichotomous variable 'psychotic impairment' was created, coded as 1 for subjects with psychotic experiences who had ratings of "1" on either help-seeking or dysfunction or both.

\section{Urbanicity}

Urbanicity was assessed at baseline by retrieving data on living location from the population registry offices of the city and the 29 counties of Munich. Consistent with previous work in this sample $38,40,41$, urbanicity was defined as either living in the city of Munich (4061 persons per square mile) or in its rural surroundings (553 persons per square mile) at the time of study inclusion.

\section{Cannabis use}

Information about cannabis use was extracted from the L-section of the DIA-X/M-CIDI interview, conducted at baseline (lifetime version), T2 (interval version), and T3 (interval version). Based on previous work in this sample ${ }^{39,41}$, lifetime cannabis use was defined as a dichotomous variable, differentiating between participants who reported cannabis use more than 5 times at either baseline or T2, and those who did not.

\section{Statistical analysis}

\section{Risk set}

Analyses regarding early and recent adversity in relation to T3 psychotic symptoms and T3 psychotic impairment outcomes were conducted in the group of individuals who had complete data on early adversity, recent adversity, and T3 psychosis outcome measures ( $n=2149$ ). In addition, since exposure to, and recall of adverse events may likely be biased by 
psychotic experiences or illness ${ }^{42}$, all participants fulfilling criteria for psychosis liability prior to T3 ( $n=427)$ were excluded from the analyses, yielding a risk set of 1722 individuals and a non-included group of 1299 individuals. A sensitivity analysis to test the effect of excluding participants fulfilling criteria for psychosis liability prior to T3 $(n=427)$ was conducted.

\section{Analysis}

Associations between 'early adversity' (prior to baseline), 'recent adversity' (after baseline up to T2), and incident psychosis outcome (T3 'psychotic symptoms'; T3 'psychotic impairment') were expressed as risk ratios (RR), with their 95\% confidence intervals, from binomial regression models in Stata, release $10.0^{43}$. In order to test for statistical non-additivity between 'early adversity' (E) and 'recent adversity' (R), RR's of 'psychotic symptoms' and 'psychotic impairment' at T3 were calculated for the eight exposure cells that make up the combination of the two exposures; $\operatorname{RR}\left(E_{0} R_{0}\right) ; \operatorname{RR}\left(E_{0} R_{1}\right) ; \operatorname{RR}\left(E_{0} R_{2}\right) ; \operatorname{RR}\left(E_{0} R_{3}\right) ; \operatorname{RR}\left(E_{1} R_{0}\right) ; \operatorname{RR}\left(E_{1} R_{1}\right)$; $R R\left(E_{1} R_{2}\right) ; R R\left(E_{1} R_{3}\right.$ ) (Table 3; Table 4), consistent with previous work in this sample ${ }^{44}$. Similar to recent work in this area ${ }^{33,45-51}$, the interaction between 'early adversity' and 'recent adversity' in the models of T3 'psychotic symptoms' and T3 'psychotic impairment' was tested under an additive model, as this yields information on the degree of synergism between causes - that is, the extent to which both causes depend on each other or coparticipate in disease causation $^{52}$. For the three interaction terms, the null hypothesis of no additive interaction (example given for $R_{3}$, similar equations for $R_{1}$ and $\left.R_{2}\right)$ : $R R\left(E_{1} R_{3}\right)-\operatorname{RR}\left(E_{1} R_{0}\right)-R R\left(E_{0} R_{3}\right)+R R\left(E_{0} R_{0}\right)$ $=0$ was assessed by Wald test, with $R R\left(E_{0} R_{0}\right)=1$ representing the reference exposure cell ${ }^{53-}$

55. Rejection of the null hypothesis suggests synergism between early and recent adversity in their association with psychosis onset. All results were interpreted against a significance threshold of $\alpha=5 \%(p=0.05)$.

\section{Results}

\section{Subject characteristics}

The distribution of demographic variables for the risk set and the non-included group at baseline is displayed in Table 1.

Within the risk set, 605 individuals (35.1\%) reported baseline early adversity, with the 
following distribution of adversity: serious physical threats or attacks ( $n=121 ; 20.0 \%$ ); serious accidents $(n=110 ; 18.2 \%)$; sexual abuse $(n=21 ; 3.5 \%)$; rape $(n=11 ; 1.8 \%)$; natural catastrophes $(n=5 ; 0.8 \%)$; terrible experiences in a war $(n=4 ; 0.7 \%)$; imprisonment, hostage or kidnap experiences $(n=1 ; 0.2 \%)$; other traumatic experiences $(n=28 ; 4.6 \%)$; witnessing any of the above $(n=61 ; 10.1 \%)$; separation from or death of a parent $(n=243 ; 40.2 \%)$. With regard to recent (i.e., after baseline up to T2) adversity, a proportion of $15.6 \%(n=268)$ reported 0-2 adverse events; $28.7 \%(n=494)$ reported $3-5$ adverse events; $30.6 \%(n=527)$ reported $6-9$ adverse events; $25.1 \%(n=433)$ reported 10 or more adverse events. Within the risk set, 170 individuals (9.9\%) displayed psychotic symptoms at T3, of which 63 individuals (3.7\% of total risk set) fulfilled criteria for T3 psychotic impairment.

\section{Associations between early adversity, recent adversity, and T3 psychotic outcome}

Unadjusted binomial regression indicated that early adversity was associated with T3 psychotic symptoms; 72 of 605 (11.9\%) individuals with early adversity reported T3 psychotic symptoms, compared to 98 of 1117 (8.8\%) without early adversity (RR 1.36, 95\% $\mathrm{Cl} 1.02-1.81 ; \mathrm{p}=.038)$. Similarly, early adversity was significantly associated with T3 psychotic impairment; 30 of 605 (5.0\%) individuals with early adversity fulfilling criteria for T3 psychotic impairment, compared to 33 of 1117 (3.0\%) without early adversity (RR 1.68, 95\% Cl 1.03$2.72 ; p=.036)$. Both associations were in part reducible to the effects of demographic and other risk factors (corrected for age, gender, urbanicity, and cannabis use: $\mathrm{RR} 1.24,95 \% \mathrm{Cl}$ $.92-1.67 ; p=.165$, and RR 1.47, 95\% Cl .88-2.44; $p=.140$, respectively).

Recent adversity, particularly at the highest severity level, was strongly associated with an increased risk of T3 psychotic symptoms; $16.6 \%(n=72$ of 433$)$ of individuals in the highest exposure group ( $\geq 10$ events) reported T3 psychotic symptoms, compared to $5.2 \%$ ( $n=14$ of 268 ) in the lowest exposure group (0-2 events) ( $R R$ 3.18, 95\% Cl 1.83-5.53; $p=.0001$; Table 2). Similarly, recent adversity was associated with T3 psychotic impairment; $7.2 \%$ ( $n=31$ of 433 ) of individuals in the highest exposure group fulfilled criteria for T3 psychotic impairment, compared to $1.5 \%$ ( $n=4$ of 268 ) in the lowest exposure group $(0-2$ events) (RR $4.80,95 \% \mathrm{Cl}$ 1.71-13.44; $p=.003$; Table 2). Both associations remained significant after correction for age, gender, urbanicity, and cannabis use (RR 3.18; 95\% $\mathrm{Cl} 1.79-5.64 ; p=.0001$, and $\mathrm{RR} 4.59,95 \%$ Cl 1.62-13.00; $p=.004$, respectively).

Finally, individuals who had experienced early adversity were more likely to report $\geq 10$ recent adverse events at T2 than those who had not; 185 of 605 (30.6\%) individuals who 
had experienced early adversity reported $\geq 10$ recent adverse events, compared to 248 of 1117 (22.2\%) individuals without early adversity ( $R R 1.51,95 \% \mathrm{Cl} 1.21-1.88 ; \mathrm{p}=.0001$ ). This association remained significant after correction for age, gender, urbanicity, and cannabis use (RR 1.32, 95\% Cl 1.06-1.66; $p=.014$ ).

\section{Non-additivity between early and recent adversity}

The risk ratios for T3 psychotic symptoms in the 8 exposure states are depicted in Table 3. Significant associations were apparent only for the highest levels of exposure to recent adverse events $\left(R_{3}\right)$, with or without exposure to early adversity. The adjusted risk ratio for the combined $R R\left(E_{1} R_{3}\right)$ exposure category was 4.08 , whereas for early adversity alone $\left(R R\left(E_{1} R_{0}\right)\right)$ it was 1.10, and for those exposed to $\geq 10$ recent adverse events alone $\left(R R\left(E_{0} R_{3}\right)\right)$ it was 2.67. Considering a risk ratio of 1.00 for the reference exposure category $\left(R R\left(E_{0} R_{0}\right)\right)$, this suggests a departure from independence, as the expected risk ratio for the combined $R R\left(E_{1} R_{3}\right)$ exposure category in the case of independence would have been $1.10+2.67$ $1.00=2.77^{52,54,55}$. In other words, the effect size of the highest level of exposure to recent adversity for psychotic symptoms in those without early adversity was, on the additive scale, 2.67-1.00=1.67, whereas for those with early adversity it was 4.08-1.10=2.98. The Wald test for additive interaction between these two exposures in the model of psychotic symptoms, adjusted for age, gender, urbanicity, and cannabis use, was statistically significant for the highest level of exposure to recent adversity $\left(\chi^{2}=4.59 ; p=.032 ;\right.$ Table 3$)$.

Repeating the analysis of additive interaction in the whole set of individuals who had complete data on early life trauma, later life trauma, and T3 psychotic symptoms ( $n=2149)$, including those individuals who fulfilled criteria for psychosis liability prior to T3, yielded increased significance of the test for additive interaction for the highest level of exposure to recent adversity ( $\chi^{2}=8.19 ; p=.004$; adjusted for age, gender, urbanicity, and cannabis use).

The analysis of additive interaction between early and recent adversity in the model of psychotic symptoms was not significant for the other, less severe levels of recent adversity exposure $\left(R_{1}\right.$ and $R_{2}$; Table 3$)$

The risk ratios for T3 psychotic impairment in the 8 exposure states are depicted in Table 4. A significant association was apparent only for the highest level of exposure to recent adversity in combination with exposure to early adversity. Thus, the adjusted risk ratio for the combined $R R\left(E_{1} R_{3}\right)$ exposure category was 6.41 , whereas for early adversity alone $\left(R R\left(E_{1} R_{0}\right)\right)$ it was 0.84 , and for those exposed to $\geq 10$ recent adverse events alone $\left(R R\left(E_{0} R_{3}\right)\right)$ 
it was 2.87. Considering a risk ratio of 1.00 for the reference exposure category $\left(R R\left(E_{0} R_{0}\right)\right)$, this suggests a departure from independence, as the expected risk ratio for the combined $R R\left(E_{1} L_{3}\right)$ exposure category in the case of independence would have been $0.84+2.87$ $1.00=2.71^{52,54,55}$. In other words, the effect size of the highest level of recent adversity for T3 psychotic impairment in those without early adversity was, on the additive scale, 2.87$1.00=1.87$, whereas for those with early adversity it was $6.41-0.84=5.57$. The Wald test for additive interaction between these two exposures in the model of psychotic impairment, adjusted for age, gender, urbanicity and cannabis use, was suggestive albeit not statistically significant at conventional alpha for the highest level of exposure to recent adversity $\left(\chi^{2}=2.72 ; p=.099 ;\right.$ Table 4).

Repeating the analysis of additive interaction in the whole set of individuals who had complete data on early adversity, recent adversity, and T3 psychotic impairment $(n=2149)$, including individuals who fulfilled criteria for psychosis liability prior to T3, yielded increased precision of the test for additive interaction for the highest level of exposure to recent adversity, although not at conventional alpha $\left(\chi^{2}=3.35 ; p=.067\right.$; adjusted for age, gender, urbanicity, and cannabis use).

The analysis of additive interaction between early and recent adversity in the model of psychotic impairment was not suggestive or significant for the other, less severe levels of recent adversity exposure $\left(\mathrm{R}_{1}\right.$ and $\mathrm{R}_{2}$; Table 4$)$.

\section{Discussion}

This longitudinal prospective study showed that experiences of early and recent adversity were strongly correlated and interacted additively, at the level of severe recent adversity, in increasing the risk of psychosis. Although the effect of early adversity on psychotic symptoms was - unlike recent adversity - in part reducible to other demographic and risk factors, the adjusted association between severe recent adversity and psychotic symptoms was much stronger in individuals who were exposed to early adversity compared to those who were not. This latter finding was not reducible to urbanicity and cannabis use, other risk factors for psychosis ${ }^{2}$, or reporting bias due to presence of psychotic symptoms or illness ${ }^{42}$. The current study, thus, is suggestive of environment-environment correlation (exposure to early adversity increases risk of exposure to recent adversity which in turn increases risk for psychotic outcome) and/or environment $x$ environment interaction (exposure to early 
adversity enhances sensitivity to the psychotogenic effects of recent adversity) within the social stress pathogen of psychosis.

\section{Psychosocial stress and psychosis: possible mechanisms and implications}

The findings from the current study shed light on the suggested causal role of adversity in the pathogenesis of psychosis ${ }^{56,57}$, derived from previously observed dose-response associations between trauma and psychosis (e.g., Janssen et al..$^{58}$; Whitfield et al. ${ }^{59}$ ). The current study extends previous findings that early adversity increases risk of psychosis ${ }^{60-}$ ${ }^{63}$ by illustrating the interplay between early and recent adversity in predicting psychotic symptoms. In line with these findings is a recent 20-year follow-up study by Galletly and colleagues $^{64}$, who reported that lifetime exposure to multiple adverse events, but not a single major trauma in childhood, was associated with increased risk of later psychosis. Nonadditivity between early and recent adversity, however, was not tested. Furthermore, our findings are in line with a recent momentary assessment study showing that a history of trauma increases psychotic reactivity to later daily-life stress ${ }^{15}$. This pattern may reflect an underlying process of behavioral sensitization, i.e., individuals who are traumatized early in life may become 'sensitized' to subsequent stressors, reacting progressively more psychotic in response to stress ${ }^{6,15,65}$.

The diathesis-stress model of psychosis ${ }^{66-68}$, which states that psychotic symptoms will emerge whenever a threshold of stressors exceeds an individual's predetermined vulnerability level, classically classifies environmental effects as precipitants against a background of genetic vulnerability. The current findings, however, imply that early environmental effects can also occasion enduring liabilities in which the timing of the stressor determines its position in the equation. Therefore, the experience of psychosocial stress early in life may also contribute to the diathesis for psychosis by accentuating the vulnerability state ${ }^{19,69}$, whereas the cumulative impact of stressors occurring later in life may subsequently trigger psychotic expression ${ }^{19}$. The current findings are suggestive of a threshold effect, in that nonadditivity between early and recent adversity in the model of psychotic symptoms was only observed at the level of severe recent adversity ( $\geq 10$ recent adverse events). In addition, the strong correlation between early and recent adversity indicates that both environmentenvironment correlation (early adversity increases risk for later adversity increasing risk for psychosis) and environment-environment interaction (early adversity determines sensitivity for the psychotogenic effects of later adversity) may underlie the diathesis. These findings may provide, in addition to the issue of methodological inconsistency, a possible explanation 
for the conflicting results from previous studies on the association between life events and psychosis ${ }^{8}$. Since the current study found an association between recent adversity and psychosis to be moderated by early adversity, lack of attention to early life adversity may have contributed, in part, to imprecise results.

\section{Biological plausibility}

Biological mechanisms involved in both stress and psychosis are the dopamine neurotransmitter system and hypothalamic-pituitary-adrenal (HPA) axis. Both systems are involved in the processing of psychosocial stress ${ }^{70-73}$, and display alterations in psychotic patients $^{74-80}$, giving rise to the notion that they may play an important and possibly explanatory role in the stress-pathogenesis of psychosis ${ }^{81}$. It is suggested that stressful or adverse experiences early in life may induce developmental alterations of the HPA-axis and dopamine system, resulting in, or accentuating, vulnerabilities in the adult brain ${ }^{82-84}$. In addition, successive or cumulative exposure to stressful or adverse events may increase the stress-responsiveness of the HPA-axis and dopamine system through a process of sensitization, individuals exposed repeatedly to psychological stress developing progressively greater hormonal and neurotransmitter responses over time, finally resulting in lasting changes in response amplitude ${ }^{6,65,85}$. There is evidence of reciprocal and augmenting dopamine-HPA-axis interactions ${ }^{81}$. Hyperactivity of the dopamine system, possibly mediated by the experience of early life stress ${ }^{86}$, may enhance HPA-activation to stress, the resulting hormonal response, in turn, augmenting dopamine release in the already hyperactive dopamine system. Given the proposed mediating role of dopamine in salience attribution ${ }^{87}$, a hyperactive state may cause 'aberrant salience' (the assignment of salience to otherwise unimportant stimuli), and fuel psychotic experiences. Without confirmation by experimental studies investigating the biological mechanisms that underlie the relationship between early and later life stress and psychosis, such interpretations remain speculative. With a recent explosion of methodologically strong studies underlining a role for stress and adversity in the pathogenesis of psychosis ${ }^{60,62,63}$, however, it seems only a matter of time for these data to follow.

\section{Strengths and limitations}

Strengths of the study are the prospective study design, the relatively large sample size and the attention to confounding factors. Limitations are, first, that the data presented in the current paper were gathered in a large epidemiological study, therefore instruments and 
tools used were not refined with regard to the hypotheses under investigation. Second, early and later life adverse events were assessed retrospectively, even though the analyses relating these factors to the psychosis outcome were prospective. Previous research has indicated that recall of experiences that have occurred more than three months ago, can yield erroneous memories, most notably when these experiences are adverse or traumatic in nature ${ }^{8}$. Although this would argue against the use of T3 reported death or separation from a parent, these events are, due to their strong objective framing within the individual's social surroundings, much less liable to recall bias than, for example, sexual abuse or other 'shame-secret' traumas ${ }^{88}$. Furthermore, it cannot be completely excluded that the presence of psychosis may lead to an alteration in the recall of adverse experiences. However, because we controlled, by exclusion, for the presence of baseline and T2 psychosis liability, the results are unlikely attributable to an inverse relationship. Third, we examined psychotic symptoms according to the M-CIDI at follow up in a non-clinical sample. Although the finding of additive interaction between early and recent adversity did not, in terms of statistical significance, extend to the psychotic impairment outcome, a similar distribution of risk ratios for the combined exposures to early and recent adversity in the models of psychotic impairment and psychotic symptoms suggests this was likely due to a lack of statistical power. Symptoms were more prevalent than the combination of symptoms and impairment, diagnosable as $\mathrm{DSM}^{89}$ disorder, but nevertheless have been shown to be on the same continuum of experiences as more severe, DSM diagnosable, states of psychosis, such as schizophrenia ${ }^{90-92}$. Furthermore, in general population samples, the dimensional nature of the largely subsyndromal expression of psychosis is better reflected by the presence of symptoms than actual diagnoses. Fourth, at baseline and T2, we used self-reported psychotic experiences on the symptom checklist to determine predisposition for psychosis, whereas at follow up four years later we used the M-CIDI to determine psychosis outcome. Fifth, it must be acknowledged that the baseline lifetime self-reported trauma prevalence rates produced by this study could represent an underestimation, because respondents, for a variety of possible reasons, could have chosen not to admit to traumatic experience early in life. The relatively high adversity rates in our sample, however, do not seem to support this. Finally, in spite of the large sample, the cross-tabulations of psychotic experiences, early and late adversity exposure and impairment were such that type II results may have ensued. 


\section{Acknowledgements}

This work is further part of the Early Developmental Stages of Psychopathology (EDSP) Study, and is supported by the German Federal Ministry of Education and Research (BMBF) project no. 01EB9405/6, 01EB9910/6, EB10106200, 01EB0140, and 01EB0440. Part of the field work and analyses were also additionally supported by grants of the Deutsche Forschungsgemeinschaft (DFG) LA1148/1-1, WI2246/7-1, and WI709/8-1. Prof. dr. Inez Myin-Germeys was, furthermore, supported by a 2006 NARSAD Young Investigator Award and by the Dutch Medical Research Council (VENI and VIDI grants).

Core staff members of the EDSP group are: Dr. Katja Beesdo, Dr. Petra Zimmermann, Dr. Axel Perkonigg, Dr. Michael Höfler, Dr. Tanja Brückl, Dr. Agnes Nocon, Dipl.-Inf. Hildegard Pfister, Dipl.-Soz. Barbara Spiegel, Dr. Andrea Schreier. Scientific advisors are Dr. Jules Angst (Zurich), Dr. Kathleen Merikangas (NIMH, Bethesda), Dr. Ron Kessler (Harvard, Boston) and Prof. dr. Jim van Os (Maastricht).

\section{Declaration of Interest}

All authors declare that they have no conflicts of interest. 
Table 1 | Demographic characteristics of the risk set $(n=1722)$ and non-included individuals $(n=1299)$ at baseline.

\begin{tabular}{lcc}
\hline Characteristic & Risk Set & Non-included $^{a}$ \\
\hline Age (y; mean (SD)) & $18.4(3.4)$ & $18.1(3.3)$ \\
Gender (n, \%) & & \\
$\quad$ Male & $887(51.5)$ & $653(50.3)$ \\
$\quad$ Female & $835(48.5)$ & $300(23.1)$ \\
Level of education (n, \%) & & $424(32.6)$ \\
$\quad$ Low (mandatory basic school or learning a profession) & $175(10.2)$ & $575(44.3)$ \\
$\quad$ Medium (high school) & $491(28.5)$ & $115(8.9)$ \\
$\quad$ High (university or high school preparing for university) & $1056(61.3)$ & $798(61.4)$ \\
Social status (n, \%) & & $356(27.4)$ \\
$\quad$ Lower (lower class; lower middle class) & $92(5.4)$ & $30(2.3)$ \\
$\quad$ Middle (middle middle class) & $1006(58.4)$ & $594(34.5)$ \\
$\quad$ Upper (higher middle class; upper class) & $30(1.7)$ & $338(26.0)$ \\
$\quad$ Other (none of the above or missing values) & & $961(74.0)$ \\
Urbanicity (n, \%) & &
\end{tabular}

${ }^{a}$ Individuals not included in the risk set, including those with psychotic symptoms at $\mathrm{T} 2$.

${ }^{b}$ The participants were asked which level of education they were attending or, in the case of discontinuation, which was the highest level they had attended (Munich-CIDI item A3).

${ }^{\mathrm{c}}$ The participants were asked to choose from the specified options the class he or she believed to be in (MunichCIDI item A16).

${ }^{d}$ Obtained through German government population registries. The population density of the Munich surrounding areas was 553 persons per square mile, and that of the city 4,061 persons per square mile. 
Table 2 | Risk Ratios of psychotic symptoms and psychotic impairment, depicted for different levels of exposure to recent adverse events.

\begin{tabular}{|c|c|c|c|c|c|}
\hline \multicolumn{6}{|c|}{ Psychotic symptoms } \\
\hline $\begin{array}{l}\mathrm{N}^{\circ} \text { recent } \\
\text { adverse } \\
\text { events }\end{array}$ & $\begin{array}{c}\mathrm{N}^{\circ} \text { with } \\
\text { psychotic } \\
\text { symptoms (\%) }\end{array}$ & $\begin{array}{c}\mathrm{N}^{\circ} \text { without } \\
\text { psychotic } \\
\text { symptoms (\%) }\end{array}$ & $\begin{array}{c}\mathrm{RR} \\
\text { unadjusted }\end{array}$ & $\begin{array}{c}\text { RR } \\
\text { adjusted }^{\mathrm{a}} \\
(95 \% \mathrm{Cl})\end{array}$ & $\mathrm{p}^{\mathrm{a}}$ \\
\hline $0-2$ & $14(5.2)$ & $254(94.8)$ & $1.00^{b}$ & $1.00^{\mathrm{b}}$ & $\mathrm{b}$ \\
\hline $3-5$ & $41(8.3)$ & 453 (91.7) & 1.59 & $1.63(.89-2.99)$ & .113 \\
\hline $6-9$ & $43(8.2)$ & $484(91.8)$ & 1.56 & $1.82(.85-2.85)$ & .150 \\
\hline$\geq 10$ & $72(16.6)$ & $361(83.4)$ & 3.18 & $3.18(1.79-5.64)$ & .0001 \\
\hline \multicolumn{6}{|c|}{ Psychotic impairment } \\
\hline $\begin{array}{l}\mathrm{N}^{\circ} \text { recent } \\
\text { adverse } \\
\text { events }\end{array}$ & $\begin{array}{c}\mathrm{N}^{\circ} \text { with } \\
\text { psychotic } \\
\text { impairment (\%) }\end{array}$ & $\begin{array}{c}\mathrm{N}^{\circ} \text { without } \\
\text { psychotic } \\
\text { impairment (\%) }\end{array}$ & $\begin{array}{c}\mathrm{RR} \\
\text { unadjusted }\end{array}$ & $\begin{array}{c}\mathrm{RR} \\
\text { adjusted }^{\mathrm{a}} \\
(95 \% \mathrm{Cl})\end{array}$ & $\mathrm{p}^{\mathrm{a}}$ \\
\hline $0-2$ & $4(1.5)$ & $264(98.5)$ & $1.00^{b}$ & $1.00^{\mathrm{b}}$ & $\mathrm{b}$ \\
\hline $3-5$ & $14(2.8)$ & $480(97.2)$ & 1.90 & $1.65(.54-5.04)$ & .383 \\
\hline $6-9$ & $14(2.7)$ & $513(97.3)$ & 1.78 & $1.77(.59-5.33)$ & .309 \\
\hline$\geq 10$ & $31(7.2)$ & $402(92.8)$ & 4.80 & $4.59(1.62-13.00)$ & .004 \\
\hline
\end{tabular}

adjusted for age, gender, urbanicity and cannabis use.

${ }^{\mathrm{b}}$ Reference exposure group.

RR = Risk Ratio.

Table 3 | Risk Ratios of psychotic symptoms, according to the 8 exposure states formed by early and recent adversity.

\begin{tabular}{|c|c|c|c|c|c|c|c|}
\hline \multicolumn{3}{|c|}{ Exposure } & \multicolumn{5}{|c|}{ Outcome } \\
\hline & $\begin{array}{l}\text { Early life } \\
\text { adversity }\end{array}$ & $\begin{array}{l}\mathrm{N}^{\circ} \text { recent } \\
\text { adverse } \\
\text { events }\end{array}$ & $\begin{array}{l}N^{\circ} \text { with } \\
\text { psychotic } \\
\text { symptoms } \\
\text { (\%) }\end{array}$ & $\begin{array}{l}N^{\circ} \text { without } \\
\text { psychotic } \\
\text { symptoms } \\
\text { (\%) }\end{array}$ & $\begin{array}{c}\mathrm{RR} \\
\text { unadjusted }\end{array}$ & $\begin{array}{l}\mathrm{RR} \\
\text { adjusted }^{\mathrm{a}} \\
(95 \% \mathrm{Cl})\end{array}$ & $\mathrm{p}^{\mathrm{a}}$ \\
\hline$E_{0} R_{0}$ & \multirow{4}{*}{ No } & $0-2$ & $10(5.2)$ & $182(94.8)$ & $1.00^{\mathrm{b}}$ & $1.00^{\mathrm{b}}$ & $\mathrm{b}$ \\
\hline $\mathrm{E}_{0} \mathrm{R}_{1}$ & & $3-5$ & $25(7.4)$ & $311(92.6)$ & 1.43 & $1.58(.76-3.31)$ & .221 \\
\hline $\mathrm{E}_{0} \mathrm{R}_{2}$ & & $6-9$ & $31(9.1)$ & 310 (90.9) & 1.75 & $1.82(.88-3.73)$ & .104 \\
\hline $\mathrm{E}_{0} \mathrm{R}_{3}$ & & $\geq 10$ & 32 (12.9) & $216(87.1)$ & 2.48 & $2.67(1.31-5.47)$ & .007 \\
\hline$E_{1} R_{0}$ & \multirow{4}{*}{ Yes } & $0-2$ & $4(5.3)$ & $72(94.7)$ & 1.01 & $1.10(.35-3.43)$ & .874 \\
\hline$E_{1} R_{1}$ & & $3-5$ & $16(10.1)$ & 142 (89.9) & 1.94 & $1.89(.84-4.25)$ & .121 \\
\hline$E_{1} R_{2}$ & & $6-9$ & $12(6.5)$ & 174 (93.5) & 1.24 & $1.23(.52-2.89)$ & .639 \\
\hline $\mathrm{E}_{1} \mathrm{R}_{3}$ & & $\geq 10$ & $40(21.6)$ & 145 (78.4) & 4.15 & $4.08(2.02-8.24)$ & .0001 \\
\hline \multicolumn{3}{|c|}{ Test for additive interaction: } & \multicolumn{5}{|c|}{$\begin{array}{l}\left(R R\left(E_{1} R_{1}\right)-R R\left(E_{1} R_{0}\right)-R R\left(E_{0} R_{1}\right)+R R\left(E_{0} R_{0}\right)=0\right): \chi^{2}=2.69 ; p=.101^{a} \\
\left(R R\left(E_{1} R_{2}\right)-R R\left(E_{1} R_{0}\right)-R R\left(E_{0} R_{2}\right)+R R\left(E_{0} R_{0}\right)=0\right): \chi^{2}=0.59 ; p=.443^{a} \\
\left(R R\left(E_{1} R_{3}\right)-R R\left(E_{1} R_{0}\right)-R R\left(E_{0} R_{3}\right)+R R\left(E_{0} R_{0}\right)=0\right): \chi^{2}=4.59 ; p=.032^{a}\end{array}$} \\
\hline
\end{tabular}

${ }^{a}$ Adjusted for age, gender, urbanicity and cannabis use.

${ }^{\mathrm{b}}$ Reference exposure group.

$\mathrm{E}=$ Early life adversity (0="no"; 1="yes"); R = Recent adversity ( $0=$ "0-2"; $1=$ " $3-4$ "; $2=$ "6-9"; 3 =" $\geq 10$ adverse events"); RR = Risk Ratio. 
Table 4 | Risk Ratios of psychotic impairment, according to the 8 exposure states formed by early and recent adversity.

\begin{tabular}{|c|c|c|c|c|c|c|c|}
\hline \multicolumn{3}{|c|}{ Exposure } & \multicolumn{5}{|c|}{ Outcome } \\
\hline & $\begin{array}{l}\text { Early life } \\
\text { adversity }\end{array}$ & $\begin{array}{l}\mathrm{N}^{\circ} \text { recent } \\
\text { adverse } \\
\text { events }\end{array}$ & $\begin{array}{l}\mathrm{N}^{\circ} \text { with } \\
\text { psychotic } \\
\text { impairment } \\
\text { (\%) }\end{array}$ & $\begin{array}{l}\mathrm{N}^{\circ} \text { without } \\
\text { psychotic } \\
\text { impairment } \\
\text { (\%) }\end{array}$ & $\begin{array}{c}\mathrm{RR} \\
\text { unadjusted }\end{array}$ & $\begin{array}{l}\mathrm{RR} \\
\text { adjusted }^{\mathrm{a}} \\
(95 \% \mathrm{Cl})\end{array}$ & $\mathrm{p}^{\mathrm{a}}$ \\
\hline $\mathrm{E}_{0} \mathrm{R}_{0}$ & \multirow{4}{*}{ No } & $0-2$ & $3(1.6)$ & $189(98.4)$ & $1.00^{\mathrm{b}}$ & $1.00^{\mathrm{b}}$ & $\mathrm{b}$ \\
\hline $\mathrm{E}_{0} \mathrm{R}_{1}$ & & $3-5$ & $9(2.7)$ & $327(97.3)$ & 1.71 & $1.72(.47-6.25)$ & .413 \\
\hline $\mathrm{E}_{0} \mathrm{R}_{2}$ & & $6-9$ & $10(2.9)$ & $331(97.1)$ & 1.88 & $1.86(.52-6.70)$ & .340 \\
\hline $\mathrm{E}_{0} \mathrm{R}_{3}$ & & $\geq 10$ & $11(4.4)$ & $237(95.6)$ & 2.84 & $2.87(.81-10.21)$ & .104 \\
\hline$E_{1} R_{0}$ & \multirow{4}{*}{ Yes } & $0-2$ & $1(1.3)$ & 75 (98.7) & 0.84 & $0.84(.09-7.89)$ & .878 \\
\hline $\mathrm{E}_{1} \mathrm{R}_{1}$ & & $3-5$ & $5(3.2)$ & $153(96.8)$ & 2.03 & $1.27(.26-6.24)$ & .769 \\
\hline$E_{1} R_{2}$ & & $6-9$ & $4(2.1)$ & $182(97.9)$ & 1.38 & $1.40(.31-6.16)$ & .665 \\
\hline$E_{1} R_{3}$ & & $\geq 10$ & $20(10.8)$ & $165(89.2)$ & 6.92 & $6.41(1.90-21.69)$ & .003 \\
\hline \multicolumn{3}{|c|}{ Test for additive interaction: } & \multicolumn{5}{|c|}{$\begin{array}{l}\left(R R\left(E_{1} R_{1}\right)-R R\left(E_{1} R_{0}\right)-R R\left(E_{0} R_{1}\right)+R R\left(E_{0} R_{0}\right)=0\right): \chi^{2}=2.69 ; p=.508^{a} \\
\left(R R\left(E_{1} R_{2}\right)-R R\left(E_{1} R_{0}\right)-R R\left(E_{0} R_{2}\right)+R R\left(E_{0} R_{0}\right)=0\right): \chi^{2}=0.59 ; p=.492^{a} \\
\left(R R\left(E_{1} R_{3}\right)-R R\left(E_{1} R_{0}\right)-R R\left(E_{0} R_{3}\right)+R R\left(E_{0} R_{0}\right)=0\right): \chi^{2}=4.59 ; p=.099^{a}\end{array}$} \\
\hline
\end{tabular}

${ }^{a}$ Adjusted for age, gender, urbanicity and cannabis use.

${ }^{\mathrm{b}}$ Reference exposure group.

$\mathrm{E}=$ Early life adversity (0="no"; 1="yes"); R = Recent adversity ( $0=$ "0-2"; 1 ="3-4"; $2=$ "6-9"; 3 =" $\geq 10$ adverse events"); RR = Risk Ratio. 


\section{References}

1. Caspi A and Moffitt TE. Gene-environment interactions in psychiatry: joining forces with neuroscience. Nat Rev Neurosci, 2006. 7(7): p. 583-90.

2. van Os J, Kenis G, and Rutten BP. The environment and schizophrenia. Nature, 2010. 468(7321): p. $203-12$.

3. Bebbington P, Wilkins S, Jones P, Foerster A, Murray R, Toone B, and Lewis S. Life events and psychosis. Initial results from the Camberwell Collaborative Psychosis Study. Br J Psychiatry, 1993. 162: p. 72-9.

4. Brown GW and Birley JL. Crises and life changes and the onset of schizophrenia. J Health Soc Behav, 1968. 9(3): p. 203-14.

5. Johns LC, Cannon M, Singleton N, Murray RM, Farrell M, Brugha T, Bebbington P, Jenkins R, and Meltzer H. Prevalence and correlates of self-reported psychotic symptoms in the British population. Br J Psychiatry, 2004. 185: p. 298-305.

6. van Winkel R, Stefanis NC, and Myin-Germeys I. Psychosocial stress and psychosis. A review of the neurobiological mechanisms and the evidence for gene-stress interaction. Schizophr Bull, 2008. 34(6): p. 1095-105.

7. Wiles NJ, Zammit S, Bebbington P, Singleton N, Meltzer H, and Lewis G. Self-reported psychotic symptoms in the general population: results from the longitudinal study of the British National Psychiatric Morbidity Survey. Br J Psychiatry, 2006. 188: p. 519-26.

8. Fallon P. Life events; their role in onset and relapse in psychosis, research utilizing semi-structured interview methods: a literature review. J Psychiatr Ment Health Nurs, 2008. 15(5): p. 386-92.

9. Leff J, Kuipers L, Berkowitz R, Vaughn C, and Sturgeon D. Life events, relatives' expressed emotion and maintenance neuroleptics in schizophrenic relapse. Psychol Med, 1983. 13(4): p. 799-806.

10. Gureje $\mathrm{O}$ and Adewunmi A. Life events and schizophrenia in Nigerians. A controlled investigation. $\mathrm{Br} J$ Psychiatry, 1988. 153: p. 367-75.

11. Horan WP, Ventura J, Nuechterlein KH, Subotnik KL, Hwang SS, and Mintz J. Stressful life events in recentonset schizophrenia: reduced frequencies and altered subjective appraisals. Schizophr Res, 2005. 75(2-3): p. 363-74.

12. Malla AK, Cortese L, Shaw TS, and Ginsberg B. Life events and relapse in schizophrenia. A one year prospective study. Soc Psychiatry Psychiatr Epidemiol, 1990. 25(4): p. 221-4.

13. Mason O, Startup M, Halpin S, Schall U, Conrad A, and Carr V. Risk factors for transition to first episode psychosis among individuals with 'at-risk mental states'. Schizophr Res, 2004. 71(2-3): p. 227-37.

14. Miller P, Lawrie SM, Hodges A, Clafferty R, Cosway R, and Johnstone EC. Genetic liability, illicit drug use, life stress and psychotic symptoms: preliminary findings from the Edinburgh study of people at high risk for schizophrenia. Soc Psychiatry Psychiatr Epidemiol, 2001. 36(7): p. 338-42. 
15. Lardinois M, Lataster T, Mengelers R, Van Os J, and Myin-Germeys I. Childhood trauma and increased stress sensitivity in psychosis. Acta Psychiatr Scand, 2011. 123(1): p. 28-35.

16. Hirsch S, Bowen J, Emami J, Cramer P, Jolley A, Haw C, and Dickinson M. A one year prospective study of the effect of life events and medication in the aetiology of schizophrenic relapse. Br J Psychiatry, 1996. 168(1): p. 49-56.

17. Ventura J, Nuechterlein KH, Lukoff D, and Hardesty JP. A prospective study of stressful life events and schizophrenic relapse. J Abnorm Psychol, 1989. 98(4): p. 407-11.

18. Hogarty GE and Ulrich RF. The limitations of antipsychotic medication on schizophrenia relapse and adjustment and the contributions of psychosocial treatment. J Psychiatr Res, 1998. 32(3-4): p. 243-50.

19. Lim C, Chong SA, and Keefe RS. Psychosocial factors in the neurobiology of schizophrenia: a selective review. Ann Acad Med Singapore, 2009. 38(5): p. 402-6.

20. Glaser JP, van Os J, Portegijs PJ, and Myin-Germeys I. Childhood trauma and emotional reactivity to daily life stress in adult frequent attenders of general practitioners. J Psychosom Res, 2006. 61(2): p. 229-36.

21. Wichers M, Schrijvers D, Geschwind N, Jacobs N, Myin-Germeys I, Thiery E, Derom C, Sabbe B, Peeters F, Delespaul P, and van Os J. Mechanisms of gene-environment interactions in depression: evidence that genes potentiate multiple sources of adversity. Psychol Med, 2009. 39(7): p. 1077-86.

22. Bendall S, Jackson HJ, Hulbert CA, and McGorry PD. Childhood trauma and psychotic disorders: a systematic, critical review of the evidence. Schizophr Bull, 2008. 34(3): p. 568-79.

23. Lieb R, Isensee B, von Sydow K, and Wittchen HU. The Early Developmental Stages of Psychopathology Study (EDSP): a methodological update. Eur Addict Res, 2000. 6(4): p. 170-82.

24. Wittchen HU, Perkonigg A, Lachner G, and Nelson CB. Early developmental stages of psychopathology study (EDSP): objectives and design. Eur Addict Res, 1998. 4(1-2): p. 18-27.

25. Anthony JC, Folstein M, Romanoski AJ, Von Korff MR, Nestadt GR, Chahal R, Merchant A, Brown CH, Shapiro $\mathrm{S}$, and Kramer M. Comparison of the lay Diagnostic Interview Schedule and a standardized psychiatric diagnosis. Experience in eastern Baltimore. Arch Gen Psychiatry, 1985. 42(7): p. 667-75.

26. Wittchen H and Pfister H. DIA-X-Interviews: Manual für Screening-Verfahren und Interview; Interviewheft Längsschnittsuntersuchung (DIA-X Lifetime); Ergänzungsheft (DIA-X Lifetime); Interviewheft Querschnittsuntersuchung (DIA-X 12 Monate); Ergänzungsheft (DIA-X 12 Monate); PC-Programm zur Durchführung der Interviews (Längs- und Querschnittsuntersuchung); Auswertungsprogramm. [computer program]. 1997, Swets \& Zeitlinger: Frankfurt.

27. WorldHealthOrganization. Composite International Diagnostic Interview (CIDI), Version 1.0. 1990, Geneva, Switzerland: WHO.

28. Wittchen HU. Reliability and validity studies of the WHO--Composite International Diagnostic Interview (CIDI): a critical review. J Psychiatr Res, 1994. 28(1): p. 57-84. 
29. Derogatis LR and Cleary PA. Factorial invariance across gender for the primary symptom dimensions of the SCL-90. Br J Soc Clin Psychol, 1977. 16(4): p. 347-56.

30. Bonicatto S, Dew MA, Soria JJ, and Seghezzo ME. Validity and reliability of Symptom Checklist ' 90 (SCL90) in an Argentine population sample. Soc Psychiatry Psychiatr Epidemiol, 1997. 32(6): p. 332-8.

31. Maier-Diewald W, Wittchen HU, Hecht $\mathrm{H}$, and Werner-Eilert K. Die Münchner Ereignisliste (MEL): Anwendungsmanual., in Unpublished manuscript. 1983: Max-Planck-Institut für Psychiatrie, München.

32. Wittchen HU, Essau CA, Hecht H, Teder W, and Pfister H. Reliability of life event assessments: test-retest reliability and fall-off effects of the Munich Interview for the Assessment of Life Events and Conditions. J Affect Disord, 1989. 16(1): p. 77-91.

33. Spauwen J, Krabbendam L, Lieb R, Wittchen HU, and van Os J. Evidence that the outcome of developmental expression of psychosis is worse for adolescents growing up in an urban environment. Psychol Med, 2006. 36(3): p. 407-15.

34. Tijssen MJ, Van Os J, Wittchen HU, Lieb R, Beesdo K, and Wichers M. Risk factors predicting onset and persistence of subthreshold expression of bipolar psychopathology among youth from the community. Acta Psychiatr Scand, 2010. 122(3): p. 255-66.

35. Alvarez-Jimenez M, Gleeson JF, Henry LP, Harrigan SM, Harris MG, Amminger GP, Killackey E, Yung AR, Herrman H, Jackson HJ, and McGorry PD. Prediction of a single psychotic episode: A 7.5-year, prospective study in first-episode psychosis. Schizophr Res, 2011. 125(2-3): p. 236-46.

36. Morgan C, Fisher H, Hutchinson G, Kirkbride J, Craig TK, Morgan K, Dazzan P, Boydell J, Doody GA, Jones PB, Murray RM, Leff J, and Fearon P. Ethnicity, social disadvantage and psychotic-like experiences in a healthy population based sample. Acta Psychiatr Scand, 2009. 119(3): p. 226-35.

37. Morgan C, Kirkbride J, Leff J, Craig T, Hutchinson G, McKenzie K, Morgan K, Dazzan P, Doody GA, Jones P, Murray R, and Fearon P. Parental separation, loss and psychosis in different ethnic groups: a case-control study. Psychol Med, 2007. 37(4): p. 495-503.

38. Dominguez MD, Wichers M, Lieb R, Wittchen HU, and van Os J. Evidence that onset of clinical psychosis is an outcome of progressively more persistent subclinical psychotic experiences: an 8-year cohort study. Schizophr Bull, 2011. 37(1): p. 84-93.

39. Henquet C, Krabbendam L, Spauwen J, Kaplan C, Lieb R, Wittchen HU, and van Os J. Prospective cohort study of cannabis use, predisposition for psychosis, and psychotic symptoms in young people. BMJ, 2005. 330(7481): p. 11.

40. Dominguez MD, Saka MC, Lieb R, Wittchen HU, and van Os J. Early expression of negative/disorganized symptoms predicting psychotic experiences and subsequent clinical psychosis: a 10-year study. Am J Psychiatry, 2010. 167(9): p. 1075-82.

41. Smeets F, Lataster T, Dominguez MD, Hommes J, Lieb R, Wittchen HU, and van Os J. Evidence That Onset of 
Psychosis in the Population Reflects Early Hallucinatory Experiences That Through Environmental Risks and Affective Dysregulation Become Complicated by Delusions. Schizophr Bull, 2010. epub ahead of print.

42. Ventura J and Liberman RP. Psychotic Disorders, in Encyclopedia of Stress, G. Fink, Editor. 2000, Academic Press.

43. StataCorp. Stata Statistical Software: Release 10. College Station, TX: StataCorp LP, 2007.

44. Spauwen J, Krabbendam L, Lieb R, Wittchen HU, and van Os J. Impact of psychological trauma on the development of psychotic symptoms: relationship with psychosis proneness. Br J Psychiatry, 2006. 188: p. 527-33.

45. Clarke MC, Tanskanen A, Huttunen M, Whittaker JC, and Cannon M. Evidence for an interaction between familial liability and prenatal exposure to infection in the causation of schizophrenia. Am J Psychiatry, 2009. 166(9): p. 1025-30.

46. Malaspina D, Goetz RR, Friedman JH, Kaufmann CA, Faraone SV, Tsuang M, Cloninger CR, Nurnberger JI, Jr., and Blehar MC. Traumatic brain injury and schizophrenia in members of schizophrenia and bipolar disorder pedigrees. Am J Psychiatry, 2001. 158(3): p. 440-6.

47. Ormel J, Oldehinkel AJ, and Brilman El. The interplay and etiological continuity of neuroticism, difficulties, and life events in the etiology of major and subsyndromal, first and recurrent depressive episodes in later life. Am J Psychiatry, 2001. 158(6): p. 885-91.

48. Tienari P, Wynne LC, Sorri A, Lahti I, Laksy K, Moring J, Naarala M, Nieminen P, and Wahlberg KE. Genotypeenvironment interaction in schizophrenia-spectrum disorder. Long-term follow-up study of Finnish adoptees. Br J Psychiatry, 2004. 184: p. 216-22.

49. van Os J, Bak M, Hanssen M, Bijl RV, de Graaf R, and Verdoux H. Cannabis use and psychosis: a longitudinal population-based study. Am J Epidemiol, 2002. 156(4): p. 319-27.

50. Weiser M, van Os J, Reichenberg A, Rabinowitz J, Nahon D, Kravitz E, Lubin G, Shmushkevitz M, Knobler HY, Noy S, and Davidson M. Social and cognitive functioning, urbanicity and risk for schizophrenia. Br J Psychiatry, 2007. 191: p. 320-4.

51. Zimmermann P, Bruckl T, Lieb R, Nocon A, Ising M, Beesdo K, and Wittchen HU. The interplay of familial depression liability and adverse events in predicting the first onset of depression during a 10-year follow-up. Biol Psychiatry, 2008. 63(4): p. 406-14.

52. Darroch J. Biologic synergism and parallelism. Am J Epidemiol, 1997. 145(7): p. 661-8.

53. Kalilani L and Atashili J. Measuring additive interaction using odds ratios. Epidemiol Perspect Innov, 2006. 3: p. 5 .

54. Rothman KJ. Modern epidemiology. 1986: Little, Brown and Company, Boston.

55. Rothman KJ and Greenland S. Modern epidemiology. 1998: Lippincott Williams and Wilkins, Philadelphia.

56. Larkin W and Read J. Childhood trauma and psychosis: evidence, pathways, and implications. J Postgrad 
Med, 2008. 54(4): p. 287-93.

57. Read J, van Os J, Morrison AP, and Ross CA. Childhood trauma, psychosis and schizophrenia: a literature review with theoretical and clinical implications. Acta Psychiatr Scand, 2005. 112(5): p. 330-50.

58. Janssen I, Krabbendam L, Bak M, Hanssen M, Vollebergh W, de Graaf R, and van Os J. Childhood abuse as a risk factor for psychotic experiences. Acta Psychiatr Scand, 2004. 109(1): p. 38-45.

59. Whitfield CL, Dube SR, Felitti VJ, and Anda RF. Adverse childhood experiences and hallucinations. Child Abuse Negl, 2005. 29(7): p. 797-810.

60. Arseneault L, Cannon M, Fisher HL, Polanczyk G, Moffitt TE, and Caspi A. Childhood trauma and children's emerging psychotic symptoms: A genetically sensitive longitudinal cohort study. Am J Psychiatry, 2011. 168(1): p. $65-72$.

61. Cutajar MC, Mullen PE, Ogloff JR, Thomas SD, Wells DL, and Spataro J. Schizophrenia and other psychotic disorders in a cohort of sexually abused children. Arch Gen Psychiatry, 2010. 67(11): p. 1114-9.

62. Elklit A and Shevlin M. Female Sexual Victimization Predicts Psychosis: A Case-Control Study Based on the Danish Registry System. Schizophr Bull, 2011. 37(6): p. 1305-10

63. Schreier A, Wolke D, Thomas K, Horwood J, Hollis C, Gunnell D, Lewis G, Thompson A, Zammit S, Duffy L, Salvi G, and Harrison G. Prospective study of peer victimization in childhood and psychotic symptoms in a nonclinical population at age 12 years. Arch Gen Psychiatry, 2009. 66(5): p. 527-36.

64. Galletly C, Van Hooff M, and McFarlane A. Psychotic symptoms in young adults exposed to childhood trauma-A 20year follow-up study. Schizophr Res, 2011. 127(1-3): p. 76-82.

65. Collip D, Myin-Germeys I, and Van Os J. Does the concept of "sensitization" provide a plausible mechanism for the putative link between the environment and schizophrenia? Schizophr Bull, 2008. 34(2): p. 220-5.

66. Katschnig H. Vulnerability models for schizophrenia: Discussion. In Häfner, H \& Gattaz, WF (Eds.), Search for the causes of schizophrenia, Vol. II. Search for the causes of schizophrenia, Vol. II., ed. H. Häfner and W. Gattaz. 1991, Berlin: Springer-Verlag.

67. Nuechterlein KH and Dawson ME. A heuristic vulnerability/stress model of schizophrenic episodes. Schizophr Bull, 1984. 10(2): p. 300-12.

68. Zubin J and Spring B. Vulnerability--a new view of schizophrenia. J Abnorm Psychol, 1977. 86(2): p. 103-26.

69. Read J, Perry BD, Moskowitz A, and Connolly J. The contribution of early traumatic events to schizophrenia in some patients: a traumagenic neurodevelopmental model. Psychiatry, 2001. 64(4): p. 319-45.

70. Deutch AY, Clark WA, and Roth RH. Prefrontal cortical dopamine depletion enhances the responsiveness of mesolimbic dopamine neurons to stress. Brain Res, 1990. 521(1-2): p. 311-5.

71. Herman JP and Cullinan WE. Neurocircuitry of stress: central control of the hypothalamo-pituitaryadrenocortical axis. Trends Neurosci, 1997. 20(2): p. 78-84.

72. Pruessner JC, Champagne F, Meaney MJ, and Dagher A. Dopamine release in response to a psychological 
stress in humans and its relationship to early life maternal care: a positron emission tomography study using [11C]raclopride. J Neurosci, 2004. 24(11): p. 2825-31.

73. Roth RH, Tam SY, Ida Y, Yang JX, and Deutch AY. Stress and the mesocorticolimbic dopamine systems. Ann N Y Acad Sci, 1988. 537: p. 138-47.

74. Abi-Dargham A, Rodenhiser J, Printz D, Zea-Ponce Y, Gil R, Kegeles LS, Weiss R, Cooper TB, Mann JJ, Van Heertum RL, Gorman JM, and Laruelle M. Increased baseline occupancy of D2 receptors by dopamine in schizophrenia. Proc Natl Acad Sci U S A, 2000. 97(14): p. 8104-9.

75. Dao-Castellana MH, Paillere-Martinot ML, Hantraye P, Attar-Levy D, Remy P, Crouzel C, Artiges E, Feline A, Syrota A, and Martinot JL. Presynaptic dopaminergic function in the striatum of schizophrenic patients. Schizophr Res, 1997. 23(2): p. 167-74.

76. Heckers S. Neuroimaging studies of the hippocampus in schizophrenia. Hippocampus, 2001. 11(5): p. 5208.

77. Hietala J, Syvalahti E, Vuorio K, Rakkolainen V, Bergman J, Haaparanta M, Solin O, Kuoppamaki M, Kirvela $\mathrm{O}$, Ruotsalainen $\mathrm{U}$, and et al. Presynaptic dopamine function in striatum of neuroleptic-naive schizophrenic patients. Lancet, 1995. 346(8983): p. 1130-1.

78. Laruelle M, Abi-Dargham A, van Dyck CH, Gil R, D'Souza CD, Erdos J, McCance E, Rosenblatt W, Fingado C, Zoghbi SS, Baldwin RM, Seibyl JP, Krystal JH, Charney DS, and Innis RB. Single photon emission computerized tomography imaging of amphetamine-induced dopamine release in drug-free schizophrenic subjects. Proc Natl Acad Sci U S A, 1996. 93(17): p. 9235-40.

79. Pariante CM, Vassilopoulou K, Velakoulis D, Phillips L, Soulsby B, Wood SJ, Brewer W, Smith DJ, Dazzan P, Yung AR, Zervas IM, Christodoulou GN, Murray R, McGorry PD, and Pantelis C. Pituitary volume in psychosis. Br J Psychiatry, 2004. 185: p. 5-10.

80. Weinberger DR, Berman KF, Suddath R, and Torrey EF. Evidence of dysfunction of a prefrontal-limbic network in schizophrenia: a magnetic resonance imaging and regional cerebral blood flow study of discordant monozygotic twins. Am J Psychiatry, 1992. 149(7): p. 890-7.

81. Walker EF and Diforio D. Schizophrenia: a neural diathesis-stress model. Psychol Rev, 1997. 104(4): p. 66785.

82. Andersen SL. Trajectories of brain development: point of vulnerability or window of opportunity? Neurosci Biobehav Rev, 2003. 27(1-2): p. 3-18.

83. Gunnar MR and Donzella B. Social regulation of the cortisol levels in early human development. Psychoneuroendocrinology, 2002. 27(1-2): p. 199-220.

84. Walker EF. Developmentally moderated expressions of the neuropathology underlying schizophrenia. Schizophr Bull, 1994. 20(3): p. 453-80.

85. Yuii K, Suzuki M, and Kurachi M. Stress sensitization in schizophrenia. Ann N Y Acad Sci, 2007. 1113: p. 276- 
90.

86. Hall FS, Wilkinson LS, Humby T, and Robbins TW. Maternal deprivation of neonatal rats produces enduring changes in dopamine function. Synapse, 1999. 32(1): p. 37-43.

87. Kapur S. Psychosis as a state of aberrant salience: a framework linking biology, phenomenology, and pharmacology in schizophrenia. Am J Psychiatry, 2003. 160(1): p. 13-23.

88. Schatzow E and Herman JL. Breaking secrecy. Adult survivors disclose to their families. Psychiatr Clin North $A m, 1989$. 12(2): p. 337-49.

89. The American Psychiatric Association. Diagnostic and Statistical Manual of Mental Disorders, 4th Edition, Text Revision (C) 2000, Washington DC.

90. Gruzelier JH. The factorial structure of schizotypy: Part I. Affinities with syndromes of schizophrenia. Schizophr Bull, 1996. 22(4): p. 611-20.

91. Linscott RJ and van Os J. Systematic reviews of categorical versus continuum models in psychosis: evidence for discontinuous subpopulations underlying a psychometric continuum. Implications for DSM-V, DSM-VI, and DSM-VII. Annu Rev Clin Psychol, 2010. 6: p. 391-419.

92. Vollema MG and van den Bosch RJ. The multidimensionality of schizotypy. Schizophr Bull, 1995. 21(1): p. 19-31. 
58

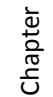




\section{Psychosocial stress}

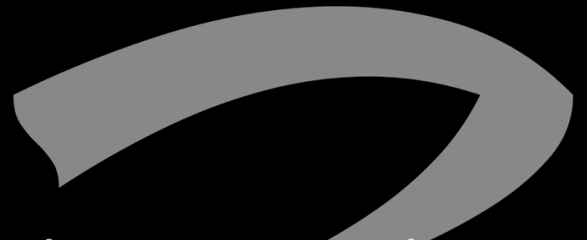

is associated with in vivo dopamine release in human ventromedial prefrontal cortex

a positron emission tomography study using $\left[{ }^{18} \mathrm{~F}\right]$ fallypride.

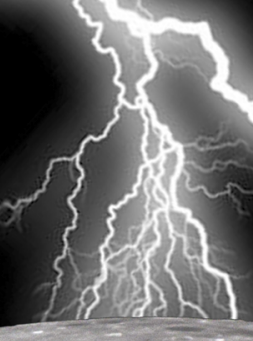

Johan Lataster ${ }^{1}$ Dina Collip ${ }^{1, *}$ Jenny Ceccarini ${ }^{2, *}$ David Haas ${ }^{1}$ Linda Booij ${ }^{3,4,5}$ Jim van $O s^{1,6}$ Jens Pruessner ${ }^{7}$ Koen Van Laere ${ }^{2}$ Inez Myin-Germeys ${ }^{1}$ 
${ }^{1}$ Department of Psychiatry and Psychology, South Limburg Mental Health Research and Teaching Network, EURON, Maastricht University Medical Center, Maastricht, the Netherlands.

${ }^{2}$ Division of Nuclear Medicine, University Hospital and Catholic University Leuven, Belgium.

${ }^{3}$ Sainte-Justine Hospital Research Center, Montreal, Canada.

${ }^{4}$ Department of Psychiatry, University of Montreal, Montreal, Canada.

${ }^{5}$ Department of Psychiatry, McGill University, Montreal, Canada.

${ }^{6}$ King's College London, King's Health Partners, Department of Psychosis Studies, Institute of Psychiatry, London, UK.

${ }^{7}$ Douglas Mental Health Institute, Department of Psychiatry, McGill University, Montreal, Canada.

*These authors contributed equally to this work.

Published as:

Lataster J, Collip D, Ceccarini J, Haas D, Booij L, van Os J, Pruessner J, Van Laere K, Myin-Germeys I. Psychosocial stress is associated with in vivo dopamine release in human ventromedial prefrontal cortex: a positron emission tomography study using $\left[{ }^{18} \mathrm{~F}\right]$ fallypride.

Neurolmage, 2011. 58(4): p. 1081-9. 


\section{Abstract}

Objective: Rodent studies suggest that prefrontal dopamine neurotransmission plays an important role in the neural processing of psychosocial stress. Human studies investigating stress-induced changes in dopamine levels, however, have focused solely on striatal dopamine transmission. The aim of this study was to investigate in vivo dopamine release in the human prefrontal cortex in response to a psychosocial stress challenge, using the highly selective dopamine $D_{2 / 3}$ PET radioligand $\left[{ }^{18} \mathrm{~F}\right]$ fallypride in healthy subjects.

Method: 12 healthy subjects (39.8 yrs; SD $=15.8$ ) underwent a single dynamic Positron Emission Tomography (PET) scanning session after intravenous administration of 185.2 (SD $=10.2) \mathrm{MBq}\left[{ }^{18} \mathrm{~F}\right]$ fallypride. Psychosocial stress was initiated at 100 minutes postinjection. PET data were analyzed using the linearized simplified reference region model (LSRRM), which accounts for time-dependent changes in $\left[{ }^{18} \mathrm{~F}\right]$ fallypride displacement. Voxel-based statistical maps, representing specific $\mathrm{D}_{2 / 3}$ binding changes, were computed to localize areas with increased ligand displacement after task initiation, reflecting dopamine release.

Results: The psychosocial stress challenge induced detectable amounts of dopamine release throughout the prefrontal cortex, with dopaminergic activity in bilateral ventromedial prefrontal cortex being associated with subjectively rated experiences of psychosocial stress.

Conclusion: The novel finding that a mild psychosocial stress in humans induces increased levels of endogenous dopamine in the PFC indicates that the dynamics of the dopaminerelated stress response cannot be interpreted by focusing on mesolimbic brain regions alone. 


\section{Introduction}

The experience of psychosocial stress has been linked to dopaminergic neurotransmission, both in animals and in humans ${ }^{1,2}$, involving both frontocortical and mesolimbic structures ${ }^{3}$. In rodents, exposure to both physical ${ }^{4}$ and psychosocial ${ }^{5}$ stress has been associated with an increase in extracellular dopamine levels predominantly in prefrontal cortex (PFC), and to a lesser extent in mesolimbic areas. Moreover, rodent studies have shown that depletion of dopamine in the PFC increases stress-induced dopamine release in the mesolimbic system ${ }^{3}$ 6,7 , leading to the hypothesis that prefrontal dopamine transmission attenuates mesolimbic dopamine release, thereby controlling for the adverse consequences of stress on the brain. The proposed influence of prefrontal dopamine in regulating mesolimbic dopamine release under stressful conditions is of clinical interest since disturbance of mesolimbic dopamine transmission has been implicated in various stress-related psychopathologies across the

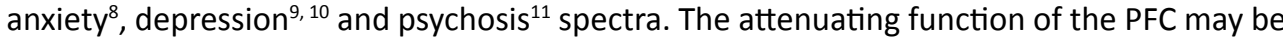
impaired in these pathologies, a hypothesis that is partly supported by evidence of prefrontal dysfunction in posttraumatic stress disorder ${ }^{12}$, depression ${ }^{10}$, and schizophrenia ${ }^{13}$.

In vivo human studies investigating stress-induced changes in dopamine levels are scarce, however, and have focused almost exclusively on mesolimbic striatal dopamine transmission ${ }^{1,}$ 14, 15. Findings from these studies seem to suggest that there is no evidence for stress being associated with increased striatal dopamine levels in healthy humans, but that the effects of stress on striatal dopamine might be restricted to subjects with psychometric abnormalities. However, despite its possible vital role in stress regulation, no single study has, thus far and to the best of our knowledge, investigated stress-induced dopamine release in the human PFC. This is mainly due to methodological restrictions. All studies, thus far, have investigated the dopaminergic stress system using Positron Emission Tomography (PET) with the radioligand $\left[{ }^{11} \mathrm{C}\right]$ raclopride ${ }^{1,14,15}$. The relatively low affinity of $\left[{ }^{11} \mathrm{C}\right]$ raclopride for $\mathrm{D}_{2 / 3}$ receptors has limited exploration of dopaminergic transmission to brain regions with high $\mathrm{D}_{2}$ receptor density, primarily the striatum. Recent development of high affinity $D_{2 / 3}$ radioligands, among which $\left[{ }^{18} \mathrm{~F}\right]$ fallypride, offers possibilities for exploration of extrastriatal dopamine sites such as the prefrontal cortex ${ }^{16-20}$. Due to the role of the PFC in stress regulation ${ }^{21-23}$, the question of dopamine activity in the PFC under stress is a very pertinent one.

The present study is the first to use the high affinity $D_{2 / 3}$ receptor ligand $\left[{ }^{18} \mathrm{~F}\right]$ fallypride to examine in vivo dopamine release in the human PFC in response to a psychosocial stress challenge developed and used previously by Pruessner et al. ${ }^{1}$. Given the suggested 
attenuating function of the PFC, and observations of increased dopamine levels in rodent PFC in response to stress ${ }^{4,5}$, the experience of psychosocial stress was hypothesized to be associated with dopamine release in human PFC, reflected by increased $\left[{ }^{18} \mathrm{~F}\right]$ fallypride ligand displacement.

\section{Materials and methods}

\section{Subjects}

Healthy subjects were recruited through flyers and advertisements in newspapers. Inclusion criteria were (i) ages 18-60 years; and (ii) sufficient command of the Dutch language to understand instructions and informed consent. Exclusion criteria were (i) intellectual impairment; (ii) head trauma with loss of consciousness or central neurological disorder; (iii) endocrine disorder; (iv) cardiovascular disorder; (v) present or history of psychiatric illness according to the explicit diagnostic criteria of the DSM-IV-TR ${ }^{24}$, generated with the OPCRIT computer program ${ }^{25}$; (vi) current use of psychotropic medication; (vii) current or previous use of illicit drugs; (viii) use of alcohol in excess of five standard units per day; (ix) presence of metal elements in the body; $(x)$ previous experience of claustrophobia; and (xi) pregnancy or lactation (women only). The study was approved by the standing medical ethics committee; subjects signed informed consent after complete description of the study. Drug and medication use were assessed at the day of scanning by urinalysis (MultiTest (C) 1990-2010 SureScreen Diagnostics Ltd.) in order to ensure that subjects were drug free at the moment of scanning. In addition, pregnancy tests (Clearblue (C) 2008 Swiss Precision Diagnostics) were carried out in female subjects, in order to exclude pregnancy at the moment of scanning.

\section{Psychosocial stress task}

Psychosocial stress was induced in the PET-scanner using the Montreal Imaging Stress Task (MIST), the psychosocial stress paradigm developed by Pruessner and colleagues (see Pruessner et al. ${ }^{1}$ and Dedovic et al. ${ }^{26}$ for a detailed description of the task). The experiment consisted of a control and stress condition, administered consecutively during a single-day PET scan protocol. In the control condition, subjects performed 6 minute blocks of mental arithmetic on a computer screen with no time constraints or performance feedback, 
resulting in an average performance of $90 \%$ correct responses. In the stress condition, subjects performed similar mental arithmetic as in the control condition, with the addition of information about the total number of errors, expected average number of errors, time spent on the current problem, and performance feedback (correct, incorrect, timeout), displayed on the computer screen. In addition, a time constraint, slightly below the time needed according to the subject's ability, was set for solving each problem. The constraint was automatically adjusted by the computer algorithm for each individual subject, based on the average time needed to solve a problem during a practice session before start of the PET scan. Moreover, a tone rising in frequency indicated the remaining time for the subject to solve each problem.

Subjects were informed that an average performance of $80-90 \%$ correct answers was expected. However, due to the manipulation of the time constraint, subjects achieved, on average, only $20-30 \%$ correct answers. In addition, psychosocial stress was induced through negative verbal feedback from a confederate investigator, who commented upon subjects' performance and emphasized that they needed to achieve at least minimal performance requirements. An extensive debriefing session took place at the end of the experiment, in which subjects were told that the task was specifically designed to be out of reach of their mental capacity, and that in reality it did not assess their ability to perform mental arithmetic.

\section{Behavioral measures and analysis}

Subjective perceptions of stress were assessed every 12 minutes, with six stress-related items, rated on 7-point Likert scales (rating from not at all [=1] to very [=7]), adapted from Experience Sampling Methodology (ESM) ${ }^{27,28}$. Items were presented on the same computer screen that was used for the psychosocial stress task, and subjects responded by selecting a number with a computer mouse. All scores were recoded such that an increase in scores corresponded to increased feelings of stress. Averages of the (recoded) scores on the items "I feel relaxed", "I'm in control", "I feel pressured", "I feel comfortable among these people", "I feel judged by these people", and "I do not live up to expectations" constituted the subjective stress scale (Cronbach's alpha $=.81$ ).

In order to investigate whether the stress-task induced stress at the behavioral level, a one-sided, paired t-test was performed, comparing average scores on the subjective stress scale between the control and stress conditions of the MIST. In addition, linear regression analysis was used to investigate associations between task-induced changes in subjective 
perceptions of stress and task-induced changes in $\left[{ }^{18} \mathrm{~F}\right]$ fallypride ligand displacement. All significance tests were performed in STATA release 10.0 (C 1985-2007 StataCorp. LP).

\section{Cortisol sampling and analysis}

Five milliliter blood samples were drawn from each subject into free-anticoagulant vacuum tubes. Blood samples were taken every 10 to 12 minutes during the scan, resulting in a total number of 12 samples. Immediately after the experiment was completed, blood samples were delivered to the laboratory for assaying. Intra-assay and inter-assay variability were $\leq 5,8 \%$ and $\leq 9,2 \%$, respectively. The area under the curve (AUC; cortisol in nanomoles per liter by time in minutes) was computed with the trapezoid formula as described by Pruessner and colleagues ${ }^{29}$.

A one-sided, paired t-test was performed to compare the AUC of cortisol between the control and stress condition of the MIST. In addition, linear regression analysis was performed to investigate whether task-induced changes in cortisol levels were associated with taskinduced changes in subjective perceptions of stress.

\section{Radiotracer preparation}

The fluorinated substituted benzamide $\left[{ }^{18} \mathrm{~F}\right]$ fallypride ${ }^{30}$ is a high affinity dopamine $D_{2 / 3}$ receptor antagonist radiotracer previously used to visualize and estimate both striatal and extrastriatal dopamine levels ${ }^{18,30}$. The precursor for tracer synthesis was obtained from ABX (Radeberg, Germany) and labeling was performed on-site using a Raytest Synchrom R\&D synthesis module (Raytest, Straubenhardt, Germany). The final product was obtained after reverse-phase high performance liquid chromatographic (HPLC) purification using a Waters XTerra' ${ }^{\text {TM }}$ RP18 $5 \mu \mathrm{m} 7.8 \mathrm{~mm} \times 150 \mathrm{~mm}$ column and sodium acetate 0.05M pH5.5 / Ethanol $70: 30 \mathrm{~V} / \mathrm{V}$ as mobile phase at a flow rate of $1.5 \mathrm{ml} / \mathrm{min}$. The $\left[{ }^{18} \mathrm{~F}\right]$ fallypride eluted after 18 minutes. The collected peak $(2 \mathrm{ml}$ ) was diluted with $8 \mathrm{ml}$ of $\mathrm{NaCl} 0.9 \%$ and sterile filtered over a Millipore Cathivex-GS $0.22 \mu \mathrm{m}$ filter. The final product of the radioligand was administered as a sterile solution of $7 \mathrm{mM}$ sodium acetate buffer $\mathrm{pH} 5.5,0.72 \% \mathrm{NaCl} 0.72 \%$ and $6 \%$ ethanol. The specific activity at the time of injection was $\geq 37 \mathrm{GBq} / \mu \mathrm{mol}(1000 \mathrm{Ci} /$ $\mathrm{mmol}$ ), and radiochemical purity was $>95 \%$.

\section{PET acquisition}

In order to minimize interference of task-induced stress and PET procedure-induced stress, the catheter used for ligand injection and blood sampling was placed 3 hours before the 
actual experiment took place. For the same reason, subjects were familiarized with the test setup and briefly placed in the scanner 3 hours before the actual scan to complete the practice session of the psychosocial stress task. An example of the psychosocial stress task was presented on the computer screen and the positions of the mouse and computer monitor were adjusted for comfortable viewing (outside the field of view of the scanner). After completing the practice session (duration approximately 5 minutes), subjects were removed from the scanner, awaiting the actual PET experiment, taking place approximately 3 hours later.

For the actual experimental PET session, subjects were again installed on the scanner bed with their head fixated using a vacuum pillow and foam inserts. If needed, the positions of the mouse and computer monitor were once more adjusted to allow for optimal comfort. Subjects received 185.2 (SD = 10.2) MBq of [ ${ }^{18} \mathrm{~F}$ fallypride in a slow intravenous bolus injection through a catheter in the left or right antecubital vein, depending on subject handedness. Simultaneously upon radiotracer injection, dynamic emission scans were initiated in threedimensional mode using a HiRez Biograph 16 PET/CT camera (Siemens Medical Solutions, Inc.). Data were obtained in 60 second frames during the first 6 minutes and in 120 second frames thereafter.

PET emission was performed conform the one-day PET imaging protocol for $\left[{ }^{18} \mathrm{~F}\right]$ fallypride described and used previously by Christian and colleagues ${ }^{17}$. Emission data were collected in two segments, one during the control condition and one during the stress condition of the MIST psychosocial stress task. Given the use of an "activation" parameter in the kinetic model used for analyses (Alpert et al. ${ }^{31}$; discussed below), representing presence or absence of additional dopamine release, and the hypothesis of stress being associated with increased dopaminergic activity, the stress condition of the MIST was always presented after the control condition.

The first PET segment, with a duration of 70 minutes, thus represented the $\left[{ }^{18} \mathrm{~F}\right]$ fallypride kinetics during the control condition, in which subjects performed 6 minute blocks of mental arithmetic without time constraints or performance feedback. The control session was followed by a brief break period of 10 minutes, after which subjects were, if necessary, repositioned on the scanner bed and the second PET emission data were collected for another 86 minutes in total. In order to ensure that "activation" (i.e., presence or absence of additional dopamine release, reflected by changes in ligand displacement) was not a result of repositioning or the simple act of getting up from the scanner for a break in the experiment, no task was presented during the first 20 minutes of this second emission scan. 
This, additionally, minimized risk of carry-over effects from the control condition into the stress condition, and maximized psychological impact of the stressor.

At 100 minutes postinjection, the psychosocial stress task was initiated and performed for the remaining 66 minutes of dynamic imaging. Cortisol sampling took place every 12 minutes during control and stress conditions, simultaneously with assessment of subjective ratings of stress. To correct for attenuation, a low-dose ( $80 \mathrm{kV}$ tube potential, $11 \mathrm{~mA} \cdot \mathrm{s}) \mathrm{CT}$ scan without contrast agent was conducted at the beginning of each PET segment (immediately before tracer injection and at 80 minutes postinjection) and at the end of emission scan. Images were reconstructed using a 3D OSEM (ordered-subset expectation maximization) iterative reconstruction including model-based scatter as well as attenuation correction based on a measured attenuation map acquired by the CT, with a final spatial resolution of 4 $\mathrm{mm}$. Additionally, in order to exclude structural brain abnormalities and perform anatomical coregistration, all subjects received a volumetric T1-weighted and standard transverse T2 brain magnetic resonance image (MRI; 1.5 Tesla Vision Scanner, Siemens, Germany). Parameters for the T1 3D Magnetization Prepared Rapid Acquisition Gradient Echo sequence were: $T R=0 \mathrm{~ms}, \mathrm{TE}=4 \mathrm{~ms}$, flip angle $=12^{\circ}$, inversion time $=300 \mathrm{~ms}$, matrix $256 \times 256,160$ sagittal contiguous slices of $1 \mathrm{~mm}$.

To guarantee the consistency of $\left[{ }^{18} \mathrm{~F}\right]$ fallypride metabolism among scans and to minimize potential changes in dopamine or cortisol levels, all subjects fasted 2 hours prior to radiotracer injection and abstained from nicotine, medication, and alcohol- or caffeinecontaining drinks on the day of scanning. All PET acquisitions were conducted the same time of day (14:30 $\pm 00: 30)$ in order to keep diurnal patterns of cortisol comparable for all subjects.

\section{PET data reduction and statistical analysis}

For each subject, brain reconstructed PET data were transferred in DICOM (Digital Imaging and Communications in Medicine) and converted to Analyze using PMOD software v. 2.95 (PMOD Inc., Zürich, Switzerland). To minimize effects of head movement during the scan, all $\left[{ }^{18} \mathrm{~F}\right]$ fallypride frames for each PET scan were realigned, coregistered to the subject's MRI and then spatially normalized to a specific T1-weighted template constructed in MNI (Montreal Neurological Institute) stereotaxic space using SPM8 (Statistical Parametric Mapping, The Wellcome Department of Cognitive Neurology, London, UK). To increase signal to noise ratio, the normalized images were then smoothed with a 3D gaussian filter (4-mm full width at half maximum) before applying the kinetic model. 
For each subject, volume-of-interest (VOI) analysis was performed by estimating the kinetic parameters using the LSRRM kinetic model (discussed below) and the PET time-activity curves (TACS) for all VOIs. The cerebellum was used as a reference region for $\left[{ }^{18} \mathrm{~F}\right]$ fallypride, representing a cerebral area with a paucity of dopamine $D_{2 / 3}$ receptors ${ }^{32}$. For each subject, two binary masks were created based on the corresponding normalized MRI, using an inhouse created set of VOls, defined according to prefrontal Brodmann areas (BA) with the aid of the Talairach atlas ${ }^{33}$. One binary mask image was designed to include all brain regions of interest (BA9/BA46=dorsolateral prefrontal cortex; BA10=ventromedial prefrontal cortex; $\mathrm{BA} 11=$ medial orbitofrontal cortex; $\mathrm{BA} 24=$ ventral anterior cingulate cortex; $\mathrm{BA} 32=\mathrm{dorsal}$ anterior cingulate cortex; BA44=inferior frontal gyrus, pars opercularis; BA45=inferior frontal gyrus, pars triangularis; BA47=inferior frontal gyrus, pars orbitalis), and a second mask was drawn only on the cerebellum.

\section{The kinetic model}

Conform previous work ${ }^{16,17,31}$, estimation of kinetic parameters was performed by applying the linearized simplified reference region model (LSRRM) ${ }^{31}$, an extension of the simplified reference region model $(S R R M)^{34,35}$, modified to include time-dependent parameters and linearized for all estimated parameters ${ }^{36}$. A detailed description of the LSRRM kinetic model can be found in earlier publications ${ }^{17,31}$. As previously described ${ }^{16,17,31}$, the LSRRM takes into account temporal perturbations in ligand specific binding by assuming that the steady physiological state is not maintained, making it suitable for assessing task-related ligand displacement in an experimental design that involves a change of task condition from control to a dopamine activation paradigm during one single scan session. The LSRRM therefore allows the dissociation rate of ligand from the receptor, $\mathrm{k}_{2 \mathrm{a}}$, to change through the paradigm in response to fluctuating levels of dopamine $\left(k_{2 a}=k_{2} /\left[1+B P_{N D}\right]\right)$, where $k_{2}$ is the tissue to plasma efflux constant in the tissue region and $\mathrm{BP}_{\mathrm{ND}}$ is the nondisplaceable binding potential ${ }^{37}$. Changes in $\mathrm{BP}_{\mathrm{ND}}$ in activation studies are usually assumed to reflect changes in the concentration of available neuroreceptor sites $\left(\mathrm{B}_{\text {avail }}\right)$, and a decrease in $\mathrm{BP}_{\mathrm{ND}}$ is assumed to reflect increased dopamine release. The temporal change of $k_{2 a}$ (via a change in $\mathrm{BP}_{\mathrm{ND}}$ ) is obtained by introducing the additional term $v \cdot h(t)$, where $\gamma$ represents the amplitude of the ligand displacement and the function $\mathrm{h}(\mathrm{t})$ describes a rapid change following task onset and dissipation over time. The exponential decay function $h(t)=\exp [-\tau(t-T)]$ accounts for temporal variation in the model parameters, where $\tau$ controls the rate at which activation effects die away (set to $\tau=0.03 \mathrm{~min}^{-1}$, conform Christian et al. ${ }^{17}$ and $\mathrm{T}$ indicates the task 
initiation time ( $T=100$ minutes postinjection). It follows that, through linearization of the simplified reference region model (SRRM), an increased $k_{2 a}$ reflected in a decreased $B P_{N D}$ for dopamine receptors, due to increased dopamine release, would result in a positive value of $\gamma$. The LSSRM model uses weighted linear least squares analysis for parameter estimation ${ }^{31}$.

\section{Main analysis}

For the voxel-based analysis, the same binary mask image used for VOI analysis was applied, including only prefrontal regions (BA9; BA10; BA11; BA24; BA32; BA44; BA45; BA46; $B A 47$, resp.) to limit the volume for calculation of the parametric images. A voxel-wise $t$ statistic map was computed to localize those areas for which the time varying parameter, $\gamma$, yielded a significant improvement in the model (i.e., rejection of the null hypothesis; Christian et al. ${ }^{17}$; Alpert et al. $\left.{ }^{31}\right)$, representing increased dopamine release after initiation of the stress condition. These statistic $t$-maps were generated as $t=\gamma / s d(\gamma)$, the standard deviation parametric image of $\gamma$ being created based on the estimated covariance matrix ${ }^{17}$, ${ }^{31}$. The false discovery rate $(F D R)^{38}$ correction was utilized to control statistical significance thresholds in the context of multiple ( $n=28832$ ) comparisons at the voxel level ${ }^{39}$, interpreting ordered $p_{(i)}$-values within the FDR-constraint of $p_{(i)} \leq 0.05 i / 28832$. In order to identify the spatial extent of the neuromodulation, the number of voxels satisfying the FDR-constraint (hereafter: exceeding the FDR corrected significance threshold of $\left.p_{(\alpha(F D R)=5 \%)} \leq 0.05\right)$ was determined for each volume of interest. Finally, conform previous work ${ }^{17}$, linear regression analysis was performed in order to identify those brain regions for which the spatial extent of task-induced dopamine release was predictive for task-induced increases in scores on the subjective stress scale and cortisol levels. All analyses were a priori corrected for age, gender, nicotine use (continuous: number of cigarettes / day), and alcohol consumption (continuous: grams of alcohol / week).

\section{Results}

\section{Subject characteristics}

The sample consisted of 13 healthy subjects. One subject was excluded from analyses because of excessive movement during the scan, yielding uncorrectable movement artifacts in the functional imaging data. Sociodemographic characteristics of the 12 remaining subjects, 
and alcohol consumption, nicotine use, and contraceptive-, and psychotropic medication use are summarized in Table 1.

\section{Behavioral and cortisol stress measures}

For one subject, data on the subjective stress scale were missing due to a technical (i.e., computer) failure. Consequently, behavioral analyses were performed in the remaining sample of 11 subjects.

The stress condition was experienced as significantly more stressful compared to the control condition, reflected by higher scores on the subjective stress scale (Mean control $=2.97(S D=$. 49); Mean $\left._{\text {stress }}=4.21(\mathrm{SD}=.93) ; \mathrm{t}_{(\mathrm{df}=10)}=5.03 ; \mathrm{p}=.0003\right)$. Task-induced changes in scores on the subjective stress scale were not associated with age (Adjusted $\left.R_{(d f=10)}^{2}=-.03 ; \beta=-.02 ; p=.416\right)$, gender (Adjusted $\left.R_{(d f=10)}^{2}=-.10 ; \beta=.22 ; p=.769\right)$, nicotine use (Adjusted $R_{(d f=10)}^{2}=-.02 ; \beta=.02$; $\mathrm{p}=.399$ ), or alcohol consumption (Adjusted $\mathrm{R}_{(\mathrm{df}=10)}=-.003 ; \beta=.06 ; \mathrm{p}=.350$ ).

Overall cortisol concentrations were not associated with age (Adjusted $R_{(d f=11)}^{2}=.14 ; \beta=.06$; $p=.129$ ), gender (Adjusted $R_{(d f=11)}=-.07 ; \beta=-.33 ; p=.614$ ), nicotine use (Adjusted $R_{(d f=11)}=-.05$; $\beta=-.04 ; p=.515$ ), or alcohol consumption (Adjusted $R_{(d f=11)}^{2}=-.01 ; \beta=.05 ; p=.367$ ). One subject displayed very high mean AUC cortisol throughout the experiment $(610.4$ ( $\mathrm{nmol} / \mathrm{I}) / \mathrm{min})$ and was excluded from AUC cortisol analyses based on Grubbs' test for outliers ${ }^{40}\left(Z_{12}=3.04\right.$; $\left.Z_{\text {critical }}(\alpha=5 \%)=2.41\right)$. Analysis on data from the remaining subjects revealed a significant difference between the AUC $((\mathrm{nmol} / \mathrm{l}) \mathrm{min})$ of cortisol between the stress and the control condition (Mean control $=221.6(\mathrm{SD}=45.0) ;$ Mean $\left._{\text {stress }}=279.3(\mathrm{SD}=76.4) ; \mathrm{t}_{(\mathrm{df}=10)}=1.89 ; \mathrm{p}=.04\right)$, with higher levels of AUC cortisol during the stress condition.

Linear regression analysis revealed a significant association between task-induced changes in AUC cortisol and task-induced changes in scores on the subjective stress scale (Adjusted $\mathrm{R}_{(\mathrm{df}=9)}=.57 ; \beta=.007 ; \mathrm{p}=.031$; corrected for age, gender, nicotine use, and alcohol consumption), higher cortisol levels being associated with increased feelings of subjectively experienced stress. This association remained significant with inclusion of the outlying subject in the analysis (Adjusted $\mathrm{R}_{(\mathrm{df}=10)}=.62 ; \beta=.006 ; \mathrm{p}=.016$; corrected for age, gender, nicotine use, and alcohol consumption).

\section{In vivo dopamine release in response to the psychosocial stress condition}

The psychosocial stress task induced detectable amounts of $\left[{ }^{18} \mathrm{~F}\right]$ fallypride ligand displacement throughout the prefrontal cortex (see Figure 1). Age, gender, alcohol consumption, and nicotine use were not associated with task-induced ligand displacement in any of the 
prefrontal regions of interest.

Linear regression analysis, corrected for age, gender, nicotine use, and alcohol consumption, revealed significant associations between task-induced changes in ligand displacement quantified as the number of voxels within a region, exceeding the FDR corrected significance threshold of $\mathrm{p}_{(\alpha(\mathrm{FDR})=5 \%)} \leq 0.05$ - and task-induced changes in scores on the subjective stress scale for the left (Adjusted $R_{(d f=9)}^{2}=.94 ; \beta=.03 ; p=.002$ ) and right (Adjusted $R_{(d f=9)}^{2}=.95 ; \beta=.04$; $\mathrm{p}=.001$ ) ventromedial prefrontal cortex (vmPFC; BA10; see Table 2; significance interpreted in light of the Simes-Hochberg correction for multiple comparisons ${ }^{41,42}$. More ligand displacement in these prefrontal brain regions was associated with increased feelings of subjectively experienced stress (see Table 3; Figure 2; one subject not included in regression due to missing data on subjective stress scale during stress condition; another subject was identified as an outlier based on Cook's distance test for influential cases $^{43}\left(D_{i(\text { threshold })}=4 /[n-k-\right.$ 1]) and was excluded from regression analyses).

For illustrative purposes, following Christian et al. ${ }^{17}$, Figure 3 shows an example of a dynamic PET time-activity curve obtained from the volume of interest drawn on the left vmPFC of one subject, for which model fit improved with inclusion of the $y$ parameter.

No significant associations were found between task-induced ligand displacement and taskinduced changes in AUC cortisol levels for any of the prefrontal regions of interest (corrected for age, gender, alcohol consumption, and nicotine use; significance interpreted in light of the Simes-Hochberg correction for multiple comparisons) $)^{41,42}$.

\section{Discussion}

The results of this study indicate that the Montreal Imaging Stress Task (MIST) induces detectable amounts of dopamine release throughout the prefrontal cortex, with dopaminergic activity in bilateral ventromedial prefrontal cortex being associated with subjectively rated experiences of psychosocial stress. Furthermore, as expected from previous findings ${ }^{1}$, the MIST stress paradigm resulted in significant increases in cortisol secretion. Although animal studies ${ }^{3-5}$, and Functional Magnetic Resonance Imaging (fMRI) studies in humans ${ }^{21-}$ $23,44,45$ have repeatedly implicated a role for PFC neurons in stress regulation, this is, to our knowledge, the first in vivo human imaging study showing prefrontal dopamine release in response to a psychosocial stressor. 


\section{Stress-induced dopamine release in the ventromedial prefrontal cortex}

The current findings suggest a direct involvement of vmPFC dopamine in the human stress response, given that dopaminergic activity in this region was highly correlated with subjective ratings of stress. The vmPFC is strongly connected to the amygdala, ventral striatum, and hypothalamus ${ }^{46-51}$, and is suggested to be involved in emotion regulation ${ }^{52}$, impulse control ${ }^{53}$, self-control ${ }^{54}$, and fear extinction ${ }^{55}$. The infralimbic prefrontal cortex, considered the rat homologue of the human vmPFC ${ }^{56}$, inhibits fear responses in rats when stimulated ${ }^{57}$. Furthermore, the loss of top-down control by the vmPFC is implicated in mood and anxiety disorders ${ }^{12,46,58,59}$, supporting a role for the vmPFC as emotion control center. Although projections from the vmPFC to subcortical structures are largely glutamatergic ${ }^{46-51}$, there is substantial evidence of dopamine-glutamate interactions in the PFC ${ }^{60-63}$. Although the current study provides evidence for vmPFC dopamine activity constituting part of the neurochemical response to stress, the exact neural mechanisms involved in the human stress response and the role of possible neurotransmitter interactions herein remain unclear.

\section{The role of the PFC in the stress response: possible mechanisms}

Due to a scarcity of in vivo human studies investigating stress-induced changes in prefrontal dopamine levels, little is known about the role of prefrontal dopamine in the regulation of stress in humans, thus far. Rodent studies have indicated that depletion of dopamine in the PFC increases stress-induced dopamine release in the mesolimbic system ${ }^{3,6,7}$. This has led to the hypothesis that prefrontal dopamine transmission attenuates stress-induced mesolimbic dopamine release. As suggested by Pascucci et al. ${ }^{64}$, the prefrontal dopamine system may not only constrain, but also determine mesolimbic dopamine activity in response to stress. A possible function of this mechanism could be to protect the organism for the adverse consequences of stress on the brain. This is supported by the observation that stress-related psychopathologies are associated with disturbed mesolimbic dopamine transmission ${ }^{8-11}$ and prefrontal dysfunctions ${ }^{10,12,13}$. Our finding that healthy subjects respond to a mild psychosocial stressor with increased levels of endogenous dopamine in the PFC, whereas a similar stressor in previous studies did not necessarily induce dopamine release in mesolimbic brain regions ${ }^{1,}$ 14,15 , supports the hypothesis that the organism may benefit from such a stress-reducing mechanism, with a suggested attenuating role of the prefrontal dopamine system, in line with reports of medial prefrontal cortex damage being associated with heightened self-reported stress responses to the Trier Social Stress Test ${ }^{65}$. It appears unlikely, however, that a loss of control of the PFC dopamine system over subcortical dopaminergic neurotransmission can 
solely and exclusively explain the diverse range of affective, psychotic and neurotic symptoms observed across the spectrum of stress-pathology, particularly given the broad variety and, to some extent, paradoxality of dopamine anomalies observed across various stress-related disorders $^{8,9,12,66,67}$. Rather, a range of complex and diverse neural (patho)dynamics, involving multiple interacting neurotransmitter systems ${ }^{8,12,63,66,68-71}$ that are functionally shaped by unique genetic, neurodevelopmental and social environmental factors, direct the individual towards a specific behavioral phenotype. Although impaired attenuation of mesolimbic dopamine by the PFC dopamine system may represent one important stress-vulnerability mechanism, future imaging studies are challenged with the daunting task of unraveling the neurochemical dynamics of stress processing in healthy humans and psychopathological populations that are characterized by disturbances in stress regulation.

The findings reported in this study result from significant advances made in the field of neuroimaging and show, for the first time, human in vivo PFC dopamine release in response to a psychological stressor. The development of highly selective dopamine $D_{2 / 3} P E T$ radioligands such as $\left[{ }^{18} \mathrm{~F}\right]$ fallypride opens up avenues for the investigation of extrastriatal dopamine neurotransmission, and the current study is the first to successfully implement this technology in stress research. Further strengths of the study lie in the use of a laboratory stressor that attempts to emulate real-world social interactions and succeeds in eliciting stress not only at a physiological level, but also at the level of subjective experience. Some limitations require consideration. First, the study design did not permit simultaneous and additional investigation of subcortical dopamine release. Subcortical dopamine regions, primarily striatal areas, are relatively high in dopamine $D_{2 / 3}$ receptor density and require, for that reason, a longer scan duration in order to reach a similar proportion of receptors to be occupied by the dopamine-competing ligand fallypride than is the case in low density dopamine $D_{2 / 3}$ regions such as the $\mathrm{PFC}^{72}$. Consequently, assessing dopamine transmission simultaneously in two regions that differ in terms of receptor density is not feasible, since the timing of task-initiation has to be adjusted for each region in such a way that the proportional distribution of radioligand is optimized, i.e., regions which are low in dopamine $D_{2 / 3}$ receptor density would require earlier onset of task initiation than regions with higher dopamine $D_{2 / 3}$ receptor density. A compromising solution, with intermittent task initiation timing will, at best, result in overestimation of dopamine release in relatively low dopamine $D_{2 / 3}$ receptor dense structures and underestimation of dopamine release in relatively high $D_{2 / 3}$ receptor dense 
structures ${ }^{17}$. Second, although application of the LSRRM has several practical advantages, such as the requirement for only one single radiochemical synthesis and administration and avoidance of session effects, practical implementation of the model implies that timedependent alterations in regional cerebral blood flow (rCBF) are not fully accounted for. However, as argued by Christian et al. ${ }^{17}$, using a single injection protocol in combination with the in vivo kinetics of fallypride minimizes the possible confounds of changing rCBF under psychological task paradigm conditions. Third, no performance measure was implemented in the psychosocial stress paradigm. We can, therefore, not ascertain that the findings are not confounded by variations in task performance. However, as argued by Pruessner et al. ${ }^{1}$, controlling for task performance would be redundant, since manipulation of the time constraint yields an average proportion of $20-30 \%$ correct answers in the stress condition for each individual subject. Furthermore, the strong correlation between subjectively experienced feelings of stress and fallypride ligand displacement in ventromedial PFC in the current study suggests that neural activity in this region is unlikely to be related purely to cognition. Fourth, consequential to the one-day scanning protocol utilized in the current study, the stress and control conditions of the MIST were consistently administered in the same sequence, i.e., the control condition preceded the stress condition for each subject. This increases risk of carry-over effects from the control condition into the stress condition. Although it was attempted to minimize these effects by separating the two conditions by a baseline condition, it cannot be ascertained that the outcome measures were not affected by carry-over effects. However, a two-scan protocol, with counterbalanced administration of stress and control conditions, would have meant that the extensive and important debriefing session, in which subjects were told that the task was specifically designed to be out of reach of their mental capacity, and that it did not assess their ability to perform mental arithmetic, could only take place after the second scan, which was considered to be ethically problematic. Furthermore, a one-day scan protocol has an advantage in avoiding session effects. Fifth, the actual scanning procedure might have been perceived as stressful, possibly interfering with the task-specific stress measures. The amount of interference was minimized by placing the catheter used for ligand injection and blood sampling 3 hours before the actual experiment took place. For the same reason, subjects were familiarized with the test setup and placed in the scanner 3 hours before the actual scan. Sixth, although unobserved heterogeneity is particularly important in non-linear regression analysis - unlike in linear regression models as utilized in the current study - the possibility of unobserved heterogeneity (e.g., due to unmeasured, yet outcome-relevant variations among subjects) 
may have biased results and calls for careful interpretation and replication of the current findings. Finally, it should be noted that our results do not imply causality and the specific function of each brain region in the human stress response remains an important subject for further investigation. 


\section{Acknowledgements}

This work was supported by a 2006 NARSAD Young Investigator Award and by the Dutch Medical Research Council (VENI and VIDI grants). We thank Wendy Beuken, Rufa Diederen, Stijn Dirix, Truda Driesen, Bernice Gulpers, Kwinten Porters, and Mieke Steukers for their assistance with data-collection, Nancy Nicolson for sharing her knowledge on cortisol sampling and analysis, and Ron Mengelers for technical support.

\section{Declaration of Interest}

The authors declare no competing interests. 
Table 1 | Subject characteristics.

\begin{tabular}{|c|c|}
\hline Characteristic & $(n=12)$ \\
\hline \multirow{2}{*}{ Age (y; mean (SD)) } & $39.8(15.8)$ \\
\hline & ranges $23-60$ \\
\hline \multicolumn{2}{|l|}{ Gender (n, \%) } \\
\hline Male & $8(67)$ \\
\hline Female & $4(33)$ \\
\hline \multicolumn{2}{|l|}{ Level of education ( $n, \%)^{a}$} \\
\hline Secondary education & $1(8)$ \\
\hline Bachelor degree & $7(58)$ \\
\hline Master degree & $4(33)$ \\
\hline \multicolumn{2}{|l|}{ Work situation $(n, \%)^{a}$} \\
\hline Household & 0 \\
\hline School/education & $2(17)$ \\
\hline Regular job (fulltime) & $6(50)$ \\
\hline Regular job (parttime) & $2(17)$ \\
\hline Other activities & $2(17)$ \\
\hline \multicolumn{2}{|l|}{ Marital status (n, \%) } \\
\hline Married or cohabitating & $6(50)$ \\
\hline Divorced & $1(8)$ \\
\hline Never married & $5(42)$ \\
\hline \multicolumn{2}{|c|}{ Nicotine use (cigarettes/day; $n, \%)^{a}$} \\
\hline 0 & $10(83)$ \\
\hline $1-10$ & $1(8)$ \\
\hline $10-20$ & $1(8)$ \\
\hline \multicolumn{2}{|c|}{ Alcohol consumption (grams/week ; n, \%) } \\
\hline $0-50$ & $6(50)$ \\
\hline $50-100$ & $2(17)$ \\
\hline $100-150$ & $4(33)$ \\
\hline \multicolumn{2}{|l|}{ Contraceptive use (n, \%) } \\
\hline Yes & 0 \\
\hline No & $12(100)$ \\
\hline \multicolumn{2}{|l|}{ Medication use (n, \%) } \\
\hline Yes & $3(25)^{c}$ \\
\hline No & $9(75)$ \\
\hline
\end{tabular}

a Percentages do not total 100 because of rounding.

${ }^{\mathrm{b}}$ Standard drink / unit size in the Netherlands contains 9.9 grams of ethanol.

c Three subjects sporadically used acetaminophen (paracetamol) to relieve headaches.

All subjects abstained from nicotine, alcohol and medication use on the day of scanning. 
Table 2 | Associations between task-induced dopamine release, quantified as the number of voxels showing significant ligand displacement within each activated region, and task-induced changes in scores on the subjective stres scale.

$\mathrm{N}^{\circ}$ of voxels with significant ${ }^{\mathrm{a}}$ task- Association with task-induced changes in scores on induced ligand displacement the subjective stress scale

\begin{tabular}{|c|c|c|c|c|c|}
\hline \multirow[b]{2}{*}{ Brodmann area } & & & & & \\
\hline & Mean, $\mathrm{n}(\%)^{\mathrm{b}}$ & SD & Adjusted $\mathrm{R}^{2}$ & $\beta$ & $p$ \\
\hline BA9L & $619(36)$ & 378 & 0.67 & 0.03 & 0.048 \\
\hline BA9R & $704(41)$ & 377 & 0.78 & 0.03 & 0.020 \\
\hline BA10L & $1319(50)$ & 580 & 0.94 & 0.03 & $0.002^{c}$ \\
\hline BA10R & $1365(53)$ & 567 & 0.95 & 0.04 & $0.001^{c}$ \\
\hline BA11L & $794(41)$ & 387 & 0.23 & -0.03 & 0.355 \\
\hline BA11R & $763(40)$ & 439 & 0.16 & -0.01 & 0.460 \\
\hline BA24L & $437(45)$ & 223 & 0.42 & 0.02 & 0.174 \\
\hline BA24R & $398(41)$ & 194 & 0.67 & 0.03 & 0.049 \\
\hline BA32L & $566(60)$ & 198 & 0.44 & 0.02 & 0.160 \\
\hline BA32R & $590(58)$ & 203 & 0.90 & 0.04 & 0.004 \\
\hline BA44L & $257(25)$ & 175 & 0.47 & 0.04 & 0.140 \\
\hline BA44R & $336(32)$ & 242 & 0.24 & 0.02 & 0.335 \\
\hline BA45L & $117(38)$ & 77 & 0.34 & 0.02 & 0.235 \\
\hline BA45R & $113(48)$ & 57 & 0.58 & 0.02 & 0.082 \\
\hline BA46L & $782(46)$ & 425 & 0.57 & 0.03 & 0.092 \\
\hline BA46R & 858 (49) & 420 & 0.77 & 0.03 & 0.022 \\
\hline BA47L & $337(26)$ & 259 & 0.57 & 0.02 & 0.085 \\
\hline BA47R & $315(26)$ & 230 & 0.75 & 0.04 & 0.027 \\
\hline
\end{tabular}

${ }^{a}$ Exceeding significance threshold of $p(\alpha(F D R)=5 \%) \leq 0.05$.

${ }^{b}$ Percentages reflect the number of significant voxels relative to the total number of voxels within the mask of the respective brain region.

c Exceeding significance threshold of $\mathrm{p}$ (corrected) $\leq 0.05$ according to Simes-Hochberg correction for multiple comparisons.

BA9 \& BA46=dorsolateral prefrontal cortex; $B A 10=$ ventromedial prefrontal cortex; $B A 11=$ medial orbitofrontal cortex; BA24=ventral anterior cingulate cortex; BA32=dorsal anterior cingulate cortex; BA44=inferior frontal gyrus, pars opercularis; BA45=inferior frontal gyrus, pars triangularis; BA47=inferior frontal gyrus, pars orbitalis.

$\mathrm{R}=$ right; $\mathrm{L}=$ left. Mask used for analysis contained an average total volume of 28832 voxels. 
Table 3 | Stress-induced dopamine displacement of $\left[{ }^{18} \mathrm{~F}\right]$ fallypride in left and right ventromedial prefrontal cortex (BA10; see also Figure 2).

\begin{tabular}{|c|c|c|c|}
\hline \multirow[b]{2}{*}{ Subject } & \multicolumn{2}{|c|}{$\begin{array}{l}\mathrm{N}^{\circ} \text { of voxels with significant }{ }^{\mathrm{a}} \\
\text { task-induced ligand displacement }\end{array}$} & \multirow[b]{2}{*}{$\begin{array}{c}\text { Task-induced changes in scores } \\
\text { on the subjective stress scale }\end{array}$} \\
\hline & $\begin{array}{l}\text { Left ventromedial } \\
\text { prefrontal cortex (BA10L) }\end{array}$ & 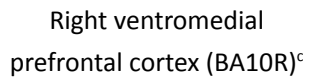 & \\
\hline$\# 1$ & 1522 & 1531 & 0.98 \\
\hline$\# 2$ & 1213 & 1080 & 0.54 \\
\hline$\# 3$ & 1155 & 1560 & 1.70 \\
\hline$\# 4^{\mathrm{d}}$ & 976 & 970 & 2.82 \\
\hline$\# 5$ & 1862 & 1776 & 1.75 \\
\hline$\# 6$ & 1160 & 1455 & 0.71 \\
\hline$\# 7$ & 2343 & 2404 & 2.08 \\
\hline \#8 & 1547 & 1737 & 1.11 \\
\hline$\# 9$ & 1137 & 1585 & 0.62 \\
\hline \#10 & 529 & 456 & 0.26 \\
\hline$\# 11$ & 385 & 345 & 0.04 \\
\hline$\# 12^{\mathrm{e}}$ & 2101 & 1547 & - \\
\hline
\end{tabular}

${ }^{a}$ Exceeding significance threshold of $p(\alpha(F D R)=5 \%) \leq 0.05$.

${ }^{b}$ Left vmPFC mask contained an average volume of 2638 voxels.

${ }^{\mathrm{c}}$ Right vmPFC mask contained an average volume of 2576 voxels.

' Subject was identified as outlier based on Cook's distance test for influential cases and excluded from regression analyses.

e Subject not included in regression analyses due to missing data on stress scale during stress condition. 
Figure 1 | Mean statistical parametric $t$-map of $\gamma$ in coronal (a), sagittal (b), and transverse (c) sections overlaid on a T1-weighted MRI template, showing task-induced $\left[{ }^{18} \mathrm{~F}\right]$ fallypride ligand displacement throughout prefrontal cortex in response to the psychosocial stress task. Image is thresholded for visualization purposes.

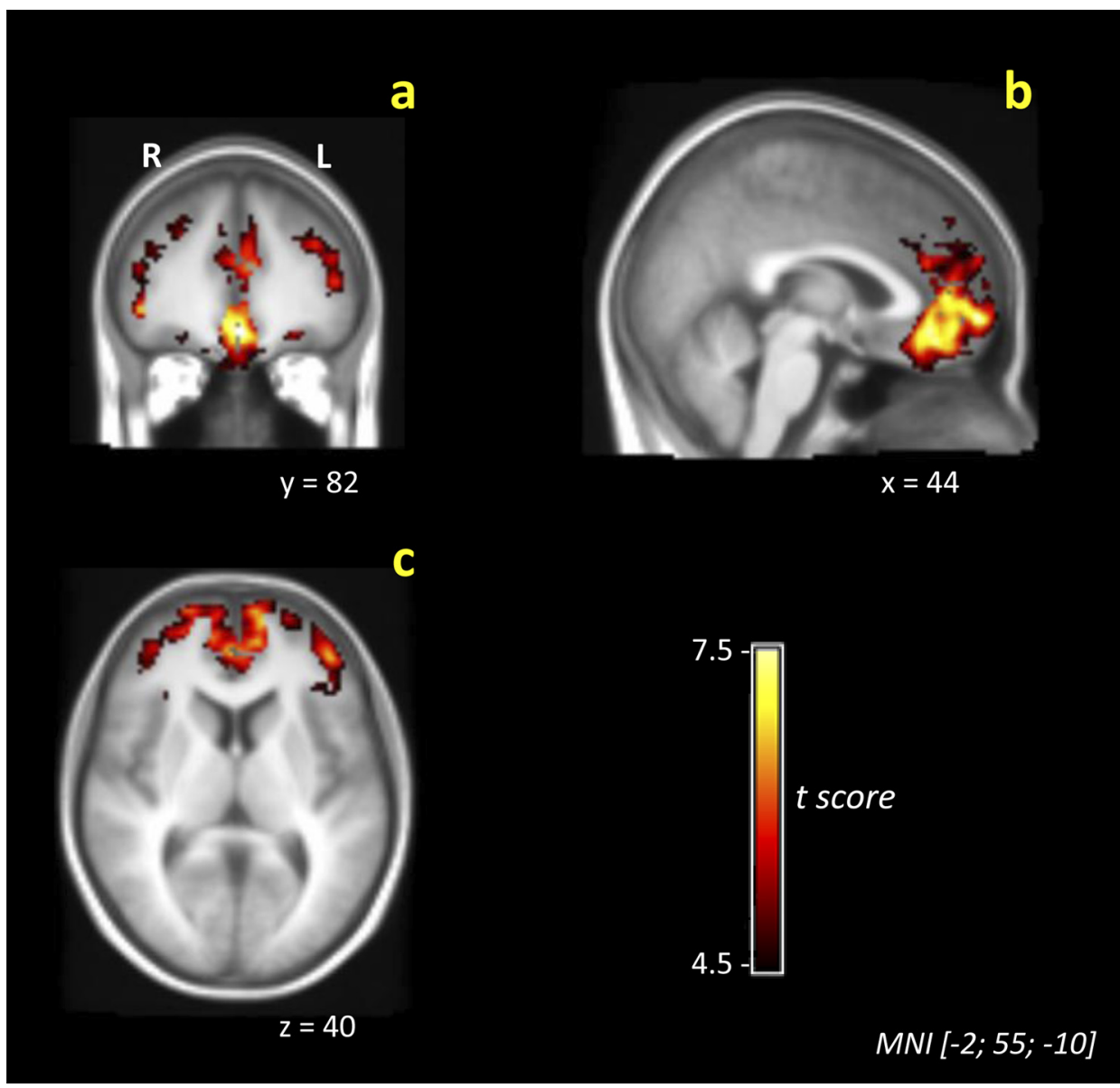


Figure 2 I Significant associations between task-induced feelings of subjective stress and task-induced ligand displacement in left $(\mathrm{I})$ and right ( $\mathrm{r}$ ) ventromedial prefrontal cortex (vmPFC), increased feelings of subjective stress being associated with increased ligand displacement.

vmPFC (I)

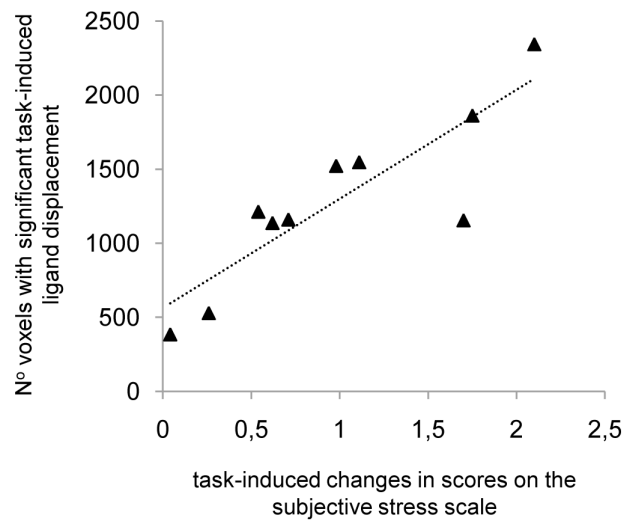

$\operatorname{vmPFC}(r)$

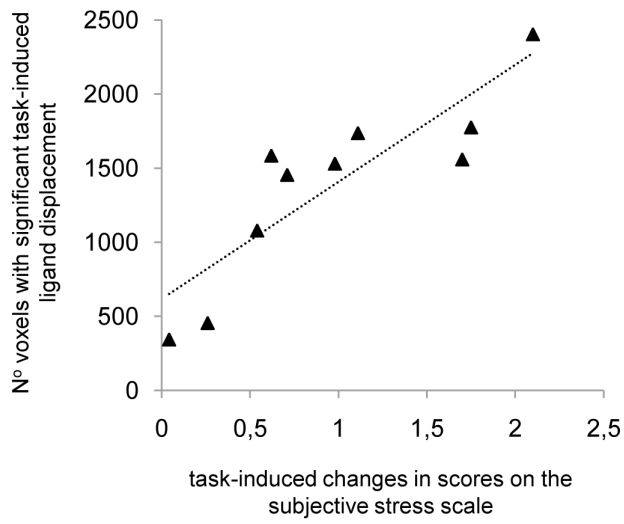

Figure 3 | Top row - example of PET dynamic data from one of the subjects scanned, black dots $(\bullet)$ representing data taken from the volume of interest drawn on the ventromedial prefrontal cortex and $(\times)$ symbol representing data from the cerebellar reference region. Model fit to the data is represented by the solid line. Stress condition was initiated at $\mathrm{T}=100 \mathrm{~min}$.

Bottom row - normalized residuals of the model fit with the $\gamma$ parameter $(+)$ and with $\gamma$ fixed to zero (0). The graph illustrates the improvement in the quality of the model fit for this particular volume of interest when $\gamma$ is included.
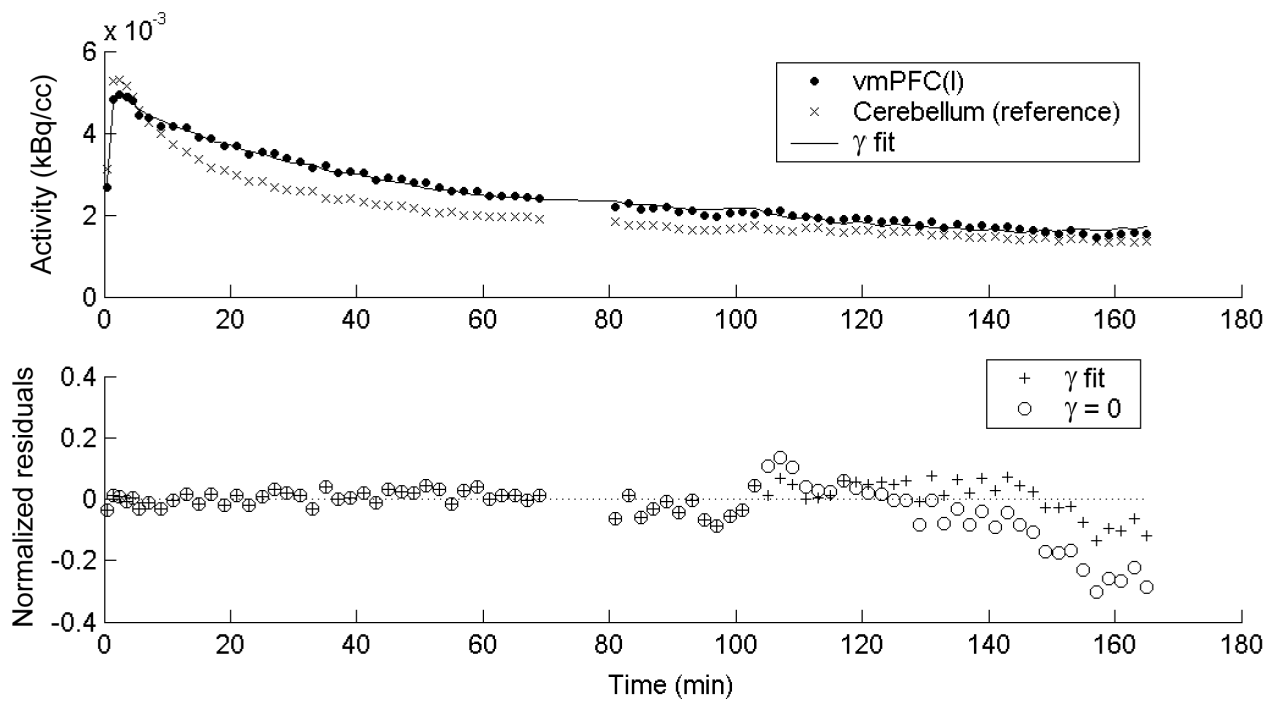


\section{References}

1. Pruessner JC, Champagne F, Meaney MJ, and Dagher A. Dopamine release in response to a psychological stress in humans and its relationship to early life maternal care: a positron emission tomography study using [11C]raclopride. J Neurosci, 2004. 24(11): p. 2825-31.

2. Roth RH, Tam SY, Ida Y, Yang JX, and Deutch AY. Stress and the mesocorticolimbic dopamine systems. Ann N Y Acad Sci, 1988. 537: p. 138-47.

3. Deutch AY, Clark WA, and Roth RH. Prefrontal cortical dopamine depletion enhances the responsiveness of mesolimbic dopamine neurons to stress. Brain Res, 1990. 521(1-2): p. 311-5.

4. Abercrombie ED, Keefe KA, DiFrischia DS, and Zigmond MJ. Differential effect of stress on in vivo dopamine release in striatum, nucleus accumbens, and medial frontal cortex. J Neurochem, 1989. 52(5): p. 1655-8.

5. Tidey JW and Miczek KA. Social defeat stress selectively alters mesocorticolimbic dopamine release: an in vivo microdialysis study. Brain Res, 1996. 721(1-2): p. 140-9.

6. King D, Zigmond MJ, and Finlay JM. Effects of dopamine depletion in the medial prefrontal cortex on the stress-induced increase in extracellular dopamine in the nucleus accumbens core and shell. Neuroscience, 1997. 77(1): p. 141-53.

7. Scornaiencki R, Cantrup R, Rushlow WJ, and Rajakumar N. Prefrontal cortical D1 dopamine receptors modulate subcortical D2 dopamine receptor-mediated stress responsiveness. Int J Neuropsychopharmacol, 2009. 12(9): p. 1195-208.

8. Nikolaus S, Antke C, Beu M, and Muller HW. Cortical GABA, striatal dopamine and midbrain serotonin as the key players in compulsive and anxiety disorders--results from in vivo imaging studies. Rev Neurosci, 2010. 21(2): p. 119-39.

9. Dailly E, Chenu F, Renard CE, and Bourin M. Dopamine, depression and antidepressants. Fundam Clin Pharmacol, 2004. 18(6): p. 601-7.

10. Gorwood P. Neurobiological mechanisms of anhedonia. Dialogues Clin Neurosci, 2008. 10(3): p. 291-9.

11. Laruelle M. The role of endogenous sensitization in the pathophysiology of schizophrenia: implications from recent brain imaging studies. Brain Res Brain Res Rev, 2000. 31(2-3): p. 371-84.

12. Rauch SL, Shin LM, and Phelps EA. Neurocircuitry models of posttraumatic stress disorder and extinction: human neuroimaging research--past, present, and future. Biol Psychiatry, 2006. 60(4): p. 376-82.

13. Weinberger DR, Egan MF, Bertolino A, Callicott JH, Mattay VS, Lipska BK, Berman KF, and Goldberg TE. Prefrontal neurons and the genetics of schizophrenia. Biol Psychiatry, 2001. 50(11): p. 825-44.

14. Montgomery AJ, Mehta MA, and Grasby PM. Is psychological stress in man associated with increased striatal dopamine levels?: A [11C]raclopride PET study. Synapse, 2006. 60(2): p. 124-31.

15. Soliman A, O'Driscoll GA, Pruessner J, Holahan AL, Boileau I, Gagnon D, and Dagher A. Stress-induced 
dopamine release in humans at risk of psychosis: a [11C]raclopride PET study. Neuropsychopharmacology, 2008. 33(8): p. 2033-41.

16. Badgaiyan RD, Fischman AJ, and Alpert NM. Dopamine release during human emotional processing. Neuroimage, 2009. 47(4): p. 2041-5.

17. Christian BT, Lehrer DS, Shi B, Narayanan TK, Strohmeyer PS, Buchsbaum MS, and Mantil JC. Measuring dopamine neuromodulation in the thalamus: using [F-18]fallypride PET to study dopamine release during a spatial attention task. Neuroimage, 2006. 31(1): p. 139-52.

18. Mukherjee J, Christian BT, Dunigan KA, Shi B, Narayanan TK, Satter M, and Mantil J. Brain imaging of 18Ffallypride in normal volunteers: blood analysis, distribution, test-retest studies, and preliminary assessment of sensitivity to aging effects on dopamine D-2/D-3 receptors. Synapse, 2002. 46(3): p. 170-88.

19. Riccardi P, Zald D, Li R, Park S, Ansari MS, Dawant B, Anderson S, Woodward N, Schmidt D, Baldwin R, and Kessler R. Sex differences in amphetamine-induced displacement of [(18)F]fallypride in striatal and extrastriatal regions: a PET study. Am J Psychiatry, 2006. 163(9): p. 1639-41.

20. Woodward ND, Cowan RL, Park S, Ansari MS, Baldwin RM, Li R, Doop M, Kessler RM, and Zald DH. Correlation of individual differences in schizotypal personality traits with amphetamine-induced dopamine release in striatal and extrastriatal brain regions. Am J Psychiatry, 2011. 168(4): p. 418-26.

21. Dedovic K, Duchesne A, Andrews J, Engert V, and Pruessner JC. The brain and the stress axis: the neural correlates of cortisol regulation in response to stress. Neuroimage, 2009. 47(3): p. 864-71.

22. Dedovic K, Rexroth M, Wolff E, Duchesne A, Scherling C, Beaudry T, Lue SD, Lord C, Engert V, and Pruessner JC. Neural correlates of processing stressful information: an event-related fMRI study. Brain Res, 2009. 1293: p. 49-60.

23. Pruessner JC, Dedovic K, Khalili-Mahani N, Engert V, Pruessner M, Buss C, Renwick R, Dagher A, Meaney MJ, and Lupien S. Deactivation of the limbic system during acute psychosocial stress: evidence from positron emission tomography and functional magnetic resonance imaging studies. Biol Psychiatry, 2008. 63(2): p. 234-40.

24. The American Psychiatric Association. Diagnostic and Statistical Manual of Mental Disorders, 4th Edition, Text Revision (C) 2000, Washington DC.

25. McGuffin P, Farmer A, and Harvey I. A polydiagnostic application of operational criteria in studies of psychotic illness. Development and reliability of the OPCRIT system. Arch Gen Psychiatry, 1991. 48(8): p. 764-70.

26. Dedovic K, Renwick R, Mahani NK, Engert V, Lupien SJ, and Pruessner JC. The Montreal Imaging Stress Task: using functional imaging to investigate the effects of perceiving and processing psychosocial stress in the human brain. J Psychiatry Neurosci, 2005. 30(5): p. 319-25.

27. Delespaul PAEG. Assessing Schizophrenia in Daily Life. 1995, Maastricht: University Press.

28. Myin-Germeys I, Oorschot M, Collip D, Lataster J, Delespaul P, and van Os J. Experience sampling research in 
psychopathology: opening the black box of daily life. Psychol Med, 2009. 39(9): p. 1533-47.

29. Pruessner JC, Kirschbaum C, Meinlschmid G, and Hellhammer DH. Two formulas for computation of the area under the curve represent measures of total hormone concentration versus time-dependent change. Psychoneuroendocrinology, 2003. 28(7): p. 916-31.

30. Mukherjee J, Yang ZY, Brown T, Lew R, Wernick M, Ouyang X, Yasillo N, Chen CT, Mintzer R, and Cooper M. Preliminary assessment of extrastriatal dopamine D-2 receptor binding in the rodent and nonhuman primate brains using the high affinity radioligand, 18F-fallypride. Nucl Med Biol, 1999. 26(5): p. 519-27.

31. Alpert NM, Badgaiyan RD, Livni E, and Fischman AJ. A novel method for noninvasive detection of neuromodulatory changes in specific neurotransmitter systems. Neuroimage, 2003. 19(3): p. 1049-60.

32. Lammertsma AA, Bench CJ, Hume SP, Osman S, Gunn K, Brooks DJ, and Frackowiak RS. Comparison of methods for analysis of clinical [11C]raclopride studies. J Cereb Blood Flow Metab, 1996. 16(1): p. 42-52.

33. Talairach J and Tournoux P. Co-planar stereotaxic atlas of the human brain. 1988, New York: Thieme.

34. Gunn RN, Lammertsma AA, Hume SP, and Cunningham VJ. Parametric imaging of ligand-receptor binding in PET using a simplified reference region model. Neuroimage, 1997. 6(4): p. 279-87.

35. Lammertsma AA and Hume SP. Simplified reference tissue model for PET receptor studies. Neuroimage, 1996. 4(3 Pt 1): p. 153-8.

36. Friston KJ, Malizia AL, Wilson S, Cunningham VJ, Jones T, and Nutt DJ. Analysis of dynamic radioligand displacement or "activation" studies. J Cereb Blood Flow Metab, 1997. 17(1): p. 80-93.

37. Innis RB, Cunningham VJ, Delforge J, Fujita M, Gjedde A, Gunn RN, Holden J, Houle S, Huang SC, Ichise M, lida H, Ito H, Kimura Y, Koeppe RA, Knudsen GM, Knuuti J, Lammertsma AA, Laruelle M, Logan J, Maguire RP, Mintun MA, Morris ED, Parsey R, Price JC, Slifstein M, Sossi V, Suhara T, Votaw JR, Wong DF, and Carson RE. Consensus nomenclature for in vivo imaging of reversibly binding radioligands. J Cereb Blood Flow Metab, 2007. 27(9): p. 1533-9.

38. Benjamini $\mathrm{Y}$ and Hochberg $\mathrm{Y}$. Controlling the false discovery rate: a practical and powerful approach to multiple testing. J R Stat Soc Series B Stat Methodol, 1995. 57(1): p. 289-300.

39. Genovese CR, Lazar NA, and Nichols T. Thresholding of statistical maps in functional neuroimaging using the false discovery rate. Neuroimage, 2002. 15(4): p. 870-8.

40. Grubbs F. Procedures for Detecting Outlying Observations in Samples. Technometrics, 1969. 11(1): p. 1-21.

41. Simes, JR. An improved Bonferroni procedure for multiple tests of significance. Biometrika, 1986. 73: $\mathrm{p}$. 75-754.

42. Hochberg, Y. A sharper Bonferroni procedure for multiple tests of significance. Biometrika, 1988. 75: $\mathrm{p}$. $800-2$.

43. Cook R. Detection of influential observations in linear regression. Technometrics, 1977. 19(1): p. 15-18.

44. Wang J, Rao H, Wetmore GS, Furlan PM, Korczykowski M, Dinges DF, and Detre JA. Perfusion functional MRI 
reveals cerebral blood flow pattern under psychological stress. Proc Natl Acad Sci U S A, 2005. 102(49): p. 17804-9.

45. Bush G, Luu P, and Posner MI. Cognitive and emotional influences in anterior cingulate cortex. Trends Cogn Sci, 2000. 4(6): p. 215-222.

46. Drevets WC. Neuroimaging and neuropathological studies of depression: implications for the cognitiveemotional features of mood disorders. Curr Opin Neurobiol, 2001. 11(2): p. 240-9.

47. Ghashghaei HT and Barbas H. Pathways for emotion: interactions of prefrontal and anterior temporal pathways in the amygdala of the rhesus monkey. Neuroscience, 2002. 115(4): p. 1261-79.

48. Ghashghaei HT, Hilgetag CC, and Barbas H. Sequence of information processing for emotions based on the anatomic dialogue between prefrontal cortex and amygdala. Neuroimage, 2007. 34(3): p. 905-23.

49. Ongur D, An X, and Price JL. Prefrontal cortical projections to the hypothalamus in macaque monkeys. J Comp Neurol, 1998. 401(4): p. 480-505.

50. Price JL. Prefrontal cortical networks related to visceral function and mood. Ann N Y Acad Sci, 1999. 877: p. 383-96.

51. Stefanacci $L$ and Amaral DG. Some observations on cortical inputs to the macaque monkey amygdala: an anterograde tracing study. J Comp Neurol, 2002. 451(4): p. 301-23.

52. Damasio AR. The somatic marker hypothesis and the possible functions of the prefrontal cortex. Philos Trans R Soc Lond B Biol Sci, 1996. 351(1346): p. 1413-20.

53. Boes AD, Bechara A, Tranel D, Anderson SW, Richman L, and Nopoulos P. Right ventromedial prefrontal cortex: a neuroanatomical correlate of impulse control in boys. Soc Cogn Affect Neurosci, 2009. 4(1): p. 19.

54. Hare TA, Tottenham N, Galvan A, Voss HU, Glover GH, and Casey BJ. Biological substrates of emotional reactivity and regulation in adolescence during an emotional go-nogo task. Biol Psychiatry, 2008. 63(10): p. 927-34.

55. Morgan MA, Romanski LM, and LeDoux JE. Extinction of emotional learning: contribution of medial prefrontal cortex. Neurosci Lett, 1993. 163(1): p. 109-13.

56. Peters J, Kalivas PW, and Quirk GJ. Extinction circuits for fear and addiction overlap in prefrontal cortex. Learn Mem, 2009. 16(5): p. 279-88.

57. Vidal-Gonzalez I, Vidal-Gonzalez B, Rauch SL, and Quirk GJ. Microstimulation reveals opposing influences of prelimbic and infralimbic cortex on the expression of conditioned fear. Learn Mem, 2006. 13(6): p. 728-33.

58. Cannistraro PA and Rauch SL. Neural circuitry of anxiety: evidence from structural and functional neuroimaging studies. Psychopharmacol Bull, 2003. 37(4): p. 8-25.

59. Ongur D, Drevets WC, and Price JL. Glial reduction in the subgenual prefrontal cortex in mood disorders. Proc Natl Acad Sci U S A, 1998. 95(22): p. 13290-5. 
60. Abekawa T, Ohmori T, Ito K, and Koyama T. D1 dopamine receptor activation reduces extracellular glutamate and GABA concentrations in the medial prefrontal cortex. Brain Res, 2000. 867(1-2): p. 250-4.

61. Del Arco A and Mora F. Glutamate-dopamine in vivo interaction in the prefrontal cortex modulates the release of dopamine and acetylcholine in the nucleus accumbens of the awake rat. J Neural Transm, 2005. 112(1): p. 97-109.

62. Karreman $M$ and Moghaddam B. The prefrontal cortex regulates the basal release of dopamine in the limbic striatum: an effect mediated by ventral tegmental area. J Neurochem, 1996. 66(2): p. 589-98.

63. Moghaddam B. Stress activation of glutamate neurotransmission in the prefrontal cortex: implications for dopamine-associated psychiatric disorders. Biol Psychiatry, 2002. 51(10): p. 775-87.

64. Pascucci T, Ventura R, Latagliata EC, Cabib S, and Puglisi-Allegra S. The medial prefrontal cortex determines the accumbens dopamine response to stress through the opposing influences of norepinephrine and dopamine. Cereb Cortex, 2007. 17(12): p. 2796-804.

65. Buchanan TW, Driscoll D, Mowrer SM, Sollers JJ, 3rd, Thayer JF, Kirschbaum C, and Tranel D. Medial prefrontal cortex damage affects physiological and psychological stress responses differently in men and women. Psychoneuroendocrinology, 2010. 35(1): p. 56-66.

66. Charney DS. Psychobiological mechanisms of resilience and vulnerability: implications for successful adaptation to extreme stress. Am J Psychiatry, 2004. 161(2): p. 195-216.

67. Davis KL, Kahn RS, Ko G, and Davidson M. Dopamine in schizophrenia: a review and reconceptualization. Am J Psychiatry, 1991. 148(11): p. 1474-86.

68. Cepeda C, Andre VM, Jocoy EL, and Levine MS. NMDA and Dopamine: Diverse Mechanisms Applied to Interacting Receptor Systems. 2009.

69. Kahn RS and Davidson M. Serotonin, dopamine and their interactions in schizophrenia. Psychopharmacology (Berl), 1993. 112(1 Suppl): p. S1-4.

70. Pehek EA, Nocjar C, Roth BL, Byrd TA, and Mabrouk OS. Evidence for the preferential involvement of 5$\mathrm{HT} 2 \mathrm{~A}$ serotonin receptors in stress- and drug-induced dopamine release in the rat medial prefrontal cortex. Neuropsychopharmacology, 2006. 31(2): p. 265-77.

71. Yoo JH, Lee HK, Kim HC, Lee SY, and Jang CG. GABA(A) receptors mediate the attenuating effects of a 5-HT(3) receptor antagonist on methamphetamine-induced behavioral sensitization in mice. Synapse, 2010. 64(4): p. 274-9.

72. Christian BT, Narayanan TK, Shi B, and Mukherjee J. Quantitation of striatal and extrastriatal D-2 dopamine receptors using PET imaging of [(18)F]fallypride in nonhuman primates. Synapse, 2000. 38(1): p. 71-9. 
88

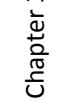




\title{
Familial liability to
}

psychosis is associated with altered

dopamine stress signaling in

ventromedial prefrontal cortex.

\author{
Johan Lataster ${ }^{1, *}$ \\ Dina Collip ${ }^{1, *}$ \\ Jenny Ceccarini ${ }^{2, * *}$ \\ Dennis Hernaus ${ }^{1, * *}$ \\ David Haas ${ }^{1}$ \\ Linda Booij ${ }^{3,4,5}$ \\ Jim van $0 s^{1,6}$ \\ Jens Pruessner ${ }^{7}$ \\ Koen Van Laere ${ }^{2}$ \\ Inez Myin-Germeys ${ }^{1}$
}


${ }^{1}$ Department of Psychiatry and Psychology, South Limburg Mental Health Research and Teaching Network, EURON, Maastricht University Medical Center, Maastricht, the Netherlands.

${ }^{2}$ Division of Nuclear Medicine, University Hospital and Catholic University Leuven, Belgium.

${ }^{3}$ Sainte-Justine Hospital Research Center, Montreal, Canada.

${ }^{4}$ Department of Psychiatry, University of Montreal, Montreal, Canada.

${ }^{5}$ Department of Psychiatry, McGill University, Montreal, Canada.

${ }^{6}$ King's College London, King's Health Partners, Department of Psychosis Studies, Institute of Psychiatry, London, UK.

${ }^{7}$ Douglas Mental Health Institute, Department of Psychiatry, McGill University, Montreal, Canada.

*These authors contributed equally to this work.

**These authors contributed equally to this work. 


\section{Abstract}

Objective: Patients diagnosed with a psychotic disorder and their first-degree relatives display increased reactivity to stress. Theory predicts that experience of psychosocial stress is associated both with ventromedial prefrontal and mesolimbic dopamine neurotransmission. However, while there is evidence of aberrant striatal dopamine processing in psychotic disorder, the role of the prefrontal cortex remains under-researched. The aim of the current study was to investigate in vivo dopamine release in ventromedial prefrontal cortex (vmPFC) of individuals at familial risk for psychosis in response to psychosocial stress.

Method: 14 healthy first-degree relatives of patients with a diagnosis of psychotic disorder and 10 control subjects underwent a single dynamic PET scanning session after intravenous administration of 183.2 (SD = 7.6) $\mathrm{MBq}\left[{ }^{18} \mathrm{~F}\right]$ fallypride. Psychosocial stress was initiated at 100 minutes postinjection. PET data were analyzed using the linearized simplified reference region model, which accounts for time-dependent changes in $\left[{ }^{18} \mathrm{~F}\right]$ fallypride displacement. Voxel-based statistical maps were computed to localize areas with increased ligand displacement after task initiation, reflecting dopamine release. Finally, regression analyses were performed to compare the amount of task-related ligand displacement between control subjects and relatives, and how it related to self-rated experiences of psychosocial stress and psychosis.

Results: First-degree relatives displayed altered (i.e., hyporeactive) dopamine signaling in the vmPFC in response to stress. Furthermore, hyporeactivity of the vmPFC dopamine stress system was accompanied by increased psychotic reactions to stress.

Conclusion: Although previous studies have hypothesized a role for prefrontal dopamine dysfunction in psychosis, this study, to our knowledge, is the first in vivo human imaging study showing that psychotic reactivity to stress in individuals with familial risk for psychosis is associated with altered (i.e., hyporeactive) dopamine stress processing in vmPFC. 


\section{Introduction}

Patients diagnosed with a psychotic disorder, as well as their unaffected first-degree relatives, display increased reactivity to stress, responding to minor daily stressors with increased intensity of psychotic experiences ${ }^{1}$. Given the suggested involvement of dopaminergic neurotransmission in the human stress response $\mathrm{e}^{2-4}$, and the central role for dopamine dysfunction in patients with a psychotic disorder (see Howes and Kapur ${ }^{5}$ for review of the literature), observations of increased stress reactivity in psychosis-prone individuals may represent a functional state of underlying anomalies in dopamine stress signaling ${ }^{6}$. In vivo human imaging studies investigating stress-induced changes in dopamine levels are scarce, however, and do not include assessment of the context of psychosis ${ }^{3,7,8}$. Moreover, although the experience of psychosocial stress is suggested to involve both frontocortical and mesolimbic neurotransmission ${ }^{9-15}$, these studies have focused solely on striatal dopamine release $\mathrm{s}^{3,7}$.

Rodent studies, however, suggest a cardinal role for prefrontal dopamine in stress processing, as exposure to both physical ${ }^{16}$ and social ${ }^{17}$ stress is associated with increased extracellular dopamine levels predominantly in prefrontal cortex (PFC), and to a lesser extent in mesolimbic areas. Moreover, depletion of dopamine in rodent PFC increases dopamine reactivity to stress in mesolimbic brain regions ${ }^{11,12,14}$, suggesting that PFC dopamine transmission plays a role in the attenuation of mesolimbic dopamine release, exerting a 'brake-like' function that may play a vital role in diminishing the adverse effects of stress on the brain ${ }^{18}$. Individuals vulnerable to psychosis, similar to PFC dopamine-depleted rodents, display abnormally low PFC activity (i.e., "hypofrontality") ${ }^{19-21}$, and increased reactivity of mesolimbic dopamine neurons ${ }^{19-23}$, the latter seemingly predicting conversion to psychotic disorder in individuals at ultra-high-risk for psychosis ${ }^{24,25}$. These data suggest underlying alterations resulting in failure of the prefrontal dopamine system to exert control over stress-induced mesolimbic dopaminergic neurotransmission, the behavioral expression of which is increased psychotic reactivity to stress ${ }^{1,26}$. However, direct in vivo evidence for an impaired stress-attenuating function of the prefrontal dopamine system in psychosis is currently lacking. This is mainly due to methodological restrictions, a lack of high affinity $D_{2 / 3}$ ligands limiting positron emission tomography (PET) exploration of dopaminergic transmission to brain regions with high $\mathrm{D}_{2}$ receptor density, primarily the striatum. Recent development of high affinity $\mathrm{D}_{2 / 3}$ radioligands, among which $\left[{ }^{18} \mathrm{~F}\right]$ fallypride, has offered possibilities for exploration of extrastriatal dopamine sites such as the $\mathrm{PFC}^{2,27-32}$. In a previous study (see Chapter $\left.\mathbf{3}\right)^{2}$, we 
used $\left[{ }^{18} \mathrm{~F}\right]$ fallypride to detect in vivo prefrontal dopamine release in healthy human subjects in response to the Montreal Imaging Stress Task (MIST), a psychosocial stress challenge developed and used previously by Pruessner et al. ${ }^{3}$. Subjectively rated experiences of psychosocial stress were positively associated with dopaminergic activity in ventromedial PFC (vmPFC), implicating an important role for vmPFC dopamine neurotransmission in human stress processing, in line with abnormal stress responsivity in neurological patients with medial PFC damage ${ }^{33}$. The present study aimed at extending this work to the domain of psychosis, utilizing the same $\left[{ }^{18} \mathrm{~F}\right]$ fallypride PET stress paradigm ${ }^{2,3,28}$ in a sample of healthy subjects and first-degree relatives of patients with a psychotic disorder to examine to what degree the vmPFC dopamine stress response mediates the stress reactivity endophenotype of psychosis. It was hypothesized that first-degree relatives would display impaired attenuation of stress-induced mesolimbic dopamine release by the prefrontal dopamine system, reflected by anomalies in stress-induced vmPFC dopamine signaling associated with psychotic reactivity to the MIST laboratory stressor.

\section{Materials and methods}

\section{Subjects}

The sample consisted of 14 healthy first-degree relatives of individuals with a psychotic disorder and 12 healthy control subjects with no family history of psychotic illness (control sample has been described in previous work; see Chapter 3$)^{2}$. Subjects were recruited through pamphlets, advertisements in local newspapers and random mailing procedures in the local area. Relatives were additionally recruited by contacting local family organizations for relatives of patients with a psychotic disorder.

Inclusion criteria were (i) age 18-65 years; and (ii) sufficient command of the Dutch language to understand instructions and give informed consent. Exclusion criteria were (i) intellectual impairment (ii) head trauma with loss of consciousness or central neurological disorder; (iii) endocrine disorder; (iv) cardiovascular disorder; (v) present or history of psychiatric illness according to the explicit diagnostic criteria of the DSM-IV-TR ${ }^{34}$, generated with the OPCRIT computer program 35 ; (vi) positive family history of psychosis (controls only); (vii) current use of psychotropic medication; (viii) current or previous use of illicit drugs; (ix) use of alcohol in excess of five standard units per day; $(x)$ presence of metal elements in the body; 
(xi) previous experience of claustrophobia; and (xii) pregnancy or lactation (women only). The study was approved by the standing medical ethics committee; subjects signed informed consent after description of the study. Drug and medication use were assessed at the day of scanning by urinalysis (MultiTest (C) 1990-2010 SureScreen Diagnostics Ltd.) in order to ensure that subjects were drug free at the moment of scanning. In addition, pregnancy tests (Clearblue @ 2008 Swiss Precision Diagnostics) were carried out in female subjects, in order to exclude pregnancy at the moment of scanning.

\section{Psychosocial stress task}

Psychosocial stress was induced in the PET-scanner using the Montreal Imaging Stress Task (MIST), the psychosocial stress paradigm developed by Pruessner et al. ${ }^{3,36}$. The experiment consisted of a control and a stress condition. In the control condition, subjects performed 6-minute blocks of mental arithmetic on a computer screen with no time constraints or performance feedback, resulting in an average performance of $90 \%$ correct responses. In the stress condition, subjects performed similar mental arithmetic as in the control condition, with the addition of information about the total number of errors, expected average number of errors, time spent on the current problem, and performance feedback (correct, incorrect, timeout), displayed on the computer screen. In addition, a time constraint, slightly below the time needed according to the subject's ability, was set for solving each problem. The constraint was automatically adjusted by the computer algorithm for each individual subject, based on the average time needed to solve a problem during a practice session before start of the PET scan. A tone rising in frequency indicated the remaining time for the subject to solve each problem.

Subjects were informed that an average performance of $80-90 \%$ correct answers was expected. However, due to the manipulation of the time constraint, subjects achieved, on average, only 20-30\% correct answers. Psychosocial stress was additionally induced through negative verbal feedback from a confederate investigator, who commented upon subjects' performance, emphasizing that they needed to achieve at least minimal performance requirements. An extensive debriefing session took place at the end of the experiment, in which subjects were told that the task was specifically designed to be out of reach of their mental capacity, and that in reality it did not assess their ability to perform mental arithmetic. 


\section{Behavioral measures}

Self-rated experiences of stress and psychosis were assessed every twelve minutes, throughout the experiment, and consisted of six stress and seven psychosis items, rated on 7point Likert scales (rating from not at all [=1] to very [=7]), adapted from Experience Sampling Methodology (ESM) ${ }^{37}$. All scores were recoded such that an increase in scores corresponded to increased intensity of subjective stress or psychotic experiences, respectively. Averages of the (recoded) scores on the items "I feel relaxed", "This takes effort", "I feel pressured", "I feel comfortable among these people", "I feel judged by these people", and "I do not live up to expectations" constituted the subjective stress scale (Cronbach's alpha $=.69$ ). The psychosis scale consisted of averages of the (recoded) scores on the items "I feel suspicious", "I feel unreal", "My thoughts are being influenced by others", "I can't get rid of my thoughts", "I see things that aren't really there", "I hear voices", and "I'm afraid I'll lose control" (Cronbach's alpha $=.73)$.

\section{PET acquisition}

In order to minimize interference of task-induced stress with PET procedure-induced stress, the catheter used for ligand injection was placed 3 hours before the actual experiment took place. For the same reason, subjects were familiarized with the test setup and placed in the scanner three hours before the actual scan to complete the practice session of the psychosocial stress task. An example of the psychosocial stress task was presented on the computer screen for adjusting the positions of the mouse and computer monitor for comfortable viewing (outside the field of view of the scanner). After completing the test session, subjects were removed from the scanner, awaiting the actual PET experiment. For the actual experimental PET session, subjects were again installed on the scanner bed with their head fixated using a vacuum pillow and foam inserts. If needed, the positions of the mouse and computer monitor were once more adjusted to allow for optimal comfort. Subjects received 183.2 (SD = 7.6) MBq of $\left[{ }^{18} \mathrm{~F}\right]$ fallypride (see Chapter 3, p. 65 for detailed description of radiotracer preparation) ${ }^{2}$ in a slow intravenous bolus injection through a catheter in the left or right antecubital vein, depending on subject handedness. Simultaneously upon radiotracer injection, dynamic emission scans were initiated in threedimensional mode using a HiRez Biograph 16 PET/CT camera (Siemens Medical Solutions, Inc.). Data were obtained in 60 second frames during the first 6 minutes and in 120 second frames thereafter.

PET emission was performed conform the one-day PET imaging protocol for $\left[{ }^{18} \mathrm{~F}\right]$ fallypride 
used previously (see Chapter 3) 2, 28,31. Emission data were collected in two segments, one during the control condition and one during the stress condition of the MIST psychosocial stress task. Given the use of an "activation" parameter in the kinetic model used for analyses (for details see Chapter 3$)^{2,38}$, representing presence or absence of additional dopamine release, and the hypothesis of stress being associated with increased dopaminergic activity, the stress condition of the MIST was always presented after the control condition.

The first PET segment, with a duration of 70 minutes, thus represented the $\left[{ }^{18} \mathrm{~F}\right]$ fallypride kinetics during the control condition, in which subjects performed 6-minute blocks of mental arithmetic without time constraints or performance feedback. The control session was followed by a brief break period of 10 minutes, after which subjects were, if necessary, repositioned on the scanner bed and the second PET emission data were collected for another 86 minutes in total. In order to ensure that "activation" (i.e., presence or absence of additional dopamine release, reflected by changes in ligand displacement) was not a result of repositioning or the simple act of getting up from the scanner from a break in the experiment, no task was presented during the first 20 minutes of this second emission scan. This, additionally, minimized risk of carry-over effects from the control condition into the stress condition, and maximized psychological impact of the stressor.

At 100 minutes post-injection, the psychosocial stress task was initiated and performed for the remaining 66 minutes of dynamic imaging. Subjective ratings of stress and psychosis were assessed every 12 minutes. To correct for attenuation, a low-dose ( $80 \mathrm{kV}$ tube potential, $11 \mathrm{~mA} \cdot \mathrm{s}$ ) CT scan was conducted at the beginning of each PET segment (immediately before tracer injection and at 80 minutes post-injection) and at the end of emission scan.

Images were reconstructed using a 3D OSEM (ordered-subset expectation maximization) iterative reconstruction including model-based scatter as well as attenuation correction based on a measured attenuation map acquired by the CT, with a final spatial resolution of 4 $\mathrm{mm}$. Additionally, in order to exclude structural brain abnormalities and perform anatomical co-registration, all subjects received a volumetric T1-weighted and standard transverse T2 brain magnetic resonance image (MRI; 1.5 Tesla Vision Scanner, Siemens, Germany). Parameters for the T1 3D Magnetization Prepared Rapid Acquisition Gradient Echo sequence were: $\mathrm{TR}=0 \mathrm{~ms}, \mathrm{TE}=4 \mathrm{~ms}$, flip angle $=12^{\circ}$, inversion time $=300 \mathrm{~ms}$, matrix $256 \times 256,160$ sagittal contiguous slices of $1 \mathrm{~mm}$.

To guarantee the consistency of $\left[{ }^{18} \mathrm{~F}\right]$ fallypride metabolism among scans and to minimize potential changes in dopamine levels, PET acquisitions were conducted at the same time of day (14:30 $\pm 00: 30)$, and all subjects fasted two hours prior to radiotracer injection and 
abstained from nicotine, medication, and alcohol- or caffeine-containing drinks on the day of scanning.

\section{PET data reduction and statistical analysis}

For each subject, brain reconstructed PET data were transferred in DICOM (Digital Imaging and Communications in Medicine) and converted to Analyze using PMOD software v. 2.95 (PMOD Inc., Zurich, Switzerland). To minimize effects of head movement during the scan, all $\left[{ }^{18} \mathrm{~F}\right]$ fallypride frames for each PET were realigned, co-registered to the subject's MRI and then spatially normalized to a specific T1-weighted template constructed in MNI (Montreal Neurological Institute) stereotaxic space using SPM8 (Statistical Parametric Mapping, The Wellcome Department of Cognitive Neurology, London, UK). To increase signal to noise ratio, the normalized images were then smoothed with a 3D gaussian filter (4-mm full width at half maximum) before applying the kinetic model.

For each subject, volume-of-interest (VOI) analysis was performed by estimating the kinetic parameters using the LSRRM kinetic model ${ }^{38}$ (see Chapter 3, p. 68 for detailed description of the model) ${ }^{2}$ and the PET time-activity curves (TACs) for left and right vmPFC. The cerebellum was used as a reference region for $\left[{ }^{18} \mathrm{~F}\right]$ fallypride, representing a cerebral area with a paucity of dopamine $D_{2 / 3}$ receptors ${ }^{39}$. For each subject, two binary masks were created based on the corresponding normalized MRI. With the aid of the Talairach atlas ${ }^{40}$, one binary mask image was designed to include left and right vmPFC (Brodmann area 10), and a second mask was drawn only on the cerebellum. A voxel-wise t-statistic map was computed to localize areas that displayed increased $\left[{ }^{18} \mathrm{~F}\right]$ fallypride ligand displacement after initiation of the stress condition.

\section{Main analysis}

Linear regression analyses were conducted with group (control $[=0]$ vs. relative $[=1]$ ), task-induced changes in scores on the subjective stress scale (quantified as the difference between mean scores on the scale under stress vs. control conditions) or respectively taskinduced changes in scores on the psychosis scale (quantified as the difference between mean scores on the scale under stress vs. control conditions), as well as their interaction (i.e., group $x$ subjective_stress, and group $x$ psychosis) as independent variable, and taskinduced changes in $\left[{ }^{18} \mathrm{~F}\right]$ fallypride ligand displacement in left, and right vmPFC (quantified as the percentage of voxels exceeding the false discovery rate (FDR $)^{41}$ corrected significance threshold of $p(\alpha(F D R)=5 \%)<0.05$; see Chapter 3, p. 69 for details $)^{2}$ as dependent variable. 
Finally, linear regression analysis was performed with group (control $[=0]$ vs. relative $[=1]$ ), task-induced changes in scores on the subjective stress scale (quantified as the difference between mean scores on the scale under stress vs. control conditions), as well as their interaction (i.e., group $x$ subjective_stress) as independent variable, and task-induced changes in scores on the psychosis scale (quantified as the difference between mean scores on the scale under stress vs. control conditions) as dependent variable.

Significance tests were performed in STATA release $10.0^{42}$. When interactions were detected, simple effects were calculated using the LINCOM command in STATA. All analyses were $a$ priori corrected for age, gender, nicotine use ${ }^{43}$ (continuous: number of cigarettes / day), and alcohol consumption ${ }^{44}$ (continuous: grams of alcohol / week).

\section{Results}

\section{Subjects}

Of the 26 subjects who entered the study, one control subject was excluded because of excessive stress during the control condition of the experimental PET paradigm, attributable to uncomfortable placement of the catheter for bolus injection. For another control subject, data on the subjective stress- and psychosis scale were lost due to a computer failure. Consequently, final analyses were performed in a sample of 10 control subjects and 14 firstdegree relatives.

\section{Subject characteristics}

No large or significant sociodemographic differences were observed between groups (see Table 1). Task-induced changes in subjective stress, psychotic experiences, and [ $\left.{ }^{18} \mathrm{~F}\right]$ fallypride ligand displacement are summarized in Table 2. Mean levels of task-induced stress, psychosis, and $\left[{ }^{18} \mathrm{~F}\right]$ fallypride ligand displacement in vmPFC were similar between groups (see Table 2). The stress condition was experienced as significantly more stressful compared to the control condition, reflected by higher scores on the subjective stress scale (Mean (control) $=2.86$ $[S D=.56] ;$ Mean $\left._{(\text {stress) }}=4.03[S D=.78] ; \mathrm{t}_{(d f=23)}=-7.98 ; p=.0001\right)$. 


\section{Main results}

Effect of familial liability to psychosis on the association between task-induced changes in subjective stress and $\left.{ }^{18} \mathrm{~F}\right]$ fallypride ligand displacement

Linear regression analyses showed significant interactions between group (control vs. relative) and subjective, task-induced stress in the models of task-induced $\left[{ }^{18} \mathrm{~F}\right]$ fallypride ligand displacement in left and right vmPFC (left: $F=19.12 ; \beta=-2.04$ [SE=.47]; $p=.0005$; right: $F=12.32 ; \beta=-1.92$ [SE=.55]; $p=.003$; Figure 1), indicating a differential association between the experience of stress and task-induced dopamine activity in these brain regions in controls versus relatives.

In relatives, higher levels of subjective stress were associated with decreased $\left[{ }^{18} \mathrm{~F}\right]$ fallypride ligand displacement in bilateral vmPFC (left: $\beta=-1.02 ; 95 \% \mathrm{Cl}[-1.54 ;-.49] ; \mathrm{p}=.001$; right: $\beta=-.85 ; 95 \% \mathrm{Cl}[-1.47 ;-.23] ; p=.010$ ), suggesting lower dopaminergic activity in these brain regions. Conversely, in controls, higher levels of subjective stress were associated with increased $\left[{ }^{18} \mathrm{~F}\right]$ fallypride ligand displacement in bilateral vmPFC (left: $\beta=1.02 ; 95 \%$ $\mathrm{Cl}[.28 ; 1.77] ; p=.010$; right: $\beta=1.07 ; 95 \% \mathrm{Cl}[.19 ; 1.95] ; p=.020)$, suggestive of increased dopaminergic activity.

Effect of familial liability to psychosis on the association between taskinduced changes in self-rated psychotic experiences and $\left[{ }^{18} \mathrm{~F}\right]$ fallypride ligand displacement

Linear regression analyses showed significant interactions between group (control vs. relative) and task-induced psychotic experiences in the model of task-induced $\left[{ }^{18} \mathrm{~F}\right]$ fallypride ligand displacement in left and right vmPFC (left: $F=9.03 ; \beta=-4.20$ [SE=1.40]; $p=.008$; right: $F=6.89 ; \beta=-4.03$ [SE=1.54]; $p=.018$; Figure 2 ), indicating a differential association between task-induced psychotic experiences and task-induced dopamine release in controls versus relatives.

In relatives, increased intensity of subjective psychotic experiences was associated with decreased $\left[{ }^{18} \mathrm{~F}\right]$ fallypride ligand displacement in bilateral vmPFC (left: $\beta=-2.21 ; 95 \% \mathrm{Cl}$ [-3.78; -.65]; $p=.008$; right: $\beta=-1.96 ; 95 \% \mathrm{Cl}[-3.69 ;-.25] ; p=.028)$, suggestive of reduced dopaminergic activity in these brain regions. In controls, no association was found between psychotic experiences and $\left[{ }^{18} \mathrm{~F}\right]$ fallypride ligand displacement in vmPFC (left: $\beta=1.98 ; 95 \% \mathrm{Cl}$ $[-.49 ; 4.46] ; p=.109 ;$ right: $\beta=2.07 ; 95 \% \mathrm{Cl}[-.66 ; 4.80] ; p=.128)$. 
Effect of familial liability to psychosis on the association between task-induced changes in subjective stress and task-induced changes in subjective psychotic experiences

Linear regression analyses revealed no significant interaction effect between group (control vs. relative) and task-induced subjective stress on subjectively rated psychotic experiences $(F=1.15 ; \beta=.58$ [SE=.54]; $p=.299$; corrected for age and gender). Nevertheless, post hoc simple effects analyses, using the LINCOM command in STATA version $10.0^{42}$, revealed higher levels of subjective task-induced stress to be associated with increased intensity of subjective psychotic experiences in relatives $(\beta=1.19 ; 95 \% \mathrm{Cl}[.57 ; 1.81] ; p=.001$; corrected for age and gender), but not in controls ( $\beta=.61 ; 95 \% \mathrm{Cl}[-.27 ; 1.50] ; p=.161$; corrected for age and gender).

\section{Discussion}

Results from the current study indicate that individuals at familial risk for psychosis display altered dopamine stress processing in ventromedial prefrontal cortex (vmPFC), a brain region previously identified to play a key role in human dopaminergic stress regulation ${ }^{2}$. Furthermore, alterations in the VmPFC dopamine stress response were accompanied by increased psychotic reactions to stress, fitting previously reported associations between abnormal dopamine reactivity and increased stress reactivity in the daily life of subjects at familial risk of developing psychosis ${ }^{6}$. Although previous studies have suggested a role for prefrontal dysfunctions in psychosis ${ }^{20,21,45,46}$, this is, to our knowledge, the first in vivo human imaging study showing that psychotic reactivity to stress in individuals at familial risk for psychosis is associated with alterations in dopamine stress processing in PFC.

\section{Ventromedial prefrontal cortex involvement in stress regulation}

The current findings underline a regulatory role for vmPFC dopamine neurotransmission in the human stress response ${ }^{2}$, given that individuals at familial risk for psychosis, characterized by impairments in stress regulation ${ }^{1}$, display alterations in VmPFC dopamine stress transmission. These findings are in line with reports of medial prefrontal cortex damage being associated with heightened self-reported stress responses to the Trier Social Stress Test $^{33}$.

The vmPFC strongly connects to the amygdala, ventral striatum, and hypothalamus ${ }^{47-51}$, and 
is thought to be involved in emotion regulation ${ }^{52}$, impulse control ${ }^{53}$, self-control ${ }^{54}$, and fear extinction ${ }^{55}$. The infralimbic prefrontal cortex, which is considered the rat homologue of the human vmPFC ${ }^{56}$, inhibits fear responses in rats when stimulated ${ }^{57}$. Furthermore, the loss of top-down control by the vmPFC is implicated in mood and anxiety disorders ${ }^{58-61}$, supporting a role for the vmPFC as emotion control centre, further emphasized by observations of an association between vmPFC damage and deficits in emotion regulation ${ }^{62,63}$.

Importantly, the human stress response is uniquely determined by the interaction between a stressor and the individual's appraisal thereof, which may be incongruous with the actual threat of the stressful situation ${ }^{64}$. The vmPFC is implicated in the neural processing of these appraisals ${ }^{65}$, in turn activating subcortical brain regions involved in the initiation of the physiological stress response ${ }^{49}$. Similar to patients with a psychotic disorder ${ }^{66,67, v m P F C-}$ damaged patients display difficulty appraising social and emotional cues ${ }^{68,69}$. Inappropriate psychological (e.g., psychotic) and physiological reactions to social stress, as observed in individuals at risk of psychosis ${ }^{1,26,70}$, may therefore result from impaired appreciation of the stressful nature of a situation, mediated by alterations in vmPFC functioning.

\section{A role for prefrontal-mesolimbic dopamine asymmetry in psychotic stress processing}

Although previous studies suggest a role for asymmetry of prefrontal-mesolimbic dopamine networks in psychotic disorders, implicating 'hypoactivity' of prefrontal and 'hyperactivity' of mesolimbic dopamine structures ${ }^{19}$, a scarcity of in vivo human studies investigating stress-induced changes in prefrontal dopamine levels limits our understanding of the role of this neurochemical asymmetry in the stress reactivity endophenotype of psychosis. Rodent studies indicating that depletion of dopamine in the PFC increases stress-induced dopamine release in the mesolimbic system ${ }^{11}, 12,14$ have advanced the hypothesis that prefrontal dopamine transmission attenuates stress-induced mesolimbic dopamine release. In fact, the prefrontal dopamine system may not only constrain, but also determine mesolimbic dopamine activity in response to stress ${ }^{71}$. A possible function of this mechanism could be to protect the organism for the adverse consequences of stress on the brain, supported by the observation that stress-related psychopathologies are characterized by disturbed mesolimbic dopamine transmission ${ }^{72-75}$ and prefrontal diminution ${ }^{73,76,77}$. Our previous finding of healthy subjects responding to psychosocial stress with increased levels of endogenous dopamine in the $\mathrm{PFC}^{2}$, whereas a similar stressor in previous studies did not necessarily induce dopamine release in mesolimbic brain regions ${ }^{3,7,8}$, further supports the 
hypothesis that the organism may benefit from such a stress-reducing mechanism, with a suggested regulatory role of the prefrontal dopamine system. Findings from the current study, showing an association between altered stress-induced dopamine signaling in vmPFC and increased behavioral reactivity to psychosocial stress in first-degree relatives of patients with a psychotic disorder, suggest familial risk for psychosis is mediated, amongst others, by impaired attenuating control of the prefrontal dopamine system, and hence increased stress reactivity of mesolimbic dopamine neurons. Given the proposed mediating role of mesolimbic dopamine in salience attribution ${ }^{78}$, a stress-induced hyperactive state of the mesolimbic dopamine system may result in 'aberrant salience' (the assignment of salience to otherwise unimportant stimuli), and fuel psychotic experiences ${ }^{22}$, supported by current and previous ${ }^{6,26}$ observations of stress-induced psychotic experiences in individuals at risk of psychosis.

Animal studies suggest that excessive stimulation of prefrontal dopamine neurons (e.g., by stress) can put the prefrontal cortex 'off-line ${ }^{79,80}$, disrupting the attenuating control over subcortical brain regions, rendering these regions hyperreactive and enabling them to dominate behavior. This mechanism may have survival value, since it enables the organism to automatically switch from complex, slow, prefrontally regulated behaviors to instinctive, fast (e.g., 'fight'-'flight') ${ }^{81}$ behaviors guided by subcortical brain regions, when exposed to severe stress ${ }^{82}$. Incorrect tuning of this mechanism, however, may render the organism hyper- or hyporesponsive to stress. The current findings suggest that individuals at familial risk for psychosis may be prone to stress-induced 'overload' of the vmPFC dopamine system, reflected by observations of inverse dopamine stress-reactivity in vmPFC when compared to healthy control subjects. Consequently, attenuating control of the vmPFC dopamine system over the stress-induced mesolimbic dopamine response may be lost, increasing likelihood of stress-induced psychotic experiences ${ }^{22}$.

\section{Strengths and limitations}

The findings reported in this study result from significant advances made in the field of neuroimaging and show, for the first time, aberrant in vivo dopamine stress signalling in the PFC of individuals at familial risk for psychosis. Further strengths of the study include the use of a laboratory stressor that attempts to emulate real-world social interactions and succeeds in eliciting stress not only at a neural level, but also at the level of subjective experience. Some limitations require consideration. First, the study design did not permit simultaneous and additional investigation of subcortical dopamine release. Subcortical dopamine regions 
differ from cortical brain regions with regard to dopamine $D_{2 / 3}$ receptor density as well as dopamine kinetics, and therefore require a longer scan duration in order to reach a similar proportion of receptors to be occupied by the dopamine-competing ligand fallypride than is the case in low density dopamine $\mathrm{D}_{2 / 3}$ regions such as the $\mathrm{PFC}^{83}$. Consequently, assessing dopamine transmission simultaneously in two regions that differ in terms of receptor density was not feasible using the current study design, since the timing of task-initiation would have to be adjusted for each region in such a way that the proportional distribution of radioligand would be optimized. A compromising solution, in the form of intermittent task initiation timing would, at best, have resulted in overestimation of dopamine release in relatively low dopamine $D_{2 / 3}$ receptor dense structures and underestimation of dopamine release in relatively high $D_{2 / 3}$ receptor dense structures ${ }^{28}$. Second, although application of the LSRRM has several practical advantages, such as the requirement for only a single radiochemical synthesis and administration and avoidance of session effects, practical implementation of the model implies that time-dependent alterations in regional cerebral blood flow (rCBF) are not fully accounted for. However, as argued by Christian and colleagues $^{28}$, using a single injection protocol in combination with the in vivo kinetics of fallypride minimizes the possible confounds of changing rCBF under psychological task paradigm conditions. Third, consequential to the one-day scanning protocol utilized in the current study, the stress and control conditions of the MIST were consistently administered in the same sequence, i.e., the control condition preceded the stress condition for each subject. This increases risk of carry-over effects from the control condition into the stress condition. However, these effects were minimized by separating the two conditions by a baseline condition. Most importantly, a two-scan protocol, with counterbalanced administration of stress and control conditions, would have meant that the extensive and important debriefing session, in which subjects were told that the task was specifically designed to be out of reach of their mental capacity, and that it did not assess their ability to perform mental arithmetic, could only take place after the second scan, which was considered to be ethically problematic. Furthermore, a oneday scan protocol has the advantage of avoiding session effects. Fourth, generalizability of the current findings to clinical populations is hampered by the fact that the current study did not include patients with a psychotic disorder. Nonetheless, there is substantial evidence of familial and aetiological continuity between the transitory subclinical phenomena reported by non-clinical populations at increased risk of developing psychosis (e.g., first-degree relatives of patients with a psychotic disorder or psychometrically identified individuals with high schizotypy scores) and clinically relevant psychotic disorders ${ }^{84-87}$. Examining psychotic 
symptoms in first-degree relatives of patients with a psychotic disorder may therefore help clarifying the underlying aetiology of psychosis. An additional advantage of this approach is the circumvention of potential confounding factors that are inherent to the clinical illness (e.g., illness chronicity, antipsychotic drug treatment, or cognitive deficits). Fifth, no performance measure was implemented in the psychosocial stress paradigm. We can, therefore, not ascertain to what degree the findings may be confounded by variations in task performance. However, as argued by Pruessner et al. ${ }^{3}$, controlling for task performance would be redundant, since manipulation of the time constraint yields an average proportion of $20-30 \%$ correct answers in the stress condition for each individual subject. Furthermore, the strong correlation between subjectively experienced feelings of stress and fallypride ligand displacement in ventromedial PFC reported by Lataster et al. ${ }^{2}$ in a previous study utilizing the same PET stress paradigm (see Chapter $\mathbf{3}$ ), suggests that neural activity in this region is unlikely to be related purely to cognition. Finally, it should be noted that our results do not imply causality and the specific function of each brain region in the human stress response remains an important subject for further investigation. 


\section{Acknowledgements}

This work was supported by a 2006 NARSAD Young Investigator Award (to Prof. dr. I. MyinGermeys) and by the Dutch Medical Research Council (VENI and VIDI grants to Prof. dr. I. Myin-Germeys), and the European Community's Seventh Framework Program under grant agreement Nº HEALTH-F2-2009-241909 (Project EU-GEI). We thank Wendy Beuken, Rufa Diederen, Stijn Dirix, Truda Driesen, Bernice Gulpers, Kwinten Porters, and Mieke Steukers for their assistance in collecting data, and Ron Mengelers for technical support.

\section{Declaration of Interest}

The authors declare no competing interests. 
Table 1 | Sociodemographic characteristics of the sample, nicotine use and alcohol consumption.

\begin{tabular}{|c|c|c|c|c|}
\hline Characteristic & $\begin{array}{l}\text { Control subjects } \\
\qquad(n=10)\end{array}$ & $\begin{array}{l}1^{\text {st }} \text { degree relatives } \\
\qquad(n=14)\end{array}$ & Test-statistic & $\mathrm{p}$ \\
\hline Age (y; mean (SD)) & $\begin{array}{l}36.6(15.3) \\
\text { ranges 23-60 }\end{array}$ & $\begin{array}{c}40.6(15.0) \\
\text { ranges 19-63 }\end{array}$ & $-0.65^{a}$ & .525 \\
\hline Gender (n, \%) & & & $2.24^{b}$ & $.134^{c}$ \\
\hline Male & $8(80)$ & $7(50)$ & & \\
\hline Female & $2(20)$ & $7(50)$ & & \\
\hline Level of education $(n, \%)^{d}$ & & & $0.64^{\mathrm{b}}$ & .727 \\
\hline Secondary education & $1(10)$ & $3(21)$ & & \\
\hline Bachelor degree & $6(60)$ & $8(57)$ & & \\
\hline Master degree & $3(30)$ & $3(21)$ & & \\
\hline Work situation $(n, \%)^{d}$ & & & $1.92^{\mathrm{b}}$ & .750 \\
\hline Household & 0 & $2(14)$ & & \\
\hline School/education & $2(20)$ & $3(21)$ & & \\
\hline Regular job (fulltime) & $6(60)$ & $6(43)$ & & \\
\hline Regular job (parttime) & $1(10)$ & $2(14)$ & & \\
\hline Other activities & $1(10)$ & $1(7)$ & & \\
\hline Marital status (n, \%) & & & $1.05^{\mathrm{b}}$ & .590 \\
\hline Married or cohabitating & $5(50)$ & $8(57)$ & & \\
\hline Divorced & 0 & $1(7)$ & & \\
\hline Never married & $5(50)$ & $5(36)$ & & \\
\hline Nicotine use (cigarettes/day; $n, \%$ ) & & & $0.24^{\mathrm{a}}$ & .810 \\
\hline 0 & $8(80)$ & $12(86)$ & & \\
\hline $1-10$ & $1(10)$ & $1(7)$ & & \\
\hline $10-20$ & $1(10)$ & $1(7)$ & & \\
\hline Alcohol consumption (grams/week ${ }^{\mathrm{e}} ; \mathrm{n}, \%$ ) & & & $0.72^{\mathrm{a}}$ & .476 \\
\hline $0-50$ & $5(50)$ & $8(57)$ & & \\
\hline $50-100$ & $1(10)$ & $2(14)$ & & \\
\hline $100-150$ & $4(40)$ & $4(29)$ & & \\
\hline \multicolumn{5}{|l|}{ GAF-score (mean (SD)) } \\
\hline GAF-symptoms & $87.2(7.6)$ & $81.4(8.4)$ & $1.72^{\mathrm{a}}$ & .100 \\
\hline GAF-handicap & $87.0(8.6)$ & $84.3(6.9)$ & $0.86^{a}$ & .400 \\
\hline
\end{tabular}

a t-value (comparing group means; two-sided p-value presented).

b Pearson's $\chi^{2}$ (comparing categorical distributions between groups).

${ }^{\mathrm{c}}$ Fisher's exact $\mathrm{p}$-value $=.210$.

d Percentages do not total 100 because of rounding.

e Standard drink / unit size in the Netherlands contains 9.9 grams of ethanol. 
Table 2 | Mean (SD) values and $t$-test statistics of task-induced stress, psychotic experiences, and $\left[{ }^{18} \mathrm{~F}\right] \mathrm{fallyp}$ ride ligand displacement for control subjects and first-degree relatives.

\begin{tabular}{|c|c|c|c|c|}
\hline \multirow[b]{3}{*}{ Task-induced changes in: } & \multicolumn{2}{|c|}{ Mean (SD) } & \multirow[b]{3}{*}{$\mathrm{t}$} & \multirow[b]{3}{*}{$\mathrm{p}$} \\
\hline & Control subjects & $1^{\text {st }}$ degree relatives & & \\
\hline & $(n=10)$ & $(n=14)$ & & \\
\hline Subjective stress ${ }^{a}$ & $0.98(0.68)$ & $1.31(0.74)$ & -1.13 & .270 \\
\hline Subjective psychosis ${ }^{b}$ & $0.09(0.22)$ & $0.03(0.30)$ & 0.53 & 601 \\
\hline \multicolumn{5}{|c|}{$\left[{ }^{18} \mathrm{~F}\right]$ fallypride ligand displacement $(\%)^{c}$} \\
\hline vmPFC (right) & $48.7(22.0)$ & $38.1(28.2)$ & 0.99 & .333 \\
\hline vmPFC (left) & $54.1(24.0)$ & $41.6(27.0)$ & 1.16 & .258 \\
\hline
\end{tabular}

a Difference between mean scores on the subjective stress scale under stress vs. control conditions of the MIST psychosocial stress task.

${ }^{\mathrm{b}}$ Difference between mean scores on the psychosis scale under stress vs. control conditions of the MIST psychosocial stress task.

c Percentage of voxels exceeding the FDR corrected significance threshold of $p(\alpha(F D R)=5 \%)<0.05$. Percentages reflect the number of significant voxels relative to the total number of voxels within the mask of the respective brain region. 
Figure 1 | Associations between task-induced feelings of subjective stress and taskinduced $\left[{ }^{18} \mathrm{~F}\right]$ fallypride ligand displacement in left and right ventromedial prefrontal cortex of healthy control subjects and healthy first-degree relatives of patients diagnosed with a psychotic disorder. Increased feelings of subjective stress were associated with increased ligand displacement in controls vs. decreased ligand displacement in first-degree relatives.

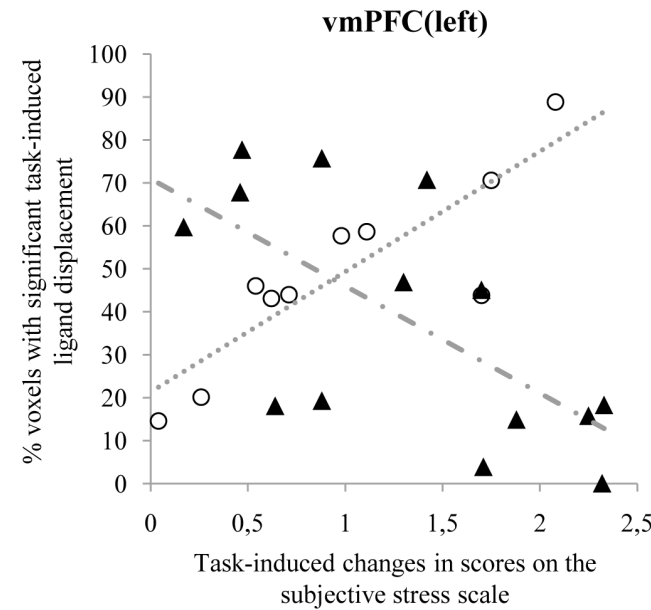
subjective stress scale
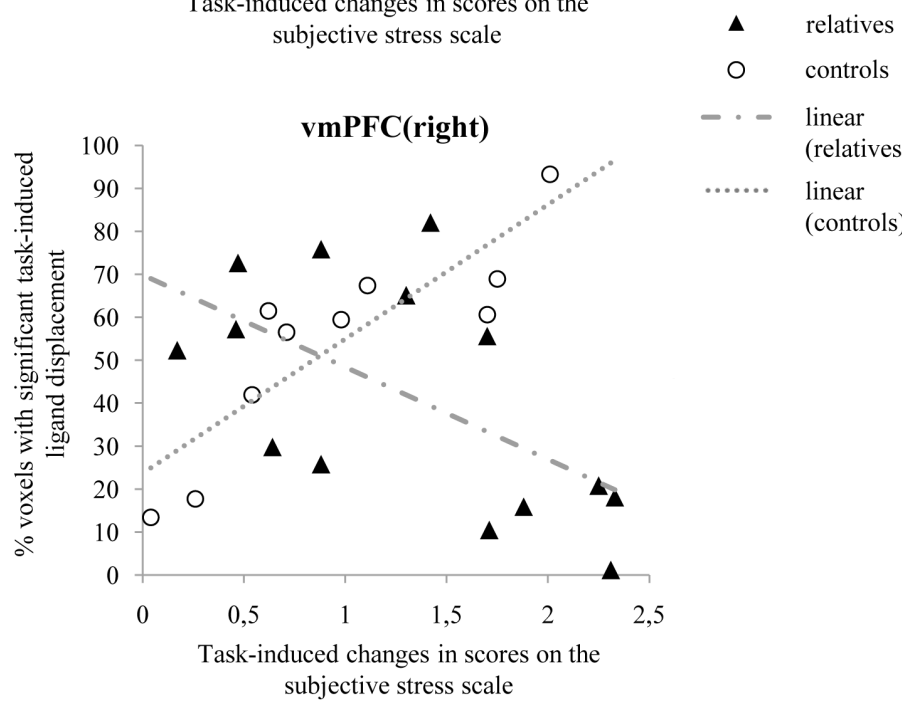

- - linear (relatives) linear (controls) 
Figure 2 | Associations between task-induced psychotic experiences and task-induced $\left[{ }^{18} \mathrm{~F}\right]$ fallypride ligand displacement in left and right ventromedial prefrontal cortex of healthy control subjects and healthy first-degree relatives of patients diagnosed with a psychotic disorder. Increased intensity of psychotic experiences was associated with decreased ligand displacement in first-degree relatives but not in controls.
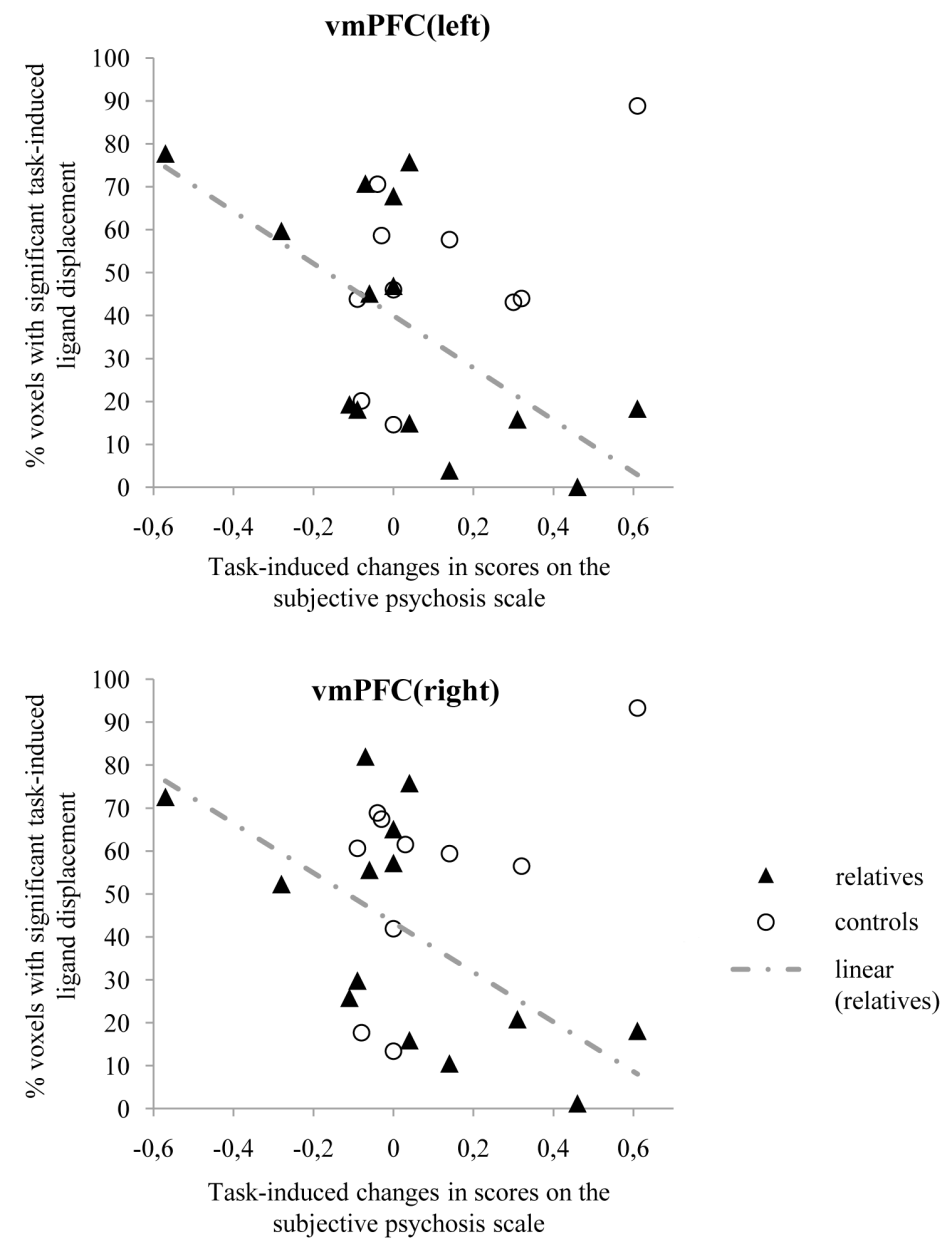


\section{References}

1. Myin-Germeys I, van Os J, Schwartz JE, Stone AA, and Delespaul PA. Emotional reactivity to daily life stress in psychosis. Arch Gen Psychiatry, 2001. 58(12): p. 1137-44.

2. Lataster J, Collip D, Ceccarini J, Haas D, Booij L, van Os J, Pruessner J, Van Laere K, and Myin-Germeys I. Psychosocial stress is associated with in vivo dopamine release in human ventromedial prefrontal cortex: A positron emission tomography study using [(18)F]fallypride. Neuroimage, 2011.

3. Pruessner JC, Champagne F, Meaney MJ, and Dagher A. Dopamine release in response to a psychological stress in humans and its relationship to early life maternal care: a positron emission tomography study using [11C]raclopride. J Neurosci, 2004. 24(11): p. 2825-31.

4. Pruessner JC, Dedovic K, Pruessner M, Lord C, Buss C, Collins L, Dagher A, and Lupien SJ. Stress regulation in the central nervous system: evidence from structural and functional neuroimaging studies in human populations - 2008 Curt Richter Award Winner. Psychoneuroendocrinology, 2010. 35(1): p. 179-91.

5. Howes OD and Kapur S. The dopamine hypothesis of schizophrenia: version III--the final common pathway. Schizophr Bull, 2009. 35(3): p. 549-62.

6. Myin-Germeys I, Marcelis M, Krabbendam L, Delespaul P, and van Os J. Subtle fluctuations in psychotic phenomena as functional states of abnormal dopamine reactivity in individuals at risk. Biol Psychiatry, 2005. 58(2): p. 105-10.

7. Montgomery AJ, Mehta MA, and Grasby PM. Is psychological stress in man associated with increased striatal dopamine levels?: A [11C]raclopride PET study. Synapse, 2006. 60(2): p. 124-31.

8. Soliman A, O’Driscoll GA, Pruessner J, Holahan AL, Boileau I, Gagnon D, and Dagher A. Stress-induced dopamine release in humans at risk of psychosis: a [11C]raclopride PET study. Neuropsychopharmacology, 2008. 33(8): p. 2033-41.

9. Dedovic K, Duchesne A, Andrews J, Engert V, and Pruessner JC. The brain and the stress axis: the neural correlates of cortisol regulation in response to stress. Neuroimage, 2009. 47(3): p. 864-71.

10. Dedovic K, Rexroth M, Wolff E, Duchesne A, Scherling C, Beaudry T, Lue SD, Lord C, Engert V, and Pruessner JC. Neural correlates of processing stressful information: an event-related fMRI study. Brain Res, 2009. 1293: p. $49-60$.

11. Deutch AY, Clark WA, and Roth RH. Prefrontal cortical dopamine depletion enhances the responsiveness of mesolimbic dopamine neurons to stress. Brain Res, 1990. 521(1-2): p. 311-5.

12. King D, Zigmond MJ, and Finlay JM. Effects of dopamine depletion in the medial prefrontal cortex on the stress-induced increase in extracellular dopamine in the nucleus accumbens core and shell. Neuroscience, 1997. 77(1): p. 141-53.

13. Roth RH, Tam SY, Ida Y, Yang JX, and Deutch AY. Stress and the mesocorticolimbic dopamine systems. Ann N 
Y Acad Sci, 1988. 537: p. 138-47.

14. Scornaiencki R, Cantrup R, Rushlow WJ, and Rajakumar N. Prefrontal cortical D1 dopamine receptors modulate subcortical D2 dopamine receptor-mediated stress responsiveness. Int J Neuropsychopharmacol, 2009. 12(9): p. 1195-208.

15. Wang J, Rao H, Wetmore GS, Furlan PM, Korczykowski M, Dinges DF, and Detre JA. Perfusion functional MRI reveals cerebral blood flow pattern under psychological stress. Proc Natl Acad Sci U S A, 2005. 102(49): p. 17804-9.

16. Abercrombie ED, Keefe KA, DiFrischia DS, and Zigmond MJ. Differential effect of stress on in vivo dopamine release in striatum, nucleus accumbens, and medial frontal cortex. J Neurochem, 1989. 52(5): p. 1655-8.

17. Tidey JW and Miczek KA. Social defeat stress selectively alters mesocorticolimbic dopamine release: an in vivo microdialysis study. Brain Res, 1996. 721(1-2): p. 140-9.

18. Karreman M and Moghaddam B. The prefrontal cortex regulates the basal release of dopamine in the limbic striatum: an effect mediated by ventral tegmental area. J Neurochem, 1996. 66(2): p. 589-98.

19. Davis KL, Kahn RS, Ko G, and Davidson M. Dopamine in schizophrenia: a review and reconceptualization. Am J Psychiatry, 1991. 148(11): p. 1474-86.

20. Geraud G, Arne-Bes MC, Guell A, and Bes A. Reversibility of hemodynamic hypofrontality in schizophrenia. J Cereb Blood Flow Metab, 1987. 7(1): p. 9-12.

21. Park IH, Kim JJ, Chun J, Jung YC, Seok JH, Park HJ, and Lee JD. Medial prefrontal default-mode hypoactivity affecting trait physical anhedonia in schizophrenia. Psychiatry Res, 2009. 171(3): p. 155-65.

22. Abi-Dargham A, Gil R, Krystal J, Baldwin RM, Seibyl JP, Bowers M, van Dyck CH, Charney DS, Innis RB, and Laruelle M. Increased striatal dopamine transmission in schizophrenia: confirmation in a second cohort. Am J Psychiatry, 1998. 155(6): p. 761-7.

23. Laruelle M, Abi-Dargham A, van Dyck CH, Gil R, D'Souza CD, Erdos J, McCance E, Rosenblatt W, Fingado C, Zoghbi SS, Baldwin RM, Seibyl JP, Krystal JH, Charney DS, and Innis RB. Single photon emission computerized tomography imaging of amphetamine-induced dopamine release in drug-free schizophrenic subjects. Proc Natl Acad Sci U S A, 1996. 93(17): p. 9235-40.

24. Howes O, Bose S, Turkheimer F, Valli I, Egerton A, Stahl D, Valmaggia L, Allen P, Murray R, and McGuire P. Progressive increase in striatal dopamine synthesis capacity as patients develop psychosis: a PET study. Mol Psychiatry, 2011. 16(9): p. 885-6.

25. Howes OD, Bose SK, Turkheimer F, Valli I, Egerton A, Valmaggia LR, Murray RM, and McGuire P. Dopamine Synthesis Capacity Before Onset of Psychosis: A Prospective [18F]-DOPA PET Imaging Study. Am J Psychiatry, 2011.

26. Myin-Germeys I, Delespaul P, and van Os J. Behavioural sensitization to daily life stress in psychosis. Psychol Med, 2005. 35(5): p. 733-41. 
27. Badgaiyan RD, Fischman AJ, and Alpert NM. Dopamine release during human emotional processing. Neuroimage, 2009. 47(4): p. 2041-5.

28. Christian BT, Lehrer DS, Shi B, Narayanan TK, Strohmeyer PS, Buchsbaum MS, and Mantil JC. Measuring dopamine neuromodulation in the thalamus: using [F-18]fallypride PET to study dopamine release during a spatial attention task. Neuroimage, 2006. 31(1): p. 139-52.

29. Mukherjee J, Christian BT, Dunigan KA, Shi B, Narayanan TK, Satter M, and Mantil J. Brain imaging of 18Ffallypride in normal volunteers: blood analysis, distribution, test-retest studies, and preliminary assessment of sensitivity to aging effects on dopamine D-2/D-3 receptors. Synapse, 2002. 46(3): p. 170-88.

30. Riccardi P, Zald D, Li R, Park S, Ansari MS, Dawant B, Anderson S, Woodward N, Schmidt D, Baldwin R, and Kessler R. Sex differences in amphetamine-induced displacement of [(18)F]fallypride in striatal and extrastriatal regions: a PET study. Am J Psychiatry, 2006. 163(9): p. 1639-41.

31. Vrieze E, Ceccarini J, Pizzagalli D, Bormans G, Vandenbulcke M, Demyttenaere K, Van Laere K, and Claes S. Measuring extrastriatal dopamine release during a reward learning task. Human Brain Mapping, in press.

32. Woodward ND, Cowan RL, Park S, Ansari MS, Baldwin RM, Li R, Doop M, Kessler RM, and Zald DH. Correlation of individual differences in schizotypal personality traits with amphetamine-induced dopamine release in striatal and extrastriatal brain regions. Am J Psychiatry, 2011. 168(4): p. 418-26.

33. Buchanan TW, Driscoll D, Mowrer SM, Sollers JJ, 3rd, Thayer JF, Kirschbaum C, and Tranel D. Medial prefrontal cortex damage affects physiological and psychological stress responses differently in men and women. Psychoneuroendocrinology, 2010. 35(1): p. 56-66.

34. The American Psychiatric Association. Diagnostic and Statistical Manual of Mental Disorders, 4th Edition, Text Revision (C) 2000, Washington DC.

35. McGuffin P, Farmer A, and Harvey I. A polydiagnostic application of operational criteria in studies of psychotic illness. Development and reliability of the OPCRIT system. Arch Gen Psychiatry, 1991. 48(8): p. 764-70.

36. Dedovic K, Renwick R, Mahani NK, Engert V, Lupien SJ, and Pruessner JC. The Montreal Imaging Stress Task: using functional imaging to investigate the effects of perceiving and processing psychosocial stress in the human brain. J Psychiatry Neurosci, 2005. 30(5): p. 319-25.

37. Myin-Germeys I, Oorschot M, Collip D, Lataster J, Delespaul P, and van Os J. Experience sampling research in psychopathology: opening the black box of daily life. Psychol Med, 2009. 39(9): p. 1533-47.

38. Alpert NM, Badgaiyan RD, Livni E, and Fischman AJ. A novel method for noninvasive detection of neuromodulatory changes in specific neurotransmitter systems. Neuroimage, 2003. 19(3): p. 1049-60.

39. Lammertsma AA and Hume SP. Simplified reference tissue model for PET receptor studies. Neuroimage, 1996. 4(3 Pt 1): p. 153-8.

40. Talairach J and Tournoux P. Co-planar stereotaxic atlas of the human brain. 1988, New York: Thieme.

41. Benjamini $\mathrm{Y}$ and Hochberg $\mathrm{Y}$. Controlling the false discovery rate: a practical and powerful approach to 
multiple testing. J R Stat Soc Series B Stat Methodol, 1995. 57(1): p. 289-300.

42. StataCorp. Stata Statistical Software: Release 10. College Station, TX: StataCorp LP, 2007.

43. George TP, Verrico CD, and Roth RH. Effects of repeated nicotine pre-treatment on mesoprefrontal dopaminergic and behavioral responses to acute footshock stress. Brain Res, 1998. 801(1-2): p. 36-49.

44. Fadda F, Mosca E, Meloni R, and Gessa GL. Ethanol-stress interaction on dopamine metabolism in the medial prefrontal cortex. Alcohol Drug Res, 1985. 6(6): p. 449-54.

45. Weinberger DR, Berman KF, and Illowsky BP. Physiological dysfunction of dorsolateral prefrontal cortex in schizophrenia. III. A new cohort and evidence for a monoaminergic mechanism. Arch Gen Psychiatry, 1988. 45(7): p. 609-15.

46. Weinberger DR, Berman KF, and Zec RF. Physiologic dysfunction of dorsolateral prefrontal cortex in schizophrenia. I. Regional cerebral blood flow evidence. Arch Gen Psychiatry, 1986. 43(2): p. 114-24.

47. Ghashghaei HT and Barbas H. Pathways for emotion: interactions of prefrontal and anterior temporal pathways in the amygdala of the rhesus monkey. Neuroscience, 2002. 115(4): p. 1261-79.

48. Ghashghaei HT, Hilgetag CC, and Barbas H. Sequence of information processing for emotions based on the anatomic dialogue between prefrontal cortex and amygdala. Neuroimage, 2007. 34(3): p. 905-23.

49. Ongur D, An X, and Price JL. Prefrontal cortical projections to the hypothalamus in macaque monkeys. J Comp Neurol, 1998. 401(4): p. 480-505.

50. Price JL. Prefrontal cortical networks related to visceral function and mood. Ann N Y Acad Sci, 1999. 877: p. 383-96.

51. Stefanacci $L$ and Amaral DG. Some observations on cortical inputs to the macaque monkey amygdala: an anterograde tracing study. J Comp Neurol, 2002. 451(4): p. 301-23.

52. Damasio AR. The somatic marker hypothesis and the possible functions of the prefrontal cortex. Philos Trans R Soc Lond B Biol Sci, 1996. 351(1346): p. 1413-20.

53. Boes AD, Bechara A, Tranel D, Anderson SW, Richman L, and Nopoulos P. Right ventromedial prefrontal cortex: a neuroanatomical correlate of impulse control in boys. Soc Cogn Affect Neurosci, 2009. 4(1): p. 19.

54. Hare TA, Tottenham N, Galvan A, Voss HU, Glover GH, and Casey BJ. Biological substrates of emotional reactivity and regulation in adolescence during an emotional go-nogo task. Biol Psychiatry, 2008. 63(10): p. 927-34.

55. Morgan MA, Romanski LM, and LeDoux JE. Extinction of emotional learning: contribution of medial prefrontal cortex. Neurosci Lett, 1993. 163(1): p. 109-13.

56. Peters J, Kalivas PW, and Quirk GJ. Extinction circuits for fear and addiction overlap in prefrontal cortex. Learn Mem, 2009. 16(5): p. 279-88.

57. Vidal-Gonzalez I, Vidal-Gonzalez B, Rauch SL, and Quirk GJ. Microstimulation reveals opposing influences of 
prelimbic and infralimbic cortex on the expression of conditioned fear. Learn Mem, 2006. 13(6): p. 728-33.

58. Cannistraro PA and Rauch SL. Neural circuitry of anxiety: evidence from structural and functional neuroimaging studies. Psychopharmacol Bull, 2003. 37(4): p. 8-25.

59. Drevets WC. Neuroimaging and neuropathological studies of depression: implications for the cognitiveemotional features of mood disorders. Curr Opin Neurobiol, 2001. 11(2): p. 240-9.

60. Ongur D, Drevets WC, and Price JL. Glial reduction in the subgenual prefrontal cortex in mood disorders. Proc Natl Acad Sci U S A, 1998. 95(22): p. 13290-5.

61. Shin LM, Orr SP, Carson MA, Rauch SL, Macklin ML, Lasko NB, Peters PM, Metzger LJ, Dougherty DD, Cannistraro PA, Alpert NM, Fischman AJ, and Pitman RK. Regional cerebral blood flow in the amygdala and medial prefrontal cortex during traumatic imagery in male and female Vietnam veterans with PTSD. Arch Gen Psychiatry, 2004. 61(2): p. 168-76.

62. Anderson SW, Barrash J, Bechara A, and Tranel D. Impairments of emotion and real-world complex behavior following childhood- or adult-onset damage to ventromedial prefrontal cortex. J Int Neuropsychol Soc, 2006. 12(2): p. 224-35.

63. Bechara A, Damasio AR, Damasio H, and Anderson SW. Insensitivity to future consequences following damage to human prefrontal cortex. Cognition, 1994. 50(1-3): p. 7-15.

64. Lazarus R and Folkman S. Stress, appraisal, and coping. 1984, New York: Springer Publishing Company.

65. Rudebeck PH, Bannerman DM, and Rushworth MF. The contribution of distinct subregions of the ventromedial frontal cortex to emotion, social behavior, and decision making. Cogn Affect Behav Neurosci, 2008. 8(4): p. 485-97.

66. Kohler CG and Martin EA. Emotional processing in schizophrenia. Cogn Neuropsychiatry, 2006. 11(3): p. 25071.

67. Tremeau F. A review of emotion deficits in schizophrenia. Dialogues Clin Neurosci, 2006. 8(1): p. 59-70.

68. Heberlein AS, Padon AA, Gillihan SJ, Farah MJ, and Fellows LK. Ventromedial frontal lobe plays a critical role in facial emotion recognition. J Cogn Neurosci, 2008. 20(4): p. 721-33.

69. Hornak J, Rolls ET, and Wade D. Face and voice expression identification in patients with emotional and behavioural changes following ventral frontal lobe damage. Neuropsychologia, 1996. 34(4): p. 247-61.

70. Collip D, Nicolson NA, Lardinois M, Lataster T, van Os J, and Myin-Germeys I. Daily cortisol, stress reactivity and psychotic experiences in individuals at above average genetic risk for psychosis. Psychol Med, 2011. 41(11): p. 2305-15.

71. Pascucci T, Ventura R, Latagliata EC, Cabib S, and Puglisi-Allegra S. The medial prefrontal cortex determines the accumbens dopamine response to stress through the opposing influences of norepinephrine and dopamine. Cereb Cortex, 2007. 17(12): p. 2796-804.

72. Dailly E, Chenu F, Renard CE, and Bourin M. Dopamine, depression and antidepressants. Fundam Clin 
Pharmacol, 2004. 18(6): p. 601-7.

73. Gorwood P. Neurobiological mechanisms of anhedonia. Dialogues Clin Neurosci, 2008. 10(3): p. 291-9.

74. Laruelle M. The role of endogenous sensitization in the pathophysiology of schizophrenia: implications from recent brain imaging studies. Brain Res Brain Res Rev, 2000. 31(2-3): p. 371-84.

75. Nikolaus S, Antke C, Beu M, and Muller HW. Cortical GABA, striatal dopamine and midbrain serotonin as the key players in compulsive and anxiety disorders--results from in vivo imaging studies. Rev Neurosci, 2010. 21(2): p. 119-39.

76. Rauch SL, Shin LM, and Phelps EA. Neurocircuitry models of posttraumatic stress disorder and extinction: human neuroimaging research--past, present, and future. Biol Psychiatry, 2006. 60(4): p. 376-82.

77. Weinberger DR, Egan MF, Bertolino A, Callicott JH, Mattay VS, Lipska BK, Berman KF, and Goldberg TE. Prefrontal neurons and the genetics of schizophrenia. Biol Psychiatry, 2001. 50(11): p. 825-44.

78. Kapur S. Psychosis as a state of aberrant salience: a framework linking biology, phenomenology, and pharmacology in schizophrenia. Am J Psychiatry, 2003. 160(1): p. 13-23.

79. Pani L, Porcella A, and Gessa GL. The role of stress in the pathophysiology of the dopaminergic system. Mol Psychiatry, 2000. 5(1): p. 14-21.

80. Zahrt J, Taylor JR, Mathew RG, and Arnsten AF. Supranormal stimulation of D1 dopamine receptors in the rodent prefrontal cortex impairs spatial working memory performance. J Neurosci, 1997. 17(21): p. 852835.

81. Cannon W. The emergency function of the adrenal medulla in pain and the major emotions. American Journal of Physiology, 1914. 33: p. 356-372.

82. Arnsten AF and Goldman-Rakic PS. Noise stress impairs prefrontal cortical cognitive function in monkeys: evidence for a hyperdopaminergic mechanism. Arch Gen Psychiatry, 1998. 55(4): p. 362-8.

83. Christian BT, Narayanan TK, Shi B, and Mukherjee J. Quantitation of striatal and extrastriatal D-2 dopamine receptors using PET imaging of [(18)F]fallypride in nonhuman primates. Synapse, 2000. 38(1): p. 71-9.

84. Johns LC and van Os J. The continuity of psychotic experiences in the general population. Clin Psychol Rev, 2001. 21(8): p. 1125-41.

85. Kendler KS, McGuire M, Gruenberg AM, and Walsh D. Schizotypal symptoms and signs in the Roscommon Family Study. Their factor structure and familial relationship with psychotic and affective disorders. Arch Gen Psychiatry, 1995. 52(4): p. 296-303.

86. van Os J, Verdoux H, Maurice-Tison S, Gay B, Liraud F, Salamon R, and Bourgeois M. Self-reported psychosislike symptoms and the continuum of psychosis. Soc Psychiatry Psychiatr Epidemiol, 1999. 34(9): p. 459-63.

87. van Os J, Linscott RJ, Myin-Germeys I, Delespaul P, and Krabbendam L. A systematic review and meta-analysis of the psychosis continuum: evidence for a psychosis proneness-persistence-impairment model of psychotic disorder. Psychol Med, 2009. 39(2): p. 179-95. 
$\frac{116}{\sigma}$ 
BEmotional experience and

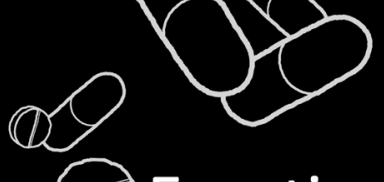

estimates of $D_{2}$ receptor occupancy in

psychotic patients treated with haloperidol, risperidone, or olanzapine

an experience sampling study.

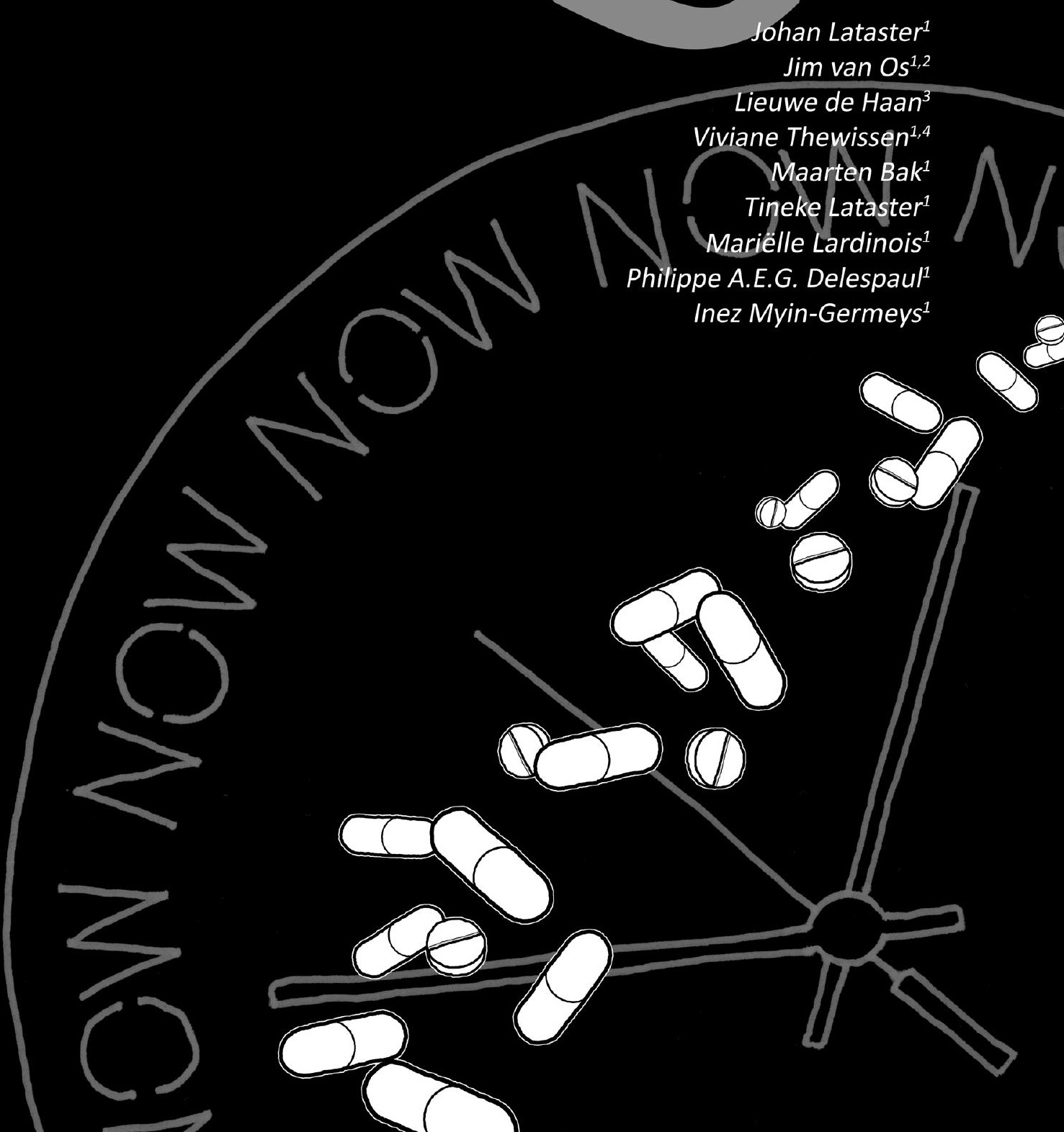


${ }^{1}$ Department of Psychiatry and Psychology, South Limburg Mental Health Research and Teaching Network, EURON, Maastricht University Medical Center, Maastricht, the Netherlands.

${ }^{2}$ King's College London, King's Health Partners, Department of Psychosis Studies, Institute of Psychiatry, London, UK.

${ }^{3}$ Department of Psychiatry, Academic Medical Center, Amsterdam, the Netherlands.

${ }^{4}$ Faculty of Psychology, Open University of the Netherlands, Heerlen, the Netherlands.

\section{Published as:}

Lataster J, van Os J, de Haan L, Thewissen V, Bak M, Lataster T, Lardinois M, Delespaul P, Myin-Germeys I. Emotional experience and estimates of $D_{2}$ receptor occupancy in psychotic patients treated with haloperidol, risperidone, or olanzapine: an experience sampling study. Journal of Clinical Psychiatry, 2011. 72(10): p. 1397-404. 


\section{Abstract}

Objective: Blockade of dopamine $D_{2}$ receptors is thought to mediate the therapeutic effects of antipsychotic medication but may also induce social indifference. As antipsychotic drugs differ in $\mathrm{D}_{2}$ receptor binding, "tight" and "loose" binding drugs may be hypothesized to differentially affect emotional experience. The present study investigates the differential effects of relatively tight versus looser binding drugs on the experience of emotions in the realm of daily life.

Method: We assessed positive and negative affect in the daily life of 109 patients with a DSM-IV diagnosis of psychotic disorder who were currently taking antipsychotic medication by using the Experience Sampling Method (a structured diary technique). Antipsychotic medication was classified as 'loose' (olanzapine; $n=35$ ) or 'tight' (haloperidol, risperidone; $n=74$ ) binding, based on the drug's dissociation constants at the $D_{2}$ receptor.

Results: Multilevel analyses showed a significant interaction between binding group (loose $v s$. tight) and $D_{2}$ receptor occupancy estimates with regard to the experience of positive $(p=.008)$ and negative $(p=.019)$ affect. For tight-binding agent users, a significant association was found between $D_{2}$ receptor binding estimates and both positive affect $(p=.040)$ and negative affect $(p=.0001)$ in the flow of daily life, with increasing levels of estimated $D_{2}$ receptor occupancy being associated with decreased feelings of positive affect and increased feelings of negative affect. For loose-binding agent users, no such association was apparent. These associations were only partly mediated by clinical symptoms.

Conclusion: These findings add ecological validity to previous laboratory findings showing an association between $D_{2}$ receptor occupancy and emotional experience. 


\section{Introduction}

Antipsychotic medication reduces dopaminergic neurotransmission and reduces positive symptoms in patients diagnosed with schizophrenia ${ }^{1-3}$. Given the fact that the dopaminergic system may mediate the experience of motivational salience or reward ${ }^{4,5}$, antipsychotic medication may act by making abnormal perceptions and delusional beliefs become less meaningful and lose part of their intensity and presence ${ }^{6}$. There is evidence, however, that by doing so they may also induce motivational indifference and block emotional experience ${ }^{7}$. Despite the apparent link between dopamine blockade and motivational indifference, symptom reduction and occurrence of extrapyramidal side-effects have long been the main outcome measures in medication studies ${ }^{8}$. However, the occurrence of emotional impairment may be a more subtle yet more important side-effect of antipsychotic medication, as it already occurs at relatively low levels of dopamine receptor blockade 9 .

Emotional experience has been shown to change in response to antipsychotic treatment ${ }^{10-12}$. More specifically, experience of emotions has been related to occupancy of the dopamine $D_{2}$ receptor, with high levels of $D_{2}$ receptor occupancy being associated with feelings of dysphoria and decreased feelings of safety and self-confidence ${ }^{13,14}$, independent of overall symptom severity ${ }^{14}$ or extrapyramidal symptoms $(E P S)^{13,14}$. Similarly, prolonged dopamine depletion has been shown to result in negative mood states ${ }^{15}$. However, the relationship between $D_{2}$ occupancy and emotional experience may not be linear ${ }^{9}$. For example, lower $D_{2}$ occupancy levels may be related to reduced motivational tone due to the presence of psychotic symptoms, whereas high $D_{2}$ receptor blockade may induce motivational indifference due to blockade of emotional experience associated with natural rewards.

Research in the area has been conducted by assessing emotional experience ("subjective well-being") using medication-related cross-sectional questionnaires in semi-experimental environments. While productive, these studies nevertheless lack ecological validity, as emotional experiences occurring in the flow of daily life are assessed retrospectively and globally using cross-sectional instruments. Assessing emotional states in the reality of daily life would allow examination of more subtle changes in emotional experience. This may be crucially important given the impact of subjective well-being on medication compliance and treatment outcome ${ }^{16,17}$. The current study therefore aimed to investigate the association between $D_{2}$ receptor occupancy and experience of emotions in daily-life reality by using the Experience Sampling Method (ESM), a fine-grained momentary assessment technique, to collect emotional experiences in the flow of daily life $\mathrm{e}^{18,19}$. 
Furthermore, although all antipsychotic drugs display some degree of blockade of the $D_{2}$ receptor, the specific mechanism of occupancy is determined by the chemical profile of the individual agent ${ }^{20}$. Antipsychotic agents differ in how strongly they compete with dopamine for occupancy of the $D_{2}$ receptor. Some agents, such as haloperidol and risperidone, bind more tightly to the $D_{2}$ receptor than dopamine itself. Others, however, such as olanzapine and clozapine, display a more loose or "rapid offset" binding profile, making them more easily displaceable by endogenous dopamine ${ }^{21}$. It is attractive to hypothesize that these differences in binding potential could result in differential effects on experience of reward. De Haan and colleagues ${ }^{9}$ described an overall effect of $D_{2}$ occupancy on emotional experience in haloperidol and olanzapine users. However, Garcia-Cabeza and co-workers ${ }^{22}$ found treatment with the more tight-binding agents haloperidol and risperidone to be associated with more negative feelings than treatment with the more loose-binding agent olanzapine. Thus, although closely linked, the overall amount of $D_{2}$ occupancy and the qualitative aspects involved in the process of dopaminergic antagonism need to be disentangled with regard to subjectively experienced medication effects impacting on the experience of emotions.

The present study thus investigated the effect of medication use on emotional experience quantified as positive affect and negative affect in the realm of daily life. In addition, the differential effects of relatively tight- and loose-binding drugs on experience of emotions were investigated. The study was naturalistic, meaning that subjects were taking antipsychotic medication as prescribed by their clinician. For the more tight-binding drugs, a first-generation antipsychotic - haloperidol - and a second generation antipsychotic - risperidone - were included, and compared with the looser binding second generation antipsychotic olanzapine.

\section{Materials and methods}

\section{Subjects}

The sample consisted of 119 patients with a lifetime diagnosis of non-affective psychosis. Inclusion criteria were (i) age 18-65 years; (ii) sufficient command of the Dutch language to understand instructions and informed consent; (iii) a lifetime diagnosis of non-affective psychosis; and (iv) current use of haloperidol, risperidone, or olanzapine. Exclusion criteria were (i) endocrine, cardiovascular, or brain disease; (ii) weekly use of illicit drugs; and (iii) use 
of alcohol in excess of five standard units per day. Patients were recruited through inpatient and outpatient mental health facilities in Maastricht (the Netherlands), as well as through patient associations in the southern part of the Netherlands.

Diagnostic inclusion of patients was based on DSM-IV diagnoses ${ }^{23}$, generated with the OPCRIT computer program ${ }^{24}$. Participants included patients with a diagnosis of schizophrenia, delusional disorder, induced psychotic disorder, brief psychotic disorder, and psychotic disorder not otherwise specified. This study was approved by the local medical ethics committee. After complete description of the study to the participants, signed informed consent was obtained.

\section{Experience Sampling Method}

The Experience Sampling Method (ESM) is a within-day momentary self-assessment technique, developed to provide measures of the frequency and patterns of mental processes in every-day-life situations ${ }^{18,19}$.

Participants received a digital wristwatch and a set of ESM self-assessment forms collated in a booklet for each day. Ten times a day on six consecutive days, the watch emitted a signal (beep) at unpredictable moments between 7:30 a.m. and 10:30 p.m. After each beep, subjects were asked to stop their activity and fill out the ESM self-assessment forms previously handed out to them, collecting reports of perceptions, thoughts, mood, current context (activity, persons present, location) and appraisals of the current situation. All selfassessment items were rated on 7-point Likert scales. Subjects were asked to complete their reports immediately after the beep, thus minimizing memory distortions, and to record the time at which they completed the form. In order to know whether the subjects had completed the form within 15 minutes of the beep, the time at which subjects indicated they completed the report was compared to the actual time of the beep. All reports completed more than 15 minutes after the signal were excluded from the analysis. Previous work has shown that reports completed after this interval are less reliable and consequently less valid $^{19}$. For the same reason, subjects with less than 20 valid reports were also excluded from the analysis.

\section{Experience of emotions}

Emotional experience was assessed with four positive affect items and six negative affect items rated on 7-point Likert scales (rating from not at all [=1] to very [=7]), derived from the Experience Sampling booklets as described above. Mean scores on the items "I feel 
cheerful", "I feel relaxed", "I feel satisfied" and "Overall, I am feeling well” (Cronbach's alpha $=.85$ ) constituted the positive affect (PA) scale. The negative affect (NA) scale consisted of mean scores on the items "I feel insecure", "I feel lonely", "I feel anxious", "I feel down", "I feel angry", and "I feel guilty" (Cronbach's alpha $=.83$ ).

\section{Psychotic symptoms}

Momentary psychotic symptomatology was assessed with two perception and two thought items rated on 7-point Likert scales (rating from not at all [=1] to very [=7]), derived from the ESM booklets. Mean scores on the items "I hear voices" and "I see phenomena" constituted the hallucinations scale (Cronbach's alpha $=.74)$, while mean scores on the items "I feel suspicious" and "I feel unreal" constituted the delusions scale (Cronbach's alpha = .66).

Overall symptom severity during the ESM-week was assessed once with the Brief Psychiatric Rating Scale (BPRS) ${ }^{25}$, a semi-structured interview. The BPRS consists of 24 pathology items scored on a 7-point severity scale (ranging from not present to extremely severe). Scoring was conducted by trained raters. Mean values of the 24 pathology item scores were used as an indicator of severity of symptomatology, with higher scores representing more severe symptoms. Additionally, in accordance with work from Velligan et al. ${ }^{26}$, BPRS depression and BPRS psychosis subscale scores were calculated for each subject, consisting of the mean scores on BPRS items that have been shown to cluster together in a depression/anxiety factor (somatic concern, anxiety, depression, suicidality, guilt, hostility, and suspiciousness) and psychosis factor (grandiosity, suspiciousness, hallucinations, unusual thought, bizarre behavior, conceptual disorganization), respectively.

\section{Medication}

Before the start of the ESM, detailed medication information was collected (medication name and daily dosage). Depot-doses were recalculated into oral daily dose values ${ }^{27}$.

\section{$D_{2}$ receptor occupancy}

No in vivo receptor occupancy measures were obtained, but $D_{2}$ receptor occupancy levels were estimated theoretically by fitting hyperbolic functions to dose-related $D_{2}$ occupancy data from previously performed medication studies (see Appendix). These functions were then applied to individual subject medication data extracted from the ESM medication forms, in order to theoretically predict occupancy estimates for each subject. 


\section{Binding potential}

Antipsychotic agents were classified as having either a "tighter" or a "looser" binding pattern (hereafter called tight- and loose-binding agents), based on their dissociation (or inhibition) constant $K$ at the $\mathrm{D}_{2}$ receptor, expressed in molar (M) units ${ }^{20}$. Following Seeman et al. ${ }^{20}$, we classified drugs with dissociation constants higher than 1,5 nM, which bind more loosely to the $D_{2}$ receptor than dopamine, as 'loose' binding ( $K>1,5 \mathrm{nM}$; olanzapine), whereas agents with dissociation constants lower than 1,5 nM, which bind more tightly to the $D_{2}$ receptor than dopamine, were classified as 'tight' binding ( $K<1,5 \mathrm{nM}$; haloperidol and risperidone $)^{20}$.

\section{Data analysis}

Since ESM data are hierarchical in nature - multiple observations (level 1) nested within subjects (level 2) - hierarchical linear models were used, taking into account that residuals are not independent, given that observations from the same subject are more similar than observations from different subjects ${ }^{28}$. All analyses were conducted with the XTREG procedure in STATA, release $10.0^{29}$.

Multilevel linear regression analyses were conducted with binding group (tight, loose), $D_{2}$ receptor occupancy estimates as well as their interaction as independent variable, and NA and PA as dependent variables, in two separate models. Stratified analyses were conducted for the loose- and the tight-binding group. In order to clarify the effect size in the stratified analyses, and due to skewness of the estimated $D_{2}$ receptor occupancy distribution, we defined a three-level dopamine $D_{2}$ receptor occupancy estimate variable (low, middle, high) for both the loose- and tight-binding group, based on the tertile scores. Sex and age were added as covariates. Concomitant use of any anxiolytic, antidepressant, mood-stabilizing, tranquilizing, or antiparkinsonian medication was also added as dichotomous co-variate due to possible confounding effects on emotional well-being.

Since emotional experience may be related to symptom severity and since medication dosage (i.e., $D_{2}$ receptor occupancy) may also be associated with symptom severity, we repeated the analyses adding, respectively, momentary hallucinations, momentary delusions, and mean severity of psychopathology (based on the BPRS score) as possible confounders. 


\section{Results}

\section{Subjects}

Ten patients were excluded due to incomplete reports or incomplete medication data. The remaining group of 109 patients consisted of 79 men and 30 women and was composed of 39 haloperidol users, 35 olanzapine users, and 35 risperidone users.

\section{Sample characteristics}

Sociodemographic characteristics and mean scores on independent, dependent, and psychopathology variables are shown in Table 1 and Table 2, respectively.

Haloperidol users were significantly older than risperidone and olanzapine users $(t=2.4$, $\mathrm{p}=.008$ ). Mean $\mathrm{D}_{2}$ occupancy estimates were higher in tight-binding agent users compared to loose-binding agent users ( $72 \%$ vs. $62 \%$, respectively). Mean scores on BPRS, BPRS subscales, momentary symptoms, positive affect, and negative affect were similar between tight-binding agent users and loose-binding agent users. Information on concomitant psychotropic medication is shown in Table 1.

\section{Effect of binding tightness on the association between $D_{2}$ occupancy and emotional experience}

Multilevel linear regression analysis with only age and sex as covariates showed no main effects of $D_{2}$ receptor occupancy on NA ( $\beta=.01$ [SE=.008], $\left.p=.074\right)$ or PA ( $\beta=-.007$ [SE=.009], $\mathrm{p}=.428$ ). However, a significant interaction effect was found between binding group (tight vs. loose) and $D_{2}$ receptor occupancy in the model of both PA ( $\beta=.05$ [SE=.02], $\left.p=.008\right)$ and NA ( $\beta=-.04$ [SE=.02], $p=.019)$, indicating a differential association between $D_{2}$ receptor occupancy and emotional experience in the loose- versus tight-binding group.

After controlling for momentary hallucinations, the effect remained significant in the models predicting PA and NA ( $\beta=.05[\mathrm{SE}=.02], p=.014)$ and $(\beta=-.04[\mathrm{SE}=.02], p=.017)$, respectively). When controlling for momentary delusions, however, the effect lost significance in both models (PA: $(\beta=.03$ [SE=.02], $p=.106) ; N A:(\beta=-.02$ [SE=.01], $p=.183))$. After controlling for overall BPRS psychopathology, the effect remained significant in the model predicting PA $(\beta=.04$ [SE=.02], $p=.050)$, but lost significance in the model predicting $N A(\beta=-.02$ [SE $=.02]$, $\mathrm{p}=.197)$.

In order to clarify the interaction, stratified analyses were conducted for the tight- versus 
the loose-binding group. For both binding groups, $D_{2}$ receptor occupancy was divided in three based on the tertiles ( $1=$ =lowest $33^{1} /{ }_{3} \%$; 2 =middle $33^{1} / 3 \%, 3=$ highest $33^{1} /{ }_{3} \%$ ).

\section{Tight-binding agents and their influence on emotional experience}

For the tight-binding group, a significant effect was found of $D_{2}$ receptor binding estimates on PA $\left(\chi_{2}^{2}=6.42, p=.040\right)$, with age, sex and concomitant medication use as covariates. There was a clear decrease in PA in the middle group ( $D_{2}$ occupancy range $\left.68-81 \%\right)$ and an even larger decrease in the group with the highest $D_{2}$ receptor occupancy $\left(D_{2}\right.$ occupancy $\left.>81 \%\right)$ (Table 3; Figure 1). This association, however, failed to reach significance when additionally controlled for momentary hallucinations $\left(\chi_{2}^{2}=4.19, p=.123\right)$, momentary delusions $\left(\chi_{2}^{2}=4.26\right.$, $p=.119)$, or overall BPRS psychopathology $\left(\chi_{2}^{2}=3.96, p=.138\right.$; Table 3$)$. This was mainly due to the comparison between the highest and the lowest tertile, for which the effect lost significance, whereas the difference in PA between the middle and low tertile remained significant (Table 3).

$D_{2}$ occupancy was, in addition, significantly related to $N A\left(\chi_{2}^{2}=29.48, p<.0001\right)$, with a significant increase in NA in the group with the highest $D_{2}$ receptor occupancy (Table 3; Figure 1), controlling for age, sex and concomitant medication use. The association remained large and significant after inclusion of momentary hallucinations $\left(\chi_{2}^{2}=24.11, p<.0001\right)$, momentary delusions $\left(\chi_{2}^{2}=17.91, p=.0001\right)$, or overall BPRS psychopathology $\left(\chi_{2}^{2}=14.83, p=.0006\right)$ in the analysis (Table 3 ).

\section{Loose-binding agents and their influence on emotional experience}

No main effect of $D_{2}$ occupancy on PA nor NA was found in the loose-binding group (PA: $\chi_{2}^{2}=1.64, p=.439 ; N A: \chi_{2}^{2}=0.71, p=.701$; covariates age, sex, and concomitant medication use; Table 3). These results did not reach significance after controlling for momentary hallucinations, momentary delusions, or overall BPRS psychopathology.

\section{Discussion}

The results of this study indicate that estimated dopamine $D_{2}$ receptor occupancy may be associated with emotional experience in the flow of daily life of patients diagnosed with psychosis, adding ecological validity to previous studies ${ }^{8-17}$. However, the effect of $D_{2}$ occupancy on experience of emotions may be particularly relevant for agents that bind more tightly than dopamine to the dopamine $D_{2}$ receptor, whereas no specific associations 
between $D_{2}$ occupancy and emotional experience were found for looser binding agents. Given that tight- and loose-binding agents showed overlap in terms of overall receptor occupancy estimates, the results suggest that the mechanisms of $D_{2}$ receptor binding rather than mere occupancy levels of the drug play an important role in predicting experience of emotions.

\section{Relatively tight versus looser binding drugs and emotional experience}

For tight-binding agents (haloperidol, risperidone), the present study found increasing levels of $D_{2}$ receptor occupancy to be associated with deteriorating emotional experience in the natural flow of daily life. These results extend previous laboratory findings, which associated higher $D_{2}$ occupancy levels with worse emotional experience assessed with questionnaires in patients under antipsychotic treatment ${ }^{9,13,14}$.

Our findings, however, revealed no effect of $D_{2}$ occupancy levels on experience of emotions in looser binding agent (olanzapine) users, indicating that loose- and tight-binding agents have differential effects on $D_{2}$ occupancy related experience of emotions. Although several previous studies have found olanzapine to be superior to both haloperidol ${ }^{22,30,31}$ and risperidone ${ }^{22,32,33}$ with regard to emotional experience and quality of life, this superiority has not been confirmed in studies looking specifically at the effects of $D_{2}$ receptor occupancy on experience of emotions ${ }^{9,13,14}$. Results from these experimental studies, however, might be hampered by the relatively low dosage of antipsychotic medication and associated nonclinical levels of $D_{2}$ occupancy ${ }^{9}$. Data from our study, performed in a naturalistic sample, suggest that not the overall level of emotional experience but, rather, the distribution of emotions as a function of $D_{2}$ receptor occupancy might distinguish relatively tight from looser binding agent users.

We were not able to replicate the $60-70 \% \mathrm{D}_{2}$ occupancy window of optimal experience of reward, found in haloperidol and olanzapine treated patients by De Haan et al. ${ }^{9}$. However, since the vast majority of estimated patient $D_{2}$ occupancy levels were well above the upper border of this window, the current results do not rule out its existence. They only imply that it might not be detectable in a naturalistic sample of treated patients.

\section{Differences between tight and looser binding agents: what is the mechanism?}

Blockade of the $D_{2}$ receptor by antipsychotics is considered to attenuate the motivational salience of not only psychotic symptoms ${ }^{5}$ but also other experiences and thoughts and 
may, therefore, equally affect the dopaminergic reward system ${ }^{4}$. The more loose-binding mechanism of olanzapine, as opposed to the stringent binding mechanism of haloperidol and risperidone, allows more brief temporal binding of endogenous dopamine to the occupied $D_{2}$ receptor. Endogenous dopamine released in response to, for instance, emotional activity might, therefore, be more capable of impacting on the dopaminergic motivation and reward system in loose-binding agent users compared to tight-binding agent users ${ }^{22}$. Kapur and Seeman ${ }^{34}$ have argued that this very mechanism of dissociation from the $D_{2}$ receptor, rather than the affinity at serotonine or other receptor sites, determines a drug's atypicality.

The observed difference in subjectively experienced side-effects between olanzapine and risperidone agent users in the current study may reflect a similar mechanism. Although both atypical antipsychotics, they differ in terms of dissociation from the $D_{2}$ receptor. Similarly, this might explain the reported difference between tight- and loose-binding agents. Looser binding agents, through their mechanism of fast dissociation, may be able to maintain a certain level of well-being, even at high doses of the compound whereas the insensitivity to endogenous dopamine associated with tighter binding agents may increasingly affect reward and emotional experience as dosage increases.

Nevertheless, blockade of 5-HT serotonin receptor sites has been suggested to be associated with a decrease in secondary negative symptoms $\mathrm{s}^{35-38}$, and emotional experience may have been partly influenced by differences in 5-HT receptor occupancy between tight- and loosebinding agent users. However, Kapur et al. ${ }^{39}$ showed that clinical doses of both risperidone and olanzapine resulted in $100 \% 5-\mathrm{HT}_{2}$ receptor blockade, thus suggesting that occupancy of the serotonin receptors does not differentiate risperidone from olanzapine users. The differential effects of risperidone and olanzapine on emotional experience, as found in our naturalistic sample, are thus more likely explained by differential dissociation from the $D_{2}$ receptor rather than occupancy of the serotonin receptor. Nonetheless, it is arguable, that the differential affinity for $5-\mathrm{HT}$ between haloperidol and olanzapine might have influenced the observed differences in emotional experience between tighter and looser binding agent users. However, the current literature does not indicate superiority of serotonin blocking antipsychotics over the pure dopamine antagonist haloperidol for regulating or alleviating depressive or negative symptoms ${ }^{40-42}$. Furthermore, Kapur and Seeman ${ }^{34}$ have shown that, unlike $D_{2}$ receptor modulation, the mechanism of serotonin receptor antagonism is neither necessary nor sufficient in producing 'atypical' effects, suggesting that actions at the $D_{2}$ receptor might be more closely related to emotional well-being. 


\section{Confounding of symptom severity or EPS}

Given that patients with more severe symptomatology might receive higher doses of medication $^{43}$, the observed decline in emotional experience in tighter binding agent users may occur as a consequence of more severe psychopathology rather than of increased $D_{2}$ receptor occupancy. For high-dose-treated patients, decreases in positive affect indeed appeared to be largely imbued with the burden of severe symptomatology. For averagedosed patients, however, the decrease in positive affect did not necessarily occur collaterally with an increase in symptoms. The experience of negative affect, on the other hand, could in no case be explained by increased symptom levels. The inability to generate positive affect, thus, seems as much a consequence of $D_{2}$ receptor occupancy as of psychopathology, whereas the induction of negative affect in high-dose treated patients appears to originate predominantly from occupancy of the $D_{2}$ receptor. Interestingly, the ability to generate positive affect is "first" affected, at lower levels of $D_{2}$ occupancy.

Since high $\mathrm{D}_{2}$ receptor occupancy levels are associated with increased severity of EPS ${ }^{22}$, feelings of negative emotional experience might be induced by the occurrence of these side-effects. EPS are considered to become evident at occupancy levels above $78 \%{ }^{44}$. The tighter binding agent users, however, already experienced decreased feelings of positive affect at estimated $D_{2}$ occupancy levels below $78 \%$, suggesting that differences in EPS may explain part, but not all of the observed variation in subjective response. These findings are in line with results from Garcia-Cabeza et al. ${ }^{22}$ who found that, although being a major contributor to negative subjective response, EPS could not completely explain variation in emotional experience.

\section{Clinical implications}

Subjective response to medication has long been neglected both in clinical routine and in clinical trials of potential antipsychotic agents ${ }^{17}$. Symptom reduction and occurrence of extrapyramidal symptoms have long been regarded the main indicators of therapeutic outcome $^{8}$. However, ongoing developments in medication research have led to increased attention for subjectively experienced side-effects ${ }^{8}$. Results from our study underline the importance of the assessment of these subjective effects, since the antidopaminergic effect of antipsychotics appears to cause deterioration in well-being not necessarily related to symptom levels or EPS, particularly evident in more tight-binding agent users. Most importantly, changes in emotional experience already occur in response to relatively low levels of $D_{2}$ receptor occupancy and might, therefore, act as a more sensitive and earlier 
indicator of adverse effects than the occurrence of EPS at $78 \% D_{2}$ receptor occupancy ${ }^{44}$. The assessment of emotional experience gains additional relevance when considering that, next to symptom reduction and EPS, experience of emotions has been shown to be strongly associated with medication compliance and illness prognosis ${ }^{16,17,45}$. We, therefore, argue that assessment of emotional experience should become part of standard assessment in both clinical routine and medication trials.

It is important to note that we used only one compound with a loose-binding profile and only two compounds with a tighter binding profile. Since the pattern of dissociation from the $D_{2}$ receptor is a continuous measure, the results may increase or decrease for drugs with an even looser or tighter binding potential. However, the current results suggest that the distinction between drugs that bind tighter and drugs that bind looser than dopamine to the dopamine $D_{2}$ receptor is clinically relevant, as has been found earlier in relation to Parkinsonism ${ }^{20}$.

\section{Strengths and limitations}

Strengths of the study are the naturalistic approach, the sample size and the use of momentary assessment technology to investigate emotional experience in the realm of daily life. Applying the Experience Sampling Method has made it possible to investigate subtle, but meaningful changes in both positive and negative affect related to clinically dosed antipsychotic medication in a large sample of patients in a real world environment. Limitations are first that no actual $D_{2}$ occupancy data were used but, rather, occupancy was estimated based on the literature. Large metabolic interindividual variety has been found in occupancy of $D_{2}$ receptor sites ${ }^{9}$, as well as intraindividual variety related to decay of the antipsychotic agent over time. This may induce noise in the $D_{2}$ occupancy variable. However, we expect the error term to be random, since intraindividual- and interindividual variability have been found for all agents under investigation. Therefore, it may decrease the power to find a meaningful association, but it is unlikely to provide spurious associations. In addition, we have optimized the accuracy of the estimation, by basing it on a large collection of published observations from the literature (see Appendix). Nonetheless, the lack of direct $D_{2}$ occupancy measures calls for conservative interpretation of the data. Second, since the current study has investigated only three agents, of which only one is considered to bind loosely to the $D_{2}$ receptor, conclusions regarding the mechanism of loose- and tight-binding should not be generalized. Third, although EPS are assumed to become evident only at occupancy levels above $78 \%$, and therefore cannot fully explain 
variation in emotional experience, the lack of direct EPS assessments cannot certify that the observed associations between affect and $D_{2}$ receptor binding are truly unconfounded by variation in EPS. Fourth, subjective reports are considered less reliable, although not necessarily less valid than objective measurements ${ }^{46}$. Fifth, the current study used ESM, a daily-life assessment technique in which subjects have to comply with a paper-and-pencil diary protocol without the researcher being present. Recently, some authors have put doubt on the reliability and subject compliance in paper-and-pencil ESM studies, favoring the use of electronic devices ${ }^{47}$. However, in a comparative study, Green and colleagues concluded that both methods yielded similar results ${ }^{48}$. In addition, a recent study by our group using a signal-contingent random time sampling procedure with multiple observations per day - such as the protocol used in the current study - also found evidence underscoring the validity of the paper-and-pencil random-time self-report data in the current study ${ }^{49}$. 


\section{Acknowledgements}

This work was supported by a 2006 NARSAD Young Investigator Award and by the Dutch Medical Research Council (VENI and VIDI grants).

\section{Declaration of Interest}

Prof. dr. De Haan and Dr. Bak have received grant/research support from Eli Lilly and Bristol Myers-Squibb, respectively, and are members of speaker/advisory boards for Eli Lilly, Janssen-Cilag, AstraZeneca, and Bristol Myers-Squibb. 
Table 1 | Sociodemographic characteristics of the sample and concomitant psychotropic medication use.

\begin{tabular}{|c|c|c|c|}
\hline Characteristic & $\begin{array}{c}\text { Tight-binding } \\
\text { agent } \\
\text { haloperidol users }\end{array}$ & $\begin{array}{l}\text { Tight-binding } \\
\text { agent } \\
\text { risperidone users }\end{array}$ & $\begin{array}{c}\text { Loose-binding } \\
\text { agent } \\
\text { olanzapine users }\end{array}$ \\
\hline Age $(y ;$ mean $(\mathrm{SD}))$ & $\begin{array}{c}37.5(8.1) \\
\text { ranges 20-60 }\end{array}$ & $\begin{array}{c}31.7(8.6) \\
\text { ranges 18-52 }\end{array}$ & $\begin{array}{c}33.7(11.8) \\
\text { ranges 19-63 }\end{array}$ \\
\hline \multicolumn{4}{|l|}{ Gender ( $n$ ) } \\
\hline Male & 27 & 23 & 29 \\
\hline Female & 12 & 12 & 6 \\
\hline \multicolumn{4}{|l|}{ Level of education (\%) } \\
\hline Elementary school & 21 & 33 & 16 \\
\hline Secondary school & 16 & 52 & 18 \\
\hline Higher education & 63 & 15 & 66 \\
\hline \multicolumn{4}{|l|}{ Work situation (\%) } \\
\hline Household & 5 & 3 & 0 \\
\hline School/education & 0 & 6 & 3 \\
\hline Regular job & 7 & 3 & 3 \\
\hline III > 3 months & 2 & 6 & 6 \\
\hline Pensioner & 0 & 0 & 3 \\
\hline Unfit for work & 59 & 60 & 66 \\
\hline Unemployed & 10 & 17 & 11 \\
\hline Sheltered work & 17 & 5 & 8 \\
\hline \multicolumn{4}{|l|}{ Marital status (\%) } \\
\hline Married or cohabitating & 22 & 14 & 13 \\
\hline Divorced & 19 & 0 & 11 \\
\hline Never married & 59 & 86 & 76 \\
\hline Inpatient status (\%) & 39 & 49 & 46 \\
\hline Outpatient status (\%) & 61 & 51 & 54 \\
\hline \multicolumn{4}{|l|}{ Medication type (n) } \\
\hline Depot & 16 & 1 & 1 \\
\hline Oral & 23 & 34 & 34 \\
\hline \multicolumn{4}{|c|}{ Concomitant psychotropic medication (n) } \\
\hline Antidepressants & 0 & 2 & 2 \\
\hline Mood stabilizers & 0 & 0 & 1 \\
\hline Antiparkinson medication & 6 & 4 & 1 \\
\hline Anxiolytics & 0 & 3 & 3 \\
\hline Tranquilizers & 0 & 3 & 2 \\
\hline Antimigraine medication & 1 & 0 & 0 \\
\hline Total (\%) & 18 & 34 & 26 \\
\hline
\end{tabular}


Table 2 | Mean (SD) values and $t$-test statistics of psychopathology, symptoms, independent, and dependent variables for tight-binding agent users and loose-binding agent users.

\begin{tabular}{|c|c|c|c|c|}
\hline & $\begin{array}{c}\text { Tight-binding agent } \\
\text { (haloperidol and risperidone) } \\
\text { users, mean (SD), } \mathrm{n}=74\end{array}$ & $\begin{array}{l}\text { Loose-binding agent } \\
\text { (olanzapine) users, } \\
\text { mean (SD), } n=35\end{array}$ & $t_{107}$ & $\mathrm{p}$ \\
\hline \multicolumn{5}{|l|}{ Psychopathology } \\
\hline BPRS total ${ }^{a}$ & $1.8(0.5)$ & $1.9(0.5)$ & -0.92 & .192 \\
\hline BPRS depression $^{b}$ & $2.3(0.1)$ & $2.6(0.2)$ & -1.26 & .106 \\
\hline BPRS psychosis $^{c}$ & $1.8(0.1)$ & $2.0(0.1)$ & -1.26 & .106 \\
\hline \multicolumn{5}{|l|}{ Symptoms } \\
\hline Momentary hallucinations ${ }^{d}$ & $1.9(1.5)$ & $1.9(1.3)$ & -0.28 & .389 \\
\hline Momentary delusions $^{\mathrm{d}}$ & $2.2(1.4)$ & $2.1(1.0)$ & 0.33 & .369 \\
\hline \multicolumn{5}{|l|}{ Independent variable } \\
\hline $\mathrm{D}_{2}$ occupancy (group average) & $72.0(16.2)$ & $61.7(14.7)$ & 3.19 & .002 \\
\hline \multicolumn{5}{|l|}{ Dependent variables } \\
\hline Positive affect ${ }^{d}$ & $4.6(1.2)$ & $4.5(1.0)$ & 0.38 & .369 \\
\hline Negative affect ${ }^{d}$ & $2.0(1.1)$ & $2.1(0.9)$ & -0.68 & .271 \\
\hline
\end{tabular}

${ }^{a}$ Group average of the mean score on all 24 BPRS items.

${ }^{b}$ Group average of the mean score on the items that form the BPRS depression scale.

${ }^{c}$ Group average of the mean score on the items that form the BPRS psychosis scale.

${ }^{d}$ For each subject, a mean was calculated over all reports, and the mean per subject was additionally aggregated over the group to obtain the group mean (SD).

BPRS = Brief Psychiatric Rating Scale. 


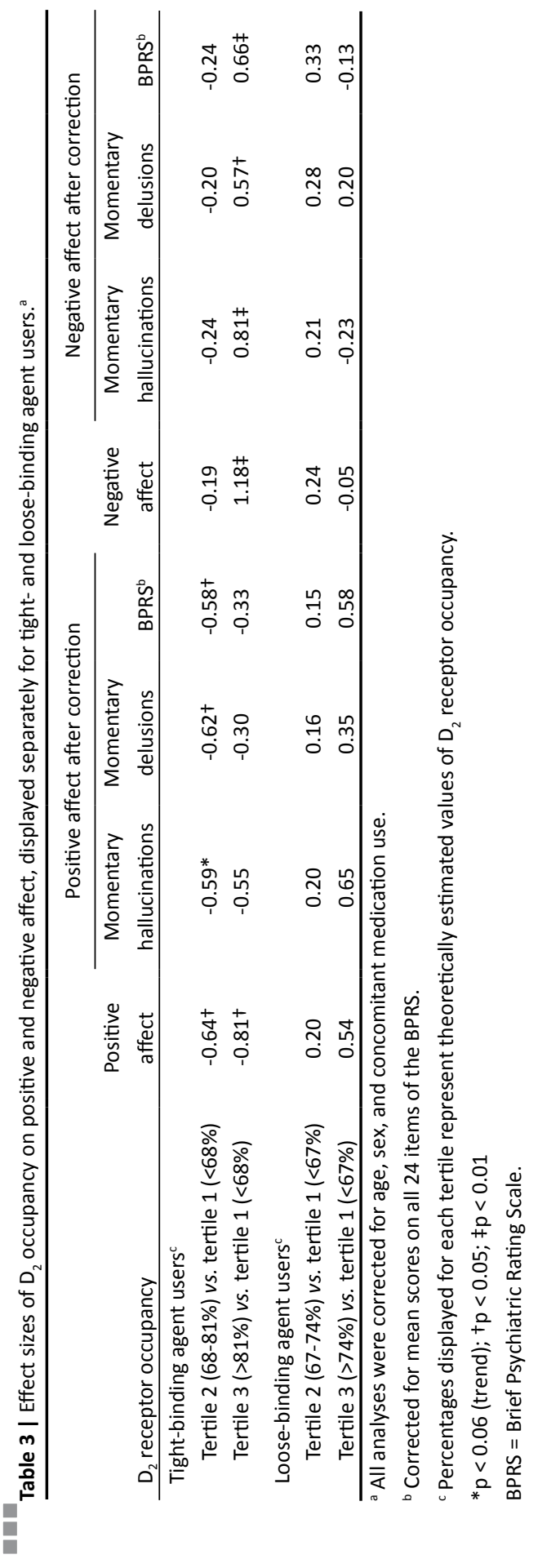


Figure 1 | Increasing theoretical estimates of $D_{2}$ receptor occupancy, divided in tertiles, are associated with a decrease in mean scores on the positive affect self-assessment Likert scale and an increase in mean scores on the negative affect self-assessment Likert scale in tight-binding agent users.
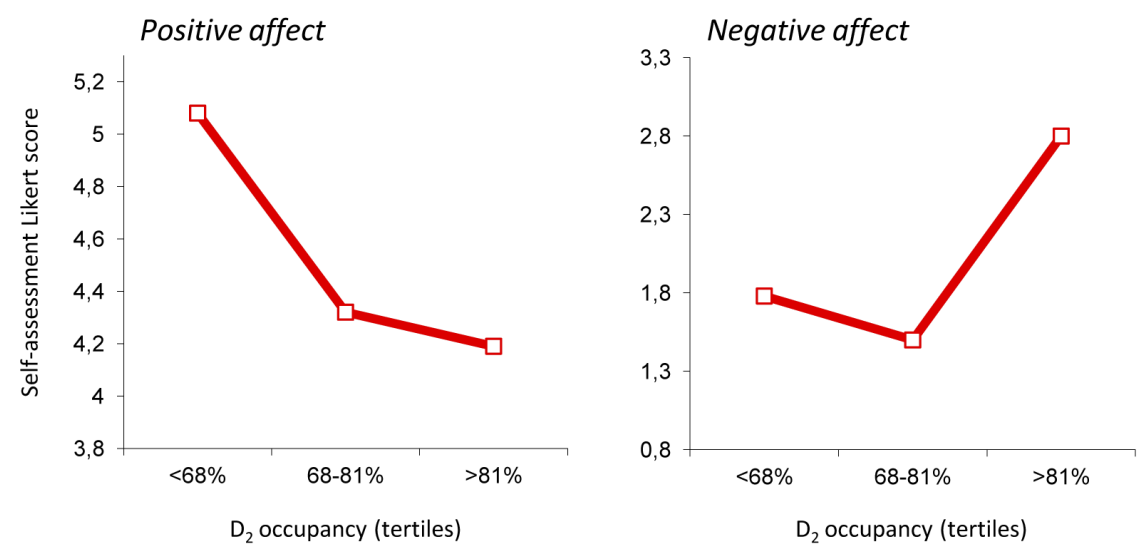


\section{References}

1. Carlsson A. The current status of the dopamine hypothesis of schizophrenia. Neuropsychopharmacology, 1988. 1(3): p. 179-86.

2. Nordstrom AL, Farde L, and Halldin C. Time course of D2-dopamine receptor occupancy examined by PET after single oral doses of haloperidol. Psychopharmacology (Berl), 1992. 106(4): p. 433-8.

3. Peroutka SJ and Synder SH. Relationship of neuroleptic drug effects at brain dopamine, serotonin, alphaadrenergic, and histamine receptors to clinical potency. Am J Psychiatry, 1980. 137(12): p. 1518-22.

4. Berridge $\mathrm{KC}$ and Robinson TE. What is the role of dopamine in reward: hedonic impact, reward learning, or incentive salience? Brain Res Brain Res Rev, 1998. 28(3): p. 309-69.

5. Kapur S. How antipsychotics become anti-"psychotic"--from dopamine to salience to psychosis. Trends Pharmacol Sci, 2004. 25(8): p. 402-6.

6. Kapur S and Mamo D. Half a century of antipsychotics and still a central role for dopamine D2 receptors. Prog Neuropsychopharmacol Biol Psychiatry, 2003. 27(7): p. 1081-90.

7. Artaloytia JF, Arango C, Lahti A, Sanz J, Pascual A, Cubero P, Prieto D, and Palomo T. Negative signs and symptoms secondary to antipsychotics: a double-blind, randomized trial of a single dose of placebo, haloperidol, and risperidone in healthy volunteers. Am J Psychiatry, 2006. 163(3): p. 488-93.

8. Karow A and Naber D. Subjective well-being and quality of life under atypical antipsychotic treatment. Psychopharmacology (Berl), 2002. 162(1): p. 3-10.

9. de Haan L, van Bruggen M, Lavalaye J, Booij J, Dingemans PM, and Linszen D. Subjective experience and D2 receptor occupancy in patients with recent-onset schizophrenia treated with low-dose olanzapine or haloperidol: a randomized, double-blind study. Am J Psychiatry, 2003. 160(2): p. 303-9.

10. Van Putten T. Why do schizophrenic patients refuse to take their drugs? Arch Gen Psychiatry, 1974. 31(1): p. 67-72.

11. Van Putten T, May PR, Marder SR, and Wittmann LA. Subjective response to antipsychotic drugs. Arch Gen Psychiatry, 1981. 38(2): p. 187-90.

12. Ashleigh EA and Larsen PD. A syndrome of increased affect in response to risperidone among patients with schizophrenia. Psychiatr Serv, 1998. 49(4): p. 526-8.

13. de Haan L, Lavalaye J, Linszen D, Dingemans PM, and Booij J. Subjective experience and striatal dopamine $D(2)$ receptor occupancy in patients with schizophrenia stabilized by olanzapine or risperidone. Am J Psychiatry, 2000. 157(6): p. 1019-20.

14. Mizrahi R, Rusjan P, Agid O, Graff A, Mamo DC, Zipursky RB, and Kapur S. Adverse subjective experience with antipsychotics and its relationship to striatal and extrastriatal D2 receptors: a PET study in schizophrenia. Am J Psychiatry, 2007. 164(4): p. 630-7. 
15. Voruganti L, Slomka P, Zabel P, Costa G, So A, Mattar A, and Awad AG. Subjective effects of AMPT-induced dopamine depletion in schizophrenia: correlation between dysphoric responses and striatal $D(2)$ binding ratios on SPECT imaging. Neuropsychopharmacology, 2001. 25(5): p. 642-50.

16. Awad AG and Hogan TP. Subjective response to neuroleptics and the quality of life: implications for treatment outcome. Acta Psychiatr Scand Suppl, 1994. 380: p. 27-32.

17. Naber D, Karow A, and Lambert M. Subjective well-being under the neuroleptic treatment and its relevance for compliance. Acta Psychiatr Scand Suppl, 2005(427): p. 29-34.

18. Myin-Germeys I, Oorschot M, Collip D, Lataster J, Delespaul P, and van Os J. Experience sampling research in psychopathology: opening the black box of daily life. Psychol Med, 2009. 39(9): p. 1533-47.

19. Delespaul PAEG. Assessing Schizophrenia in Daily Life. 1995, Maastricht: University Press.

20. Seeman P and Tallerico T. Antipsychotic drugs which elicit little or no parkinsonism bind more loosely than dopamine to brain D2 receptors, yet occupy high levels of these receptors. Mol Psychiatry, 1998. 3(2): p. 123-34.

21. Seeman P and Tallerico T. Rapid release of antipsychotic drugs from dopamine D2 receptors: an explanation for low receptor occupancy and early clinical relapse upon withdrawal of clozapine or quetiapine. Am J Psychiatry, 1999. 156(6): p. 876-84.

22. Garcia-Cabeza I, Gomez JC, Sacristan JA, Edgell E, and Gonzalez de Chavez M. Subjective response to antipsychotic treatment and compliance in schizophrenia. A naturalistic study comparing olanzapine, risperidone and haloperidol (EFESO Study). BMC Psychiatry, 2001. 1: p. 7.

23. The American Psychiatric Association. Diagnostic and Statistical Manual of Mental Disorders, Fourth Edition, Text Revision (C) 2000, Washington, DC.

24. McGuffin P, Farmer A, and Harvey I. A polydiagnostic application of operational criteria in studies of psychotic illness. Development and reliability of the OPCRIT system. Arch Gen Psychiatry, 1991. 48(8): p. 764-70.

25. Ventura J, Nuechterlein, K.H., Subotnik, K.L., Gutkind, D., Gilbert, E.A. Symptom dimensions in recent-onset schizophrenia and mania: a principal components analysis of the 24-item Brief Psychiatric Rating Scale. Psychiatry Res, 2000. 97: p. 129-135.

26. Velligan D, Prihoda T, Dennehy E, Biggs M, Shores-Wilson K, Crismon ML, Rush AJ, Miller A, Suppes T, Trivedi M, Kashner TM, Witte B, Toprac M, Carmody T, Chiles J, and Shon S. Brief psychiatric rating scale expanded version: How do new items affect factor structure? Psychiatry Res, 2005. 135(3): p. 217-28.

27. Moleman P. Praktische psychofarmacologie. Bohn Stafleu van Loghum, Houten, 2005. 4e herziene druk: p. 198-199.

28. Schwartz JE and Stone AA. Strategies for analyzing ecological momentary assessment data. Health Psychol, 1998. 17(1): p. 6-16.

29. StataCorp. Stata Statistical Software: Release 10. College Station, TX: StataCorp LP, 2007. 
30. Kongsakon R, Trinidad-Onate P, Chaudhry HR, Raza SB, Leynes CR, Khan IU, Ismail HC, Chan B, Ignacio JC, Rodriguez SC, Lowry AJ, Brnabic AJ, and Buenaventura R. Asian outpatients with schizophrenia: a doubleblind randomized comparison of quality of life and clinical outcomes for patients treated with olanzapine or haloperidol. J Med Assoc Thai, 2006. 89(8): p. 1157-70.

31. Revicki DA, Genduso LA, Hamilton SH, Ganoczy D, and Beasley CM, Jr. Olanzapine versus haloperidol in the treatment of schizophrenia and other psychotic disorders: quality of life and clinical outcomes of a randomized clinical trial. Qual Life Res, 1999. 8(5): p. 417-26.

32. Mohr P. Quality of life in the long-term treatment and the role of second-generation antipsychotics. Neuro Endocrinol Lett, 2007. 28 Suppl 1: p. 117-33.

33. Naber D, Moritz S, Lambert M, Pajonk FG, Holzbach R, Mass R, and Andresen B. Improvement of schizophrenic patients' subjective well-being under atypical antipsychotic drugs. Schizophr Res, 2001. 50(1-2): p. 79-88.

34. Kapur S and Seeman P. Does fast dissociation from the dopamine $\mathrm{d}(2)$ receptor explain the action of atypical antipsychotics?: A new hypothesis. Am J Psychiatry, 2001. 158(3): p. 360-9.

35. Canli T and Lesch KP. Long story short: the serotonin transporter in emotion regulation and social cognition. Nat Neurosci, 2007. 10(9): p. 1103-9.

36. Mackowiak M, Czyrak A, and Wedzony K. [The involvement of 5-HT1a serotonin receptors in the pathophysiology and pharmacotherapy of schizophrenia]. Psychiatr Pol, 2000. 34(4): p. 607-21.

37. Meltzer HY. The role of serotonin in schizophrenia and the place of serotonin-dopamine antagonist antipsychotics. J Clin Psychopharmacol, 1995. 15(1 Suppl 1): p. 2S-3S.

38. Millan MJ. Improving the treatment of schizophrenia: focus on serotonin (5-HT)(1A) receptors. J Pharmacol Exp Ther, 2000. 295(3): p. 853-61.

39. Kapur S, Zipursky RB, and Remington G. Clinical and theoretical implications of 5-HT2 and D2 receptor occupancy of clozapine, risperidone, and olanzapine in schizophrenia. Am J Psychiatry, 1999. 156(2): p. 28693.

40. Leucht S, Pitschel-Walz G, Abraham D, and Kissling W. Efficacy and extrapyramidal side-effects of the new antipsychotics olanzapine, quetiapine, risperidone, and sertindole compared to conventional antipsychotics and placebo. A meta-analysis of randomized controlled trials. Schizophr Res, 1999. 35(1): p. 51-68.

41. Peuskens J. Risperidone in the treatment of patients with chronic schizophrenia: a multi-national, multicentre, double-blind, parallel-group study versus haloperidol. Risperidone Study Group. Br J Psychiatry, 1995. 166(6): p. 712-26; discussion 727-33.

42. Mauri MC, Moliterno D, Rossattini M, and Colasanti A. Depression in schizophrenia: comparison of first- and second-generation antipsychotic drugs. Schizophr Res, 2008. 99(1-3): p. 7-12.

43. Lipkovich I, Baron D, Houston J, Ahl J, and Rotelli M. Flexible-dose clinical trials: predictors and outcomes of antipsychotic dose adjustments. J Clin Psychopharmacol, 2005. 25(4): p. 381-6. 
44. Kapur S, Zipursky R, Jones C, Remington G, and Houle S. Relationship between dopamine D(2) occupancy, clinical response, and side effects: a double-blind PET study of first-episode schizophrenia. Am J Psychiatry, 2000. 157(4): p. 514-20.

45. Karow A, Czekalla J, Dittmann RW, Schacht A, Wagner T, Lambert M, Schimmelmann BG, and Naber D. Association of subjective well-being, symptoms, and side effects with compliance after 12 months of treatment in schizophrenia. J Clin Psychiatry, 2007. 68(1): p. 75-80.

46. Strauss JS. The person with schizophrenia as a person. II: Approaches to the subjective and complex. $\mathrm{Br} J$ Psychiatry Suppl, 1994(23): p. 103-7.

47. Stone AA, Shiffman S, Schwartz JE, Broderick JE, and Hufford MR. Patient compliance with paper and electronic diaries. Control Clin Trials, 2003. 24(2): p. 182-99.

48. Green AS, Rafaeli E, Bolger N, Shrout PE, and Reis HT. Paper or plastic? Data equivalence in paper and electronic diaries. Psychol Methods, 2006. 11(1): p. 87-105.

49. Jacobs N, Nicolson NA, Derom C, Delespaul P, van Os J, and Myin-Germeys I. Electronic monitoring of salivary cortisol sampling compliance in daily life. Life Sci, 2005. 76(21): p. 2431-43. 


\section{Appendix}

Theoretical estimates of $D_{2}$ receptor occupancy were obtained by fitting agent-specific hyperbolic functions, defined as $\mathrm{D}_{2}$ receptor occupancy $=\mathrm{Occ}_{\max } \times$ [administered daily dose/(administered daily dose + ED50) $]^{1}$, to mean dose-occupancy values calculated from previous literature. ED50 is the dose predicted to theoretically provide $50 \%$ of maximum receptor occupancy, and $O c c_{\max }$ was replaced by 100 , assuming that all of the tracer used to investigate $D_{2}$ occupancy can be replaced by endogenous dopamine ${ }^{2}$.

We screened the PubMed database for published studies reporting dose- $D_{2}$ occupancy data for the agents olanzapine, risperidone, and haloperidol, by using combinations of the following keywords: "olanzapine", "risperidone", "haloperidol", "occupancy", and "schizophrenia". Only papers reporting individual dose-occupancy data points, rather than group averages, were included and further screened for additional literature. Animal studies were not included. Qualitative criteria were utilized to weight data from these studies: (i) sample size $>10$, (ii) investigation of $D_{2}$ receptor occupancy in striatal areas, (iii) patient sample consisting of patients diagnosed with schizophrenic disorder. Data from papers fulfilling all three criteria received a weight factor of 2 in the calculations, whereas papers that did not, received a weight factor of 1 (Figures 2-4). This search strategy led to a total of 24 papers, with 10 papers $(n=99)$ reporting dose-occupancy measures for olanzapine users ${ }^{1-}$ ${ }^{10}, 9$ papers $(n=84)$ reporting dose-occupancy measures for risperidone users ${ }^{2,10-17}$, and 5 papers ( $n=33$ ) reporting dose-occupancy measures for haloperidol users 3, 9, 10, 18, 19 .

Dose-occupancy measures extracted from these papers were used to calculate theoretical estimates of ED50 for haloperidol, risperidone, and olanzapine, resulting in the following hyperbolic formulas (see also Figures 2-4):

\section{Haloperidol:}

theoretical estimate of $D_{2}$ receptor occupancy $=100 \% \times \frac{\text { daily dose }}{(\text { daily dose }+1.75)}$

Risperidone:

theoretical estimate of $D_{2}$ receptor occupancy $=100 \% \times \frac{\text { daily dose }}{\text { (daily dose }+1.43)}$

Olanzapine:

theoretical estimate of $D_{2}$ receptor occupancy $=100 \% \times \frac{\text { daily dose }}{(\text { daily dose }+7.35)}$ 
These functions were then applied to individual subject medication data extracted from the ESM medication forms (see Methods), in order to predict occupancy estimates from daily medication dose for each individual subject.

Da

Figure 2 | Theoretical estimation of $D_{2}$ receptor occupancy, with estimated doseoccupancy function displayed for the agent haloperidol. ${ }^{a}$

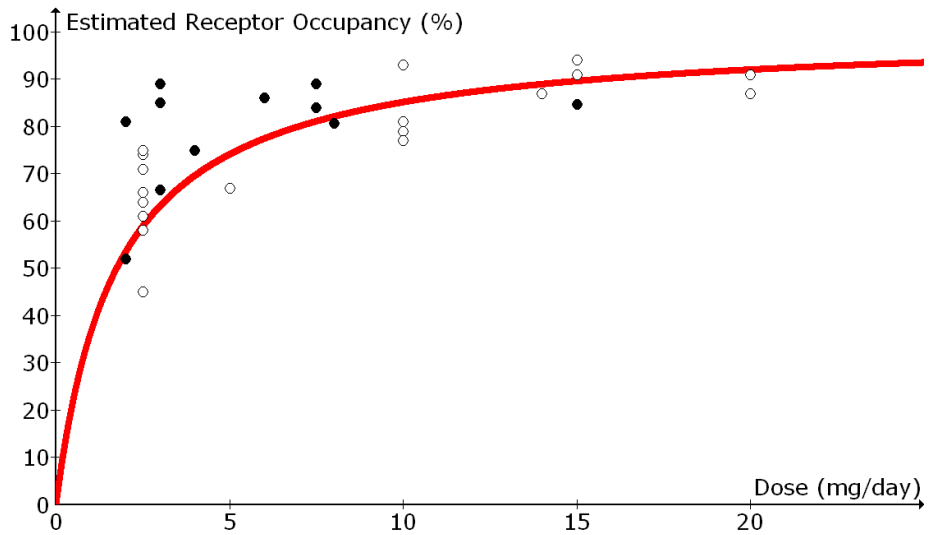

a Curve fitting was based on weighted mean values of dose-occupancy data extracted from the literature (dots). White dots represent data points that received a weight factor of 2 for the calculation of mean values, whereas data represented by black dots received a weight factor of 1 .

Figure 3 | Theoretical estimation of $D_{2}$ receptor occupancy, with estimated doseoccupancy function displayed for the agent risperidone. ${ }^{\mathrm{a}}$

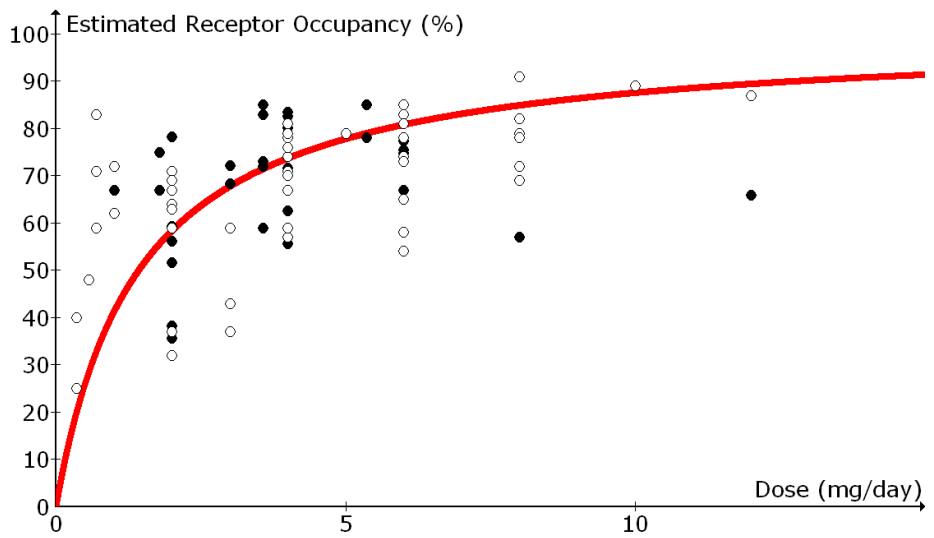

a Curve fitting was based on weighted mean values of dose-occupancy data extracted from the literature (dots). White dots represent data points that received a weight factor of 2 for the calculation of mean values, whereas data represented by black dots received a weight factor of 1 . 
Figure 4 | Theoretical estimation of $D_{2}$ receptor occupancy, with estimated doseoccupancy function displayed for the agent olanzapine. ${ }^{a}$

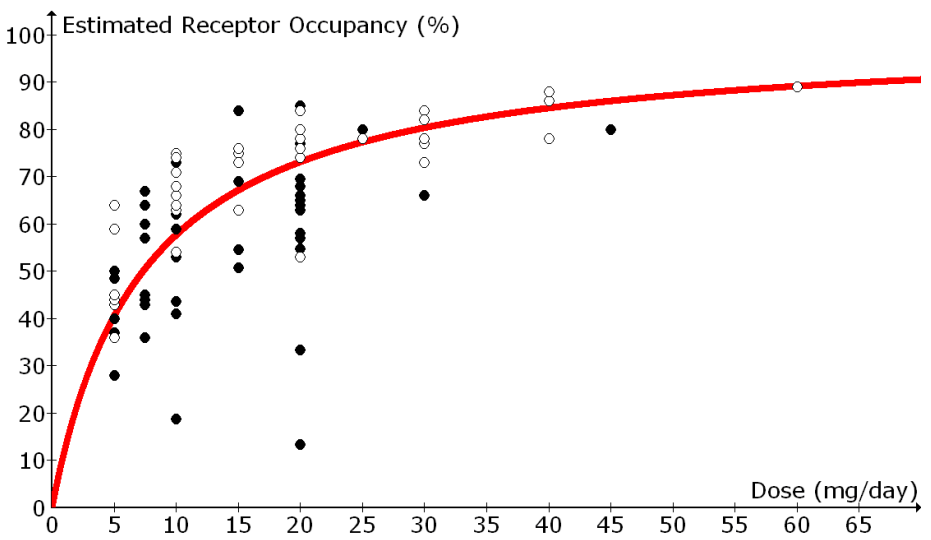

a Curve fitting was based on weighted mean values of dose-occupancy data extracted from the literature (dots). White dots represent data points that received a weight factor of 2 for the calculation of mean values, whereas data represented by black dots received a weight factor of 1 . 


\section{References (appendix)}

1. Kapur S, Zipursky RB, Remington G, Jones C, DaSilva J, Wilson AA, and Houle S. 5-HT2 and D2 receptor occupancy of olanzapine in schizophrenia: a PET investigation. Am J Psychiatry, 1998. 155(7): p. 921-8.

2. Kapur S, Zipursky RB, and Remington G. Clinical and theoretical implications of 5-HT2 and D2 receptor occupancy of clozapine, risperidone, and olanzapine in schizophrenia. Am J Psychiatry, 1999. 156(2): p. 28693.

3. Attarbaschi T, Sacher J, Geiss-Granadia T, Klein N, Mossaheb N, Lanzenberger R, Asenbaum S, Dudczak R, Kasper S, and Tauscher J. Striatal D(2) receptor occupancy in bipolar patients treated with olanzapine. Eur Neuropsychopharmacol, 2007. 17(2): p. 102-7.

4. Bigliani V, Mulligan RS, Acton PD, Ohlsen RI, Pike VW, Ell PJ, Gacinovic S, Kerwin RW, and Pilowsky LS. Striatal and temporal cortical D2/D3 receptor occupancy by olanzapine and sertindole in vivo: a [123I]epidepride single photon emission tomography (SPET) study. Psychopharmacology (Berl), 2000. 150(2): p. 132-40.

5. de Haan L, van Bruggen M, Lavalaye J, Booij J, Dingemans PM, and Linszen D. Subjective experience and D2 receptor occupancy in patients with recent-onset schizophrenia treated with low-dose olanzapine or haloperidol: a randomized, double-blind study. Am J Psychiatry, 2003. 160(2): p. 303-9.

6. Meisenzahl EM, Dresel S, Frodl T, Schmitt GJ, Preuss UW, Rossmuller B, Tatsch K, Mager T, Hahn K, and Moller HJ. D2 receptor occupancy under recommended and high doses of olanzapine: an iodine-123iodobenzamide SPECT study. J Psychopharmacol, 2000. 14(4): p. 364-70.

7. Nordstrom AL, Nyberg S, Olsson H, and Farde L. Positron emission tomography finding of a high striatal D2 receptor occupancy in olanzapine-treated patients. Arch Gen Psychiatry, 1998. 55(3): p. 283-4.

8. Nyberg S, Farde L, and Halldin C. A PET study of 5-HT2 and D2 dopamine receptor occupancy induced by olanzapine in healthy subjects. Neuropsychopharmacology, 1997. 16(1): p. 1-7.

9. Tauscher J, Kufferle B, Asenbaum S, Fischer P, Pezawas L, Barnas C, Tauscher-Wisniewski S, Brucke T, and Kasper S. In vivo 123I IBZM SPECT imaging of striatal dopamine-2 receptor occupancy in schizophrenic patients treated with olanzapine in comparison to clozapine and haloperidol. Psychopharmacology (Berl), 1999. 141(2): p. 175-81.

10. Xiberas X, Martinot JL, Mallet L, Artiges E, Loc HC, Maziere B, and Paillere-Martinot ML. Extrastriatal and striatal $D(2)$ dopamine receptor blockade with haloperidol or new antipsychotic drugs in patients with schizophrenia. Br J Psychiatry, 2001. 179: p. 503-8.

11. Gefvert O, Eriksson B, Persson P, Helldin L, Bjorner A, Mannaert E, Remmerie B, Eerdekens M, and Nyberg S. Pharmacokinetics and D2 receptor occupancy of long-acting injectable risperidone (Risperdal Consta) in patients with schizophrenia. Int J Neuropsychopharmacol, 2005. 8(1): p. 27-36.

12. Kapur S, Remington G, Zipursky RB, Wilson AA, and Houle S. The D2 dopamine receptor occupancy of 
risperidone and its relationship to extrapyramidal symptoms: a PET study. Life Sci, 1995. 57(10): p. PL1037.

13. Remington G, Mamo D, Labelle A, Reiss J, Shammi C, Mannaert E, Mann S, and Kapur S. A PET study evaluating dopamine D2 receptor occupancy for long-acting injectable risperidone. Am J Psychiatry, 2006. 163(3): p. 396-401.

14. Schmitt GJ, Meisenzahl EM, Dresel S, Tatsch K, Rossmuller B, Frodl T, Preuss UW, Hahn K, and Moller HJ. Striatal dopamine D2 receptor binding of risperidone in schizophrenic patients as assessed by $123 \mathrm{I}-$ iodobenzamide SPECT: a comparative study with olanzapine. J Psychopharmacol, 2002. 16(3): p. 200-6.

15. Takano A, Suhara T, Ikoma Y, Yasuno F, Maeda J, Ichimiya T, Sudo Y, Inoue M, and Okubo Y. Estimation of the time-course of dopamine D2 receptor occupancy in living human brain from plasma pharmacokinetics of antipsychotics. Int J Neuropsychopharmacol, 2004. 7(1): p. 19-26.

16. Uchida H, Graff-Guerrero A, Mulsant BH, Pollock BG, and Mamo DC. Long-term stability of measuring D(2) receptors in schizophrenia patients treated with antipsychotics. Schizophr Res, 2009. 109(1-3): p. 130-3.

17. Yasuno F, Suhara T, Okubo Y, Sudo Y, Inoue M, Ichimiya T, and Tanada S. Dose relationship of limbic-cortical D2-dopamine receptor occupancy with risperidone. Psychopharmacology (Berl), 2001. 154(1): p. 112-4.

18. Farde L, Wiesel FA, Nordstrom AL, and Sedvall G. D1- and D2-dopamine receptor occupancy during treatment with conventional and atypical neuroleptics. Psychopharmacology (Berl), 1989. 99 Suppl: p. S28-31.

19. Nordstrom AL, Farde L, and Halldin C. Time course of D2-dopamine receptor occupancy examined by PET after single oral doses of haloperidol. Psychopharmacology (Berl), 1992. 106(4): p. 433-8. 
146 


\section{Psychotic exacerbation and}

emotional dampening in the daily life of

patients with schizophrenia switched to

\section{aripiprazole therapy}

a collection of standardized case reports.

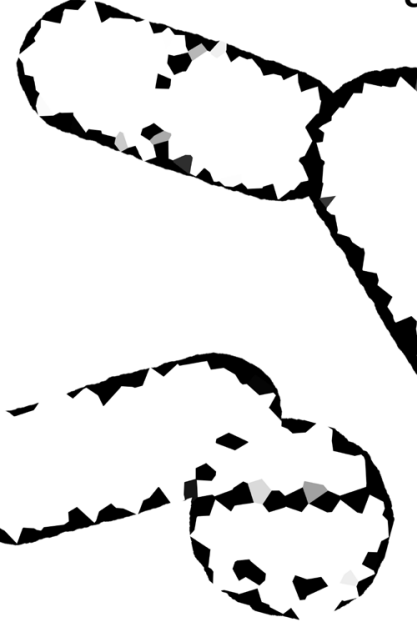

Johan Lataster ${ }^{1}$

Inez Myin-Germeys ${ }^{1}$

Marieke Wichers ${ }^{1}$

Philippe A.E.G. Delespaul ${ }^{1}$

Jim van $O s^{1,2}$

Maarten Bak

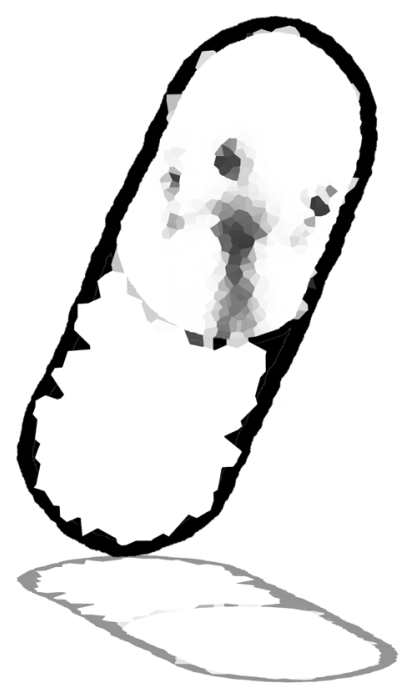


${ }^{1}$ Department of Psychiatry and Psychology, South Limburg Mental Health Research and Teaching Network,

EURON, Maastricht University Medical Center, Maastricht, the Netherlands.

${ }^{2}$ King's College London, King's Health Partners, Department of Psychosis Studies, Institute of Psychiatry, London, UK.

Published as:

Lataster J, Myin-Germeys I, Wichers M, Delespaul P, van Os J, Bak M.

Psychotic exacerbation and emotional dampening in the daily life of patients with schizophrenia switched to aripiprazole therapy: a collection of standardized case reports.

Therapeutic Advances in Psychopharmacology, 2011. 1(5): p. 145-51. 


\section{Abstract}

Objective: Blockade of the dopamine $D_{2}$ receptor is a key mechanism in the antipsychotic treatment of patients with a psychotic disorder, but may also induce emotional deficits. The partial $D_{2}$ agonistic profile of aripiprazole has, therefore, been suggested to favor emotional well-being compared to the pure dopamine antagonistic properties of traditional antipsychotics.

Method: The current study used the Experience Sampling Method (a structured diary technique) to assess the effects of switching from treatment with traditional dopamine antagonist antipsychotics to treatment with the partial dopamine agonist aripiprazole on emotional well-being, in the daily life of 13 patients with a diagnosis of schizophrenia.

Results: More than half of all patients experienced exacerbation of psychotic symptoms after they had switched to the aripiprazole medication regime, consequently resulting in drop-out of the study. Furthermore, switching to aripiprazole treatment, when effective in terms of symptom reduction, was accompanied by decreased feelings of both positive and negative affect in daily life, suggestive of a general state of emotional dampening.

Conclusion: Although the scale of the current study and the $54 \%$ drop-out rate call for careful interpretation of these data, implementation of ecological monitoring in psychopharmacological research may open up new avenues for untangling the working mechanisms of compounds with regard to their impact on mental states. 


\section{Introduction}

Blockade of the dopamine $D_{2}$ receptor is a key mechanism in the antipsychotic treatment of patients diagnosed with a psychotic disorder, but has also been associated with emotional impairments ${ }^{1-3}$. Evidence for a negative impact of $D_{2}$ blockade on emotional experience, however, has been based mainly on results from data collected with medication-related, cross-sectional questionnaires in semi-experimental environments, lacking ecological validity. In a previous study (see Chapter $\mathbf{5})^{4}$ the association between $D_{2}$ receptor occupancy and experience of emotions in daily life reality was investigated using the Experience Sampling Method (ESM), a fine-grained momentary assessment technique for collecting emotional experiences in the flow of daily life ${ }^{5,6}$. Results from this study showed that occupancy of the $D_{2}$ receptor, occasioned by the antipsychotics haloperidol and risperidone, was associated with impaired emotional experience ${ }^{4}$.

In the current experiment, the same method was used to investigate the effects of aripiprazole treatment on psychotic symptoms and emotional experience in a sample of 13 patients with schizophrenia who were switched from treatment with traditional dopamine antagonist antipsychotics to treatment with the partial dopamine agonist aripiprazole. Aripiprazole has been shown to be adequate in reducing psychotic symptoms ${ }^{7}$ and may, because of its partial $D_{2}$ agonistic properties, have preferential effects on the dopaminergic motivation and reward system compared to pure dopamine antagonist antipsychotics, possibly resulting in a different subjectively experienced side-effects profile. Indeed, despite very high levels of $D_{2}$ occupancy, aripiprazole treatment has been associated with better scores on the Subjective Well-being under Neuroleptics (SWN) scale compared to traditional $\mathrm{D}_{2}$ antagonist antipsychotics ${ }^{8}$. The current study aimed at adding ecological validity to these results by monitoring emotional experience and psychotic symptoms in daily-life reality.

\section{Methods}

\section{Sample}

The sample consisted of 13 patients with a diagnosis of schizophrenia, displaying insufficient therapeutic response to antipsychotic treatment. Inclusion criteria were (i) age 18-65 years; (ii) sufficient command of the Dutch language to understand instructions and informed consent; (iii) DSM-IV9 diagnosis of schizophrenia, generated with the OPCRIT computer 
program $^{10}$; and (iv) current use of traditional dopamine antagonist antipsychotic. Exclusion criteria were (i) hospitalization within two months prior to study entry; (ii) endocrine, cardiovascular, or brain disease; (iii) history of neuroleptic malignant syndrome; and (iv) pregnancy or lactation (women only).

The procedures followed in this study were in accordance with the ethical standards of the local institutional committee on human experimentation. After complete description of the study to the participants, signed informed consent was obtained. Stop criteria were formulated if patients requested to stop for any given reason, or the investigator or treating physician was concerned about the safety of the patient.

\section{Study design}

At study entry $\left(T_{0}\right)$, while continuing use of traditional dopamine antagonist medication as prescribed by their psychiatrist, subjects received a digital wristwatch and a set of ESM selfassessment forms collated in a booklet for each day. Ten times a day on 6 consecutive days, the watch emitted a signal (beep) at unpredictable moments between 7:30 a.m. and 10:30 p.m. After each beep, subjects were asked to stop their activity and fill out the ESM selfassessment forms previously handed out to them, collecting reports of psychopathology and emotional experience. Subjects were asked to complete their reports immediately after the beep, thus minimizing memory distortions, and to record the time at which they completed the form.

After completion of the 6-day assessment, aripiprazole treatment was initialized in dosages of 15-30 mg a day, titrated against clinical response. Simultaneously, dosage of previously prescribed antipsychotic medication was gradually reduced over a three-week period, to be discontinued altogether at the start of the fourth week of aripiprazole administration. After five weeks of aripiprazole treatment, subjects again completed a 6-day ESM-assessment $\left(\mathrm{T}_{1}\right)$, while continuing aripiprazole therapy. No additional antipsychotic medication was administered during this final treatment phase.

In order to estimate whether antipsychotic dosage increased or decreased after the treatment switch to aripiprazole, all antipsychotic medication dosages were additionally recalculated into chlorpromazine equivalent terms ${ }^{11}$. Throughout the study, any change in prescribed concomitant medication was discussed with the principal investigator and registered. 


\section{Emotional experience}

Emotional experience was assessed with 4 positive affect items and 7 negative affect items rated on 7-point Likert scales (rating from not at all [=1] to very [=7]), derived from the ESM booklets as described above. Mean scores on the items "I feel cheerful", "I feel relaxed", "I feel satisfied" and "Overall, I am feeling well" (Cronbach's alpha $=.83$ ) constituted the positive affect (PA) scale. The negative affect (NA) scale consisted of mean scores on the items "I feel insecure", "I feel lonely", "I feel anxious", "I feel down", "I have difficulty concentrating", "I feel angry", and "I feel guilty" (Cronbach's alpha $=.85$ ).

\section{Psychotic symptoms}

Symptomatology was assessed with 8 psychosis items, rated on 7-point Likert scales (rating from not at all [=1] to very [=7]): "I feel suspicious", "My thoughts are influenced by others", "My thoughts can't be expressed in words", "I can't get these thoughts out of my head", "I feel unreal", "I hear voices", "I see things that aren't really there", "I'm afraid I'Il lose control" (Cronbach's alpha $=.81$ ). Symptom severity was additionally assessed at $\mathrm{T}_{0}$ with the Brief Psychiatric Rating Scale (BPRS) ${ }^{12}$.

\section{Statistical analyses}

For each ESM-report, the time at which subjects indicated they completed the report was compared to the actual time of the beep. All reports completed more than 15 minutes after the signal were excluded from the analysis. Previous work has shown that reports completed after this interval are less reliable and consequently less valid ${ }^{5}$. For the same reason, subjects with less than 20 valid reports at either $T_{0}$ or $T_{1}$ were also excluded from the analyses. $T_{0}$ data from subjects that dropped out of the study at $T_{1}$ were not included in the analyses. All analyses, therefore, were performed on the subject sample that had completed both $\mathrm{T}_{0}$ and $\mathrm{T}_{1}$ assessments.

Multilevel linear regression analyses, using the XTREG procedure in STATA release $10.0^{13}$ were conducted with aripiprazole treatment as independent dichotomous variable $\left(0=T_{0}\right.$ - pre medication switch to aripiprazole; $1=\mathrm{T}_{1}$ - post medication switch to aripiprazole), and NA, PA, and psychosis as dependent variables, in three separate models, with sex and any change of concomitant medication (entered as dummies of the respective medications) added as covariates. 


\section{Results}

\section{Subjects}

Sociodemographic characteristics of the sample, and details on antipsychotic and concomitant medication use are summarized in Table 1, and Table 2, respectively.

After five weeks of aripiprazole treatment, 6 of the initial 13 patients again completed a 6 day ESM-assessment $\left(T_{1}\right)$, while continuing aripiprazole therapy. At $T_{0}$, these 6 subjects had received olanzapine $(n=3)$, pimozide $(n=1)$, haloperidol $(n=1)$ or quetiapine $(n=1)$ treatment. After recalculation of medication dosages in chlorpromazine equivalent terms, 4 of these subjects received relatively lower dosages of antipsychotic after the switch to aripiprazole therapy, whereas the remaining 2 subjects received relatively higher chlorpromazine equivalent dosages after being switched to aripiprazole.

Seven patients experienced exacerbation of psychotic symptoms after they had been switched to the aripiprazole medication regime, leading to discontinuation of aripiprazole treatment and drop-out of the study at $T_{1}$. No instance of drop-out was related to patients being unable to comply with the ESM protocol. This was supported by high compliance rates at $\mathrm{T}_{0}$ for both those who completed treatment (44 reports [73\%], SD $=7.9 \%$ ) and those who dropped out (42 reports [70\%], $\mathrm{SD}=2.9 \% ; \mathrm{t}_{(\mathrm{df}=11)}=-0.68,95 \% \mathrm{Cl}[-9.10 ; 4.81], \mathrm{p}=.512$ ). Furthermore, mean total baseline BPRS scores did not significantly differ between those who completed treatment and those who dropped out (see Table 1).

In addition, compliance rates at $\mathrm{T}_{1}$ for those who completed treatment were high and similar to those observed at $\mathrm{T}_{0}$ (44 reports [73\%], $\mathrm{SD}=4.8 \%$ ).

\section{Effect of switching to aripiprazole therapy on subjectively experienced symptoms and emotions}

The results are summarized in Figure 1. Multilevel linear regression analysis showed a main effect of aripiprazole treatment on psychosis ( $\beta=-.38$ [SE=.064], $p=.001)$, with lower levels of psychotic symptoms after the start of aripiprazole treatment, supported by a significant decrease in mean total BPRS score (Mean $_{(\mathrm{T})}=37.7$ [SD=17.2]; Mean ${ }_{(\mathrm{T} 1)}=34.2[\mathrm{SD}=17.9]$; $\left.t_{(d f=5)}=3.42,95 \% \mathrm{Cl}[0.87 ; 6.13], p=.019\right)$. Additionally, a decrease in feelings of both positive $(\beta=-.26$ [SE=.117], $p=.027)$ and negative affect ( $\beta=-.50$ [SE=.072], $p=.001)$ became apparent after the start of aripiprazole treatment. All analyses were corrected for gender and concomitant medication change. 


\section{Discussion}

The findings of the current study, first, indicate that switching patients with schizophrenia from treatment with traditional dopamine antagonist antipsychotics to treatment with the partial dopamine agonist aripiprazole increases risk of psychotic exacerbation, even when switching is performed gradually by tapering off previous antipsychotics over a threeweek period. More than half of the patients included in the current study experienced exacerbation of psychotic symptoms after being switched to the aripiprazole medication regime, a phenomenon that has been described in previous reports ${ }^{14-16}$. As suggested by Adan-Manes and Garcia-Parajua ${ }^{14}$, chronic administration of dopamine antagonists, in these patients, may have induced hypersensitivity to the agonistic effects of aripiprazole, resulting in a worsening of psychotic symptoms in response to aripiprazole treatment. Although it can be argued that aripiprazole dosage in the current study was well above the established clinical optimum of $10 \mathrm{mg} / \mathrm{day}^{17}$, clinical response to aripiprazole has not been shown to decline with increasing dosage ${ }^{18}$.

Secondly, the current findings suggest that, when effective in terms of reducing psychotic experiences, switching from a traditional $D_{2}$ antagonist antipsychotic medication to the partial $D_{2}$ agonist aripiprazole results in a decrease in both positive and negative affect, suggesting the induction of emotional dampening in the context of daily life. Previous studies have suggested that the partial dopamine agonistic properties of aripiprazole, as opposed to the dopamine antagonistic properties of other antipsychotics, have a more favorable effect on subjectively experienced side-effects ${ }^{8,19,20}$. These studies, however, lack ecological validity, since emotional experiences were assessed retrospectively and globally using cross-sectional instruments. The current study assessed emotional states in the reality of daily life, thereby allowing examination of more subtle changes in emotional experience. Therefore, although conceptualized as a 'dopamine system stabilizer'21, 22, the current findings of emotional dampening suggest that aripiprazole may nonetheless induce behaviorally relevant inhibition of the dopamine-regulated reward system ${ }^{23,24}$. Although it is arguable that these effects may have been purely due to an increase in $D_{2}$ receptor occupancy related to administration of relatively high dosages of aripiprazole in the current study, recalculation of medication dosages in chlorpromazine equivalent terms indicated that the majority of subjects in fact received relatively lower dosages of antipsychotic when switched to aripiprazole therapy. Furthermore, as shown by Mizrahi and colleagues ${ }^{8}$, the effects of aripiprazole on subjective well-being do not appear to be mediated by $D_{2}$ receptor 
occupancy levels.

It should be noted that actions at 5-HT serotonin receptor sites have been implicated in emotion regulation in depression and schizophrenia ${ }^{25-27}$ and changes in emotional experience, therefore, may have been partly influenced by changes in 5-HT receptor occupancy as a consequence of the switch to aripiprazole treatment. However, Kapur and Seeman ${ }^{28}$ have argued that, unlike $D_{2}$ receptor modulation, the mechanism of serotonin receptor antagonism is neither necessary nor sufficient in producing 'atypical' effects, suggesting that actions at the $D_{2}$ receptor might be more closely related to emotional well-being.

It must be acknowledged that the scale and naturalistic setting of the current study, and the $54 \%$ drop-out rate call for careful interpretation of the data, and replication of the findings in larger, randomized controlled studies. Nonetheless, we argue that implementation of the Experience Sampling Method in psychopharmacological research, as previously shown by Lataster and co-workers ${ }^{4}$, can form a novel and valuable tool for untangling the working mechanisms of compounds with regard to their impact on mental states. No instance of drop-out was related to patients being unable to comply with the ESM protocol, consistent with previous studies demonstrating that ESM-assessments are not restricted to small subsamples of relatively asymptomatic schizophrenia patients ${ }^{4,5,29}$. The addition of established subjective side-effects questionnaires (e.g., SWN ${ }^{30}$; SRA ${ }^{31}$ ) may help to validate subjectively experienced side-effects in future pharmacological ESM studies. 


\section{Acknowledgements}

This work was supported by an unrestricted grant of Bristol-Myers Squibb, the Netherlands.

\section{Declaration of Interest}

Dr. M. Bak has received grant/research support from Bristol-Myers Squibb and is a member of speaker/advisory boards for Eli-Lilly, Janssen-Cilag, and Bristol-Myers Squibb. 
Table 1 | Sociodemographic characteristics of the sample at $\mathrm{T}_{0}$ ('baseline').

\begin{tabular}{|c|c|c|c|c|}
\hline Characteristic & $\begin{array}{l}\text { Patients who } \\
\text { completed } \\
\text { treatment }(n=6)\end{array}$ & $\begin{array}{c}\text { Patients who } \\
\text { dropped out }(n=7)\end{array}$ & Test-statistic & $\mathrm{p}$ \\
\hline Age (y; mean (SD)) & $\begin{array}{c}34.1(9.2) \\
\text { (ranges 24-48) }\end{array}$ & $\begin{array}{c}30.4(9.4) \\
\text { (ranges 21-44) }\end{array}$ & $-0.71^{\mathrm{a}}$ & .490 \\
\hline Gender ( $n, \%)$ & & & $0.63^{b}$ & .429 \\
\hline Male & $3(50)$ & $5(71)$ & & \\
\hline Female & $3(50)$ & $2(29)$ & & \\
\hline Level of education ( $n, \%)$ & & & $0.93^{b}$ & .335 \\
\hline Secondary education & $6(100)$ & $6(86)$ & & \\
\hline Bachelor degree & 0 & $1(14)$ & & \\
\hline Work situation (n, \%) & & & $2.03^{b}$ & .363 \\
\hline Unemployed & $1(17)$ & 0 & & \\
\hline Sheltered work & 0 & $1(14)$ & & \\
\hline Unfit for work & $5(83)$ & $6(86)$ & & \\
\hline Living situation $(n, \%)^{c}$ & & & $7.97^{b}$ & .047 \\
\hline Specialized psychiatric setting & 0 & $3(43)$ & & \\
\hline With partner / family & $1(17)$ & $1(14)$ & & \\
\hline With parents / relatives & $1(17)$ & $3(43)$ & & \\
\hline Alone & $4(67)$ & 0 & & \\
\hline BPRS total (mean (SD)) & $37.7(17.2)$ & $31.9(5.8)$ & $-0.84^{a}$ & .417 \\
\hline
\end{tabular}

a t-value (comparing group means; two-sided $p$-value presented).

b Pearson's $\chi^{2}$ (comparing categorical distributions between groups).

${ }^{c}$ Percentages do not total 100 because of rounding. 
Table 2 | Antipsychotic and concomitant medication use throughout the study (see text for details).

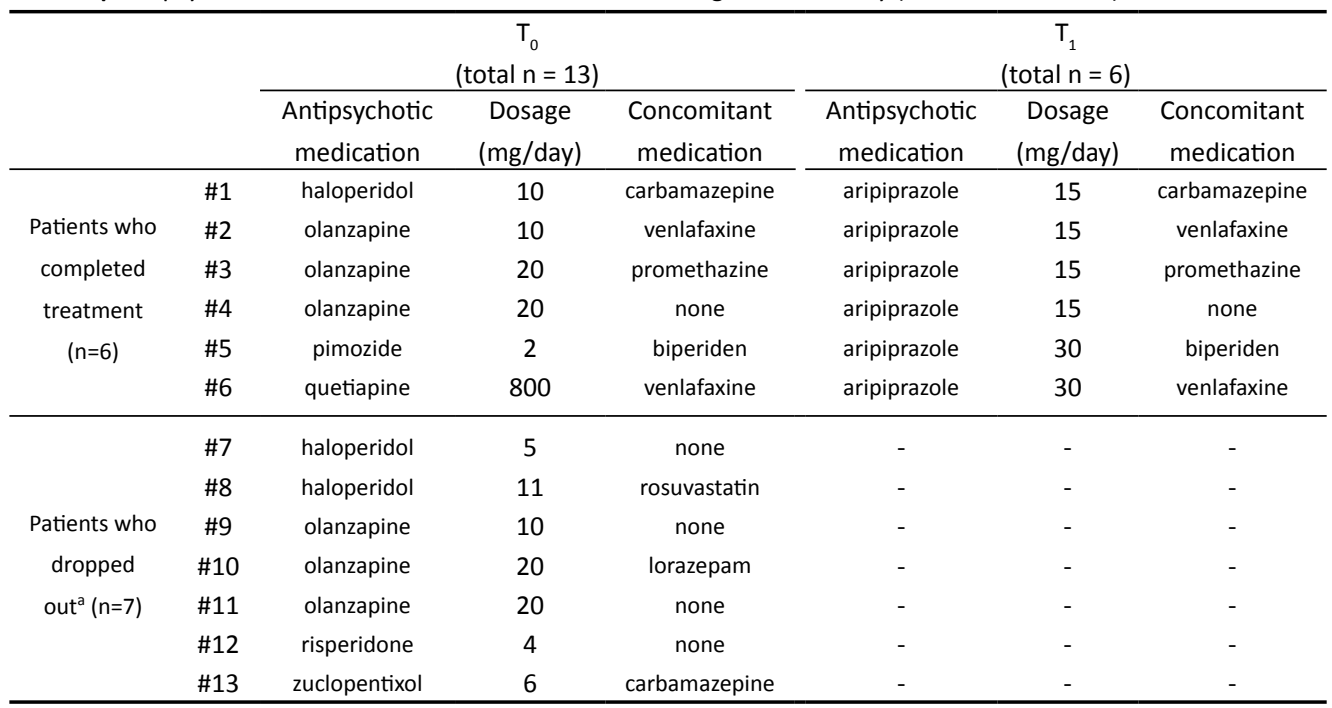

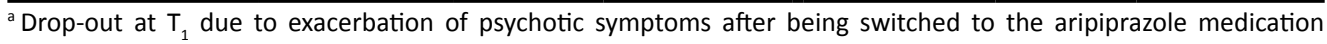
regime.

Figure 1 | Reduced experience of subjectively rated psychosis, and positive and negative affect, after 5-week treatment with the partial $D_{2}$ agonist antipsychotic aripiprazole, compared to previous antipsychotic treatment with traditional $\mathrm{D}_{2}$ antagonistic compounds.

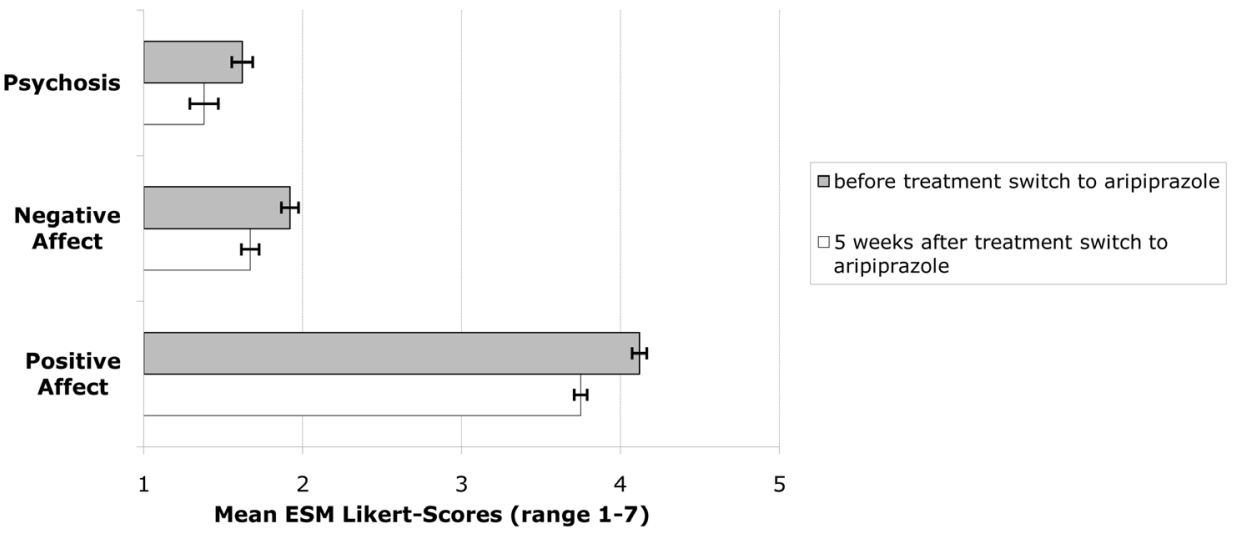




\section{References}

1. Artaloytia JF, Arango C, Lahti A, Sanz J, Pascual A, Cubero P, Prieto D, and Palomo T. Negative signs and symptoms secondary to antipsychotics: a double-blind, randomized trial of a single dose of placebo, haloperidol, and risperidone in healthy volunteers. Am J Psychiatry, 2006. 163(3): p. 488-93.

2. Carlsson A. The current status of the dopamine hypothesis of schizophrenia. Neuropsychopharmacology, 1988. 1(3): p. 179-86

3. Van Putten T, May PR, Marder SR, and Wittmann LA. Subjective response to antipsychotic drugs. Arch Gen Psychiatry, 1981. 38(2): p. 187-90.

4. Lataster J, van Os J, de Haan L, Thewissen V, Bak M, Lataster T, Lardinois M, Delespaul PA, and MyinGermeys I. Emotional experience and estimates of $D(2)$ receptor occupancy in psychotic patients treated with haloperidol, risperidone, or olanzapine: an experience sampling study. J Clin Psychiatry, 2011. 72(10): p. $1397-404$.

5. Delespaul PAEG. Assessing Schizophrenia in Daily Life. 1995, Maastricht: University Press.

6. Myin-Germeys I, Oorschot M, Collip D, Lataster J, Delespaul P, and van Os J. Experience sampling research in psychopathology: opening the black box of daily life. Psychol Med, 2009. 39(9): p. 1533-47.

7. Kim SW, Shin IS, Kim JM, Lee JH, Lee YH, Yang SJ, and Yoon JS. Effectiveness of switching to aripiprazole from atypical antipsychotics in patients with schizophrenia. Clin Neuropharmacol, 2009. 32(5): p. 243-9.

8. Mizrahi R, Mamo D, Rusjan P, Graff A, Houle S, and Kapur S. The relationship between subjective wellbeing and dopamine D2 receptors in patients treated with a dopamine partial agonist and full antagonist antipsychotics. Int J Neuropsychopharmacol, 2009. 12(5): p. 715-21.

9. The American Psychiatric Association. Diagnostic and Statistical Manual of Mental Disorders, 4th Edition, Text Revision (C) 2000, Washington DC.

10. McGuffin P, Farmer A, and Harvey I. A polydiagnostic application of operational criteria in studies of psychotic illness. Development and reliability of the OPCRIT system. Arch Gen Psychiatry, 1991. 48(8): p. 764-70.

11. Woods SW. Chlorpromazine equivalent doses for the newer atypical antipsychotics. J Clin Psychiatry, 2003. 64(6): p. 663-7.

12. Ventura J, Green, M.F., Shaner, A., Liberman, R.P. Training and quality assurance in the use of the expanded Brief Psychiatric Rating Scale: the 'drift busters'. Int J Methods Psychiatry Res, 1993. 3: p. 221-244.

13. StataCorp. Stata Statistical Software: Release 10. College Station, TX: StataCorp LP, 2007.

14. Adan-Manes J and Garcia-Parajua P. Aripiprazole in combination with other antipsychotic drugs may worsen psychosis. J Clin Pharm Ther, 2009. 34(2): p. 245-6.

15. Pae CU, Serretti A, Chiesa A, Mandelli L, Lee C, Lee C, Kim J, De Ronchi D, and Paik IH. Immediate versus gradual suspension of previous treatments during switch to aripiprazole: results of a randomized, open label 
study. Eur Neuropsychopharmacol, 2009. 19(8): p. 562-70.

16. Ramaswamy S, Vijay D, William M, Sattar SP, Praveen F, and Petty F. Aripiprazole possibly worsens psychosis. Int Clin Psychopharmacol, 2004. 19(1): p. 45-8.

17. Sparshatt A, Taylor D, Patel MX, and Kapur S. A systematic review of aripiprazole--dose, plasma concentration, receptor occupancy, and response: implications for therapeutic drug monitoring. J Clin Psychiatry, 2010. 71(11): p. 1447-56.

18. Mace S and Taylor D. Aripiprazole: dose-response relationship in schizophrenia and schizoaffective disorder. CNS Drugs, 2009. 23(9): p. 773-80.

19. Liemburg E, Aleman A, Bous J, Hollander K, and Knegtering H. An open randomized pilot trial on the differential effects of aripiprazole versus risperidone on anhedonia and subjective well-being. Pharmacopsychiatry, 2011. 44(3): p. 109-13.

20. Ohlsen RI and Pilowsky LS. The place of partial agonism in psychiatry: recent developments. JPsychopharmacol, 2005. 19(4): p. 408-13.

21. Stahl SM. Dopamine system stabilizers, aripiprazole, and the next generation of antipsychotics, part 2: illustrating their mechanism of action. J Clin Psychiatry, 2001. 62(12): p. 923-4.

22. Stahl SM. Dopamine system stabilizers, aripiprazole, and the next generation of antipsychotics, part 1 , "Goldilocks" actions at dopamine receptors. J Clin Psychiatry, 2001. 62(11): p. 841-2.

23. Berridge $\mathrm{KC}$ and Robinson TE. What is the role of dopamine in reward: hedonic impact, reward learning, or incentive salience? Brain Res Brain Res Rev, 1998. 28(3): p. 309-69.

24. Kapur S. How antipsychotics become anti-"psychotic"--from dopamine to salience to psychosis. Trends Pharmacol Sci, 2004. 25(8): p. 402-6.

25. Hedlund PB and Sutcliffe JG. Functional, molecular and pharmacological advances in 5-HT7 receptor research. Trends Pharmacol Sci, 2004. 25(9): p. 481-6.

26. Kranz GS, Kasper S, and Lanzenberger R. Reward and the serotonergic system. Neuroscience, 2010. 166(4): p. $1023-35$.

27. Meltzer HY. The role of serotonin in schizophrenia and the place of serotonin-dopamine antagonist antipsychotics. J Clin Psychopharmacol, 1995. 15(1 Suppl 1): p. 2S-3S.

28. Kapur S and Seeman P. Does fast dissociation from the dopamine $\mathrm{d}(2)$ receptor explain the action of atypical antipsychotics?: A new hypothesis. Am J Psychiatry, 2001. 158(3): p. 360-9.

29. Myin-Germeys I, Nicolson NA, and Delespaul PA. The context of delusional experiences in the daily life of patients with schizophrenia. Psychol Med, 2001. 31(3): p. 489-98.

30. Naber D. A self-rating to measure subjective effects of neuroleptic drugs, relationships to objective psychopathology, quality of life, compliance and other clinical variables. Int Clin Psychopharmacol, 1995. 10 Suppl 3: p. 133-8. 
31. Wolters HA, Knegtering R, Wiersma D, and van den Bosch RJ. Evaluation of the subjects' response to antipsychotics questionnaire. Int Clin Psychopharmacol, 2006. 21(1): p. 63-9. 
162

0
$\frac{0}{ \pm}$
$\frac{0}{0}$
$\frac{0}{5}$ 


\section{Summary and Discussion}

The pioneering work of Myin-Germeys and colleagues ${ }^{1}$ launched behavioral reactivity to daily-life stress as vulnerability marker for psychosis. Subsequent studies have established stress reactivity as a useful endophenotype for examining psychosocial ${ }^{2-7}$, physiological ${ }^{8,9}$, and genetic $^{10-12}$ determinants of psychosis. Nonetheless, these studies have left several questions unanswered and raised many new ones. At the unavoidable risk of generating new uncertainties, the work presented in this thesis pursued at answering some of those questions, ultimately aiming at expanding our understanding of the putative link between stress and psychosis.

\section{Sensitization: cause and effect}

The research presented in the first part of this thesis aimed at examining causality of the behavioral sensitization mechanism ${ }^{13-15}$, suggested to underlie observations of increased sensitivity to daily-life stress in psychotic patients reporting a history of adversity ${ }^{2,5}$. Exposure to adversity is hypothesized to have rendered these individuals more stress-sensitive, reacting progressively more psychotic in response to stress ${ }^{2,13,14}$, and eventually crossing the clinical threshold for psychotic disorder. This interpretation, however, is hampered by the cross-sectional design employed by the preponderance of studies on which the hypothesis is based; experience and reports of adversity cannot be excluded to be uncontaminated by the presence of psychotic symptoms or illness ${ }^{16}$. Although several methodologically strong prospective studies underline a definite role for stress and adversity in the pathogenesis of psychosis $^{17-19}$, the possibility of interacting events in the stress-pathogen of psychosis has not been tested prospectively. The study presented in Chapter 2, therefore, used a longitudinal prospective design ( $n=3021)$ to examine whether the association between recent adversity and psychosis is moderated by exposure to previous adverse events, thereby providing the necessary but lacking causal perspective on the behavioral sensitization pathway to psychosis. 
Results from this study showed that experiences of early and recent adversity (i) were strongly correlated, and (ii) interacted additively in increasing the risk of psychosis. In addition, the findings were suggestive of a threshold effect, in that non-additivity between early and recent adversity in the model of psychotic symptoms was only observed at the level of severe recent adversity ( $\geq 10$ recent adverse events). Importantly, the design of the study minimized the possibility of reverse causality, (re)active gene-environment correlation and reporting bias due to presence of psychotic symptoms or illness, and results were not reducible to urbanicity or cannabis use, other well established risk factors for psychosis ${ }^{20}$. Nonetheless, findings do not rule out the possibility of passive gene-environment correlation, i.e., adversity representing a marker of genetic risk for psychosis, rather than being a causative factor in the development of psychotic symptoms. This is unlikely, however, given that recent work has shown the association between trauma and psychotic symptoms to be equally strong across varying levels of genetic risk for psychosis ${ }^{21}$.

In line with the behavioral sensitization hypothesis and observations of increased sensitivity to daily-life stress in psychotic patients with a history of adversity ${ }^{2,5}$, exposure to early adversity enhanced sensitivity to the psychotogenic effects of recent adverse events (environment $\boldsymbol{x}$ environment interaction). Similar findings were reported in a recent study from Galletly and colleagues ${ }^{22}$, showing lifetime exposure to multiple adverse events, but not a single major trauma in childhood, to be associated with increased risk of later psychosis. Non-additivity between early and recent adversity, however, was not tested in their study. The findings from the study presented in Chapter 2, furthermore, suggest that exposure to early adversity increases risk of exposure to subsequent adverse events (environmentenvironment correlation) which in turn increases risk for psychotic outcome.

Taken together, the work described in Chapter $\mathbf{2}$ of this thesis establishes causality of the behavioral sensitization model and, additionally, suggests that adverse events early in life predispose individuals to more frequently experience psychotogenic adversity later in life. These findings may provide, in addition to the issue of methodological inconsistency, a possible explanation for the conflicting results from previous studies on the association between life events and psychosis ${ }^{23}$. Since the current study found an association between recent adversity and psychosis to be moderated by early adversity, lack of attention to early life adversity in these studies may have contributed, in part, to imprecise results. 


\section{Back to the future: diathesis-stress revisited}

The diathesis-stress model ${ }^{24-26}$ states that psychotic symptoms will emerge whenever a threshold of stressors exceeds an individual's vulnerability level. Although classic publications ${ }^{27,} 28$ conceptualize schizophrenia as a genetic vulnerability that converts into disease through environmental stress, the model advanced by Zubin and Spring ${ }^{25}$ acknowledged, alongside 'inborn' (i.e., genetic) vulnerability, the possibility of 'acquired' (i.e., environmental) vulnerability. Nonetheless, encouraged by the categorical approach to psychopathology and the hunt for schizophrenia genes, the view of environmental effects acting as precipitants against a background of genetic vulnerability has continued to dominate the field. Although schizophrenia, indeed, appears to run in families largely for genetic reasons ${ }^{29}, 30$, findings from the study presented in Chapter $\mathbf{2}$ support the notion of 'acquired' vulnerability"25, by implying that early environmental stress can also occasion enduring liabilities. Accordingly, the timing of the stressor may determine its position in the diathesis stress equation, i.e., the experience of psychosocial stress early in life may contribute to the diathesis for psychosis by accentuating the vulnerability state ${ }^{31,32}$, whereas the cumulative impact of stressors occurring later in life may subsequently trigger psychotic expression $^{32}$. In addition, the strong correlation between early and recent adversity that was observed in the study described in Chapter $\mathbf{2}$ indicates that both environment-environment correlation and environment $\boldsymbol{x}$ environment interaction may underlie the diathesis.

Although molecular geneticists have argued that environmental stress is common to many disorders and, as such, may not help in predicting the specific trajectory to psychotic disorder (e.g., Rosentha ${ }^{28}$ ), molecular genetic studies are now also demonstrating that there is more overlap between the susceptibility genes for, e.g., schizophrenia and bipolar disorder than previously suspected ${ }^{33}$. Moreover, although the contribution of environmental stressors (e.g. childhood trauma) to psychosis risk has been convincingly replicated ${ }^{17-19}$, the last two decades of genetic research have provided several candidate schizophrenia genes but failed to consistently replicate them across or even within populations ${ }^{33}$. Therefore, as suggested by van Os and co-workers ${ }^{20}$ and underlined by the current findings, heritability may be of limited explanatory power unless viewed in the context of interaction with environmental effects. 


\section{II}

\section{Moving forward: stress and prefrontal dopamine}

Despite the apparent link between stress and psychosis, and suggested shared involvement of (abnormal) prefrontal dopaminergic neurotransmission ${ }^{34-37}$, the pertinent question of prefrontal dopamine involvement in the stress reactivity endophenotype of psychosis has remained unanswered. Rodents with prefrontal cortex lesions display increased amphetamine-induced striatal dopamine release $\mathrm{e}^{38,39}$, mirroring hyperreactivity of the striatal dopamine system of psychotic patients in response to amphetamine ${ }^{40}$. Similarly, stress-induced dopamine release in mesolimbic brain regions is increased following depletion of dopamine in the rat prefrontal cortex ${ }^{41-43}$. These findings suggest mesolimbic dopaminergic neurotransmission to be attenuated by prefrontal dopamine release, given disruption of prefrontal control results in increased mesolimbic dopamine reactivity to stress and amphetamine, both instigators of psychotic symptoms ${ }^{1,44}$.

Human studies investigating stress-induced changes in dopamine levels, however, have focused solely on striatal dopamine transmission ${ }^{36,45,46}$. As a result, the putative role of prefrontal dopamine in stress-regulation, and possible impairment thereof in psychosis, remain unclear. The second aim of the work presented in this thesis was, therefore, to (i) develop a study paradigm that enables investigation of in vivo dopamine release in human prefrontal cortex under stressful circumstances, and to (ii) investigate whether psychosocial stress is associated with in vivo dopamine release in human prefrontal cortex. In Chapter 3, a study is presented that used the novel and highly selective dopamine $D_{2 / 3}$ PET radioligand $\left[{ }^{18} \mathrm{~F}\right]$ fallypride ${ }^{47-52}$ to detect in vivo prefrontal dopamine release in healthy human subjects $(n=12)$ in response to a laboratory stressor that attempted to emulate real-world social interactions (Montreal Imaging Stress Task; MIST) ${ }^{36}$. The psychosocial stress challenge succeeded in eliciting stress not only at a physiological level (cortisol secretion), but also at the level of subjective experience, and induced detectable amounts of dopamine release throughout the prefrontal cortex. Moreover, dopaminergic activity in bilateral ventromedial prefrontal cortex (VmPFC) was positively associated with subjectively rated experiences of psychosocial stress.

The findings from the study presented in Chapter 3 (i) provide validation for the use of $\left[{ }^{18} \mathrm{~F}\right]$ fallypride $\mathrm{PET}$ to detect in vivo dopamine neuromodulation in extrastriatal (cortical) 
brain regions in response to a psychological challenge; (ii) support the use of the MIST paradigm to investigate neurobiological (dopamine) stress systems; (iii) confirm (ventromedial) prefrontal cortex dopamine involvement in stress processing, thereby underlining that the dynamics of the dopamine-related stress response cannot be interpreted by focusing on mesolimbic brain regions alone.

\section{Alterations in stress-induced prefrontal dopamine firing - vulnerability marker for psychosis?}

The finding that healthy subjects respond to a mild psychosocial stressor with increased levels of endogenous dopamine in the prefrontal cortex (Chapter 3), whereas a similar stressor in previous studies did not necessarily induce dopamine release in mesolimbic brain regions $^{36,45,46}$, supports the hypothesis that prefrontal dopamine transmission attenuates stress-induced mesolimbic dopamine release ${ }^{41-43,53}$. A possible function of this mechanism could be to protect the organism against the adverse consequences of stress on the brain, a loss of control of the prefrontal dopamine system rendering the mesolimbic dopaminergic system hypersensitive to stress. This is supported by the observation that psychotic patients, displaying increased sensitivity to stress ${ }^{1,4}$, are characterized by 'hypofrontality' (i.e., declined prefrontal neural processing $)^{54-57}$, and increased mesolimbic dopamine transmission ${ }^{40,44,58-67}$. However, although Myin-Germeys and colleagues ${ }^{8}$ reported psychotic reactivity to daily-life stress to be associated with - crudely estimated - hyperresponsivity of the dopamine system to metabolic stress in first-degree relatives of psychotic patients, direct in vivo evidence for an impaired attenuating function of the prefrontal dopamine system in psychosis is currently lacking, and, moreover, does not pertain to the context of stress reactivity. Therefore, as described in Chapter 4, we used the $\left[{ }^{18} \mathrm{~F}\right]$ fallypride PET stress paradigm that was developed and validated previously (see Chapter 3 ) to examine, in a sample of healthy first-degree relatives of patients with a psychotic disorder $(n=14)$ and control subjects $(n=10)$, how the prefrontal dopamine stress-response pertains to the stress reactivity endophenotype of psychosis.

Results from the study revealed that, whereas control subjects - in consonance with the findings presented in Chapter $\mathbf{3}$ - displayed positive associations between subjectively rated experiences of task-induced psychosocial stress and dopaminergic activity in bilateral ventromedial prefrontal cortex (VmPFC), first-degree relatives, conversely, displayed 
negative associations between task-induced subjective experiences of psychosocial stress and vmPFC cortex dopamine activity. Moreover, although control subjects and first-degree relatives reacted equally psychotic to the laboratory stress challenge, increased psychotic reactivity to stress was associated with reduced prefrontal dopamine reactivity in firstdegree relatives, whereas no such association was observed in controls. Presuming impaired attenuation of the prefrontal dopamine system to be reflected by reduced prefrontal dopamine release in response to stress, and the experience of psychotic occurrences to be associated with increased mesolimbic dopamine firing ${ }^{44}$, these findings support a loss of control of the prefrontal dopamine system over stress-induced mesolimbic dopamine activity to underlie the stress reactivity endophenotype of psychosis. In order to clarify the interacting contributions of prefrontal and mesolimbic dopamine neurons in the psychotic stress response, however, future studies are needed that simultaneously monitor stressinduced prefrontal and mesolimbic dopamine activity in patients diagnosed with a psychotic disorder.

\section{Boulevard of broken dreams - facing the walls of sensitization alley}

Stress responsiveness of the dopamine system changes dramatically during development, stress-mediated changes in the dopamine system displaying a wider magnitude of effect during development than during adulthood ${ }^{68,69}$. Moreover, the impact of developmental stress may be incorporated into the maturation of anatomy and function of the dopamine system, thereby determining set points for adult function of this system ${ }^{70}$. Childhood stress or adversity, thereby, can potentially have lasting effects on the adult dopamine stress system ${ }^{69}$. The system may become sensitized to stress ${ }^{13,15}$ which may consequently increase the likelihood of stress-induced psychotic symptoms or illness. The findings reported in Chapter $\mathbf{2}$ of this thesis support the notion that exposure to stressful events early in life enhances sensitivity to the psychotogenic effects of later occurring stress, fitting sensitization theory ${ }^{13,15}$ and previous observations of increased psychotic reactivity to daily-life stress in psychotic patients reporting a history of adversity ${ }^{2}$. In addition, the studies presented in Chapters $\mathbf{3}$ and $\mathbf{4}$ confirm previously ${ }^{36,37,71}$ suggested involvement of prefrontal dopaminergic neurotransmission in the human stress response, and aberrations therein in individuals vulnerable to psychosis $^{8}$. More specifically, the findings suggest that psychosis may involve a loss of control of the prefrontal dopamine system over stress- 
induced mesolimbic dopamine activity, by showing that increased psychotic reactions to a laboratory stressor are associated with reduced in vivo prefrontal dopamine activity in individuals at familial risk for psychosis.

In animals, excessive stimulation of prefrontal dopamine neurons (e.g., by stress) temporarily puts the prefrontal cortex 'off-line' ${ }^{72,73}$, disrupting the attenuating control over subcortical brain regions, thereby rendering these regions hyperreactive to the environment and enabling them to dominate behavior. This mechanism may have survival value, since it enables the organism to automatically switch from complex, slow, prefrontally regulated behaviors to instinctive, fast behaviors (e.g., 'fight'-'flight' $)^{74}$ guided by these subcortical brain regions when exposed to threatful, hence stressful situations ${ }^{75}$. Incorrect tuning of this mechanism, however, may render the organism hyper- or hyporesponsive to stress. The findings presented in Chapter $\mathbf{4}$ of this thesis suggest that individuals vulnerable to psychosis may be prone to stress-induced 'overload' of the prefrontal dopamine system, thereby possibly losing attenuating control over mesolimbic dopamine regions and increasing the likelihood of psychotic reactions to stress. In addition, observations of increased stressinduced mesolimbic dopamine signaling in animals behaviorally sensitized to stress ${ }^{72,76-78}$, and in individuals exposed to early life adversity ${ }^{36}$ suggest that repeated exposure to stress may additionally induce or accentuate a shift in balance of frontal-subcortical dopamine stress signaling toward increased stress reactivity of mesolimbic dopamine neurons.

Taken together, findings from Chapters $\mathbf{2}$ to $\mathbf{4}$ of this thesis suggest that (innate) impaired attenuation of stress-induced mesolimbic dopamine firing by the prefrontal dopamine system, possibly mediated by repeated exposure to environmental stress, may represent an important vulnerability mechanism for psychosis (see Figure 1). Future challenges lie in further establishing the role of stress in disease causation, and illuminating the interplay between prefrontal and mesolimbic dopamine signaling therein.

\section{Stress and the psychotic brain: interacting contributions?}

There is evidence of reciprocal and augmenting interactions between dopamine neurons and the hypothalamic-pituitary-adrenal (HPA) axis ${ }^{79}$. Hyperactivity of the mesolimbic dopamine system, mediated by the experience of early life stress ${ }^{36,80}$, may enhance HPA-activation to stress, the resulting hormonal response, in turn, augmenting dopamine release in the already hyperactive mesolimbic dopamine system. Given the proposed mediating role of 
Figure 1 | Proposed pathogenic mechanisms involved in the aetiology of psychosis, integrating findings from the studies presented in Chapters $\mathbf{2}$ to $\mathbf{4}$ of the current thesis. (Innate) impaired attenuation of stress-induced mesolimbic dopamine firing by the prefrontal (PFC) dopamine system, possibly mediated by (repeated) exposure to environmental stress, increases stress-responsiveness of mesolimbic dopamine neurons and thereby likelihood of psychosis through 'aberrant salience' (i.e., psychotic reactions) in response to stress.

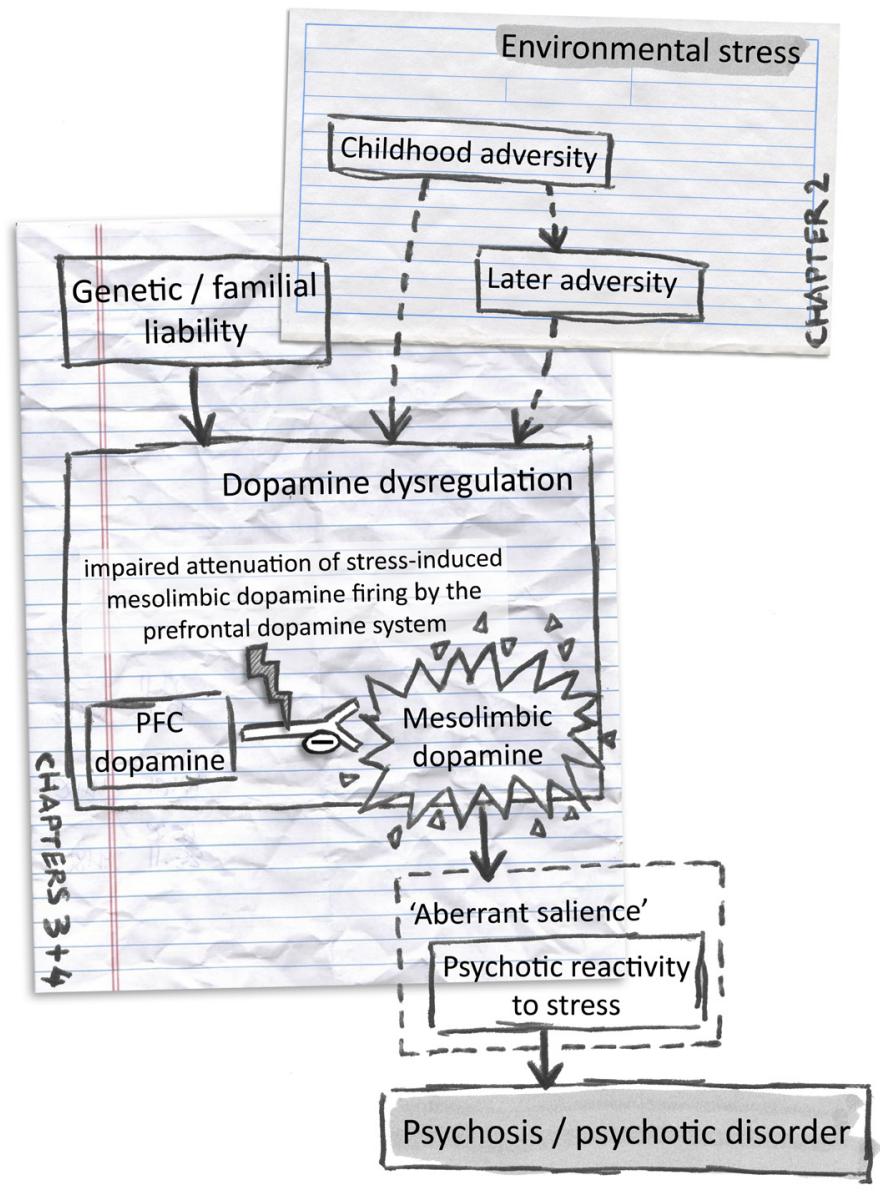

dopamine in salience attribution ${ }^{81}$, a hyperactive state may cause 'aberrant salience' (the assignment of salience to otherwise unimportant stimuli), and fuel psychotic experiences, underlined by the observation of delusions and hallucinations being directly linked to hyperactivity of striatal dopamine receptors ${ }^{44}$. As reviewed by Moghaddam ${ }^{82}$, stressinduced activation of the HPA-axis and dopamine system appears, in turn, to be modulated by prefrontal glutamate neurotransmission. Abnormal stress-activated dopamine 
neurotransmission in prefrontal cortex or subcortical regions may, therefore, be secondary to cortical glutamatergic dysregulation. Conversely, cortical dopamine deficiency appears to disrupt the activity of prefrontal glutamatergic efferents to the ventral tegmental area and cause an exaggerated striatal dopamine response to stress, suggesting the attenuating function of prefrontal dopamine to be mediated by cortical glutamate neurotransmission ${ }^{83}$, 84.

It appears unlikely that a loss of control of the prefrontal dopamine system over subcortical dopaminergic neurotransmission can solely and exclusively explain the diverse range of affective, psychotic and neurotic symptoms observed across the spectrum of stresspathology, particularly given the broad variety and, to some extent, paradoxality of dopamine anomalies observed across various stress-related disorders ${ }^{34,85-88}$. Rather, a range of complex and diverse neural (patho)dynamics, involving multiple interacting neurotransmitter systems ${ }^{82,85,87-92}$ that are functionally shaped by unique genetic, neurodevelopmental and social environmental factors, direct the individual towards a specific behavioral phenotype. Future imaging studies are challenged with the daunting task of unraveling the neurochemical dynamics of stress processing in healthy humans and psychopathological populations that are characterized by disturbances in stress regulation. Nonetheless, findings from the studies presented in Chapters $\mathbf{3}$ and $\mathbf{4}$ of this thesis seem to suggest that impaired attenuation of mesolimbic dopamine by the prefrontal dopamine system may represent an important stress-vulnerability mechanism for psychosis.

III

\section{To quit or not to quit: the patient's perspective on medication adherence}

The primary form of treatment for psychosis is pharmacological therapy. However, medication compliance forms a cardinal difficulty in the ongoing treatment of psychotic disorders - most patients will discontinue medication use within the first year of treatment ${ }^{93-}$ 96. Given the overwhelming evidence for medication non-adherence being the most important risk factor for psychotic relapse ${ }^{97}$, it is paramount to increase our understanding of the mechanisms involved in discontinuance of psychopharmacotherapy.

Blockade of the dopamine $\left(D_{2}\right)$ receptor is necessary for antipsychotic action ${ }^{44,98-100}$ but induces a range of burdensome effects, extrapyramidal symptoms (EPS; i.e., drug-induced 
movement disorders) ${ }^{101}$ representing the best documented source of adversity. As a consequence, medication non-adherence has long been viewed in the light of such motor disturbances, in addition to a lack of clinical, i.e., antipsychotic, effect ${ }^{102}$. Recent studies, however, have identified subjective well-being as key determinant of medication compliance in schizophrenia ${ }^{95,97,103-106}$, patients and their psychiatrists displaying striking differences with regard to their perspectives on treatment satisfaction ${ }^{107}$.

Although the patient's subjective response to antipsychotic medication represents an important and independent outcome measure, relevant for adherence and recovery ${ }^{103-105}$, 108 , it has remained poorly incorporated in clinical pharmacology. The studies presented in Chapters 5 and 6, therefore, aimed at elucidating the working mechanisms of antipsychotic compounds with regard to their impact on subjective mental states, adding ecological validity to previous evaluations of neuroleptic-induced subjective complaints ${ }^{103-108}$ by monitoring emotional well-being and psychotic symptoms in daily-life reality with the aid of the Experience Sampling Method (ESM) ${ }^{109,110 .}$

\section{Enjoying life is all about loosening up: $D_{2}$ receptor blockade and emotional well-being}

Antipsychotic medication reduces psychotic symptoms through blockade of the dopamine $D_{2}$ receptor ${ }^{98-100}$. However, although all antipsychotic drugs display some degree of $D_{2}$ receptor antagonism, the specific mechanism of occupancy is determined by the chemical profile of the individual agent ${ }^{111}$. That is, dopamine $D_{2}$ antagonists, although all blocking the $D_{2}$ receptor, differ in how strongly they compete with dopamine for occupancy of the $\mathrm{D}_{2}$ receptor ${ }^{112}$. Given that the dopaminergic system may also mediate the experience of motivational salience or reward ${ }^{113,114}$, these differences in binding potential could result in differential effects on emotional well-being, supported by the observation that treatment with the more 'tight' binding agents haloperidol and risperidone is associated with more negative subjective medication effects than treatment with the more 'loose' or 'rapid offset' binding agent olanzapine $^{115}$. The large naturalistic study described in Chapter $\mathbf{5}$ of this thesis aimed at adding ecological validity to these findings, by investigating whether tight (haloperidol and risperidone) and loose (olanzapine) binding $D_{2}$ receptor antagonists differentially affected emotional experience in the daily life of 109 patients with a diagnosis of schizophrenia, taking into account overall levels of $D_{2}$ receptor occupancy. 
Results showed that overall levels of positive and negative affect, experienced in the realm of daily life, did not differ between tight and loose binding agent users. However, for tight binding agents (haloperidol, risperidone), increasing levels of $D_{2}$ receptor occupancy were found to be associated with deteriorating emotional experience in the natural flow of daily life, in line with previous laboratory findings ${ }^{116-118}$. Contrarily, no effect of $D_{2}$ occupancy levels on experience of emotions was found in looser binding agent (olanzapine) users, indicating that loose and tight binding agents display differential effects on $D_{2}$ occupancy related experience of emotions. As such, given that tight and loose binding agents showed overlap in terms of overall $D_{2}$ receptor occupancy, not the overall level of emotional ill-being but, rather, the distribution of emotional experience as a function of $D_{2}$ receptor occupancy distinguishes relatively tight from looser binding agent users.

Blockade of the $D_{2}$ receptor by antipsychotics is considered to attenuate the motivational salience of psychotic symptoms ${ }^{114}$, but also the motivational salience of other experiences and thoughts and may, therefore, equally affect the dopaminergic reward system ${ }^{113}$. The more loose binding mechanism of olanzapine, as opposed to the stringent binding mechanism of haloperidol and risperidone, allows more brief temporal binding of endogenous dopamine to the occupied $D_{2}$ receptor. Endogenous dopamine released in response to natural rewards might, therefore, be more capable of impacting on the dopaminergic motivation and reward system in loose binding agent users compared to tight binding agent users ${ }^{115}$. Whereas looser binding agents, through their mechanism of fast dissociation from the $\mathrm{D}_{2}$ receptor, may therefore be able to maintain a certain level of well-being, even at high doses of the drug, the insensitivity to reward-related endogenous dopamine release associated with more tight binding agents may increasingly affect motivation and emotional well-being as dosage increases. Kapur and Seeman ${ }^{119}$ have even argued that this very mechanism of dissociation from the $D_{2}$ receptor, rather than the affinity at serotonine or other receptor sites, determines a drug's atypicality. Importantly, changes in emotional experience, in the sample discussed in Chapter 5, already occurred in response to relatively low levels of $D_{2}$ receptor occupancy and might, therefore, act as a more sensitive and earlier indicator of adversity than the occurrence of EPS above $78 \% D_{2}$ receptor occupancy ${ }^{120}$. 


\section{Aripiprazole - a new dawn in schizophrenia treatment?}

As stated previously, both typical (first-generation) and atypical (second generation) neuroleptics achieve their antipsychotic effects through blockade of the dopamine $D_{2}$ receptor. Aripiprazole differs from all antipsychotics on the market, by exerting its effects through dopamine $D_{2}$ partial agonism. Given that a partial agonist displays agonistic or antagonistic action, depending on the given concentration of a specific neurotransmitter (i.e., at low dopamine levels a $D_{2}$ partial agonist will stimulate dopamine $D_{2}$ receptors, whereas at high dopamine levels it will inhibit dopamine $D_{2}$ receptors) ${ }^{121}$, aripiprazole holds promise as a 'dopamine system stabilizer'122, 123. That is, rather than 'shutting down' the dopamine system, the partial agonistic properties of aripiprazole may stabilize dopamine activity in mesolimbic, -cortical and extrapyramidal pathways, thereby potentially reducing positive symptoms while minimizing motor and motivational or emotional side-effects.

Indeed, in addition to displaying a low propensity to induce EPS ${ }^{124}$, several studies have shown aripiprazole to be as effective as haloperidol and risperidone in reducing positive symptoms, while superior to haloperidol for improving negative and depressive symptoms ${ }^{122,}$ 123, 125-127. Moreover, despite very high levels of $D_{2}$ occupancy, aripiprazole treatment has been associated with better scores on the Subjective Well-being under Neuroleptics (SWN) scale compared to traditional $D_{2}$ antagonist antipsychotics ${ }^{128}$, indicative of a favorable subjective side-effect profile. The study described in Chapter 6, again, aimed at adding ecological validity to these findings by monitoring the subjective effects of gradually switching from treatment with traditional dopamine $D_{2}$ antagonist antipsychotics to treatment with the partial dopamine agonist aripiprazole on emotional well-being, in the daily life of 13 treatment-resistant patients with a diagnosis of schizophrenia.

Results showed, first, that more than half of all patients included in the study experienced exacerbation of psychotic symptoms after being switched to the aripiprazole medication regime, a phenomenon that has been described in other reports ${ }^{129-132}$. As suggested by Adan-Manes and Garcia-Parajua ${ }^{129}$, chronic administration of dopamine antagonists, in these patients, may have induced hypersensitivity to the agonistic effects of aripiprazole. Given that chronic $D_{2}$ receptor blockade by dopamine antagonistic neuroleptics may elevate $D_{2}$ receptor numbers ${ }^{133-137}$, and aripiprazole's agonistic effects are positively associated with $D_{2}$ receptor availability ${ }^{125}$, the combination of a hypodopaminergic state and increased $D_{2}$ receptor availability, in these patients, may have temporarily augmented dopaminergic activity, thereby worsening psychotic symptoms. 
It should be pointed out that akathisia, occurring in response to aripiprazole treatment ${ }^{138}$ and antipsychotic treatment in general, is frequently confused with other conditions ${ }^{139}$ and akathisia-related feelings of agitation or restlessness ${ }^{139}$, commonly reported by aripiprazoletreated patients ${ }^{124}$, may have been misinterpreted as worsening of psychosis either by the clinician or by the patient himself. Either way, the findings presented in Chapter 6 underline the importance of a gradual and well-monitored switch program when considering aripiprazole treatment ${ }^{140}$, and may even argue against administration of aripiprazole in treatment-resistant patients chronically medicated with traditional dopamine antagonists. Second, switching to aripiprazole treatment, when effective in terms of objectively and subjectively rated positive symptom reduction, was accompanied by decreased feelings of negative affect in daily life, possibly accounting for the drug's previously reported antidepressant-like effects ${ }^{141}{ }^{142}$. However, in addition to a reduction in negative affect, patients switched to aripiprazole experienced decreased feelings of positive affect, suggestive of a general state of emotional dampening, possibly related to inhibition of the dopamine-regulated reward system ${ }^{113,114}$.

Taken together, although theoretically a 'dopamine system stabilizer'122, 123, ecologically valid findings from the naturalistic study described in Chapter 6 do not necessarily support the promised "Goldilocks"123, i.e., 'just right' effect of aripiprazole on the regulation of dopaminergic tone in patients with a diagnosis of schizophrenia. That said, interpretation of the results is considerably hampered by the study's small scale and $54 \%$ drop-out rate. A growing body of literature seems to suggest that aripiprazole treatment is, in fact, well-tolerable and effective against the positive, negative, and cognitive symptoms of schizophrenia (see Stip and Tourjman ${ }^{143}$ for review), although data on treatment-resistant schizophrenia are currently scarce. Given the serious adverse effects (e.g., seizures ${ }^{144}$, myocarditis ${ }^{145}$ and agranulocytosis ${ }^{146}$ ) associated with clozapine treatment, the current drug of last resort for treatment-resistant schizophrenia ${ }^{140}$, objective and subjective effects and tolerability of alternative treatment options such as aripiprazole demand attention in future research.

In summary, the studies described in Chapters $\mathbf{5}$ and $\mathbf{6}$ of this thesis underline that implementation of the Experience Sampling Method in clinical pharmacology, as previously shown ${ }^{147-150}$ can form a novel and valuable tool for untangling the working mechanisms of compounds with regard to their impact on mental states. 


\title{
IV
}

\section{Today's science - tomorrow's practice: clinical implications}

\author{
"...schizophrenia, it feels like it's taken over me, and who I am as a person..." \\ (ual www.schizophreniadiaries.com)
}

Psychotic disorders remain among the most burdensome and intangible mental illnesses worldwide, dramatically affecting all aspects of human thought, emotion, and expression. There is no cure for chronic psychotic disorders such as schizophrenia. Receiving a diagnosis of schizophrenia, however, does not necessarily imply a life-sentence of ever-worsening symptoms and hospitalizations. Similar to a chronic medical condition like diabetes, schizophrenia can be treated and managed with proper medication and supportive therapies. Many patients with a diagnosis of schizophrenia are able to live and work independently, build satisfying relationships, and enjoy a meaningful life. Nevertheless, facing the daily terror of obscure forces, strange voices, and feelings of not being understood can make living with schizophrenia a lifelong battle, posing multiple challenges for patients, their loved ones, and mental health professionals.

"...All children have to be deceived if they are to grow up without trauna..."

(Kazuo Ishiguro)

As with many mental disorders, the causes of psychosis are poorly understood, although gene-environment interplay is suggested to play a central role in the aetiology of psychotic disorders ${ }^{20}$. The work presented in Chapter $\mathbf{2}$ of this thesis focused on the psychosocial environment, and supports evidence from previous studies ${ }^{17-19}$ suggesting that stressful or adverse psychosocial experiences, particularly repeated or cumulative traumata, are linked to the development of psychosis.

The apparent congruence between the form and content of psychotic symptoms and the nature of traumatic experiences suggests a causal link ${ }^{151-153}$, i.e., psychosis emerging as a reaction to trauma ${ }^{154,155}$. Alternatively, however, psychotic symptoms may be viewed as 
being strongly related to the patient's developmental history, and if this contains traumata, the patient will incorporate these in the formation of explanations for anomalous experiences ${ }^{155}$. Nonetheless, it has been suggested that the vivid flashbacks experienced by patients with Post Traumatic Stress Disorder (PTSD) can go on to develop into the hallucinations associated with psychosis ${ }^{156,157}$. Furthermore, constant reliving of traumatic events through intrusive, vivid memories may instigate delusional beliefs and paranoid thoughts. Helping patients understand that some of their hallucinations and delusions are memory-based may increase coping ability and hence lessen the amount of distress these symptoms cause. Clinicians are often concerned, however, that PTSD-tailored therapies (e.g., Prolonged Exposure Therapy ${ }^{158}$; Stress-Inoculation Training ${ }^{159}$; Cognitive-Processing Therapy ${ }^{160}$; Eye Movement Desensitization and Reprocessing ${ }^{161}$ ), which are largely centered around 'reliving the trauma', may be detrimental and exacerbate symptoms in psychotic patients.

Moreover, despite high reciprocal occurrence of secondary psychosis in PTSD and PTSD in primary psychotic disorder, clinicians often neglect or fail to spot psychotic symptoms in patients with PTSD or, conversely, fail to consider a diagnosis of PTSD in patients recently recovered from a psychotic episode ${ }^{162}$. The latter, in part, attributable to clinician concerns that patients with psychotic distortions are not capable of rendering accurate or reliable trauma histories ${ }^{162}$. Consequently, patients exhibiting psychotic and PTSD symptoms are likely to be treated for either psychosis or PTSD alone. Mental health professionals and researchers are currently discussing the existence of a distinct type of psychosis that is trauma-induced, considering a separate diagnosis of 'post traumatic stress disorder with secondary psychotic features' that may advance the development of new treatments specifically meeting the needs of this patient group ${ }^{157}$.

"...It's not stress that kills us, it is our reaction to it..."

(Hans Selye)

The observation that patients with a psychotic disorder react to minor daily stressors with increased intensity of psychotic experiences ${ }^{1,4}$ possibly holds implications for treatment of the disorder. First, it underlines the importance of developing diagnostic tools that can be used to map the stress reactivity of individual patients (e.g., ESM) ${ }^{109,110}$. Second, it implies that these patients might benefit from stress-reduction programs ${ }^{6,163}$. Family 
intervention programs, employing cognitive behavioral techniques and problem solving and communication trainings, aim at enhancing the stress coping ability within a patient's social surroundings, and have been shown effective in terms of relapse prevention, hospitalization, treatment adherence, symptom reduction, and social functioning ${ }^{164-167}$.

Alternatively, individual patient intervention programs may aim at tackling the stress reactivity of the patient. Relaxation- and distraction-techniques, often imbedded within cognitive behavioral therapy ${ }^{168}$, have proven effective in reducing stress ${ }^{169-172}$ and improving well-being in chronic schizophrenia patients, although not necessarily in first-episode patients $^{173}$. In addition, an innovative and promising ESM-based electronic monitoring and coaching system (PsyMate $\left.{ }^{\circledR}\right)^{174}$ is currently being launched, offering the possibility to provide patients with real-time feedback on coping behaviors in the context of daily life. Finally, treatment protocols for other stress-related conditions or disorders (e.g., burnout, PTSD, Borderline Personality Disorder) may provide starting points for the development of new therapeutic interventions for psychotic disorders.

The findings presented in Chapter $\mathbf{4}$ of the current thesis support a loss of control of the prefrontal dopamine system over stress-induced mesolimbic dopamine activity as possible neurobiological counterpart of previously observed ${ }^{1,4}$ psychotic reactions to stress in the daily life of patients with a diagnosis of psychotic disorder. Regional disbalance of the dopamine stress response in psychosis - i.e., hyporeactivity of prefrontal dopamine neurons versus hyperreactivity of mesolimbic dopamine neurons - suggests that nonspecific dampening of the dopamine system will not achieve optimal therapeutic effects. In line with this view, pharmacological MRI studies (PhMRI) have found antipsychotic drugs that simultaneously enhance prefrontal brain activity while regulating, i.e., reducing, striatal functioning to display superior clinical efficacy in comparison to traditional dopamine blockers ${ }^{175}$. New in vivo imaging studies are needed, however, to elucidate how these findings relate to dopamine function.

"...Antipsychotics even take the fun out of alcohol..."

(ual www.health-foruns.com)

Although antipsychotic drugs have greatly improved the outlook for individual patients since their availability in the mid-1950's ${ }^{176-181}$, patient adherence to prescribed antipsychotic medication is often dismal, greatly concerning clinicians, family members, and others 
involved ${ }^{93-96}$. The 'health belief model'182, originally advanced to elucidate adherence to vaccinations and preventive health care in general, may provide a helpful perspective on treatment adherence in patients with a psychotic disorder ${ }^{183}$. According to this model ${ }^{182}$, treatment adherence is determined by the patient's assessment of the perceived benefits of treatment and risks of illness versus the costs of treatment (e.g., adverse effects; weight gain or other inconveniences; emotional or cognitive blunting; financial expense). Accordingly, in order to achieve optimal adherence, clinicians should attempt to understand the patient's treatment goals, rather than solely pursuing the reduction of illness from a medical perspective. After all, mental health does not equal the absence of mental illness but, rather, encompasses the presence of well-being ${ }^{184}$. However, matters are complicated by the lack of insight that is characteristic of psychotic disorders, making patients unaware of their symptoms, the risk of relapse, and illness-related functional impairment.

Results from the studies presented in Chapters $\mathbf{5}$ and $\mathbf{6}$ of the current thesis underline discrepancies between objective (clinician-observed) and subjective (patient-experienced) treatment effects. It appears, therefore, that antipsychotic efficacy is, above all, in the eye of the beholder. Given that no medication is effective unless taken ${ }^{183}$, and the importance of subjective treatment effects for medication adherence in schizophrenia ${ }^{95,97,104-106}$, the findings presented in Chapters $\mathbf{5}$ and $\mathbf{6}$ of this thesis argue for increased implementation of subjective treatment assessments in clinical practice, the Experience Sampling Method holding particular promise because of its accurate information retrieval and superior ecological validity ${ }^{110}$. 


\section{References}

1. Myin-Germeys I, van Os J, Schwartz JE, Stone AA, and Delespaul PA. Emotional reactivity to daily life stress in psychosis. Arch Gen Psychiatry, 2001. 58(12): p. 1137-44.

2. Lardinois M, Lataster T, Mengelers R, Van Os J, and Myin-Germeys I. Childhood trauma and increased stress sensitivity in psychosis. Acta Psychiatr Scand, 2011. 123(1): p. 28-35.

3. Lataster T, Wichers M, Jacobs N, Mengelers R, Derom C, Thiery E, Van Os J, and Myin-Germeys I. Does reactivity to stress cosegregate with subclinical psychosis? A general population twin study. Acta Psychiatr Scand, 2009. 119(1): p. 45-53.

4. Myin-Germeys I, Delespaul P, and van Os J. Behavioural sensitization to daily life stress in psychosis. Psychol Med, 2005. 35(5): p. 733-41.

5. Myin-Germeys I, Krabbendam L, Delespaul PA, and Van Os J. Do life events have their effect on psychosis by influencing the emotional reactivity to daily life stress? Psychol Med, 2003. 33(2): p. 327-33.

6. Myin-Germeys I and van Os J. Stress-reactivity in psychosis: evidence for an affective pathway to psychosis. Clin Psychol Rev, 2007. 27(4): p. 409-24.

7. Lataster T, Collip D, Lardinois M, van Os J, and Myin-Germeys I. Evidence for a familial correlation between increased reactivity to stress and positive psychotic symptoms. Acta Psychiatr Scand, 2010. 122(5): p. 395404.

8. Myin-Germeys I, Marcelis M, Krabbendam L, Delespaul P, and van Os J. Subtle fluctuations in psychotic phenomena as functional states of abnormal dopamine reactivity in individuals at risk. Biol Psychiatry, 2005. 58(2): p. 105-10.

9. Marcelis M, Myin-Germeys I, Suckling J, Woodruff P, Hofman P, Bullmore E, Delespaul P, and van Os J. Cerebral tissue alterations and daily life stress experience in psychosis. Acta Psychiatr Scand, 2003. 107(1): p. 54-9.

10. van Winkel R, Henquet C, Rosa A, Papiol S, Fananas L, De Hert M, Peuskens J, van Os J, and Myin-Germeys I. Evidence that the COMT(Val158Met) polymorphism moderates sensitivity to stress in psychosis: an experience-sampling study. Am J Med Genet B Neuropsychiatr Genet, 2008. 147B(1): p. 10-7.

11. Simons CJ, Wichers M, Derom C, Thiery E, Myin-Germeys I, Krabbendam L, and van Os J. Subtle geneenvironment interactions driving paranoia in daily life. Genes Brain Behav, 2009. 8(1): p. 5-12.

12. Collip D, Van Winkel R, Peerbooms O, Lataster T, Thewissen V, Lardinois M, Drukker M, Rutten BP, Van Os J, and Myin-Germeys I. COMT Val158Met-Stress Interaction in Psychosis: Role of Background Psychosis Risk. CNS Neurosci Ther, 2010.

13. Collip D, Myin-Germeys I, and Van Os J. Does the concept of "sensitization" provide a plausible mechanism for the putative link between the environment and schizophrenia? Schizophr Bull, 2008. 34(2): p. 220-5. 
14. van Winkel R, Stefanis NC, and Myin-Germeys I. Psychosocial stress and psychosis. A review of the neurobiological mechanisms and the evidence for gene-stress interaction. Schizophr Bull, 2008. 34(6): p. 1095-105.

15. Yuii K, Suzuki M, and Kurachi M. Stress sensitization in schizophrenia. Ann N Y Acad Sci, 2007. 1113: p. 27690.

16. Ventura J and Liberman RP. Psychotic Disorders, in Encyclopedia of Stress, G. Fink, Editor. 2000, Academic Press.

17. Arseneault L, Cannon M, Fisher HL, Polanczyk G, Moffitt TE, and Caspi A. Childhood trauma and children's emerging psychotic symptoms: A genetically sensitive longitudinal cohort study. Am J Psychiatry, 2011. 168(1): p. $65-72$.

18. Elklit A and Shevlin M. Female Sexual Victimization Predicts Psychosis: A Case-Control Study Based on the Danish Registry System. Schizophr Bull, 2010.

19. Schreier A, Wolke D, Thomas K, Horwood J, Hollis C, Gunnell D, Lewis G, Thompson A, Zammit S, Duffy L, Salvi G, and Harrison G. Prospective study of peer victimization in childhood and psychotic symptoms in a nonclinical population at age 12 years. Arch Gen Psychiatry, 2009. 66(5): p. 527-36.

20. van Os J, Kenis G, and Rutten BP. The environment and schizophrenia. Nature, 2010. 468(7321): p. 203-12.

21. Heins M, Simons C, Lataster T, Pfeifer S, Versmissen D, Lardinois M, Marcelis M, Delespaul P, Krabbendam L, van Os J, and Myin-Germeys I. Childhood Trauma and Psychosis: A Case-Control and Case-Sibling Comparison Across Different Levels of Genetic Liability, Psychopathology, and Type of Trauma. Am J Psychiatry, 2011.

22. Galletly C, Van Hooff M, and McFarlane A. Psychotic symptoms in young adults exposed to childhood trauma--a 20 year follow-up study. Schizophr Res, 2011. 127(1-3): p. 76-82.

23. Fallon P. Life events; their role in onset and relapse in psychosis, research utilizing semi-structured interview methods: a literature review. J Psychiatr Ment Health Nurs, 2008. 15(5): p. 386-92.

24. Nuechterlein KH and Dawson ME. A heuristic vulnerability/stress model of schizophrenic episodes. Schizophr Bull, 1984. 10(2): p. 300-12.

25. Zubin J and Spring B. Vulnerability--a new view of schizophrenia. J Abnorm Psychol, 1977. 86(2): p. 103-26.

26. Katschnig H. Vulnerability models for schizophrenia: Discussion. In Häfner, H \& Gattaz, WF (Eds.), Search for the causes of schizophrenia, Vol. II. Search for the causes of schizophrenia, Vol. II., ed. H. Häfner and W. Gattaz. 1991, Berlin: Springer-Verlag.

27. Meehl P. Schizotaxia, schizotypy, schizophrenia. American Psychologist, 1962. 17: p. 827-838.

28. Rosenthal D. Genetic Theory and Abnormal Behavior. 1970, New York: McGraw-Hill.

29. Gottesman I and Shields J. Schizophrenia, the epigenetic puzzle. 1982, New York: Cambridge University Press.

30. Tsuang MT and Faraone SV. Genetic heterogeneity of schizophrenia. Seishin Shinkeigaku Zasshi, 1995. 97(7): 
p. $485-501$.

31. Read J, Perry BD, Moskowitz A, and Connolly J. The contribution of early traumatic events to schizophrenia in some patients: a traumagenic neurodevelopmental model. Psychiatry, 2001. 64(4): p. 319-45.

32. Lim C, Chong SA, and Keefe RS. Psychosocial factors in the neurobiology of schizophrenia: a selective review. Ann Acad Med Singapore, 2009. 38(5): p. 402-6.

33. Tiwari AK, Zai CC, Muller DJ, and Kennedy JL. Genetics in schizophrenia: where are we and what next? Dialogues Clin Neurosci, 2010. 12(3): p. 289-303.

34. Davis KL, Kahn RS, Ko G, and Davidson M. Dopamine in schizophrenia: a review and reconceptualization. Am J Psychiatry, 1991. 148(11): p. 1474-86.

35. Howes OD and Kapur S. The dopamine hypothesis of schizophrenia: version III--the final common pathway. Schizophr Bull, 2009. 35(3): p. 549-62.

36. Pruessner JC, Champagne F, Meaney MJ, and Dagher A. Dopamine release in response to a psychological stress in humans and its relationship to early life maternal care: a positron emission tomography study using [11C]raclopride. J Neurosci, 2004. 24(11): p. 2825-31.

37. Pruessner JC, Dedovic K, Pruessner M, Lord C, Buss C, Collins L, Dagher A, and Lupien SJ. Stress regulation in the central nervous system: evidence from structural and functional neuroimaging studies in human populations - 2008 Curt Richter Award Winner. Psychoneuroendocrinology, 2010. 35(1): p. 179-91.

38. Adler MW. Changes in sensitivity to amphetamine in rats with chronic brain lesions. J Pharmacol Exp Ther, 1961. 134: p. 214-21.

39. Iversen D, Wilkinson S, and Simpson B. Enhanced amphetamine responses after frontal cortex lesions in the rat. Eur J Pharmacol, 1971. 13(3): p. 387-90.

40. Laruelle M, Abi-Dargham A, van Dyck CH, Gil R, D'Souza CD, Erdos J, McCance E, Rosenblatt W, Fingado C, Zoghbi SS, Baldwin RM, Seibyl JP, Krystal JH, Charney DS, and Innis RB. Single photon emission computerized tomography imaging of amphetamine-induced dopamine release in drug-free schizophrenic subjects. Proc Natl Acad Sci U S A, 1996. 93(17): p. 9235-40.

41. Deutch AY, Clark WA, and Roth RH. Prefrontal cortical dopamine depletion enhances the responsiveness of mesolimbic dopamine neurons to stress. Brain Res, 1990. 521(1-2): p. 311-5.

42. King D, Zigmond MJ, and Finlay JM. Effects of dopamine depletion in the medial prefrontal cortex on the stress-induced increase in extracellular dopamine in the nucleus accumbens core and shell. Neuroscience, 1997. 77(1): p. 141-53.

43. Scornaiencki R, Cantrup R, Rushlow WJ, and Rajakumar N. Prefrontal cortical D1 dopamine receptors modulate subcortical D2 dopamine receptor-mediated stress responsiveness. Int J Neuropsychopharmacol, 2009. 12(9): p. 1195-208.

44. Abi-Dargham A, Gil R, Krystal J, Baldwin RM, Seibyl JP, Bowers M, van Dyck CH, Charney DS, Innis RB, and 
Laruelle M. Increased striatal dopamine transmission in schizophrenia: confirmation in a second cohort. Am J Psychiatry, 1998. 155(6): p. 761-7.

45. Montgomery AJ, Mehta MA, and Grasby PM. Is psychological stress in man associated with increased striatal dopamine levels?: A [11C]raclopride PET study. Synapse, 2006. 60(2): p. 124-31.

46. Soliman A, O’Driscoll GA, Pruessner J, Holahan AL, Boileau I, Gagnon D, and Dagher A. Stress-induced dopamine release in humans at risk of psychosis: a [11C]raclopride PET study. Neuropsychopharmacology, 2008. 33(8): p. 2033-41.

47. Badgaiyan RD, Fischman AJ, and Alpert NM. Dopamine release during human emotional processing. Neuroimage, 2009. 47(4): p. 2041-5.

48. Christian BT, Lehrer DS, Shi B, Narayanan TK, Strohmeyer PS, Buchsbaum MS, and Mantil JC. Measuring dopamine neuromodulation in the thalamus: using [F-18]fallypride PET to study dopamine release during a spatial attention task. Neuroimage, 2006. 31(1): p. 139-52.

49. Mukherjee J, Christian BT, Dunigan KA, Shi B, Narayanan TK, Satter M, and Mantil J. Brain imaging of 18Ffallypride in normal volunteers: blood analysis, distribution, test-retest studies, and preliminary assessment of sensitivity to aging effects on dopamine D-2/D-3 receptors. Synapse, 2002. 46(3): p. 170-88.

50. Riccardi P, Zald D, Li R, Park S, Ansari MS, Dawant B, Anderson S, Woodward N, Schmidt D, Baldwin R, and Kessler R. Sex differences in amphetamine-induced displacement of [(18)F]fallypride in striatal and extrastriatal regions: a PET study. Am J Psychiatry, 2006. 163(9): p. 1639-41.

51. Vrieze E, Ceccarini J, Pizzagalli D, Bormans G, Vandenbulcke M, Demyttenaere K, Van Laere K, and Claes S. Measuring extrastriatal dopamine release during a reward learning task. Human Brain Mapping, in press.

52. Woodward ND, Cowan RL, Park S, Ansari MS, Baldwin RM, Li R, Doop M, Kessler RM, and Zald DH. Correlation of individual differences in schizotypal personality traits with amphetamine-induced dopamine release in striatal and extrastriatal brain regions. Am J Psychiatry, 2011. 168(4): p. 418-26.

53. Karreman M and Moghaddam B. The prefrontal cortex regulates the basal release of dopamine in the limbic striatum: an effect mediated by ventral tegmental area. J Neurochem, 1996. 66(2): p. 589-98.

54. Geraud G, Arne-Bes MC, Guell A, and Bes A. Reversibility of hemodynamic hypofrontality in schizophrenia. J Cereb Blood Flow Metab, 1987. 7(1): p. 9-12.

55. Park IH, Kim JJ, Chun J, Jung YC, Seok JH, Park HJ, and Lee JD. Medial prefrontal default-mode hypoactivity affecting trait physical anhedonia in schizophrenia. Psychiatry Res, 2009. 171(3): p. 155-65.

56. Weinberger DR, Berman KF, and Illowsky BP. Physiological dysfunction of dorsolateral prefrontal cortex in schizophrenia. III. A new cohort and evidence for a monoaminergic mechanism. Arch Gen Psychiatry, 1988. 45(7): p. 609-15.

57. Weinberger DR, Berman KF, and Zec RF. Physiologic dysfunction of dorsolateral prefrontal cortex in schizophrenia. I. Regional cerebral blood flow evidence. Arch Gen Psychiatry, 1986. 43(2): p. 114-24. 
58. Abi-Dargham A, Rodenhiser J, Printz D, Zea-Ponce Y, Gil R, Kegeles LS, Weiss R, Cooper TB, Mann JJ, Van Heertum RL, Gorman JM, and Laruelle M. Increased baseline occupancy of D2 receptors by dopamine in schizophrenia. Proc Natl Acad Sci U S A, 2000. 97(14): p. 8104-9.

59. Breier A, Su TP, Saunders R, Carson RE, Kolachana BS, de Bartolomeis A, Weinberger DR, Weisenfeld N, Malhotra AK, Eckelman WC, and Pickar D. Schizophrenia is associated with elevated amphetamine-induced synaptic dopamine concentrations: evidence from a novel positron emission tomography method. Proc Natl Acad Sci U S A, 1997. 94(6): p. 2569-74.

60. Dao-Castellana MH, Paillere-Martinot ML, Hantraye P, Attar-Levy D, Remy P, Crouzel C, Artiges E, Feline A, Syrota A, and Martinot JL. Presynaptic dopaminergic function in the striatum of schizophrenic patients. Schizophr Res, 1997. 23(2): p. 167-74.

61. Hietala J, Syvalahti E, Vuorio K, Rakkolainen V, Bergman J, Haaparanta M, Solin O, Kuoppamaki M, Kirvela $\mathrm{O}$, Ruotsalainen $\mathrm{U}$, and et al. Presynaptic dopamine function in striatum of neuroleptic-naive schizophrenic patients. Lancet, 1995. 346(8983): p. 1130-1.

62. Howes OD, Montgomery AJ, Asselin MC, Murray RM, Grasby PM, and McGuire PK. Molecular imaging studies of the striatal dopaminergic system in psychosis and predictions for the prodromal phase of psychosis. Br J Psychiatry Suppl, 2007. 51: p. s13-8.

63. Kestler LP, Walker E, and Vega EM. Dopamine receptors in the brains of schizophrenia patients: a metaanalysis of the findings. Behav Pharmacol, 2001. 12(5): p. 355-71.

64. Laruelle M, Abi-Dargham A, Gil R, Kegeles L, and Innis R. Increased dopamine transmission in schizophrenia: relationship to illness phases. Biol Psychiatry, 1999. 46(1): p. 56-72.

65. Lindstrom LH, Gefvert O, Hagberg G, Lundberg T, Bergstrom M, Hartvig P, and Langstrom B. Increased dopamine synthesis rate in medial prefrontal cortex and striatum in schizophrenia indicated by L-(beta-11C) DOPA and PET. Biol Psychiatry, 1999. 46(5): p. 681-8.

66. Reith J, Benkelfat C, Sherwin A, Yasuhara Y, Kuwabara H, Andermann F, Bachneff S, Cumming P, Diksic M, Dyve SE, Etienne P, Evans AC, Lal S, Shevell M, Savard G, Wong DF, Chouinard G, and Gjedde A. Elevated dopa decarboxylase activity in living brain of patients with psychosis. Proc Natl Acad Sci U S A, 1994. 91(24): p. 11651-4.

67. Wand GS, Oswald LM, McCaul ME, Wong DF, Johnson E, Zhou Y, Kuwabara H, and Kumar A. Association of amphetamine-induced striatal dopamine release and cortisol responses to psychological stress. Neuropsychopharmacology, 2007. 32(11): p. 2310-20.

68. Lyss PJ, Andersen SL, LeBlanc CJ, and Teicher MH. Degree of neuronal activation following FG-7142 changes across regions during development. Brain Res Dev Brain Res, 1999. 116(2): p. 201-3.

69. Walker EF. Developmentally moderated expressions of the neuropathology underlying schizophrenia. Schizophr Bull, 1994. 20(3): p. 453-80. 
70. Andersen SL. Trajectories of brain development: point of vulnerability or window of opportunity? Neurosci Biobehav Rev, 2003. 27(1-2): p. 3-18.

71. Pruessner JC, Dedovic K, Pruessner M, Lord C, Buss C, Collins L, Dagher A, and Lupien SJ. Stress regulation in the central nervous system: evidence from structural and functional neuroimaging studies in human populations - 2008 Curt Richter Award Winner. Psychoneuroendocrinology. 35(1): p. 179-91.

72. Pani L, Porcella A, and Gessa GL. The role of stress in the pathophysiology of the dopaminergic system. Mol Psychiatry, 2000. 5(1): p. 14-21.

73. Zahrt J, Taylor JR, Mathew RG, and Arnsten AF. Supranormal stimulation of D1 dopamine receptors in the rodent prefrontal cortex impairs spatial working memory performance. J Neurosci, 1997. 17(21): p. 852835.

74. Cannon W. The emergency function of the adrenal medulla in pain and the major emotions. American Journal of Physiology, 1914. 33: p. 356-372.

75. Arnsten AF and Goldman-Rakic PS. Noise stress impairs prefrontal cortical cognitive function in monkeys: evidence for a hyperdopaminergic mechanism. Arch Gen Psychiatry, 1998. 55(4): p. 362-8.

76. Brake WG, Zhang TY, Diorio J, Meaney MJ, and Gratton A. Influence of early postnatal rearing conditions on mesocorticolimbic dopamine and behavioural responses to psychostimulants and stressors in adult rats. Eur J Neurosci, 2004. 19(7): p. 1863-74.

77. Henry C, Guegant G, Cador M, Arnauld E, Arsaut J, Le Moal M, and Demotes-Mainard J. Prenatal stress in rats facilitates amphetamine-induced sensitization and induces long-lasting changes in dopamine receptors in the nucleus accumbens. Brain Res, 1995. 685(1-2): p. 179-86.

78. Kehoe P, Shoemaker WJ, Triano L, Hoffman J, and Arons C. Repeated isolation in the neonatal rat produces alterations in behavior and ventral striatal dopamine release in the juvenile after amphetamine challenge. Behav Neurosci, 1996. 110(6): p. 1435-44.

79. Walker EF and Diforio D. Schizophrenia: a neural diathesis-stress model. Psychol Rev, 1997. 104(4): p. 66785.

80. Hall FS, Wilkinson LS, Humby T, and Robbins TW. Maternal deprivation of neonatal rats produces enduring changes in dopamine function. Synapse, 1999. 32(1): p. 37-43.

81. Kapur S. Psychosis as a state of aberrant salience: a framework linking biology, phenomenology, and pharmacology in schizophrenia. Am J Psychiatry, 2003. 160(1): p. 13-23.

82. Moghaddam B. Stress activation of glutamate neurotransmission in the prefrontal cortex: implications for dopamine-associated psychiatric disorders. Biol Psychiatry, 2002. 51(10): p. 775-87.

83. Benes FM. The role of stress and dopamine-GABA interactions in the vulnerability for schizophrenia. $J$ Psychiatr Res, 1997. 31(2): p. 257-75.

84. Deutch A and Young C. A model of the stress-induced activation of prefrontal cortical dopamine systems., 
in Neurological and Clinical Consequences of Stress from Normal Adaptation., C.D. Friedman MJ, Deutch AY, Editor. 1995, Raven Press: New York. p. 163-175.

85. Charney DS. Psychobiological mechanisms of resilience and vulnerability: implications for successful adaptation to extreme stress. Am J Psychiatry, 2004. 161(2): p. 195-216.

86. Dailly E, Chenu F, Renard CE, and Bourin M. Dopamine, depression and antidepressants. Fundam Clin Pharmacol, 2004. 18(6): p. 601-7.

87. Nikolaus S, Antke C, Beu M, and Muller HW. Cortical GABA, striatal dopamine and midbrain serotonin as the key players in compulsive and anxiety disorders--results from in vivo imaging studies. Rev Neurosci, 2010. 21(2): p. 119-39.

88. Rauch SL, Shin LM, and Phelps EA. Neurocircuitry models of posttraumatic stress disorder and extinction: human neuroimaging research--past, present, and future. Biol Psychiatry, 2006. 60(4): p. 376-82.

89. Cepeda C, Andre VM, Jocoy EL, and Levine MS. NMDA and Dopamine: Diverse Mechanisms Applied to Interacting Receptor Systems. 2009.

90. Kahn RS and Davidson M. Serotonin, dopamine and their interactions in schizophrenia. Psychopharmacology (Berl), 1993. 112(1 Suppl): p. S1-4.

91. Pehek EA, Nocjar C, Roth BL, Byrd TA, and Mabrouk OS. Evidence for the preferential involvement of 5HT2A serotonin receptors in stress- and drug-induced dopamine release in the rat medial prefrontal cortex. Neuropsychopharmacology, 2006. 31(2): p. 265-77.

92. Yoo JH, Lee HK, Kim HC, Lee SY, and Jang CG. GABA(A) receptors mediate the attenuating effects of a 5-HT(3) receptor antagonist on methamphetamine-induced behavioral sensitization in mice. Synapse, 2010. 64(4): p. 274-9.

93. Young JL, Zonana HV, and Shepler L. Medication noncompliance in schizophrenia: codification and update. Bull Am Acad Psychiatry Law, 1986. 14(2): p. 105-22.

94. Garavan J, Browne S, Gervin M, Lane A, Larkin C, and O'Callaghan E. Compliance with neuroleptic medication in outpatients with schizophrenia; relationship to subjective response to neuroleptics; attitudes to medication and insight. Compr Psychiatry, 1998. 39(4): p. 215-9.

95. Marder SR. Facilitating compliance with antipsychotic medication. J Clin Psychiatry, 1998. 59 Suppl 3: p. 215.

96. Lacro JP, Dunn LB, Dolder CR, Leckband SG, and Jeste DV. Prevalence of and risk factors for medication nonadherence in patients with schizophrenia: a comprehensive review of recent literature. J Clin Psychiatry, 2002. 63(10): p. 892-909.

97. Fenton WS, Blyler CR, and Heinssen RK. Determinants of medication compliance in schizophrenia: empirical and clinical findings. Schizophr Bull, 1997. 23(4): p. 637-51.

98. Carlsson A. The current status of the dopamine hypothesis of schizophrenia. Neuropsychopharmacology, 
1988. 1(3): p. 179-86.

99. Nordstrom AL, Farde L, and Halldin C. Time course of D2-dopamine receptor occupancy examined by PET after single oral doses of haloperidol. Psychopharmacology (Berl), 1992. 106(4): p. 433-8.

100. Peroutka SJ and Synder SH. Relationship of neuroleptic drug effects at brain dopamine, serotonin, alphaadrenergic, and histamine receptors to clinical potency. Am J Psychiatry, 1980. 137(12): p. 1518-22.

101. Weiden P, Shaw E, and Mann J. Causes of neuroleptic noncompliance. Psychiatric Annals, 1986. 16: p. 571575 .

102. Van Putten T, May PR, Marder SR, and Wittmann LA. Subjective response to antipsychotic drugs. Arch Gen Psychiatry, 1981. 38(2): p. 187-90.

103. Awad AG and Hogan TP. Subjective response to neuroleptics and the quality of life: implications for treatment outcome. Acta Psychiatr Scand Suppl, 1994. 380: p. 27-32.

104. Karow A, Czekalla J, Dittmann RW, Schacht A, Wagner T, Lambert M, Schimmelmann BG, and Naber D. Association of subjective well-being, symptoms, and side effects with compliance after 12 months of treatment in schizophrenia. J Clin Psychiatry, 2007. 68(1): p. 75-80.

105. Naber D, Karow A, and Lambert M. Subjective well-being under the neuroleptic treatment and its relevance for compliance. Acta Psychiatr Scand Suppl, 2005(427): p. 29-34.

106. Awad AG, Hogan TP, Voruganti LN, and Heslegrave RJ. Patients' subjective experiences on antipsychotic medications: implications for outcome and quality of life. Int Clin Psychopharmacol, 1995. 10 Suppl 3: p. 123-32.

107. de Millas W, Lambert M, and Naber D. The impact of subjective well-being under neuroleptic treatment on compliance and remission. Dialogues Clin Neurosci, 2006. 8(1): p. 131-6.

108. Naber D and Karow A. Good tolerability equals good results: the patient's perspective. Eur Neuropsychopharmacol, 2001. 11 Suppl 4: p. S391-6.

109. Delespaul PAEG. Assessing Schizophrenia in Daily Life. 1995, Maastricht: University Press.

110. Myin-Germeys I, Oorschot M, Collip D, Lataster J, Delespaul P, and van Os J. Experience sampling research in psychopathology: opening the black box of daily life. Psychol Med, 2009. 39(9): p. 1533-47.

111. Seeman P and Tallerico T. Antipsychotic drugs which elicit little or no parkinsonism bind more loosely than dopamine to brain D2 receptors, yet occupy high levels of these receptors. Mol Psychiatry, 1998. 3(2): p. 123-34.

112. Seeman P and Tallerico T. Rapid release of antipsychotic drugs from dopamine D2 receptors: an explanation for low receptor occupancy and early clinical relapse upon withdrawal of clozapine or quetiapine. Am J Psychiatry, 1999. 156(6): p. 876-84.

113. Berridge KC and Robinson TE. What is the role of dopamine in reward: hedonic impact, reward learning, or incentive salience? Brain Res Brain Res Rev, 1998. 28(3): p. 309-69. 
114. Kapur S. How antipsychotics become anti-"psychotic"--from dopamine to salience to psychosis. Trends Pharmacol Sci, 2004. 25(8): p. 402-6.

115. Garcia-Cabeza I, Gomez JC, Sacristan JA, Edgell E, and Gonzalez de Chavez M. Subjective response to antipsychotic treatment and compliance in schizophrenia. A naturalistic study comparing olanzapine, risperidone and haloperidol (EFESO Study). BMC Psychiatry, 2001. 1: p. 7.

116. de Haan L, Lavalaye J, Linszen D, Dingemans PM, and Booij J. Subjective experience and striatal dopamine $\mathrm{D}(2)$ receptor occupancy in patients with schizophrenia stabilized by olanzapine or risperidone. Am J Psychiatry, 2000. 157(6): p. 1019-20.

117. de Haan L, van Bruggen M, Lavalaye J, Booij J, Dingemans PM, and Linszen D. Subjective experience and D2 receptor occupancy in patients with recent-onset schizophrenia treated with low-dose olanzapine or haloperidol: a randomized, double-blind study. Am J Psychiatry, 2003. 160(2): p. 303-9.

118. Mizrahi R, Rusjan P, Agid O, Graff A, Mamo DC, Zipursky RB, and Kapur S. Adverse subjective experience with antipsychotics and its relationship to striatal and extrastriatal D2 receptors: a PET study in schizophrenia. Am J Psychiatry, 2007. 164(4): p. 630-7.

119. Kapur S and Seeman P. Does fast dissociation from the dopamine $d(2)$ receptor explain the action of atypical antipsychotics?: A new hypothesis. Am J Psychiatry, 2001. 158(3): p. 360-9.

120. Kapur S, Zipursky R, Jones C, Remington G, and Houle S. Relationship between dopamine D(2) occupancy, clinical response, and side effects: a double-blind PET study of first-episode schizophrenia. Am J Psychiatry, 2000. 157(4): p. 514-20.

121. Tamminga CA and Carlsson A. Partial dopamine agonists and dopaminergic stabilizers, in the treatment of psychosis. Curr Drug Targets CNS Neurol Disord, 2002. 1(2): p. 141-7.

122. Stahl SM. Dopamine system stabilizers, aripiprazole, and the next generation of antipsychotics, part 2: illustrating their mechanism of action. J Clin Psychiatry, 2001. 62(12): p. 923-4.

123. Stahl SM. Dopamine system stabilizers, aripiprazole, and the next generation of antipsychotics, part 1 , “Goldilocks" actions at dopamine receptors. J Clin Psychiatry, 2001. 62(11): p. 841-2.

124. Naber D and Lambert M. Aripiprazole: a new atypical antipsychotic with a different pharmacological mechanism. Prog Neuropsychopharmacol Biol Psychiatry, 2004. 28(8): p. 1213-9.

125. Burris KD, Molski TF, Xu C, Ryan E, Tottori K, Kikuchi T, Yocca FD, and Molinoff PB. Aripiprazole, a novel antipsychotic, is a high-affinity partial agonist at human dopamine D2 receptors. J Pharmacol Exp Ther, 2002. 302(1): p. 381-9.

126. Jordan S, Koprivica V, Chen R, Tottori K, Kikuchi T, and Altar CA. The antipsychotic aripiprazole is a potent, partial agonist at the human 5-HT1A receptor. Eur J Pharmacol, 2002. 441(3): p. 137-40.

127. Kane JM, Carson WH, Saha AR, McQuade RD, Ingenito GG, Zimbroff DL, and Ali MW. Efficacy and safety of aripiprazole and haloperidol versus placebo in patients with schizophrenia and schizoaffective disorder. $J$ 
Clin Psychiatry, 2002. 63(9): p. 763-71.

128. Mizrahi R, Mamo D, Rusjan P, Graff A, Houle S, and Kapur S. The relationship between subjective wellbeing and dopamine D2 receptors in patients treated with a dopamine partial agonist and full antagonist antipsychotics. Int J Neuropsychopharmacol, 2009. 12(5): p. 715-21.

129. Adan-Manes J and Garcia-Parajua P. Aripiprazole in combination with other antipsychotic drugs may worsen psychosis. J Clin Pharm Ther, 2009. 34(2): p. 245-6.

130. Pae CU, Serretti A, Chiesa A, Mandelli L, Lee C, Lee C, Kim J, De Ronchi D, and Paik IH. Immediate versus gradual suspension of previous treatments during switch to aripiprazole: results of a randomized, open label study. Eur Neuropsychopharmacol, 2009. 19(8): p. 562-70.

131. Ramaswamy S, Vijay D, William M, Sattar SP, Praveen F, and Petty F. Aripiprazole possibly worsens psychosis. Int Clin Psychopharmacol, 2004. 19(1): p. 45-8.

132. Thone J. Worsened agitation and confusion in schizophrenia subsequent to high-dose aripiprazole. J Neuropsychiatry Clin Neurosci, 2007. 19(4): p. 481-2.

133. Joyce JN. D2 but not D3 receptors are elevated after 9 or 11 months chronic haloperidol treatment: influence of withdrawal period. Synapse, 2001. 40(2): p. 137-44.

134. Angulo JA, Coirini H, Ledoux M, and Schumacher M. Regulation by dopaminergic neurotransmission of dopamine D2 mRNA and receptor levels in the striatum and nucleus accumbens of the rat. Brain Res Mol Brain Res, 1991. 11(2): p. 161-6.

135. Laruelle M, Jaskiw GE, Lipska BK, Kolachana B, Casanova MF, Kleinman JE, and Weinberger DR. D1 and D2 receptor modulation in rat striatum and nucleus accumbens after subchronic and chronic haloperidol treatment. Brain Res, 1992. 575(1): p. 47-56.

136. Florijn WJ, Tarazi FI, and Creese I. Dopamine receptor subtypes: differential regulation after 8 months treatment with antipsychotic drugs. J Pharmacol Exp Ther, 1997. 280(2): p. 561-9.

137. Tarazi FI, Florijn WJ, and Creese I. Differential regulation of dopamine receptors after chronic typical and atypical antipsychotic drug treatment. Neuroscience, 1997. 78(4): p. 985-96.

138. Basu R and Brar JS. Dose-dependent rapid-onset akathisia with aripiprazole in patients with schizoaffective disorder. Neuropsychiatr Dis Treat, 2006. 2(2): p. 241-3.

139. Nassir Ghaemi S. Mood disorders: a practical guide 2nd ed, ed. C. Mitchell and S. Howes. 2008, Philadelphia: Lippincott Williams \& Wilkins, a Wolters Kluwer business.

140. Travis MJ, Burns T, Dursun S, Fahy T, Frangou S, Gray R, Haddad PM, Hunter R, Taylor DM, and Young AH. Aripiprazole in schizophrenia: consensus guidelines. Int J Clin Pract, 2005. 59(4): p. 485-95.

141. Berman RM, Marcus RN, Swanink R, McQuade RD, Carson WH, Corey-Lisle PK, and Khan A. The efficacy and safety of aripiprazole as adjunctive therapy in major depressive disorder: a multicenter, randomized, double-blind, placebo-controlled study. J Clin Psychiatry, 2007. 68(6): p. 843-53. 
142. Marcus RN, McQuade RD, Carson WH, Hennicken D, Fava M, Simon JS, Trivedi MH, Thase ME, and Berman RM. The efficacy and safety of aripiprazole as adjunctive therapy in major depressive disorder: a second multicenter, randomized, double-blind, placebo-controlled study. J Clin Psychopharmacol, 2008. 28(2): p. 156-65.

143. Stip E and Tourjman V. Aripiprazole in schizophrenia and schizoaffective disorder: A review. Clin Ther, 2010. 32 Suppl 1: p. S3-20.

144. Begum M. Clozapine-induced stuttering, facial tics and myoclonic seizures: a case report. Aust $N$ Z J Psychiatry, 2005. 39(3): p. 202.

145. Merrill DB, Ahmari SE, Bradford JM, and Lieberman JA. Myocarditis during clozapine treatment. Am J Psychiatry, 2006. 163(2): p. 204-8.

146. Alvir JM, Lieberman JA, Safferman AZ, Schwimmer JL, and Schaaf JA. Clozapine-induced agranulocytosis. Incidence and risk factors in the United States. N Engl J Med, 1993. 329(3): p. 162-7.

147. Wichers MC, Barge-Schaapveld DQ, Nicolson NA, Peeters F, de Vries M, Mengelers R, and van Os J. Reduced stress-sensitivity or increased reward experience: the psychological mechanism of response to antidepressant medication. Neuropsychopharmacology, 2009. 34(4): p. 923-31.

148. Barge-Schaapveld DQ and Nicolson NA. Effects of antidepressant treatment on the quality of daily life: an experience sampling study. J Clin Psychiatry, 2002. 63(6): p. 477-85.

149. Barge-Schaapveld DQ, Nicolson NA, van der Hoop RG, and De Vries MW. Changes in daily life experience associated with clinical improvement in depression. J Affect Disord, 1995. 34(2): p. 139-54.

150. Raoux N, Benoit O, Dantchev N, Denise P, Franc B, Allilaire JF, and Widlocher D. Circadian pattern of motor activity in major depressed patients undergoing antidepressant therapy: relationship between actigraphic measures and clinical course. Psychiatry Res, 1994. 52(1): p. 85-98.

151. Goff DC, Brotman AW, Kindlon D, Waites M, and Amico E. The delusion of possession in chronically psychotic patients. J Nerv Ment Dis, 1991. 179(9): p. 567-71.

152. Sansonnet-Hayden H, Haley G, Marriage K, and Fine S. Sexual abuse and psychopathology in hospitalized adolescents. J Am Acad Child Adolesc Psychiatry, 1987. 26(5): p. 753-7.

153. Heins T, Gray A, and Tennant M. Persisting hallucinations following childhood sexual abuse. Aust $N Z J$ Psychiatry, 1990. 24(4): p. 561-5.

154. Ellason JW and Ross CA. Childhood trauma and psychiatric symptoms. Psychol Rep, 1997. 80(2): p. 447-50.

155. Morrison AP, Frame L, and Larkin W. Relationships between trauma and psychosis: a review and integration. Br J Clin Psychol, 2003. 42(Pt 4): p. 331-53.

156. Ivezic S, Oruc L, and Bell P. Psychotic symptoms in post-traumatic stress disorder. Mil Med, 1999. 164(1): p. 73-5.

157. Braakman MH, Kortmann FA, and van den Brink W. Validity of 'post-traumatic stress disorder with secondary 
psychotic features': a review of the evidence. Acta Psychiatr Scand, 2009. 119(1): p. 15-24.

158. Eftekhari A, Stines LR, and Zoellner LA. Do You Need To Talk About It? Prolonged Exposure for the Treatment of Chronic PTSD. Behav Anal Today, 2006. 7(1): p. 70-83.

159. Meichenbaum D and Novaco R. Stress inoculation: a preventative approach. Issues Ment Health Nurs, 1985. 7(1-4): p. 419-35.

160. Resick PA and Schnicke MK. Cognitive processing therapy for sexual assault victims. J Consult Clin Psychol, 1992. 60(5): p. 748-56.

161. Shapiro F. Eye movement desensitization and reprocessing (EMDR): evaluation of controlled PTSD research. J Behav Ther Exp Psychiatry, 1996. 27(3): p. 209-18.

162. Seedat S, Stein MB, Oosthuizen PP, Emsley RA, and Stein DJ. Linking posttraumatic stress disorder and psychosis: a look at epidemiology, phenomenology, and treatment. J Nerv Ment Dis, 2003. 191(10): p. 67581.

163. Norman RM, Malla AK, McLean TS, McIntosh EM, Neufeld RW, Voruganti LP, and Cortese L. An evaluation of a stress management program for individuals with schizophrenia. Schizophr Res, 2002. 58(2-3): p. 293-303.

164. Gleeson JF, Cotton SM, Alvarez-Jimenez M, Wade D, Crisp K, Newman B, Spiliotacopoulos D, and McGorry PD. Family outcomes from a randomized control trial of relapse prevention therapy in first-episode psychosis. $J$ Clin Psychiatry, 2009.

165. Gleeson JF, Cotton SM, Alvarez-Jimenez M, Wade D, Gee D, Crisp K, Pearce T, Newman B, Spiliotacopoulos D, Castle D, and McGorry PD. A randomized controlled trial of relapse prevention therapy for first-episode psychosis patients. J Clin Psychiatry, 2009. 70(4): p. 477-86.

166. Leff J. Stress reduction in the social environment of schizophrenic patients. Acta Psychiatr Scand Suppl, 1994. 384: p. 133-9.

167. Pharoah F, Mari J, Rathbone J, and Wong W. Family intervention for schizophrenia. Cochrane Database Syst Rev, 2006(4): p. CD000088.

168. van der Gaag M, Hageman MC, and Birchwood M. Evidence for a cognitive model of auditory hallucinations. J Nerv Ment Dis, 2003. 191(8): p. 542-5.

169. Fowler D, Garety P, and Kuipers E. [Cognitive behavioral therapy for psychosis.]. Sante Ment Que, 1999. 24(1): p. 61-88.

170. Garety P, Fowler D, Kuipers E, Freeman D, Dunn G, Bebbington P, Hadley C, and Jones S. London-East Anglia randomised controlled trial of cognitive-behavioural therapy for psychosis. II: Predictors of outcome. $\mathrm{Br} J$ Psychiatry, 1997. 171: p. 420-6.

171. Kuipers E, Garety P, Fowler D, Dunn G, Bebbington P, Freeman D, and Hadley C. London-East Anglia randomised controlled trial of cognitive-behavioural therapy for psychosis. I: effects of the treatment phase. Br J Psychiatry, 1997. 171: p. 319-27. 
172. Valmaggia LR, van der Gaag M, Tarrier N, Pijnenborg M, and Slooff CJ. Cognitive-behavioural therapy for refractory psychotic symptoms of schizophrenia resistant to atypical antipsychotic medication. Randomised controlled trial. Br J Psychiatry, 2005. 186: p. 324-30.

173. Hodel B, Brenner HD, Merlo MC, and Teuber JF. Emotional management therapy in early psychosis. $B r \mathrm{~J}$ Psychiatry Suppl, 1998. 172(33): p. 128-33.

174. Myin-Germeys I, Birchwood M, and Kwapil T. From environment to therapy in psychosis: a real-world momentary assessment approach. Schizophr Bull, 2011. 37(2): p. 244-7.

175. Alves Fda S, Figee M, Vamelsvoort T, Veltman D, and de Haan L. The revised dopamine hypothesis of schizophrenia: evidence from pharmacological MRI studies with atypical antipsychotic medication. Psychopharmacol Bull, 2008. 41(1): p. 121-32.

176. Hogarty GE, Goldberg SC, Schooler NR, and Ulrich RF. Drug and sociotherapy in the aftercare of schizophrenic patients. II. Two-year relapse rates. Arch Gen Psychiatry, 1974. 31(5): p. 603-8.

177. Hogarty GE, Goldberg SC, and Schooler NR. Drug and sociotherapy in the aftercare of schizophrenic patients. III. Adjustment of nonrelapsed patients. Arch Gen Psychiatry, 1974. 31(5): p. 609-18.

178. Hogarty GE, Goldberg S, and Schooler N. Proceedings: Drug and sociotherapy in the aftercare of schizophrenic patients. Psychopharmacol Bull, 1974. 10(4): p. 47.

179. May PR, Tuma AH, Dixon WJ, Yale C, Thiele DA, and Kraude WH. Schizophrenia. A follow-up study of the results of five forms of treatment. Arch Gen Psychiatry, 1981. 38(7): p. 776-84.

180. May PR, Van Putten T, Jenden DJ, Yale C, and Dixon WJ. Chlorpromazine levels and the outcome of treatment in schizophrenic patients. Arch Gen Psychiatry, 1981. 38(2): p. 202-7.

181. May PR, Van Putten T, Jenden DJ, Yale C, Dixon WJ, and Goldstein MJ. Prognosis in schizophrenia: individual differences in psychological response to a test dose of antipsychotic drug and their relationship to blood and saliva levels and treatment outcome. Compr Psychiatry, 1981. 22(2): p. 147-52.

182. Becker $\mathrm{MH}$ and Maiman LA. Sociobehavioral determinants of compliance with health and medical care recommendations. Med Care, 1975. 13(1): p. 10-24.

183. Perkins DO. Adherence to antipsychotic medications. J Clin Psychiatry, 1999. 60 Suppl 21: p. 25-30.

184. Keyes C and Lopez S. Toward a science of mental health., in Handbook of Positive Psychology, C. Snyder and S. Lopez, Editors. 2005, Oxford University Press: New York. 
193 这 
194

I

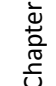




\section{Samenvatting}

Dit proefschrift, 'Connecting the dots: new perspectives on stress and psychosis', heeft tot doel meer inzicht te verschaffen in de veronderstelde samenhang tussen stress en psychose. Allereerst richt het zich daartoe op het ontleden van de vermeend oorzakelijke effecten van ingrijpende gebeurtenissen op het ontstaan van psychotische belevingen, onderzocht door middel van prospectief longitudinaal populatieonderzoek. Ten tweede worden aan de hand van hersenbeeldvormingstechnieken de neurotransmissiesystemen bestudeerd die een sleutelrol krijgen toebedeeld in de menselijke stressverwerking, met als doel vast te stellen in welke mate een psychotische kwetsbaarheid zich manifesteert op het neurochemische niveau van stressverwerking. Ten slotte buigt het werk in dit proefschrift zich over de vraag welke invloed antipsychotische medicatie uitoefent op het emotionele welbevinden van patiënten met een psychotische stoornis, zoals gemeten binnen de realiteit van het dagelijks leven.

In Hoofdstuk 1 wordt het fenomeen psychose geïntroduceerd als een entiteit die, in tegenstelling tot de kraepeliaanse dichotomie tussen stoornis en geen stoornis, in de natuur als een continuüm lijkt te bestaan dat gradueel verloopt van gezondheid tot ziekte. Stress wordt daarbij reeds lang genoemd als belangrijke factor bij het ontstaan van psychotische ervaringen. Het kwetsbaarheid-stressmodel stelt dat mensen de ziektegrens passeren wanneer hun kwetsbaarheidsdrempel - een stabiele eigenschap die tussen personen verschilt - wordt overschreden door een opeenstapeling van stressvolle ervaringen. Personen met een verlaagde kwetsbaarheidsdrempel zullen volgens dit model minder goed in staat zijn om weerstand te bieden aan stress en eerder hierop reageren met psychotische symptomen, terwijl niet-kwetsbare individuen deze stress beter het hoofd kunnen bieden. Hoewel het kwetsbaarheid-stressmodel een heuristisch kader biedt voor het begrijpen van een psychose, is relatief weinig onderzoek verricht naar de precieze rol die stress speelt in het ontstaan van een psychose en de mechanismen die hieraan ten grondslag liggen. Duidelijk is, dat mensen met een psychotische kwetsbaarheid erg gevoelig zijn voor 
stress, en hierop dan ook sterker reageren dan andere mensen. Hoewel deze verhoogde stressreactie enerzijds een genetische oorsprong lijkt te hebben, benadrukt het inleidende hoofdstuk dat deze anderzijds wordt gevormd door omgevingsinvloeden. Zo wordt de mogelijkheid naar voren geschoven dat blootstelling aan stressvolle omgevingen in de vroege levensjaren iemand gevoeliger kan maken voor latere stress en op die manier de formatie van psychotische ervaringen kan inleiden. Bewijs voor deze hypothese ontbreekt echter tot op heden. Daarnaast zijn de (neuro)biologische mechanismen onderliggend aan een verhoogde stressreactie bij mensen met een psychotische kwetsbaarheid onduidelijk. Hoewel blootstelling aan stress gepaard gaat met dopamine afgifte in de hersenen, en patiënten met een psychotische stoornis zich kenmerken door een verstoorde dopaminehuishouding, is tot op heden onduidelijk welke rol het dopaminesysteem speelt in de stressgevoeligheid van patiënten met een psychotische stoornis. Ten slotte wordt in het inleidende hoofdstuk aandacht besteed aan de ogenschijnlijk paradoxale constatering dat de medicijnen die worden voorgeschreven om het welbevinden van de psychotische patiënt te verbeteren, door diezelfde patiënt vaak juist als een bron van ellende worden gezien.

De studie beschreven in Hoofdstuk 2 had tot doel te toetsen in welke mate blootstelling aan ingrijpende, stressvolle gebeurtenissen vroeg in het leven mensen kwetsbaarder maakt voor de psychose-opwekkende effecten van latere stress. Hiertoe werd gebruik gemaakt van een prospectief longitudinaal populatie onderzoek, waarin meer dan drieduizend mensen werden gevolgd over een periode van circa tien jaar. Binnen die tien jaar werden zij drie keer geïnterviewd door getrainde psychologen die telkens nauwkeurig navraag deden naar ingrijpende, stressvolle gebeurtenissen en psychotische belevingen. Zo konden - door de tijd heen - de oorzakelijke invloeden van ingrijpende gebeurtenissen op het ontstaan van psychotische ervaringen worden getoetst.

Resultaten van deze studie lieten zien dat blootstelling aan een ingrijpende, stressvolle gebeurtenis vroeg in het leven zowel de kans op het meemaken van latere stressvolle ervaringen vergroot, als de waarschijnlijkheid van een psychose-opwekkend effect hiervan. Dit past binnen de hypothese dat blootstelling aan stressvolle omgevingen in de vroege levensjaren iemand gevoeliger kan maken voor latere stress en op die manier de formatie van psychotische ervaringen kan inleiden, een proces dat in de literatuur ook wel sensitisatie wordt genoemd. 
Hoewel deze bevindingen andermaal lijken te bevestigen dat het meemaken van stressvolle gebeurtenissen het risico op psychose verhoogt, blijft een essentieel element van het kwetsbaarheid-stressmodel, namelijk de interactie tussen een kwetsbaar persoon en zijn stressvolle omgeving, onbevraagd. Wat doet die stressvolle omgeving met deze persoon en welke mechanismen zorgen ervoor dat hij of zij dan ook effectief psychotische ervaringen ontwikkelt? De twee studies die worden gepresenteerd in Hoofdstuk 3 en $\mathbf{4}$ van dit proefschrift hadden als doel deze vragen te beantwoorden, waarbij het accent werd gelegd op de rol die neurotransmissie-systemen in de hersenen hierbij spelen.

De literatuur suggereert dat de communicatie tussen de prefrontale cortex en het zogenoemde mesolimbische systeem, die wordt gefaciliteerd door de neurotransmitter dopamine, een cruciale rol speelt in de stressverwerking bij mensen. Er wordt verondersteld dat de stress-gerelateerde activatie van dopamine-neuronen in de prefrontale cortex de mesolimbische dopamine afgifte - en daarmee de stress-beleving - reguleert. De dopamine transmissie in de prefrontale cortex wordt daarom ook wel als 'stress-buffer' beschouwd. Omdat herhaaldelijk is aangetoond dat patiënten met een psychotische stoornis zich karakteriseren door een ontremming van het mesolimbische dopaminesysteem, kan worden gehypothetiseerd dat de buffer-functie van de prefrontale dopamine-neuronen bij hen is aangetast. Echter, weinig studies hebben de directe effecten van stress op het vrijkomen van dopamine bij mensen onderzocht, en bovendien delen deze studies de beperking dat hersenbeeldvormingstechnieken slechts sinds kort directe metingen van dopamine activiteit in corticale structuren, zoals de prefrontale cortex, toelaten.

De twee studies beschreven in Hoofdstuk $\mathbf{3}$ en $\mathbf{4}$ van dit proefschrift richtten zich daarom allereerst op het ontcijferen van de rol die het prefrontale dopaminesysteem in de hersenen speelt bij de verwerking van stress (Hoofdstuk 3), om vervolgens in kaart te brengen in welke mate een disfunctie van dit systeem samenhangt met de verhoogde stressreactie van mensen met een psychotische kwetsbaarheid (Hoofdstuk 4).

Om te beginnen wordt in Hoofdstuk 3 een studie beschreven die de effecten van psychosociale stress op dopamine afgifte in de menselijke prefrontale cortex onderzocht. Hiertoe werden 12 gezonde vrijwilligers in de PET (Positron Emissie Tomografie)-scanner blootgesteld aan een psychosociale stressor in de vorm van een onmogelijke rekentaak met negatieve verbale feedback. Het gebruik van de recent ontwikkelde radioactieve vloeistof $\left[{ }^{18} \mathrm{~F}\right]$ fallypride, die door middel van injectie bij deelnemers in de bloedbaan werd gebracht, 
stelde ons in staat om, als één van de eersten, dopamine afgifte in de prefrontale cortex ten gevolge van stress in beeld te brengen. Gedurende het experiment, dat uit een controle (i.e., geen stress) en een experimentele (i.e., stress) conditie bestond, werd mensen gevraagd om aan de hand van een aantal vragen te rapporteren hoe gestresst zij zich voelden. Deze gedragsmaat werd vervolgens in verband gebracht met de mate van dopamine afgifte in de prefrontale cortex, zoals gemeten tijdens het experiment.

Resultaten van deze studie lieten zien dat een toename in subjectief gerapporteerde stress ten gevolge van de psychosociale stresstaak samenhing met een toegenomen dopamine afgifte in het ventromediale deel van de prefrontale cortex, wat lijkt te bevestigen dat dopamine-neuronen in de prefrontale cortex inderdaad een belangrijke rol spelen in de stressverwerking bij mensen.

Gezien de verhoogde stressreactie van patiënten met een psychotische stoornis, is een voor de hand liggende volgende stap om te onderzoeken of de prefrontale dopamine-stress functie bij hen is aangetast. Immers, wanneer de prefrontale dopamine-neuronen inderdaad een stress-buffer vormen, dan kan een defect hiervan mogelijk verklaren waarom patiënten met een psychotische stoornis een verstoorde stressbeleving etaleren. Echter, het gros van de patiënten met een psychotische stoornis is ingesteld op dopamineblokkerende medicijnen, die het in kaart brengen van dopamine functies in de hersenen belemmeren. Daarnaast is het nog maar de vraag of functionele afwijkingen in het brein van deze patiënten eerder deel uitmaken van de oorzaak of van het gevolg van de ziekte. Een alternatieve manier om de etiologie van psychotische stoornissen te doorgronden is om niet de patiënt zelf, maar diens eerstegraads familieleden tot onderzoekssubject te maken. "Het zit in de familie" is namelijk zonder meer van toepassing op psychotische stoornissen; eerstegraads familieleden van patiënten met een psychotische stoornis hebben een verhoogde kans op het ontwikkelen van een psychose, reageren feller op stress dan mensen zonder psychotische familie-achtergrond én delen neurobiologische kwetsbaarheden met hun zieke familieleden. Hoewel ze - bij elkaar opgeteld - hierdoor een verhoogde kwetsbaarheid voor psychose aan de dag leggen, zijn ze, in tegenstelling tot hun aangedaan familielid, zelf niet ziek. Het betrekken van eerstegraads familieleden in onderzoek naar psychose maakt het daarom mogelijk om het probleem van omgekeerde causaliteit (functionele hersenafwijkingen als gevolg, in tegenstelling tot oorzaak van de ziekte) te omzeilen, wat ons via een omweg in staat stelt de etiologie van het psychotische brein te onderzoeken. 
In Hoofdstuk 4 wordt een studie gepresenteerd waarin het experiment uit Hoofdstuk 3 werd herhaald in een groep van 14 gezonde eerstegraads familieleden van patiënten met een psychotische stoornis, die werd vergeleken met een 10-koppige controlegroep zonder psychotische familiegeschiedenis. Beide groepen werden weer blootgesteld aan dezelfde psychosociale stresstaak, en wederom werd dopamine afgifte in de hersenen gemeten. Deze keer werd tijdens het experiment navraag gedaan naar zowel gevoelens van stress alsook subjectief ervaren psychotische belevingen (e.g., het horen van stemmen; zich achterdochtig voelen; bang zijn om de controle te verliezen).

Resultaten van deze studie lieten zien dat eerstegraads familieleden van patiënten met een psychotische stoornis, in vergelijking met de controlegroep, onder stressvolle omstandigheden een sterk verminderde dopamine afgifte in de prefrontale cortex vertoonden. Tevens ging de verlaagde reactiviteit van de prefrontale dopamine-neuronen onder stress bij eerstegraads familieleden gepaard met een toegenomen intensiteit van subtiele psychotische belevingen, zoals gerapporteerd tijdens het experiment.

Deze bevindingen passen bij de hypothese dat mensen met een psychotische kwetsbaarheid te kampen hebben met een verminderde buffer-functie van de prefrontale dopamineneuronen, mogelijk ten grondslag liggend aan een stress-gemedieerde ontremming van het mesolimbische dopaminesysteem. Eerder onderzoek toonde aan dat deze mesolimbische dopamine hyperactiviteit psychotische symptomen in de hand werkt, daarmee een verklaring biedend voor de - weliswaar subtiele - psychotische belevingen die tijdens dit experiment door de eerstegraads familieleden werden gerapporteerd.

In het laatste deel van dit proefschrift (Hoofdstuk 5 en 6) wordt aandacht besteed aan de medicamenteuze bestrijding van psychotische symptomen en de impact hiervan op het dagelijks leven van de patiënt.

Zoals eerder kort aangestipt, bestaat de primaire behandeling van psychotische stoornissen uit pharmacotherapeutische interventies. Het gros van de patiënten stopt echter binnen het eerste behandeljaar op eigen verzoek met het nemen van de medicatie, daarmee een terugval in de hand werkend. Een risico waarvan de meeste patiënten zich bewust zijn. Het innemen van de medicatie weegt voor hen blijkbaar zwaarder dan het terugvallen in een psychose. Waarom?

Hoewel blokkade van de dopamine receptor in de hersenen noodzakelijk is voor het bereiken van een antipsychotisch effect, induceert deze een reeks vervelende neveneffecten waarvan bewegingsstoornissen - wellicht omdat ze zo in het oog springen - het best 
zijn gedocumenteerd. Het fenomeen medicatie discontinuatie is, mede hierdoor, lang beschouwd in het licht van deze motorische verstoringen, in samenhang met een gebrek aan antipsychotisch effect. Het dopaminesysteem mediëert echter ook de opwekking van natuurlijke beloningen en reacties op positieve gebeurtenissen, wat impliceert dat blokkade van de dopamine receptor tevens kan leiden tot gevoelens van onverschilligheid en emotioneel onwelzijn. Dit wordt ondersteund door recente studies die laten zien dat een behandeling met dopamineblokkerende medicatie bij veel patiënten gepaard gaat met een achteruitgang in emotioneel welbevinden. Sterker nog, een aantal studies suggereert dat juist het emotionele welbevinden van de patiënt, veel meer dan de hinder ondervonden van bewegingsstoornissen, bepaalt of hij al dan niet stopt met zijn medicatie.

In Hoofdstuk 5 en $\mathbf{6}$ van dit proefschrift worden twee studies beschreven die tot doel hadden om dit mechanisme te kaderen in het dagelijks leven van patiënten met een psychotische stoornis, daarbij gebruikmakend van de Experience Sampling Methode (ESM), een gestructureerde dagboektechniek waarmee het emotionele welbevinden van de patiënt werd onderzocht in de realiteit van alledag.

De studie beschreven in Hoofdstuk 5 van dit proefschrift onderzocht, in een groep van 109 patiënten met een psychotische stoornis, in welke mate het emotionele welbevinden van de patiënt kan worden toegeschreven aan het dopamineblokkerende profiel van het medicijn waarop hij is ingesteld. Patiënten werden daarvoor ingedeeld in twee groepen, gebaseerd op de medicatie die zij gebruikten. Hierbij werd onderscheid gemaakt tussen medicijnen die zich kenmerken door een sterk bindende bezetting van de dopamine receptor (hierna: 'sterk bindend') en medicijnen die bekend staan om een zwak bindende bezetting van de dopamine receptor (hierna: 'zwak bindend'). Beide patiëntgroepen werden 6 dagen gevolgd met de ESM, daarmee emotioneel welbevinden in het dagelijks leven registrerend. Getest werd of patiënten die werden behandeld met een sterk bindend medicijn $(n=74)$, bij een kwantitatief vergelijkbare bezetting van de dopamine receptor, meer emotioneel onwelzijn rapporteerden dan patiënten die behandeld werden met een zwak bindend medicijn $(n=35)$.

Resultaten lieten zien dat patiënten die behandeld werden met een sterk bindend medicijn, bij een kwantitatief vergelijkbare bezetting van de dopamine receptor, in het dagelijks leven meer negatieve en minder positieve emoties beleefden dan patiënten die behandeld werden met een zwak bindend medicijn. Dit lijkt te suggereren dat niet de bezetting van de dopamine receptor per se, maar eerder de manier waarop de bezetting plaatsvindt, het 
emotionele welzijn van de patiënt bepaalt.

In Hoofdstuk 6 wordt een tweede studie beschreven die gebruik maakt van de ESM om het emotionele welbevinden van 13 gemediceerde patiënten met een psychotische stoornis in kaart te brengen. Deze keer ging het om een groep patiënten die, wegens klinische motieven, werd ingesteld op een nieuw soort medicijn met bijzondere eigenschappen. Terwijl, zonder uitzondering, alle antipsychotische medicijnen de dopamine transmissie indammen, is dit middel in staat om de dopamine transmissie, afhankelijk van de concentratie aanwezige dopamine, te dempen of te stimuleren. Dit zou theoretisch gezien voor een gebalanceerde dopamine-huishouding en, daaraan gekoppeld, verhoogd emotioneel welbevinden moeten zorgen. Er werden twee, 6 dagen durende, ESM-metingen uitgevoerd; de eerste keer werden patiënten gevolgd terwijl ze nog ingesteld waren op hun oude, dopamine-reducerende medicijn; de tweede keer werden ze gevolgd terwijl ze reeds waren ingesteld op het nieuwe dopamine-regulerende middel. Er werd getest of patiënten, volgend op de behandeling met het nieuwe middel, een toename in emotioneel welzijn rapporteerden.

In tegenstelling tot wat werd verwacht, suggereerden de resultaten dat het gros van de patiënten emotionele demping ondervond ten gevolge van de medicatie-omschakeling. Daarnaast reageerden maar liefst 7 van de 13 patiënten op de medicatie-omschakeling met een toename in psychotische symptomen. Echter, de kleine schaal van de studie beperkt de interpretatie van de bevindingen en vraagt vooral om replicatie.

In Hoofdstuk 7 worden ten slotte de resultaten van de studies, beschreven in dit proefschrift, samengevat en geïntegreerd tot een multidimensioneel ziektemodel van psychose, waarin een disfunctie van het corticomesolimbische dopaminesysteem centraal staat. Tevens wordt aandacht besteed aan mogelijke klinische implicaties en worden er suggesties gedaan voor verder onderzoek voortvloeiend uit de bevindingen in dit proefschrift. 
202

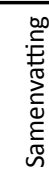




\section{Dankwoord}

Een hoop mensen hebben -direct en/of indirect- bijgedragen aan de totstandkoming van dit proefschrift. Ik maak graag van deze gelegenheid gebruik om hen te bedanken, waarbij ik met nadruk wil onderstrepen dat ik mijn uiterste best heb gedaan om niemand te vergeten..! Ik vrees echter dat dit desondanks gebeurd is. Voor diegenen, mocht het een troost zijn; vroeg of laat zal ik mij realiseren dat $i k$ jullie ben vergeten en zullen jullie - meer nog dan de mensen die hieronder worden genoemd - door mijn hoofd blijven spoken.

Well, here it goes...

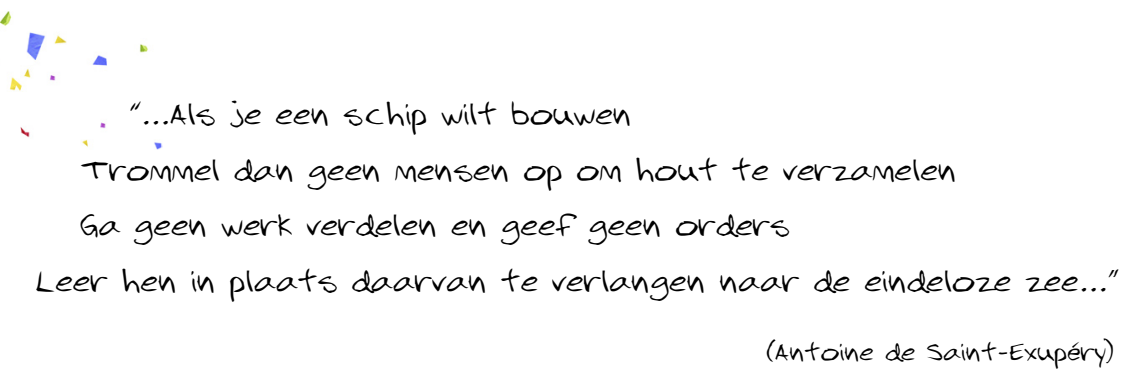

First and foremost: Inez en Jim - inspiratoren - jullie tomeloze enthousiasme lijkt niet alleen onuitputtelijk, maar werkt bovenal aanstekelijk. Life's a beach! Zo stond ik erin. Maar dat kon natuurlijk alleen dankzij jullie. SP als mijn eigen Baywatch; altijd scherp, one step ahead, aanwezig - en vooral sexy natuurlijk ;) I. O. U. Big time!

Dina, voor jou heb ik niets dan respect. Ik zie het als een eer om met jou te hebben mogen werken aan ons gezamenlijke promotie-onderzoek. Cum Laude, daarmee was niets teveel gezegd. Ook als persoon, vriendin en collega slaag je in mijn ogen met lof.

Alle andere - ooit junior-, nu senior- of zelfs ex-AiO's/Doctors van SP - in het bijzonder Margreet, Rebecca en Dennis - kom A.U.B. een keer langs op een biertje :P. Petra, bedankt voor jouw immer sympathieke aanwezigheid. 
Ook niet te vergeten: Nienke, Cécile, Steffi, Nicole G, Anne, Margriet, Sebastian (Venice was een life event), Odette en alle andere voortvluchtigen (you know who you are).

Verder natuurlijk iedereen bij SP die hier niet specifiek wordt genoemd.

| Sfeer | Belangrijk | Koesteren | !!

Ik wil graag iedereen bedanken die nauw betrokken was bij het verwerven en verwerken van alle data voor de STRIP-studie. Philippe, Frieda, Peter en alle anderen verantwoordelijk voor de database (bedankt voor alle (nachtelijke?) inspanningen), Truda (schutspatroon van de boekskes - Debora ook bedankt!), Rufa (onderhoudend en opgeruimd - altijd aangenaam), Carmen (cortisol = geen lol), David (blijf vragen..!), Thomas (hope u'r doing well), Bernice (gezellig..! :D), Dian en Machteld (kort maar krachtig ;)).

Bijzonder lof gaat uit naar Wendy Beuken; bedankt met name voor de functionele stalking met betrekking tot het afhandelen van de dossierverwerking.

Ik bedank de aardige mensen van Nucleaire Geneeskunde van de Katholieke Universiteit Leuven:

Prof. dr. Koen Van Laere - bedankt voor de prettige samenwerking die nog steeds loopt en ook in termen van publicaties vruchtbaar blijkt.

Jenny Ceccarini: "La pazienza non é mai troppa." Thanks for repeatedly (i.e., over and over) explaining Nathaniel's nasty model to me (and Dina, and David, and Rebecca), helping us set up and perform the PET-experiments, preparing all data for analysis, and contributing to the methods section of the final publications. Couldn't have done it without you! I wish you and your family all the best..!

Alle mensen die onmisbaar waren voor de praktische uitvoering van de PET-scans, in het bijzonder Stijn Dirix, Kwinten Porters en Mieke Steukers - dankzij jullie voelden onze proefpersonen zich volledig ontspannen (totdat het experiment begon XD).

ledereen van het Radiofarmacie lab KU Leuven, met name Tjibbe de Groot \& Kim Serdons. Bedankt voor de fallypride..!

De fijne dames van het wetenschappelijk secretariaat Nucleaire Geneeskunde - Silvie de Simpelaere, Francine Reniers en Mariet Vrancken - alles liep op rolletjes!

Michel Koole - "I know what I have given you. I do not know what you have received" (Antonia Porchia) - bedankt voor de, soms herhaalde, online submissie van menig .zip- of .winrar-bestand!

Verbonden aan de Universiteit van Montréal wil ik graag Dr. Jens Pruessner (Thank you!) en Dr. Linda Booij bedanken voor het toestaan van gebruik van de MIST stress taak, alsook voor 
de vitale instructies voor het effectief operationaliseren ervan.

Ganz herzlich bedanken möchte ich mich auch bei Prof. dr. Hans-Ulrich Wittchen und Prof. dr. Rosalind Lieb, die es mir ermöglicht haben mit dem einmaligen EDSP Datenset zu arbeiten. Mari, thank you for guiding me safely through boobytrapped EDSP territory!

Ik wil vooral ook alle proefpersonen bedanken die aan ons onderzoek hebben deelgenomen! Jullie kwamen helemaal uit Gent(!), uit Enschede(!), Rotterdam(!), Groningen(!), Alkmaar(!). Jullie beantwoordden duizenden vragen, collecteerden tientallen speekselmonsters en trotseerden bovendien de radioactieve straling van de PET-scan. En dat alles om een bijdrage te leveren aan de wetenschap. Het heeft me zeer ontroerd en veel van jullie gezichten staan in mijn geheugen gegrift. Bedankt!

De mensen uit de 'control room' van SP headquarters: Trees, Jolanda, Ine, Leni. Bedankt voor alle ondersteuning die ik van jullie mocht, en nog steeds mag ontvangen.

Ron (en -recenter- ook René): Bedankt voor alle ICT ondersteuning - jullie zijn onmisbaar!! Alle "outside" AiO's, in het bijzonder Hanneke Wigman, Martin Gevonden en Eva Velthorst. Bedankt voor de sociale kruisbestuiving.

Jean-Paul en Viviane - bedankt dat ik mocht meewerken aan jullie studies in mijn begintijd bij SP. Lies, bedankt voor de SPM-support. Koen, bedankt voor uw logica.

Ik wil ook alle co-auteurs bedanken die ik nog niet bij naam heb genoemd, in het bijzonder Maarten Bak; grote mond, klein hartje - dat hebben we in ieder geval gemeen ;) Daarnaast bedank ik iedereen binnen SP waarvan ik ooit een dataset heb mogen gebruiken voor analyse..!!! Hope I can return the favor!

Ik bedank ook Integrale Zorg Mondriaan, en met name alle medewerkers van Wijkteam II en IV voor de mogelijkheid die zij me gaven om ook mijn klinische grenzen te verkennen en te verleggen. Ik ben van mening dat de tijd die ik als behandelaar in de kliniek doorbracht mij minstens net zozeer heeft gevormd tot de persoon die ik nu ben als mijn werk als onderzoeker dat heeft gedaan. Ik blijf jullie ambulant volgen! (Bedankt ook voor het meedenken / meewerken bij de werving van proefpersonen).

Nancy, jij staat als geen ander tussen de AiO's. Bedankt voor al je tips, leuke gesprekken, en met name ook voor de ideeën die je aandroeg voor de titel van mijn proefschrift!

Ik draag iedereen die meewerkt of mee heeft gewerkt aan het Verfilmde Waan project 
een warm hart toe, waarbij ik met name de verbindende en motiverende inspanningen van Dorothé van Slooten wil hebben genoemd (zie ook: www.verfilmdewaan.nl).

De redactieleden van PsyCope Magazine (Paul, Ernst, Dorothé, Margreet en Marcel) bedank ik voor leuke redactievergaderingen, goede discussies en mooie stukken.

Ik bedank ook alle leden van de leescommissie en iedereen die in de corona wilde plaatsnemen. (Thank you, Dr. Oliver Howes, for being willing to be part of the thesis advisory committee).

Mede namens mijn moeder bedank ik alle luchtvaartmaatschappijen die mij veilig over de globe transporteerden.

Nele, bedankt dat ik tijdens mijn eerste maanden bij de Open Universiteit nog de ruimte kreeg om de puntjes op de i van mijn proefschrift te zetten. Verder bedank ik iedereen bij de OU (nieuwe gezichten en oude bekenden) voor de hartelijke ontvangst tijdens de laatste fase van mijn promotie. Ik voel me al helemaal thuis!

Dr. Amanda Kaas, Prof. dr. Alexander Sack en Dr. Hanneke van Mier bedank ik voor de leerzame wetenschapsstage en de kickstart van mijn wetenschappelijke carrière.

Bedankt, iedereen die mij in staat stelt om in mijn vrije tijd op andere gedachten te komen;

Dirk, Hanneke en - vooruit - Erik;) "Creation comes out of imperfection. It seems to cone out of a striving and a frustration" (Kim Krizan). E = MC Hammer. We'll get there..! Ondertussen blijf ik me met jullie verwonderen over de pareltjes die rondzwerven op het www. Spotify bedankt! (best invention since youtube).

Alle voetbalvrienden: bedankt voor de wekelijkse uitlaatklep, ook al moest ik hiervoor bijna mijn rechterpink opofferen (no hard feelings).

Ik bedank ook Jo voor het schaaf- en schuurwerk in zijn prachtige gitaaratelier. Nergens wordt een haastige analyse zo afgestraft als in de gitaarbouw.

Guido. My brother from another mother..! Wat kan ik zeggen, in een geïllustreerd woordenboek zouden wij de letter B van kleur voorzien; van bitterzoet en bolero tot bromance - nothing but love. Maar bovenal staat de letter $B$ natuurlijk voor Björn Kamycki; de derde musketier en de enige persoon waarmee een reünie nooit als een reünie aanvoelt. En nu ook nog om de hoek in sjeng city, wat kan een mens zich nog meer wensen..! 
Tiny - enige vorm van nepotisme is jou niet vreemd ;)

Altijd begaan met het lot van je broertje werd ik door jou geïntroduceerd bij SP. Mede dankzij jou wist ik ook snel mijn draai te vinden op Vijverdal, enig cross-sibling advies was immers nooit ver te zoeken. Vooral ook bedankt voor alle lekkere etentjes en gezellige avonden in Mestreech, bovenste beste zus!

Parentes - Het moet een (na)zomermiddag, -avond (-ochtend?) in augustus 1982 zijn geweest waarop de vleselijke voorwaarden voor dit proefschrift werden geschept. Het jaar waarin de Stones voor het eerst in de Kuip staan, Michael Jackson zijn bestselling album 'Thriller' uitbrengt, Simon \& Garfunkel's 'Concert in Central Park' als één van de eerste popconcerten op de Compact Disc verschijnt en Steve Jobs voor het eerst op de cover prijkt van TIME Magazine. Tijdens mijn promotie-traject valt "Keef" uit een palmboom, beleeft Michael Jackson een levensechte en uiteindelijk fatale thriller, kom ik erachter dat Paul Simon ervan wordt beschuldigd tijdens het betreffende concert een toupet te hebben gedragen, en wordt Steve Jobs - zo zal blijken - voor de laatste keer gefotografeerd voor de cover van TIME Magazine — Things fall apart. Waar ik echter altijd op kan rekenen in een immer veranderende wereld is jullie advies, steun, en relativeringsvermogen. Terugblikkend moet ik daarbij ook constateren dat de zorg en liefde die ik tijdens mijn leven mocht ontvangen, en zo lang voor vanzelfsprekend heb gehouden, eerder als uitzonderlijk moeten worden beschouwd. Met dit boek dank ik daarom jullie beiden voor alle zorgen die jullie voor en om mij hadden en de mogelijkheden die jullie voor me hebben gecreëerd.

Jenneke, zoals Jim Carrey het ooit treffend wist te verwoorden:

"Behind every [great] man is a woman rolling her eyes" $\ddot{\nabla}$

Schaamte is het begin van de moraal. Zelden heb ik iemand gekend waarbij de wil goed te doen zich werkelijk in iedere porie lijkt te nestelen. Jouw onbevooroordeelde blik heeft mij zeker de ogen geopend. En nog steeds. Dat mijn werkplek bij SP zich altijd op loopafstand van ons appartement bevond moet voor jou vooral als een vloek hebben gevoeld (..zelf vond ik het wel handig..). Jouw emotionele uithoudingsvermogen verdient in dat opzicht beslist een podiumplaats. Bedankt..!

Ten slotte bedank ik ook Loesje, de relativiteitsfactor op 4 pootjes. 
208

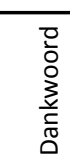




\section{List of publications}

\section{International journals}

Lataster J, van Os J, de Haan L, Thewissen V, Bak M, Lataster T, Lardinois M, Delespaul P, MyinGermeys I. Emotional experience and estimates of $D_{2}$ receptor occupancy in psychotic patients treated with haloperidol, risperidone, or olanzapine: an experience sampling study. Journal of Clinical Psychiatry, 2011. 72(10): p. 1397-404.

Lataster J, Collip D, Ceccarini J, Haas D, Booij L, van Os J, Pruessner J, Van Laere K, Myin-Germeys I. Psychosocial stress is associated with in vivo dopamine release in human ventromedial prefrontal cortex: a positron emission tomography study using $\left[{ }^{18} \mathrm{~F}\right]$ fallypride. Neurolmage, 2011. 58(4): p. 1081-9.

Lataster J, Myin-Germeys I, Wichers M, Delespaul P, van Os J, Bak M. Psychotic exacerbation and emotional dampening in the daily life of patients with schizophrenia switched to aripiprazole therapy: a collection of standardized case reports. Therapeutic Advances in Psychopharmacology, 2011. 1(5): p. 145-51.

Lataster J, Myin-Germeys I, Lieb R, Wittchen H-U, van Os J. Adversity and psychosis: a 10year prospective study investigating synergism between early and recent adversity in psychosis. Acta Psychiatrica Scandinavica, 2011; epub ahead of print. doi: 10.1111/j.16000447.2011.01805.x

Myin-Germeys I, Lataster J, Oorschot M, Collip D, Delespaul P, van Os J. Experience sampling research in psychopathology: opening the black box of daily life. Psychological Medicine, 2009. 39(9): p. 1533-47.

Kaas A, van Mier H, Lataster J, Fingal M, Sack A. The effect of visuo-haptic congruency on haptic spatial matching. Experimental Brain Research, 2007. 183(1): p. 75-85.

\section{Book chapters}

$\underline{\text { Lataster J }}$ and Myin-Germeys I. De rol van stress en dopamine bij het ontstaan van psychose. In: Psychose voor gz-psychologen. Valmaggia LR, van der Gaag, M. Assen: van Gorcum (revision pending).

\section{Submitted}

Lataster J, Collip D, Ceccarini J, Hernaus D, Haas D, Booij L, van Os J, Pruessner J, Van Laere $\mathrm{K}$, Myin-Germeys I. Familial liability to psychosis is associated with altered dopamine stress signaling in ventromedial prefrontal cortex.

Hernaus D, Lataster J, Collip D, Ceccarini J, Haas D, Booij L, van Os J, Pruessner J, van Laere K, Myin-Germeys I. Psychotic reactivity to daily life stress is associated with stress-induced in vivo prefrontal hypodopaminergia: evidence from Experience Sampling and $\left[{ }^{18} \mathrm{~F}\right]$ fallypride PET data. 
Hernaus D, Collip D, Lataster J, Kenis G, van Winkel R, Ceccarini J, Booij L, van Os J, Pruessner $J$, van Laere K, Myin-Germeys I. COMT Val ${ }^{158}$ Met genotype alters prefrontal dopamine $D_{2}$ receptor availability in vivo after a psychosocial stress challenge.

Kuepper R, Ceccarini J, Lataster J, van Os J, van Kroonenburgh M, van Laere K, van Gerven JMA, Henquet C. Studying delta-9-tetrahydrocannabinol-induced dopamine release in patients with psychotic disorder using PET and $\left[{ }^{18} \mathrm{~F}\right]$ fallypride.

\section{Conference presentations}

Lataster J, Hernaus D, Collip D, Ceccarini J, Haas D, Booij L, van Os J, Pruessner J, van Laere K, Myin-Germeys I. Psychotic reactivity to daily life stress is associated with stress-induced in vivo prefrontal hypodopaminergia: evidence from Experience Sampling and $\left[{ }^{18} \mathrm{~F}\right]$ fallypride PET data. International Congress on Schizophrenia Research, Colorado, United States, april 2011.

Lataster J, Myin-Germeys I, Wichers M, Delespaul P, van Os J, Bak M. Psychotic exacerbation and emotional dampening in the daily life of patients with schizophrenia switched to aripiprazole therapy: a collection of standardized case reports. International Early Psychosis Association Conference, Amsterdam, december 2010.

Lataster J, Myin-Germeys I, Lieb R, Wittchen H-U, van Os J. Adversity and psychosis: a 10-year prospective study investigating synergism between early and recent adversity in psychosis. GGzE Symposium "Jaren vol verwardheid", Eindhoven, the Netherlands, november 2010.

Lataster J, Myin-Germeys I, Lieb R, Wittchen H-U, van Os J. Adversity and psychosis: a 10-year prospective study investigating synergism between early and recent adversity in psychosis. Schizophrenia International Research Society Conference, Florence, Italy, april 2010.

Lataster J, Myin-Germeys I, Lieb R, Wittchen H-U, van Os J. Adversity and psychosis: a 10-year prospective study investigating synergism between early and recent adversity in psychosis. Voorjaarscongres Nederlandse Vereniging voor Psychiatrie, Maastricht, the Netherlands, april 2010.

Lataster J, van Os J, de Haan L, Thewissen V, Bak M, Lataster T, Lardinois M, Delespaul P, MyinGermeys I. Emotional experience and estimates of $D_{2}$ receptor occupancy in psychotic patients treated with haloperidol, risperidone, or olanzapine: an experience sampling study. Schizophrenia International Research Society Conference, San Diego, United States, april 2009.

Lataster J, van Os J, de Haan L, Thewissen V, Bak M, Lataster T, Lardinois M, Delespaul P, MyinGermeys I. Emotional experience and estimates of $D_{2}$ receptor occupancy in psychotic patients treated with haloperidol, risperidone, or olanzapine: an experience sampling study. Schizophrenia International Research Society Conference, Venice, Italy, july 2008.

Lataster J, Kaas A, van Mier H, Fingal M, Sack A. The effect of visuo-haptic congruency on haptic spatial matching. Endo-Neuro-Psycho Meeting, Doorwerth, the Netherlands, may 2005. 


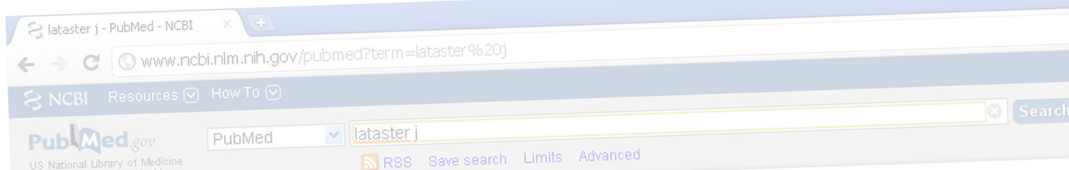

Display Settinas: (v) Summary, Sorted by Recently Added

Send to $(8)$ Filter your results:

All (5)

Review (1)

Results: 5

Find related data

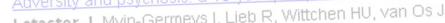

Lataster J, Myin-Germeys I, Lieb R, Wittchen Fu, van 030 J 805 x IEpub ahead of print

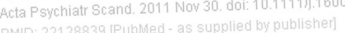

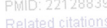

Psychosocial stress

using [18Fliallypride

Lataster J, Collip D.

Neuroimage, 2011 oct

PMD: 21801840 th

Emotional experien

experience samplin

Lataster J, van Do

$J$ Clin Psychiatry. 20

Pelated citations

Psychotic exacerbation and emoti

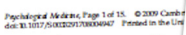

case rep

Experience samplins

Johan Lotaster, 1
S. van os and $\mathrm{Ma}_{0}$ opening the black b

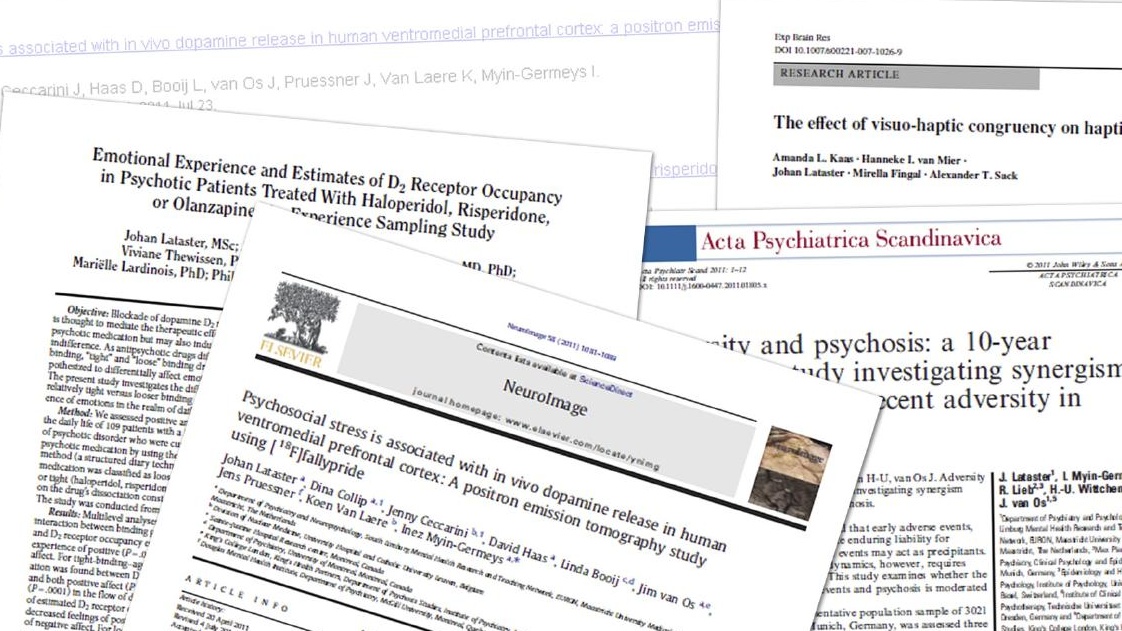



sychotic disorders remain among the most burdensome and intangible mental illnesses worldwide, perturbing the emotional and social life of those affected, and throwing their surrounding environment into great confusion. Although environmental stress has been repeatedly identified as risk factor for psychosis, the imperative aspect of interaction between a vulnerable individual and its stressful surroundings has remained largely disregarded. Using a combination of prospective population-based studies, ecological sampling, and neuroimaging techniques, the work presented in the current thesis examines how the stressful environment affects the vulnerable individual, and which mechanisms underlie its transition to illness.

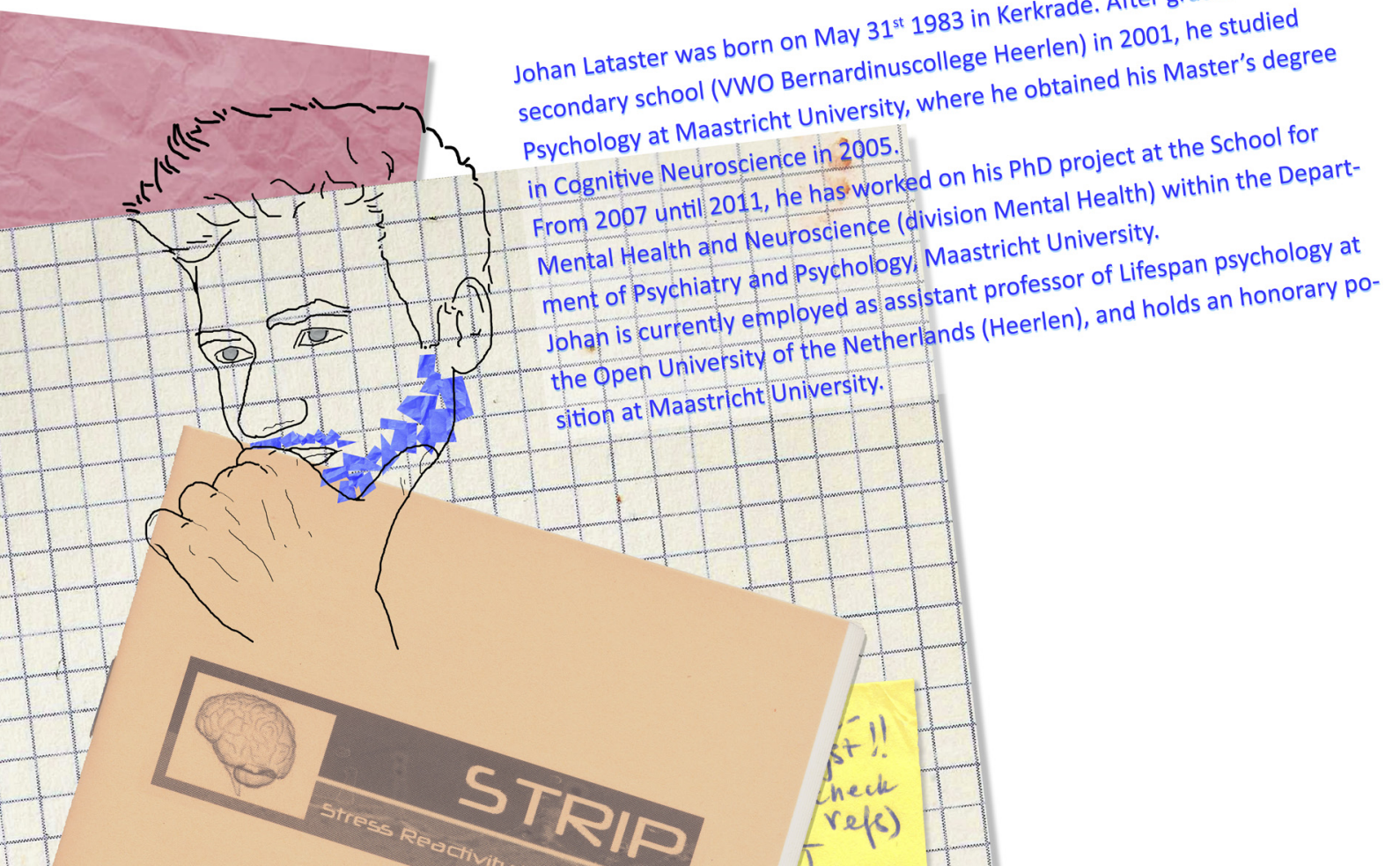

